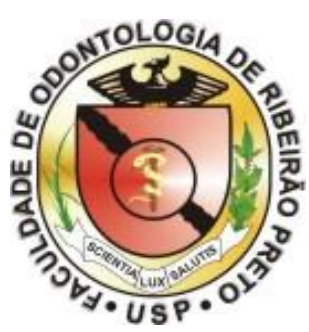

ROBERTO CESAR BIANCALANA

ANÁLISE DAS PROPRIEDADES FÍSICAS E MECÂNICAS DE MATERIAIS RESTAURADORES ODONTOLÓGICOS SUBMETIDOS À AÇÃO DO CALOR E DO FRIO PARA FINS PERICIAIS

Ribeirão Preto 

ROBERTO CESAR BIANCALANA

\title{
ANÁLISE DAS PROPRIEDADES FÍSICAS E MECÂNICAS DE MATERIAIS RESTAURADORES ODONTOLÓGICOS SUBMETIDOS À AÇÃO DO CALOR E DO FRIO PARA FINS PERICIAIS
}

\author{
Dissertação apresentada à Faculdade de \\ Odontologia de Ribeirão Preto, da \\ Universidade de São Paulo, para obtenção do \\ título de Mestre no Programa de Reabilitação \\ Oral. \\ Área de Concentração: Biologia Oral \\ Orientadora: Profa. Dra. Maria José Alves da \\ Rocha \\ VERSÃO CORRIGIDA \\ A versão original se encontra disponível na \\ Faculdade de Odontologia de Ribeirão Preto - USP
}

\author{
Ribeirão Preto
}


Ficha catalográfica elaborada pela Biblioteca Central do Campus USP - Ribeirão Preto

\section{Biancalana, Roberto Cesar}

Análise das propriedades físicas e mecânicas de materiais restauradores odontológicos submetidos à ação do calor e do frio para fins periciais.

$$
202 \text { p. : il. ; } 30 \mathrm{~cm}
$$

Dissertação de Mestrado, apresentada à Faculdade de Odontologia de Ribeirão Preto/USP. Área de Concentração: Biologia Oral.

Versão corrigida. A versão original se encontra disponível na biblioteca da unidade que aloja o programa e na Biblioteca Digital de Teses e Dissertações da USP (BDTD).

Orientadora: Rocha, Maria José Alves da 


\section{FOLHA DE APROVAÇÃO}

Roberto Cesar Biancalana

Dissertação apresentada à Faculdade de

Odontologia de Ribeirão Preto, da Universidade de São Paulo, para obtenção do título de Mestre.

Área de Concentração: Biologia Oral

Aprovado em:

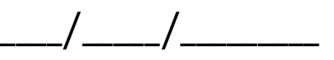

\section{Banca examinadora:}

1) Prof.(a). Dr.(a).

Institução:

Julgamento: Assinatura:

2) Prof.(a). Dr.(a).

Institução:

Julgamento: Assinatura:

3) Prof.(a). Dr.(a).

Institução:

Julgamento: Assinatura: 

"Compreendi que víver é ser livre...

Queter amigosé necessário...

Que lutar é manter-se vívo...

Que praser felizbasta querer...

Aprendi que o tempo cura..

Que mágoa passa..

Que decepção não mata...

Que hoje é reflexo de ontem...

Compreendi que podemos chorar sem derramar lágrimas...

Que um verdadeiro amor permanece...

Que dor fortalece...

Quevencer engrandece...

Aprendi que sonhar não é fantasiar..

Que pra sorrir tem que fazer alguém sorrir..

Que a beleza não está no que vemos, e sim no que sentimos...

Que ovalor está na força da conquista...

Compreendi que as palauras têm força...

Que fazer é methor que falar..

Que o othar não mente...

Que viver é aprender com os erros...

Que nunca devemos pensar que somos methores do realmente somos...

Aprendi que tudo depende da vontade...

Que o methor é sermos nós mesmos..

Que a vida se faz de encontros e despedidas...

E sei que o SEGREDO da vída... éVIVER “ 

Dedicatória 



\section{A Dens}

Por me fortalecer na fé, por me dar forças e saúde para enfrentar as batalhas da vida, por me trazer esperança em dias melhores, por realizar meus sonhos, por me proporcionar amizades, por me encher de pessoas que me amam e me fazer lembrar, a cada dia, que devo agradecê-lo por me ter feito repleto de emoção e de apenas alguns delírios de razão...

\section{A minha Mãe (in memorian)}

Por ter sido un grande exemplo de mulher, de mãe, e ter me ensinado a ser um homem de bem. Gostaria de ver $\sigma$ seu sorriso com esta minha conquista. Infelizmente, não consigo vê-lo, mas posso senti-lo. Levo comigo sua felicidade e onde estiver, saiba que este trabalho é dedicado, principalmente, à você... Mãe!

\section{Ao meu Pai}

Por ser meu melhor amigo, por sempre me incentivar e apoiar todas as minhas decisões, por acreditar nos meus sonhos, por se preocupar com a minha educação, por ser $\sigma$ exemplo de um homem correto, trabalhador, justo e honesto. Obrigado por ser este grande Pai para mim...

\section{À Vanessa, minha esposa}

Por fazer parte da minha vida, por me trazer alegria, por me respeitar, por ter paciência, por ser essa menina linda, companheira, de caráter... por enfrentar tudo o que passamos juntos, por sorrir e chorar ao meu lado, por ser uma pessoa especial. Enfim, por ser $\sigma$ men Amor... 


\section{À minha Familia}

Minhas irmãs, Patricia e Roberta e aos meus sobrinhos Ana e Caio, por serem pessoas maravilhosas... pelo companheirismo, pelo amor e carinho que sentimos uns pelos outros...

Dedico este trabalho a vocês: minha mãe; meu pai; minha esposa; minhas irmas e meus sobrinhos, porque vocês são as pessoas as quais defendo, protejo, respeito e amo com toda minha força e que tenho certeza, verdadeiramente, me amam também... 
Agradecimentos especiais 

'A Profa. Dra. Fernanda de Carvalho Panzeri Pires de Souza, por toda a sua dedicação, atenção e empenho neste trabalho. Obrigado por me abraçar nessa caminhada e acreditar que poderiamos vencer essa batalha.

Certamente, sem $\sigma$ sen apoio, este trabalho não teria a mesma qualidade. Obrigado pelos momentos de incentivo quando me sentia cansado... pelos conselhoy, sugestöes e correções.

Caminhos sinuosos, tipicos do nosso destino, me levaram até a senhora, para que eu tivesse a oportunidade e $\sigma$ prazer de aprender muitas coisas. Conhecimentos dos assuntos deste trabalho e da vida.

$N a ̃ \sigma$ consigo expressar em palarras minha gratidão por tudo $\sigma$ que a senhora representou nesse tempo em que nos conhecemos. Sem qualquer obrigação, a senhora me ajudou e fez este trabalho tornarse grandioso.

Espero ter correspondido a sua confiança e desejo do fundo do meu coração que possamos manter esse laço de amizade.

Ao men amigo Sergio Augusto de Fretas Vicente pelo companheirismo nessa trajetória da pós-graduação. Pela parceria em todas as disciplinas, seminários e, principalmente, neste trabalho.

Agradeço sua dedicação nos laboratórios e no empenho em todas as etapas deste projeto. Por isso, tenho a convicção que este trabalho não é apenas men, mas sim, nosso.

$O$ mais importante foi a construção da nossa amizade. Daqueles verdadeiros amigos, contados nos dedos das mãos, pode ter certeza que você é un deles. 
Não me esquecerei dos momentos de diversão, risadas $e$ trapalhadas, que foram muitos, e dos momentos de tensão e seriedade que, felizmente, não foram tantos assim.

Conte com minha amizade para $\sigma$ que for necessário... 
Agradecimentos 

À Profa. Dra. Maria José Alves da Rocha, minha orientadora, pela atenção e compreensão nos momentos que precisei de sua ajuda.

Ao Prof. Dr. Ricardo Henrique Alves da Silva, pelos ensinamentos desde os tempos do curso de especialização em Odontologia Legal. Agradeço pelas oportunidades oferecidas e pela supervisão no PAE (Programa de Aperfeiçoamento de Ensino).

A Profa. Dra. Fernanda Capurucho Horta Bouchardet, da Faculdade de Odontologia da Pontifícia Universidade Católica de Minas Gerais, pelas correções e sugestões dirigidas a este trabalho.

Ao Prof. Dr. Raphacl Freitas de Souza, do Departamento de Materiais Dentários e Prótese, parecerista do meu projeto de pesquisa, pelos conselhos, correçóes e ensinamentos oferecidos, os quais, certamente, enriqueceram este estudo.

À Universidade de São Paulo e à Faculdade de Odontologia de Ribeirão Preto, na pessoa de seu diretor, Prof. Dr. Valdemar Mallet da Rocha Barros, por me receber, novamente, nesta instituição, da qual tenho imenso orgulho. Hoje, sou cirurgião-dentista, especialista em Odontologia Legal e futuro mestre em Reabilitação Oral, graças à maravilhosa FORP-USP. 
Ao Programa de Pós-graduação em Reabilitação Oral, na pessoa da atual coordenadora Profa. Dra. Rossana Pereira de Almeida Antunes e, especialmente, à Profa. Dra. Fernanda de Carvalho Panzeri Pires de Souza, por todo seu esforço e competência em tornar este Programa uma referência nacional em atividades de pesquisa e extensão. Em sua luta por melhorias e preocupação em oferecer excelência de ensino aos alunos.

Ao CNPq (Conselho Nacional de Desenvolvimento Cientifico e Tecnológico), pela concessão da bolsa de estudo.

Ao Departamento de Estomatologia, Saúde Coletiva e Odontologia Legal, na pessoa de sua chefe, Profa. Dra. Marlívia Gonçalves de Carvalho Watanabe, pela pronta ajuda sempre quando necessário e aos funcionários Sr. Dorival Gaspar e Sra. Antonia Ferreira.

À equipe da Odontologia Legal : Prof. Dr. Ricardo Henrique Alves da Silva, Marta Regina Pinheiro Florese Lais Gomes de Araújo.

À equipe do LaABio (Laboratório de Análise de Biomateriais): Profa. Dra. Fernanda de Carvalho Panzeri Pires de Souza, Rafaclla Tonani, Marta Maria Martins Giamatei Contente, Carla Cecilia Alandia Román, Renata Costa de Morais, Renata Espindola Silveira, Lourenço de Moraes Rego Roselino, Francisca Daniele Jardilino Silame, Michelle Chinelatti, Gustaro da Col dos Santos Pinto, Ana Beatriz Silva Sousa e Sergio Augusto de Freitas Vicente. Agradeço pela amizade e companheirismo de todos vocês, e pelos momentos be que viremos durante esse periodo. Uma etapa se encerra por aqui, mas estarei sempre por perto. Não poderia deixar de conviver com pessoas tão bacanas e especiais, que engrandecem minha vida. 
Ao Departamento de Materiais Dentários e Prótese, na pessoa de sua chefe, Profa. Dra. Cláudia Helena Lovato da Silva, pela autorização para $\sigma$ uso dos laboratórios do Departamento para a realização dos experimentos deste estudo.

À Rafaclla Tonani, do Laboratório de Pesquisa "Prof. Dr. Heitor Panzeri", pela sua atenção, paciência e delicadeza ao me auxiliar e ensinar a utilizar os aparelhos do laboratório; em dedicar sen tempo nas programações do forno para a queima dos dentes bovinose por sempre estar solicita a qualquer ajuda.

À Ana Paula Macedo, do Laboratório de Pesquisa de Metrologia; pela ajuda com os testes de rugosidade e à Adriana Clándia Lapria Faria Queiroz, do Laboratório de Estudos Biomecânicos em Prótese e Implantes pela colaboração nos testes de microdureza. Agradeço a atenção e simpatia em todos os momentos que precisei.

Ao Nilton Nascimento dos Santos Júnior, pelo auxílio no uso do aparelho ultra freezer utilizado neste estudo, junto ao Departamento de Morfologia, Fisiologia e Patologia Básica da FORP-USP.

Às secretárias da pós-graduação. Fernanda Talita de Freitas, Regiane de Cássia Tirado Damasceno, Ana Paula Xavier, Rosângela Aparecida da Silva Troca Nascimento, Isabel Cristina Galino Sola, Regiane Cristina Moi Sacilotto e Mary Possani Carmessano. Agradeço a colaboração e esforço em auxiliar todos oy alunos.

A todos os funcionários da Faculdade de Odontologia de Ribeirão Preto, da Universidade de São Paulo (FORP-USP). 
A todos os professores e colegas da Pós-Graduação, principalmente, pela amizade e pelos ensinamentos nas diversas disciplinas.

Por mais que o tempo passe, os conhecimentos ficam na memória. Não há nada mais engrandecedor do que poder ensinar e aprender uns com os outros. Muito obrigado por contribuirem com a minha formação acadêmica, serei grato eternamente. 
Resumo 

BIANCALANA, R.C. Análise das Propriedades Físicas e Mecânicas de Materiais Restauradores Odontológicos Submetidos à Ação do Calor e do Frio para Fins Periciais. Ribeirão Preto, 2015. 202 p. Dissertação (Mestrado em Reabilitação Oral; Área de concentração: Biologia Oral). Faculdade de Odontologia de Ribeirão Preto, Universidade de São Paulo.

\section{RESUMO}

O objetivo deste trabalho foi avaliar o efeito da ação do calor e do frio sobre a estabilidade de cor, rugosidade de superfície e microdureza de restaurações de resina composta (Filtek ${ }^{\mathrm{MR}} \mathrm{Z} 250$ XT 3M ESPE ${ }^{\circledR}$ ), cimento de ionômero de vidro (Ketac ${ }^{\mathrm{TM}}$ Fil Plus $3 \mathrm{M}$ ESPE ${ }^{\circledR}$ ) e amálgama de prata em cápsulas (gs-80 SDI ${ }^{\circledR}$ ), na tentativa de simular o comportamento desses materiais, quando presentes nos elementos dentais de vítimas carbonizadas ou mortas por congelamento. Foram selecionados 180 dentes bovinos que foram preparados ( $6 \times 6 \mathrm{~mm}$ com $2 \mathrm{~mm}$ de profundidade) e separados em grupos de 30 dentes, segundo o tipo de material restaurador utilizado. Em seguida, foram realizadas as leituras iniciais de cor (Espectrofotômetro VITA Easyshade ${ }^{\circledR}$ ), rugosidade de superfície (Rugosímetro Mitutoyo ${ }^{\circledR}$ Surftest SJ-201P) e microdureza Knoop (Microdurômetro Shimadzu ${ }^{\circledR}$ Micro Hardness Tester HMV-2), que foram consideradas os padrões iniciais. Subsequentemente, os dentes foram separados, aleatoriamente, em grupos $(\mathrm{n}=10)$ segundo a temperatura utilizada para simulação de congelamento $\left(-80^{\circ} \mathrm{C}\right),\left(-20^{\circ} \mathrm{C}\right)$ e $2,5^{\circ} \mathrm{C}$; e carbonização $\left(100^{\circ} \mathrm{C}, 200^{\circ} \mathrm{C}\right.$ e $\left.300^{\circ} \mathrm{C}\right)$. A submissão a altas temperaturas foi realizada pela colocação dos dentes restaurados em forno (ALUMINI Sinter-Press $E D G^{\circledR}$ ), pelo período de 15 minutos, e as baixas temperaturas foram realizadas em refrigerador (RFGE $700 \mathrm{GE}^{\circledR}$ ) a $2,5^{\circ} \mathrm{C}$; congelador (CVU18 Consul ${ }^{\circledR}$ ) a $\left(-20^{\circ} \mathrm{C}\right)$ e freezer (Ultra Freezer AL $374-80 \mathrm{~V}$ American Lab $\left.{ }^{\circledR}\right)$ a $\left(-80^{\circ} \mathrm{C}\right)$. Após 7 e 30 dias de ação do frio e da submissão ao calor, os dentes foram submetidos às leituras finais de cor, rugosidade e microdureza. No calor, os valores de alteração de cor $\left(\Delta \mathrm{E}, \Delta \mathrm{L}^{*}, \Delta \mathrm{a}^{*} \mathrm{e}\right.$ $\left.\Delta \mathrm{b}^{*}\right)$, dos dois materiais estéticos, rugosidade superficial e microdureza dos três materiais restauradores, foram submetidos à análise estatística One-way ANOVA, Tukey $(\mathrm{p}<0,05)$, tendo como fator de variação, a temperatura. No frio, os dados foram submetidos à análise estatística 2-way ANOVA, Bonferroni $(\mathrm{p}<0,05)$, tendo como fatores de variação, o tempo e a temperatura. Verificou-se que houve alteração de cor dos materiais estéticos, tanto nas submissões ao calor quanto ao frio. Na resina composta, a rugosidade de superfície e a microdureza não se alteraram significantemente ( $p>0,05)$, independente da temperatura a que foram submetidos. No CIV, a rugosidade e a microdureza elevaram-se nos testes ao calor; e ao frio, não ocorreram alterações significativas $(\mathrm{p}>0,05)$ dessas propriedades. Para o amálgama houve alteração de rugosidade significante $(\mathrm{p}<0,05)$ no calor, nas submissões a $300^{\circ} \mathrm{C}$; e a microdureza não se modificou. Ao frio não ocorreram mudanças significantes $(p>0,05)$ na rugosidade nem na microdureza do amálgama. Concluiu-se que os materiais estéticos podem ser distinguidos, pela análise de cor, a partir de $200^{\circ} \mathrm{C}$ até $300^{\circ} \mathrm{C}$ e quando submetidos a $\left(-80^{\circ} \mathrm{C}\right)$, tanto em 7 dias como em 30 dias. 0 tempo de congelamento não é significativo para a distinção dos materiais. Testes de rugosidade e microdureza podem distinguir os materiais estéticos, independentemente, da ação do calor ou do frio.

Palavras-chave: Identificação humana, Odontologia Legal, Materiais Dentários, Estabilidade de cor, Rugosidade de superfície, Microdureza 

Abstract 

BIANCALANA, R.C. Analysis of physical and mechanical properties of dental restorative materials subjected to the action of heat and cold for forensic purposes. Ribeirão Preto, 2015. 202 p. Dissertation (Master's Degree in Oral Biology). Ribeirão Preto School of Dentistry, University of São Paulo, Brazil.

\section{$\underline{\text { ABSTRACT }}$}

The purpose of this study was to evaluate the effect of the action of heat and cold on color stability, surface roughness and microhardness of composite resin (Filtek ${ }^{\mathrm{MR}} \mathrm{Z} 250$ XT 3M ESPE ${ }^{\circledR}$ ), glass ionomer cement (Ketac ${ }^{\mathrm{TM}}$ Fil Plus 3M ESPE ${ }^{\circledR}$ ) and silver amalgam capsules (gs-80 SDI ${ }^{\circledR}$ ) restorations, in an attempt to simulate the behavior of these materials when present in dental elements of carbonized or killed by freezing victims. 180 bovine teeth were selected, prepared with a 6 × $6 \mathrm{~mm} 2 \mathrm{~mm}$ cavity and then separated into groups of 30 teeth, according to the type of restorative material. Then, initial color readings (Spectrophotometer VITA Easyshade ${ }^{\circledR}$ ), surface roughness (Rugosimeter Mitutoyo ${ }^{\circledR}$ Surftest SJ-201P) and Knoop microhardness (Shimadzu Micro Hardness tester ${ }^{\circledR}$ HMV-2) readings were performed, which were considered the initial standards. Afterwards, the teeth were randomly divided into groups $(n=10)$ according to the temperature used for freezing simulation $\left(-80^{\circ} \mathrm{C}\right),\left(-20^{\circ} \mathrm{C}\right),\left(2,5^{\circ} \mathrm{C}\right)$; and carbonization simulation $\left(100^{\circ} \mathrm{C}, 200^{\circ} \mathrm{C}, 300^{\circ} \mathrm{C}\right)$. Submission to high temperatures was performed by placing the restored teeth in an oven (ALUMINI Sinter Press EDG ${ }^{\circledR}$ ), for 15 minutes and for low temperatures, a refrigerator (RFGE $700 \mathrm{GE}^{\circledR}$ ) at $2,5^{\circ} \mathrm{C}$, a freezer (CVU18 Consul ${ }^{\circledR}$ ) at $\left(-20^{\circ} \mathrm{C}\right)$ and an ultra freezer (Ultra Freezer AL $374-80 \mathrm{~V}$ American Lab $\left.{ }^{\circledR}\right)$ at $\left(-80^{\circ} \mathrm{C}\right.$ ) were used. After the teeth being submitted to the action of cold and heat for 7 and 30 days, the color, surface roughness and microhardness final readings were performed. For the heat evaluation, the color change $\left(\Delta \mathrm{E}, \Delta \mathrm{L}^{*}, \Delta \mathrm{a}^{*}\right.$ e $\left.\Delta \mathrm{b}^{*}\right)$ of the two aesthetic materials, and the surface roughness and microhardness of the three restorative materials, were subjected to statistical analysis (One-way ANOVA, Tukey, p<.05), with one variation factor, the temperature. For the cold evaluation, the data were statistically analyzed using 2-way ANOVA, Bonferroni, ( $p>$.05) with two variation factors, time and temperature. Color alteration occurred for the aesthetic materials submitted to heat and cold. In the composite resin, the surface roughness and microhardness did not change ( $p>$.05), regardless of temperature to which they were exposed. In CIV, the surface roughness and microhardness increased with the heat. After cold submission, there were no significant changes $(p>.05)$ to these properties. For the amalgam, there was roughness change $(\mathrm{p}<.05)$ when submitted to heat at $300^{\circ} \mathrm{C}$; the microhardness did not change. There were no significant changes in amalgam roughness or microhardness when teeth were submitted to cold ( $p>$.05). It was concluded that the aesthetic materials can be distinguished by the color analysis, from $200^{\circ} \mathrm{C}$ to $300^{\circ} \mathrm{C}$ and when submitted to $\left(-80^{\circ} \mathrm{C}\right)$, both after 7 days and 30 days. The freezing time is not significant for the distinction of materials. Roughness and microhardness tests can distinguish the aesthetic materials, regardless of the action of heat or cold.

Keywords: Forensic Anthropology, Forensic Dentistry, Dental Materials, Color stability, Surface roughness, Microhardness. 



\section{LISTA DE FIGURAS}

Figura 01 - Dente bovino em face vestibular; proximal e palatina/lingual $\quad \mathbf{6 3}$

Figura 02 - Broca cilíndrica diamantada nำ1343 63

Figura 03 - Incisivo bovino hígido; Delineamento das margens do preparo; 64 Preparo cavitário na face vestibular

Figura 04 - Profundidade do preparo cavitário $\quad \mathbf{6 4}$

Figura 05 - Mensuração do preparo cavitário com o uso de um paquímetro $\mathbf{6 4}$ digital

Figura 06 - Retenção adicional com broca diamantada roda nำ1052 64

Figura 07 - Amálgama em cápsulas gs80 - 2 porções; Trituração no aparelho 66 amalgamador Ultramat 2

Figura 08 - Inserção do amálgama na cavidade; Brunidura e polimento $\quad \mathbf{6 6}$

Figura 09 - Aplicação do condicionador para ataque ácido Alpha Etch no 67 preparo cavitário

Figura 10 - Aplicação do sistema adesivo Adper Single Bond 2 no preparo 67 cavitário

Figura 11 - Confecção da restauração em resina composta Filtek ${ }^{\mathrm{MR}}$ Z250 XT e $\mathbf{6 8}$ fotopolimerização com aparelho fotopolimerizador Ultralux EL

Figura 12 - Confecção da restauração com cimento de ionômero de vidro Ketac $^{\mathrm{TM}}$ Fil Plus

Figura 13 - Escala nํ2 da ABFO e Escala milimetrada confeccionada $\quad \mathbf{7 0}$

Figura 14 - Dispositivo com a escala milimetrada $\quad \mathbf{7 0}$

Figura 15 - Registros fotográficos realizados com câmera digital Lumix DMC- $\mathbf{7 1}$ FZ100

Figura 16 - Fotografias dos dentes bovinos restaurados com amálgama; resina

71 composta e cimento de ionômero de vidro

Figura 17 - Unidade Programadora de Controle e Registro da Leitura; Unidade Transversal Motorizada Precursora de Leitura

Figura 18 - Unidade Transversal (motor e agulha); Posicionamento da agulha na superfície da restauração; Leitura da rugosidade superficial no sentido inciso-cervical

Figura 19 - Microdurômetro HMV-2; Visor acoplado ao aparelho; Lentes objetivas e ponta penetradora

Figura 20 - Focalização da área da restauração com lente objetiva de 40X e 10X; Mensuração da microdureza Knoop por carga exercida pelo penetrador

Figura 21 - Área da restauração focalizada; Impressão losangular realizada pela ponta penetradora; Mensuração da maior diagonal do losango impresso com auxílio das barras verticais I e II 
Figura 22 - Valores da microdureza Knoop dos três diferentes materiais $\mathbf{7 5}$ restauradores

Figura 23 - Espectrofotômetro VITA EasyShade ${ }^{\circledR} \quad \mathbf{7 6}$

Figura 24 - Leitura numérica de cor (CIE L*a*b*) 77

Figura 25 - Calibragem da sonda; Posição para leitura numérica da cor $\quad 77$

Figura 26 - Distribuição amostral segundo a temperatura de submissão $\quad \mathbf{7 8}$

Figura 27 - Refrigerador para os testes a $2,5^{\circ} \mathrm{C}$; Congelador vertical para os $\mathbf{7 9}$ testes a $\left(-20^{\circ} \mathrm{C}\right)$; Freezer para os testes a $\left(-80^{\circ} \mathrm{C}\right)$

Figura 28 - Termômetro infravermelho portátil; Recipientes plásticos com tampa contendo os dentes bovinos; Aferição das temperaturas internas no refrigerador e no congelador

Figura 29 - Indicador de temperatura do Ultra Freezer; Recipiente com dentes bovinos no interior do freezer; Dente retirado após 30 dias de exposição a $\left(-80^{\circ} \mathrm{C}\right)$

Figura 30 - Forno ALUMINI Sinter-Press; Acionamento do forno para início da queima

Figura 31 - Total enegrecimento das restaurações em resina composta e CIV submetidas a $400^{\circ} \mathrm{C}$

Figura 32 - Restauração em amálgama submetida a $400^{\circ} \mathrm{C}$ e $500^{\circ} \mathrm{C}$

Figura 33 - Comparação visual das restaurações de resina composta, antes e após a submissão ao calor

Figura 34 - Comparação visual das restaurações de CIV, antes e após a $\mathbf{1 0 8}$ submissão ao calor

Figura 35 - Comparação visual das restaurações de amálgama, antes e após a submissão ao calor

Figura 36 - Discreta fenda entre o CIV e o dente, na submissão a $200^{\circ} \mathrm{C}$; Pequenas rachaduras no CIV e interface dente/restauração degrada em $300^{\circ} \mathrm{C}$

Figura 37 - Formação de bolhas de mercúrio nas restaurações de amálgama submetidas a $300^{\circ} \mathrm{C}$

Figura 38 - Comparação visual das restaurações de resina composta, antes e $\mathbf{1 4 5}$ após 7 e 30 dias de submissão ao frio

Figura 39 - Comparação visual das restaurações de CIV, antes e após 7 e $30 \mathbf{1 4 6}$ dias de submissão ao frio

Figura 40 - Comparação visual das restaurações de amálgama, antes e após $7 \quad \mathbf{1 4 7}$ e 30 dias de submissão ao frio 


\section{LISTA DE TABELAS}

Tabela 01 - Materiais utilizados, marcas comerciais, composição e $\mathbf{6 5}$ fabricantes

Tabela 02 - Coordenadas $\mathrm{L}^{*}, \mathrm{a}^{*}$ e b*, antes e após exposição ao calor, e $\Delta \mathrm{L}^{*}, \mathbf{8 7}$ $\Delta \mathrm{a}^{*}, \Delta \mathrm{b}^{*} \mathrm{e} \Delta \mathrm{E}$ após a submissão da resina composta a $100^{\circ} \mathrm{C}$

Tabela 03 - Coordenadas $\mathrm{L}^{*}, \mathrm{a}^{*}$ e b*, antes e após exposição ao calor, e $\Delta \mathrm{L}^{*}, \mathbf{8 7}$ $\Delta \mathrm{a}^{*}, \Delta \mathrm{b}^{*} \mathrm{e} \Delta \mathrm{E}$ após a submissão da resina composta a $200^{\circ} \mathrm{C}$

Tabela 04 - Coordenadas $\mathrm{L}^{*}, \mathrm{a}^{*}$ e $\mathrm{b}^{*}$, antes e após exposição ao calor, e $\Delta \mathrm{L}^{*}, \mathbf{8 8}$ $\Delta \mathrm{a}^{*}, \Delta \mathrm{b}^{*} \mathrm{e} \Delta \mathrm{E}$ após a submissão da resina composta a $300^{\circ} \mathrm{C}$

Tabela 05 - Coordenadas $L^{*}, a^{*}$ e b*, antes e após exposição ao calor, e $\Delta L^{*}, 88$ $\Delta \mathrm{a}^{*}, \Delta \mathrm{b}^{*} \mathrm{e} \Delta \mathrm{E}$ após a submissão do CIV a $100^{\circ} \mathrm{C}$

Tabela 06 - Coordenadas $\mathrm{L}^{*}, \mathrm{a}^{*}$ e b*, antes e após exposição ao calor, e $\Delta \mathrm{L}^{*}, \mathbf{8 9}$ $\Delta \mathrm{a}^{*}, \Delta \mathrm{b}^{*}$ e $\Delta \mathrm{E}$ após a submissão do CIV a $200^{\circ} \mathrm{C}$

Tabela 07 - Coordenadas $\mathrm{L}^{*}, \mathrm{a}^{*}$ e b*, antes e após exposição ao calor, e $\Delta \mathrm{L}^{*}, \mathbf{8 9}$ $\Delta \mathrm{a}^{*}, \Delta \mathrm{b}^{*}$ e $\Delta \mathrm{E}$ após a submissão do CIV a $300^{\circ} \mathrm{C}$

Tabela 08 - Comparação de $\Delta \mathrm{E}$, da resina composta, do CIV e entre os materiais, nas mesmas temperaturas, na submissão ao calor

Tabela 09 - Comparação de $\Delta \mathrm{E}$, da resina composta, do CIV e entre os materiais, em diferentes temperaturas, na submissão ao calor

Tabela 10 - Comparação de $\Delta \mathrm{L}^{*}$, da resina composta, do CIV e entre os materiais, nas mesmas temperaturas, na submissão ao calor

Tabela 11 - Comparação de $\Delta \mathrm{L}^{*}$, da resina composta, do CIV e entre os materiais, em diferentes temperaturas, na submissão ao calor

Tabela 12 - Comparação de $\Delta \mathrm{a}^{*}$, da resina composta, do CIV e entre os materiais, nas mesmas temperaturas, na submissão ao calor

Tabela 13 - Comparação de $\Delta \mathrm{a}^{*}$, da resina composta, do CIV e entre os materiais, em diferentes temperaturas, na submissão ao calor

Tabela 14 - Comparação de $\Delta \mathrm{b}^{*}$, da resina composta, do CIV e entre os materiais, nas mesmas temperaturas, na submissão ao calor

Tabela 15 - Comparação de $\Delta \mathrm{b}^{*}$, da resina composta, do CIV e entre os materiais, em diferentes temperaturas, na submissão ao calor

Tabela 16 - Rugosidade de superfície (Ra), antes e após exposição ao calor, e 98 $\Delta \mathrm{Ra}$ após submissão da resina composta ao calor

Tabela 17 - Rugosidade de superfície (Ra), antes e após exposição ao calor, e 99 $\Delta$ Ra após submissão do CIV ao calor

Tabela 18 - Rugosidade de superfície (Ra), antes e após exposição ao calor, e 99 $\Delta$ Ra após submissão do amálgama ao calor

Tabela 19 - Comparação de $\Delta \mathrm{Ra}$, da resina composta, do CIV e entre os $\mathbf{1 0 0}$ materiais, nas mesmas temperaturas, na submissão ao calor 
Tabela 20 - Comparação de $\Delta \mathrm{Ra}$, da resina composta, do CIV e entre os materiais, em diferentes temperaturas, na submissão ao calor

Tabela 21 - Comparação de $\Delta \mathrm{Ra}$, do amálgama, na submissão ao calor $\quad 102$

Tabela 22 - Microdureza Knoop (KHN), antes e após exposição ao calor, e 103 $\Delta$ KHN após submissão da resina composta ao calor

Tabela 23 - Microdureza Knoop (KHN), antes e após exposição ao calor, e $\Delta$ KHN após submissão do CIV ao calor

Tabela 24 - Microdureza Knoop (KHN), antes e após exposição ao calor, e $\Delta$ KHN após submissão do amálgama ao calor

Tabela 25 - Comparação de $\Delta \mathrm{KHN}$, da resina composta, do CIV e entre os materiais, nas mesmas temperaturas, na submissão ao calor

Tabela 26 - Comparação de $\Delta \mathrm{KHN}$, da resina composta, do CIV e entre os materiais, em diferentes temperaturas, na submissão ao calor

Tabela 27 - Comparação de $\Delta$ KHN do amálgama, na submissão ao calor

Tabela 28 - Coordenadas $\mathrm{L}^{*}, \mathrm{a}^{*}$ e b*, antes e após 7 dias de exposição ao frio, e $\Delta \mathrm{L}^{*}, \Delta \mathrm{a}^{*}, \Delta \mathrm{b}^{*}$ e $\Delta \mathrm{E}$ após a submissão da resina composta a $2,5^{\circ} \mathrm{C}$

Tabela 29 - Coordenadas $\mathrm{L}^{*}, \mathrm{a}^{*}$ e b*, antes e após 30 dias de exposição ao frio, e $\Delta \mathrm{L}^{*}, \Delta \mathrm{a}^{*}, \Delta \mathrm{b}^{*}$ e $\Delta \mathrm{E}$ após a submissão da resina composta a $2,5^{\circ} \mathrm{C}$

Tabela 30 - Coordenadas $\mathrm{L}^{*}, \mathrm{a}^{*}$ e b*, antes e após 7 dias de exposição ao frio, e $\Delta \mathrm{L}^{*}, \Delta \mathrm{a}^{*}, \Delta \mathrm{b}^{*}$ e $\Delta \mathrm{E}$ após a submissão da resina composta a $\left(-20^{\circ} \mathrm{C}\right)$

Tabela 31 - Coordenadas $\mathrm{L}^{*}, \mathrm{a}^{*}$ e b*, antes e após 30 dias de exposição ao frio, e $\Delta \mathrm{L}^{*}, \Delta \mathrm{a}^{*}, \Delta \mathrm{b}^{*}$ e $\Delta \mathrm{E}$ após a submissão da resina composta a $\left(-20^{\circ} \mathrm{C}\right)$

Tabela 32 - Coordenadas $\mathrm{L}^{*}, \mathrm{a}^{*}$ e b*, antes e após 7 dias de exposição ao frio, e $\Delta \mathrm{L}^{*}, \Delta \mathrm{a}^{*}, \Delta \mathrm{b}^{*}$ e $\Delta \mathrm{E}$ após a submissão da resina composta a $\left(-80^{\circ} \mathrm{C}\right)$

Tabela 33 - Coordenadas $\mathrm{L}^{*}$, a* e b*, antes e após 30 dias de exposição ao frio, e $\Delta \mathrm{L}^{*}, \Delta \mathrm{a}^{*}, \Delta \mathrm{b}^{*}$ e $\Delta \mathrm{E}$ após a submissão da resina composta a $\left(-80^{\circ} \mathrm{C}\right)$

Tabela 34 - Coordenadas L*, a* e b*, antes e após 7 dias de exposição ao frio, e $\Delta \mathrm{L}^{*}, \Delta \mathrm{a}^{*}, \Delta \mathrm{b}^{*}$ e $\Delta \mathrm{E}$ após a submissão do $\mathrm{CIV}$ a $2,5^{\circ} \mathrm{C}$

$\begin{aligned} \text { Tabela } 35 \text { - } & \text { Coordenadas } \mathrm{L}^{*}, \mathrm{a}^{*} \text { e b*, antes e após } 30 \text { dias de exposição ao frio, } \\ & \text { e } \Delta \mathrm{L}^{*}, \Delta \mathrm{a}^{*}, \Delta \mathrm{b}^{*} \text { e } \Delta \mathrm{E} \text { após a submissão do CIV a } 2,5^{\circ} \mathrm{C}\end{aligned}$

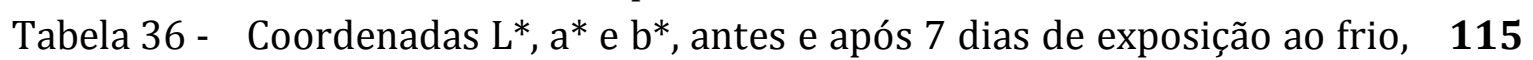
e $\Delta \mathrm{L}^{*}, \Delta \mathrm{a}^{*}, \Delta \mathrm{b}^{*}$ e $\Delta \mathrm{E}$ após a submissão do CIV a $\left(-20^{\circ} \mathrm{C}\right)$

Tabela 37 - Coordenadas $\mathrm{L}^{*}, \mathrm{a}^{*}$ e b*, antes e após 30 dias de exposição ao frio, 115 e $\Delta \mathrm{L}^{*}, \Delta \mathrm{a}^{*}, \Delta \mathrm{b}^{*}$ e $\Delta \mathrm{E}$ após a submissão do $\operatorname{CIV}$ a $\left(-20^{\circ} \mathrm{C}\right)$

Tabela 38 - Coordenadas $\mathrm{L}^{*}, \mathrm{a}^{*} \mathrm{e} \mathrm{b}$, antes e após 7 dias de exposição ao frio, 116 e $\Delta \mathrm{L}^{*}, \Delta \mathrm{a}^{*}, \Delta \mathrm{b}^{*}$ e $\Delta \mathrm{E}$ após a submissão do $\operatorname{CIV}$ a $\left(-80^{\circ} \mathrm{C}\right)$ 
Tabela 39 - Coordenadas L*, a* e b*, antes e após 30 dias de exposição ao frio, e $\Delta \mathrm{L}^{*}, \Delta \mathrm{a}^{*}, \Delta \mathrm{b}^{*}$ e $\Delta \mathrm{E}$ após a submissão do $\operatorname{CIV}$ a $\left(-80^{\circ} \mathrm{C}\right)$

Tabela 40 - Comparação de $\Delta \mathrm{E}$, da resina composta, do CIV e entre os materiais, nas mesmas temperaturas, após 7 dias de submissão ao frio

Tabela 41 - Comparação de $\Delta \mathrm{E}$, da resina composta, do CIV e entre os materiais, em diferentes temperaturas, após 7 dias de submissão ao frio

Tabela 42 - Comparação de $\Delta \mathrm{E}$, da resina composta, do CIV e entre os materiais, nas mesmas temperaturas, após 30 dias de submissão ao frio

Tabela 43 - Comparação de $\Delta \mathrm{E}$, da resina composta, do CIV e entre os materiais, em diferentes temperaturas, após 30 dias de submissão ao frio

Tabela 44 - Comparação de $\Delta \mathrm{E}$, da resina composta e do CIV, entre 7 e 30 dias, na submissão ao frio

Tabela 45 - Comparação de $\Delta \mathrm{L}^{*}$, da resina composta, do CIV e entre os materiais, nas mesmas temperaturas, após 7 dias de submissão ao frio

Tabela 46 - Comparação de $\Delta \mathrm{L}^{*}$, da resina composta, do CIV e entre os materiais, em diferentes temperaturas, após 7 dias de submissão ao frio

Tabela 47 - Comparação de $\Delta \mathrm{L}^{*}$, da resina composta, do CIV e entre os materiais, nas mesmas temperaturas, após 30 dias de submissão ao frio

Tabela 48 - Comparação de $\Delta \mathrm{L}^{*}$, da resina composta, do CIV e entre os materiais, em diferentes temperaturas, após 30 dias de submissão ao frio

Tabela 49 - Comparação de $\Delta \mathrm{L}^{*}$, da resina composta e do CIV, entre 7 e 30 dias, na submissão ao frio

Tabela 50 - Comparação de $\Delta \mathrm{a}^{*}$, da resina composta, do CIV e entre os materiais, nas mesmas temperaturas, após 7 dias de submissão ao frio

Tabela 51 - Comparação de $\Delta \mathrm{a}^{*}$, da resina composta, do CIV e entre os materiais, em diferentes temperaturas, após 7 dias de submissão ao frio

Tabela 52 - Comparação de $\Delta \mathrm{a}^{*}$, da resina composta, do CIV e entre os materiais, nas mesmas temperaturas, após 30 dias de submissão ao frio

Tabela 53 - Comparação de $\Delta \mathrm{a}^{*}$, da resina composta, do CIV e entre os materiais, em diferentes temperaturas, após 30 dias de submissão ao frio

Tabela 54 - Comparação de $\Delta \mathrm{a}^{*}$, da resina composta e do CIV, entre 7 e 30 dias, na submissão ao frio

Tabela 55 - Comparação de $\Delta \mathrm{b}^{*}$, da resina composta, do CIV e entre os materiais, nas mesmas temperaturas, após 7 dias de ação do frio 
Tabela 56 - Comparação de $\Delta \mathrm{b}^{*}$, da resina composta, do CIV e entre os materiais, em diferentes temperaturas, após 7 dias de ação do frio

Tabela 57 - Comparação de $\Delta \mathrm{b}^{*}$, da resina composta, do CIV e entre os

127 materiais, nas mesmas temperaturas, após 30 dias de submissão ao frio

Tabela 58 - Comparação de $\Delta \mathrm{b}^{*}$, da resina composta, do CIV e entre os materiais, em diferentes temperaturas, após 30 dias de submissão ao frio

Tabela 59 - Comparação de $\Delta \mathrm{b}^{*}$, da resina composta e do CIV, entre 7 e 30 dias, na submissão ao frio

Tabela 60 - Rugosidade de superfície (Ra), antes e após exposição ao frio, e $\Delta$ Ra após submissão da resina composta a $2,5^{\circ} \mathrm{C}$

Tabela 61 - Rugosidade de superfície (Ra), antes e após exposição ao frio, e $\Delta$ Ra após submissão da resina composta a $\left(-20^{\circ} \mathrm{C}\right)$

Tabela 62 - Rugosidade de superfície (Ra), antes e após exposição ao frio, e $\Delta$ Ra após submissão da resina composta a $\left(-80^{\circ} \mathrm{C}\right)$

Tabela 63 - Rugosidade de superfície (Ra), antes e após exposição ao frio, e $\Delta$ Ra após submissão do $\mathrm{CIV}$ a $2,5^{\circ} \mathrm{C}$

Tabela 64 - Rugosidade de superfície (Ra), antes e após exposição ao frio, e $\Delta$ Ra após submissão do $\mathrm{CIV}$ a $\left(-20^{\circ} \mathrm{C}\right)$

Tabela 65 - Rugosidade de superfície (Ra), antes e após exposição ao frio, e $\Delta$ Ra após submissão do $\mathrm{CIV}$ a $\left(-80^{\circ} \mathrm{C}\right)$

Tabela 66 - Rugosidade de superfície (Ra), antes e após exposição ao frio, e $\Delta$ Ra após submissão do amálgama a $2,5^{\circ} \mathrm{C}$

Tabela 67 - Rugosidade de superfície (Ra), antes e após exposição ao frio, e $\Delta$ Ra após submissão do amálgama a $\left(-20^{\circ} \mathrm{C}\right)$

Tabela 68 - Rugosidade de superfície (Ra), antes e após exposição ao frio, e $\Delta$ Ra após submissão do amálgama a $\left(-80^{\circ} \mathrm{C}\right)$

Tabela 69 - Comparação de $\Delta \mathrm{Ra}$, da resina composta, do CIV e entre os materiais, nas mesmas temperaturas, na submissão ao frio

Tabela 70 - Comparação de $\Delta \mathrm{Ra}$, da resina composta, do CIV e entre os materiais, em diferentes temperaturas, após 7 dias de exposição ao frio

Tabela 71 - Comparação de $\Delta \mathrm{Ra}$, da resina composta, do CIV e entre os materiais, em diferentes temperaturas, após 30 dias de exposição ao frio

Tabela 72 - Comparação de $\Delta \mathrm{Ra}$ do amálgama, na submissão ao frio

Tabela 73 - Microdureza Knoop (KHN), antes e após exposição ao frio, e $\Delta \mathrm{KHN}$ após submissão da resina composta a $2,5^{\circ} \mathrm{C}$

Tabela 74 - Microdureza Knoop (KHN), antes e após exposição ao frio, e $\mathbf{1 3 7}$ $\Delta \mathrm{KHN}$ após submissão da resina composta a $\left(-20^{\circ} \mathrm{C}\right)$ 
Tabela 75 - Microdureza Knoop (KHN), antes e após exposição ao frio, e 138 $\Delta \mathrm{KHN}$ após submissão da resina composta a $\left(-80^{\circ} \mathrm{C}\right)$

Tabela 76 - Microdureza Knoop (KHN), antes e após exposição ao frio, e 138 $\Delta$ KHN após submissão do CIV a $2,5^{\circ} \mathrm{C}$

Tabela 77 - Microdureza Knoop (KHN), antes e após exposição ao frio, e 139 $\Delta$ KHN após submissão do CIV a $\left(-20^{\circ} \mathrm{C}\right)$

Tabela 78 - Microdureza Knoop (KHN), antes e após exposição ao frio, e 139 $\Delta$ KHN após submissão do CIV a $\left(-80^{\circ} \mathrm{C}\right)$

Tabela 79 - Microdureza Knoop (KHN), antes e após exposição ao frio, e 140 $\Delta$ KHN após submissão do amálgama a $2,5^{\circ} \mathrm{C}$

Tabela 80 - Microdureza Knoop (KHN), antes e após exposição ao frio, e 140 $\Delta$ KHN após submissão do amálgama a $\left(-20^{\circ} \mathrm{C}\right)$

Tabela 81 - Microdureza Knoop (KHN), antes e após exposição ao frio, e $\mathbf{1 4 1}$ $\triangle \mathrm{KHN}$ após submissão do amálgama a $\left(-80^{\circ} \mathrm{C}\right)$

Tabela 82 - Comparação de $\Delta K H N$, da resina composta, do CIV e entre os $\mathbf{1 4 1}$ materiais, nas mesmas temperaturas, na submissão ao frio

Tabela 83 - Comparação de $\Delta K H N$, da resina composta, do CIV e entre os $\mathbf{1 4 2}$ materiais, em diferentes temperaturas, após 7 dias de exposição ao frio

Tabela 84 - Comparação de $\Delta \mathrm{KHN}$, da resina composta, do CIV e entre os materiais, em diferentes temperaturas, após 30 dias de exposição ao frio

Tabela 85 - Comparação de $\Delta$ KHN do amálgama, na submissão ao frio 



\section{LISTA DE GRÁFICOS}

Gráfico 01 - Comparação de $\Delta \mathrm{E}$ entre os materiais restauradores estéticos 91 submetidos à ação do calor

Gráfico 02 - Comparação de $\Delta \mathrm{L}^{*}$ entre os materiais restauradores estéticos 93 submetidos à ação do calor

Gráfico 03 - Comparação de $\Delta \mathrm{a}^{*}$ entre os materiais restauradores estéticos 95 submetidos à ação do calor

Gráfico 04 - Comparação de $\Delta \mathrm{b}^{*}$ entre os materiais restauradores estéticos 97 submetidos à ação do calor

Gráfico 05 - Comparação de $\Delta \mathrm{Ra}$ entre os materiais restauradores estéticos submetidos à ação do calor

Gráfico 06 - Comparação de $\Delta \mathrm{Ra}$ entre as restaurações de amálgama submetidas à ação do calor

Gráfico 07 - Comparação de $\Delta \mathrm{KHN}$ entre os materiais restauradores estéticos submetidos à ação do calor

Gráfico 08 - Comparação de $\Delta \mathrm{KHN}$ entre as restaurações de amálgama submetidas à ação do calor

Gráfico 09 - Comparação de $\Delta \mathrm{E}$ entre os materiais restauradores estéticos submetidos à ação do frio

Gráfico 10 - Comparação de $\Delta \mathrm{L}^{*}$ entre os materiais restauradores estéticos submetidos à ação do frio

Gráfico 11 - Comparação de $\Delta \mathrm{a}^{*}$ entre os materiais restauradores estéticos submetidos à ação do frio

Gráfico 12 - Comparação de $\Delta \mathrm{b}^{*}$ entre os materiais restauradores estéticos submetidos à ação do frio

Gráfico 13 - Comparação de $\Delta \mathrm{Ra}$ entre os materiais restauradores estéticos submetidos à ação do frio

Gráfico 14 - Comparação de $\Delta \mathrm{Ra}$ entre as restaurações de amálgama submetidas à ação do frio

Gráfico 15 - Comparação de $\Delta \mathrm{KHN}$ entre os materiais restauradores estéticos submetidos à ação do frio

Gráfico 16 - Comparação de $\Delta \mathrm{KHN}$ entre as restaurações de amálgama submetidas à ação do frio 



\section{SUMÁRIO}

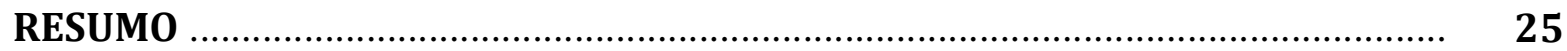

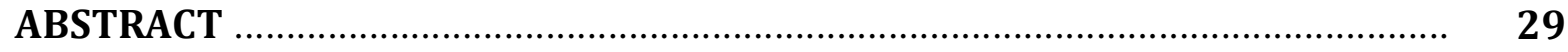

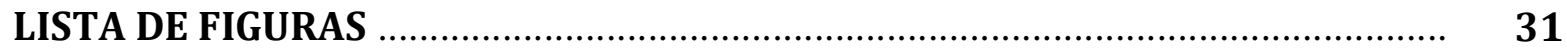

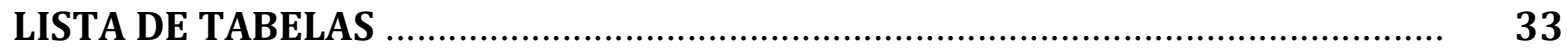

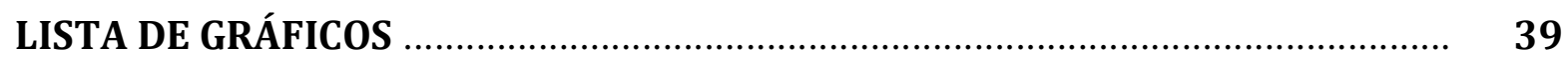

1. INTRODUÇÃ

1.1. $\quad$ Odontologia Legal ....................................................................... 45

1.2. Identificação humana ...................................................................... 46

1.3. $\quad$ Métodos de Identificação humana ……............................................... 47

1.4. Método odontológico ................................................................ 49

1.5. Identificação em corpos carbonizados ............................................. 51

1.6. Ação das altas temperaturas nos elementos dentais ........................... 52

1.7. Identificação em corpos congelados ................................................. 54

1.8. Materiais restauradores odontológicos …...................................... 55

1.9. Exposição dos materiais restauradores a altas e baixas temperaturas .............................................................................. 56

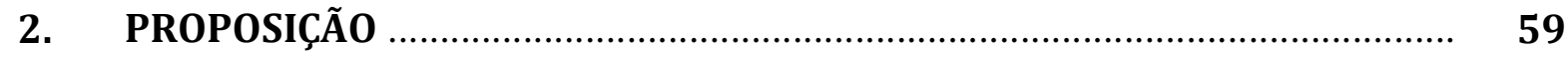

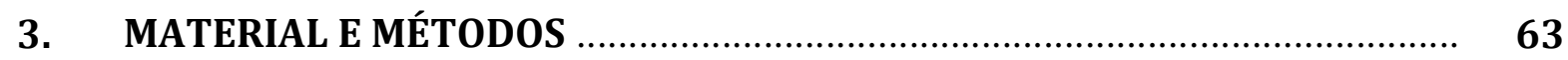

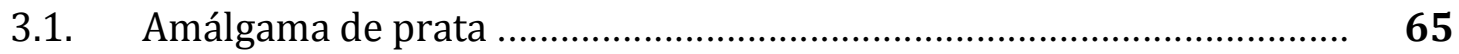

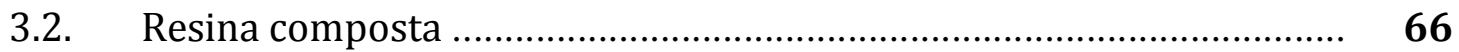

3.3. Cimento de ionômero de vidro .........................................................68

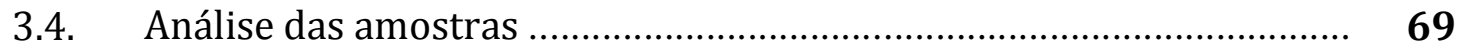

3.5. Rugosidade de superfície ……........................................................ 71

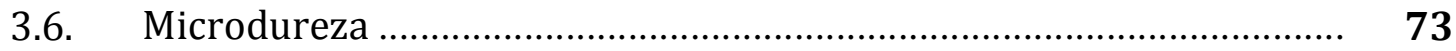

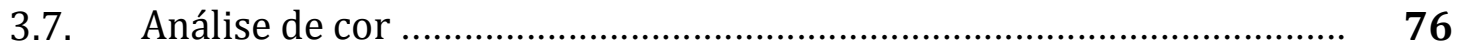

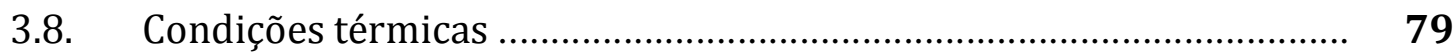


3.8.1. Baixas temperaturas (Frio) ……................................................... 79

3.8.2. Altas temperaturas (Calor) .......................................................... $\quad 80$

3.9. Análise estatística ............................................................................... 82

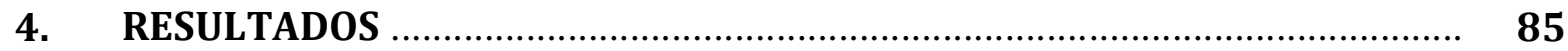

4.1. Altas temperaturas (Ação do calor) …................................................. 85

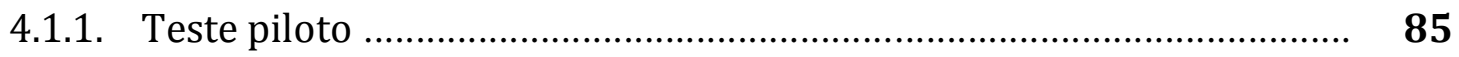

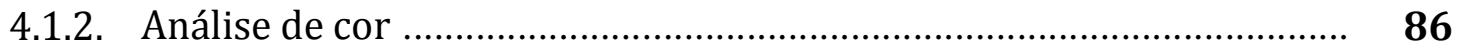

4.1.3. Rugosidade de superfície .............................................................. 98

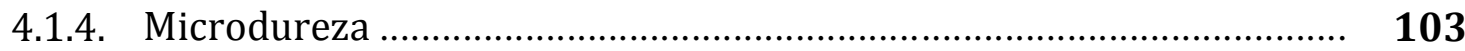

4.1.5. Análise visual ........................................................................... 108

4.2. Baixas temperaturas (Ação do frio) ….................................................... 110

4.2.1. Análise de cor ........................................................................... $\quad \mathbf{1 1 0}$

4.2.2. Rugosidade de superfície .............................................................. 129

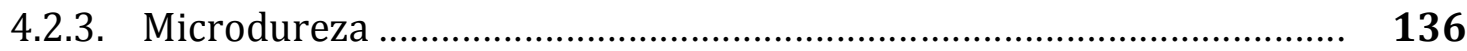

4.2.4. Análise visual .............................................................................. $\quad 144$

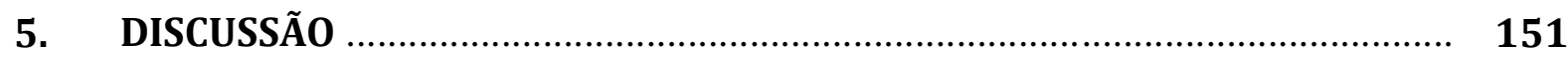

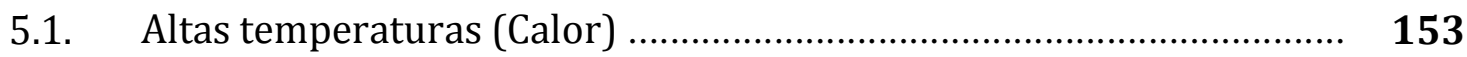

5.2. Baixas temperaturas (Frio) …................................................. 156

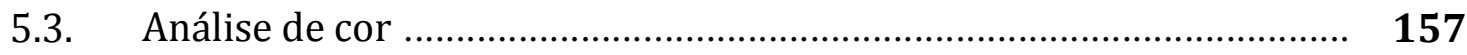

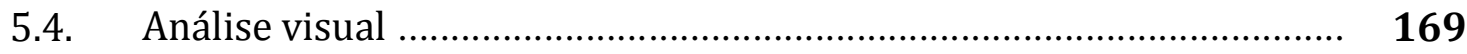

5.5. Rugosidade de superfície ...................................................... $\mathbf{1 7 1}$

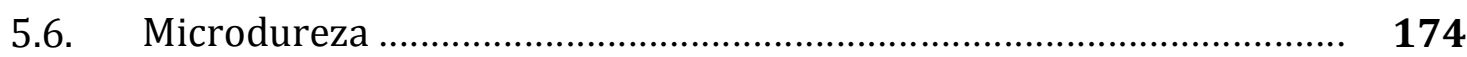

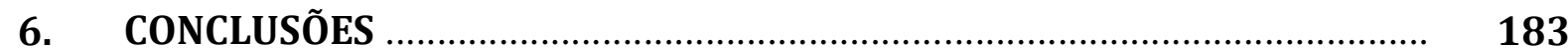

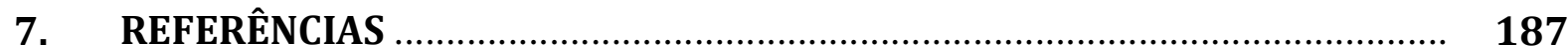


Introdução 



\section{INTRODUÇÃO}

\subsection{Odontologia Legal}

A Odontologia Legal é uma das especialidades da Odontologia, reconhecida e regulamentada, assim como as demais especialidades odontológicas, por meio da Resolução do Conselho Federal de Odontologia (CFO) 63/2005, Consolidação das Normas para Procedimentos nos Conselhos de Odontologia, atualizada em Julho/2012, sendo descrito como objetivo desta especialidade a pesquisa de fenômenos psíquicos, físicos, químicos e biológicos que podem atingir ou ter atingido o homem (vivo, morto e ossadas humanas) e, até mesmo, nos casos em que só existam fragmentos ou vestígios, resultando lesões parciais ou totais, reversíveis ou irreversíveis ${ }^{1}$.

Dentre as áreas de competência para atuação do profissional de Odontologia que exerce atividades em Odontologia Legal estão: a traumatologia odontolegal; tanatologia forense; elaboração de documentos odontolegais, como atestados, relatórios (autos e laudos) e pareceres; balística forense; perícia logística em indivíduos vivos, mortos, íntegros ou suas partes em fragmentos; perícia em vestígios correlatos, inclusive em manchas ou líquidos provenientes da cavidade bucal ou nela presentes; exames por imagens para fins periciais e para fins odontolegais; deontologia odontológica; orientação odontolegal para o exercício profissional e a identificação humana ${ }^{1}$.

Em âmbito forense, na maioria das vezes, a Odontologia é encarregada das circunstâncias envolvendo análises das regiões de cabeça e pescoço (sistema estomatognático, cavidade bucal, arcos dentais, crânio), como previsto na Lei 5081/66², que regula o exercício da Odontologia em todo o território nacional: “Art. 6. Compete ao Cirurgião-Dentista: (...) IV - proceder à perícia odontolegal em foro civil, criminal, trabalhista e em sede administrativa. (...) IX - utilizar, no exercício da função de peritoodontólogo, em casos de necropsia, as vias de acesso do pescoço e da cabeça”.

E tendo a Odontologia Legal relação direta com a execução de procedimentos periciais, esse ato pode ser definido como um procedimento especial de constatação, prova ou demonstração científica ou técnica, relacionado com a veracidade de uma situação, coisas ou fato. É a procura de elementos que formem uma opinião segura e adequada sobre um determinado fato o qual se pretende provar ${ }^{3,4}$. 
As perícias no foro criminal relacionadas com a atuação do profissional de Odontologia Legal podem envolver casos de lesões corporais, como acidentes em que a face e/ou a cavidade bucal sejam acometidas; crimes nos quais a vítima ou agressor sofram lesões faciais e/ou bucais; determinação de idade, da vítima ou do infrator; perícia de manchas ou líquidos presentes ou provenientes da cavidade bucal; determinação de embriaguez alcoólica, pelo exame salivar, e casos de identificação humana, em indivíduos vivos, mortos, no esqueleto ou fragmentos ósseos 5 .

Como visto, a Odontologia Legal é uma ciência apartada da terapia que utiliza os conhecimentos inerentes à Odontologia e suas diversas especialidades, correlacionando-os com o Direito, a fim de atender demandas legais, isto é, auxiliar a Justiça nos eventos previstos em lei ${ }^{6}$. Além da sua relação com o Direito, a Odontologia Legal está intimamente ligada à Medicina Legal devido ao seu poder de colaboração nas circunstâncias que compreendem a busca pela identificação humana ${ }^{7}$, assim como uma série de outras ciências ${ }^{5,8-10}$.

\subsection{Identificação humana}

Estabelecer a identidade de um ser humano, incontestavelmente, tem sido há muitos anos uma meta incansável. A identificação de uma pessoa requer que seja possível afirmar, com absoluta segurança e convicção, que determinado indivíduo é ele, e somente ele, e não uma pessoa diversa ${ }^{3}$.

Existem razões médico-legais, jurídicas e sociológicas, além dos complexos laços afetivos vinculados aos familiares envolvidos quando se busca a verdadeira identidade de um ser humano ${ }^{11}$. Ao citar a importância jurídica, temos a questão sucessória de bens materiais e, até mesmo, da responsabilidade civil. Com a finalidade de que um indivíduo possa gozar de direitos e deveres, ou seja, para que faça parte de uma sociedade e do convívio social é, estritamente, necessário que ele possua um documento de identificação.

Em casos de falecimento, por lei, a maioria dos países requer que o Atestado de Óbito seja emitido, não somente para revelar a causa mortis, como também para comprovar civilmente a morte e, consequentemente, solucionar problemas que abranjam: pensões alimentícias; guarda de menores; seguros de vida; a nova situação 
civil do cônjuge; a preparação do funerário; aposentadorias; repasse de dívidas, heranças e outros benefícios amparados pela Lei Civil ${ }^{12,13}$.

O processo de identificação de um ser humano pode ser conduzido de diversas maneiras, no entanto, é importante distinguir os conceitos de identificação e reconhecimento. Identificação é um processo objetivo, que visa determinar a identidade de uma pessoa, por meio de fundamentos científicos, baseados na somatoscopia (variações qualitativas) e na somatometria (variações quantitativas) do corpo humano ${ }^{12}$.

A identificação é promovida por profissionais especializados, os quais utilizam técnicas e métodos com rigor científico para a obtenção da identidade inequívoca do indivíduo ${ }^{14}$. A identidade é o conjunto formado pelas características morfofisiológicas e psíquicas exclusivas de uma única pessoa, sendo, dessa maneira, capaz de individualizála tornando-a diferente de todas as demais ${ }^{15}$.

Por outro lado, o reconhecimento é um método subjetivo, empírico, baseado num conhecimento anterior, aplicável quando os remanescentes do corpo encontram-se preservados, especialmente a face ${ }^{16}$. Portanto, é afirmar ou admitir conhecer algo que antes já se conhecia ${ }^{17}$, sendo passível de erros, de boa ou má fé.

0 reconhecimento, em geral, é realizado por familiares, amigos ou pessoas que conheciam previamente a vítima e que devido a este vínculo emocional, possivelmente, dotados de um sentimento de angústia e ansiedade, podem cometer erros na tentativa de reconhecer, por comparação, o ente querido ${ }^{18}$.

\subsection{Métodos de Identificação humana}

Enquanto na presença de indivíduos vivos ou mortos recentemente, há uma série de métodos de identificação aplicáveis, tais como: verificação de características externas (marcas no corpo, cicatrizes, tatuagens, amputações); características internas (presença de próteses, rugosidades palatinas, má-formação congênita de órgãos, tumores) ${ }^{13}$, além das análises comparativas de vídeos e fotografias.

O processo de identificação envolve métodos primários e secundários de identificação humana. Considerados como métodos primários, temos a Datiloscopia, o Perfil Genético (ou Perfil de DNA) e a Odontologia Legal' ${ }^{19-21 . ~}$ 
A Datiloscopia, por meio da verificação e estudo dos desenhos formados pelas papilas dérmicas dos dedos das mãos e das impressões físicas por elas deixadas, denominadas de impressões digitais ${ }^{22}$. 0 Perfil Genético, por meio da biologia molecular, pela investigação da presença e análise das porções variáveis do DNA (DeoxyriboNucleic Acid), ácido dexoxirribonucleico, que constitui o material genético de todas as células nucleadas de um organismo, contendo as instruções necessárias para seu funcionamento e desenvolvimento ${ }^{23,24}$.

Por fim, a Odontologia Legal, por intermédio do método odontológico ${ }^{5}$, compõem os três métodos primários de identificação humana. São ditos primários porque se um desses três métodos for capaz de conduzir a uma identificação positiva ou negativa (exclusão), de um indivíduo, não há a necessidade da aplicação de outro método para que se confirme o resultado anteriormente obtido.

No entanto, sempre que nos deparamos com a necessidade de identificação de indivíduos mortos, em que os corpos se encontram em estado avançado de decomposição, esqueletizados, carbonizados ${ }^{25,26}$, afogados em que as polpas digitais foram destruidas pela ação da fauna aquática, mutilados, despojados, entre outras condições, nas quais a datiloscopia, provavelmente, será descartada pela impossibilidade da obtenção de registros no corpo, a Odontologia Legal passa a ser o método de escolha mais viável ${ }^{27}$.

Há a possibilidade, também, da utilização do exame de DNA, mas por ser um método oneroso, com dificuldades de padronização, e pelo fato de pessoal tecnicamente preparado não estar disponível em todas as localidades, por tantas vezes é descartado. Somado a esses fatores, a falta de cuidados durante a coleta, transporte ou armazenamento do material a ser periciado, pode gerar contaminação da amostra e, consequente, falha nos resultados 28,29 .

Nessas situações, em que os corpos não se encontram íntegros, a Odontologia Legal pode representar a solução exequível para a identificação humana, propiciando redução no tempo de trabalho e custos de material, além de ser altamente confiável ${ }^{30}$, desde que feito um trabalho criterioso, minucioso e organizado por profissional especialista na área. 


\subsection{Método odontológico}

O método odontológico é um processo baseado em metodologias científicas sobre a análise especializada dos arcos dentais e dentição humana. É a inspeção visual e o estudo detalhado da anatomia dental, avaliando: posicionamento, como giroversões e apinhamentos; forma; tamanho; cor; presença de cáries; patologias; relação entre os arcos dentais, superior e inferior; envolvimento com próteses (totais ou parciais; fixas ou removíveis); implantes; aparelhos ortodônticos e materiais restauradores odontológicos $27,31,32$.

A identificação odontológica preenche todos os requisitos biológicos e técnicos ${ }^{3,5,12,17}$ de um processo de identificação humana aplicável que são: Unicidade/Individualidade (apenas um único indivíduo apresenta determinadas características). Os dentes e os arcos dentais exibem características únicas de indivíduo para indivíduo, não havendo duas pessoas com arcos dentais idênticos, ainda que não apresentem patologias bucais e/ou tratamentos odontológicos. Até mesmo gêmeos univitelinos dispõem de características dentais distintas, demonstrando a unicidade.

Imutabilidade (as características não se modificam com o passar do tempo). Os dentes não mudam com o tempo, a não ser por fatores externos, mas que são passíveis de verificação e registro prévio; Perenidade (as características têm capacidade de resistir à ação do tempo). Os elementos dentais são as estruturas mais resistentes do corpo humano à ação do tempo ${ }^{33}$; Praticabilidade (aplicável na rotina pericial - custo acessível, facilidade de obtenção e registro) e Classificabilidade (possibilidade de classificação para facilitar o arquivamento e posterior localização no momento em for necessário).

O método odontológico é rapidamente executável, congregando a facilidade de registro e classificação, além de atender também à Reprodutibilidade (capacidade de o material periciado ser verificado novamente com a mesma qualidade) ${ }^{34}$, ou seja, o estudo dos elementos dentais possibilita a execução de um novo exame com qualidade e precisão bastante similar ao do exame inicial.

A identificação pelo estudo dos arcos e elementos dentais é um método comparativo, isto porque, trata-se de um método em que são feitas comparações entre 
informações post mortem e ante mortem ${ }^{35}$. Na análise do crânio e seus respectivos arcos dentais, faz-se necessária a presença de dados odontológicos fornecidos pelos cirurgiões-dentistas que atendiam a vítima em vida ${ }^{36}$.

Os dados ante mortem são informações provenientes do prontuário odontológico, podendo ser compostos por: fotografias da vítima, com imagens em que se possa observar o sorriso para análise da dentição; radiografias odontológicas (panorâmicas, periapicais anteriores e posteriores, interproximais, oclusais) nas quais se consiga verificar as estruturas dentais e ósseas da maxila e mandíbula; tamanho, forma e número de raízes de cada dente; modelos de gesso; placas de clareamento; fichas clínicas, com a descrição dos tratamentos realizados, plano de tratamento, contrato de prestação de serviços odontológicos e outras informações que possam ser relevantes ${ }^{27,37}$.

Desse modo, evidencia-se que o prontuário odontológico, sendo um conjunto de documentos e declarações firmadas pelo paciente com o intuito da obtenção do diagnóstico, prognóstico, planejamento, execução e acompanhamento do tratamento, são documentos com funções clínica e administrativa, inclusive importante função legal, servindo como fonte de provas nos âmbitos civil e penal, sendo fundamentais no auxílio ao processo de identificação humana ${ }^{38,39}$.

No mundo atual, várias são as formas e situações de morte que tornam a identificação indispensável. Nas situações mais adversas é que se comprova o valor da Odontologia Legal ao oferecer subsídios para a identificação, devido à durabilidade e longevidade da dentição humana ${ }^{40,41}$. Os dentes não são decompostos, nem putrefeitos, suportam mudanças drásticas de temperatura e umidade ambiental ${ }^{42}$.

Dessa maneira, a identificação odontológica é capaz de ser muito valiosa, particularmente, em casos envolvendo vítimas que foram expostas diretamente ao fogo ou a altas temperaturas, isto porque, entre os prováveis remanescentes corpóreos, muito possivelmente, estarão presentes os elementos dentais, que são dentre os tecidos mineralizados do corpo humano, os mais resistentes à ação do calor ${ }^{43,44}$. 


\subsection{Identificação em corpos carbonizados}

Em corpos carbonizados, o pobre estado de conservação e a incompleta presença de tecidos remanescentes íntegros representam problemas comuns para a equipe pericial ${ }^{45}$. Em 1994, Moody e Busuttil ${ }^{46}$ descreveram que os principais métodos de identificação utilizados em um acidente aéreo, com vítimas carbonizadas, foram a Datiloscopia e a Odontologia Legal.

Há eventos em que as papilas dérmicas dos dedos das mãos, devido à ação do calor, podem encontrar-se destruídas e ressecadas de tal forma que impossibilite a coleta de impressões digitais. Em desastres em massa envolvendo corpos carbonizados, exames de DNA podem ser cruciais para a identificação. Entretanto, a coleta de material biológico para exame de DNA, nesses episódios, pode ser bastante dificultada ou até impossibilitada ${ }^{47}$.

A Biologia Molecular pode oferecer resultados extremamente confiáveis, contudo, o período de tempo para a conclusão de tais resultados, geralmente, é muito prolongado. Diante desse cenário, a Odontologia Legal, pela sua confiabilidade, pela resistência dos dentes ao calor e por preencher todos os requisitos de um adequado método de identificação humana é, comprovadamente, capaz, dependendo da situação, de ser o método mais viável ou o único aplicável para auxiliar em casos que envolvam acidentes com vítimas carbonizadas ${ }^{43}$.

Frequentemente, nos deparamos com incêndios, explosões, acidentes automobilísticos, quedas de aeronaves e outras ocorrências das quais resultam vítimas expostas ao intenso calor, seja este direto ou indireto ${ }^{48}$. De maneira constante, em incêndios a ação do fogo selvagem pode facilmente sair do controle e, com isso, causar efeitos devastadores fatais. Acidentes provenientes da ação do fogo permanecem sendo uma das principais causas de mortalidade em todo o mundo e a identificação dos corpos das vítimas continua sendo uma tarefa árdua ${ }^{49}$.

A temperatura assumida por um corpo humano em um incêndio depende da duração do mesmo, da intensidade e exposição direta às chamas ${ }^{50}$. De acordo com Aragão ${ }^{51}$ (2010), a energia calorífica desenvolvida por chamas de gasolina chegam, aproximadamente, a $1026^{\circ} \mathrm{C}$; chamas de querosene, $990^{\circ} \mathrm{C}$; chamas de benzeno, $920^{\circ} \mathrm{C}$; 
chamas de vela, de 600 a $1400^{\circ} \mathrm{C}$ e fósforos de fricção ("palitos de fósforo") acesos, de 600 a $800^{\circ} \mathrm{C}$.

Em locais com ventilação limitada e sem dispositivos de combate automático ao fogo, a temperatura local pode atingir em torno de $1100^{\circ} \mathrm{C}$. Porém, o tempo requerido para a instalação de tais níveis de calor, normalmente, são prolongados, por volta de 480 minutos. Em exposições mais curtas, análises em estruturas de concreto de edificações, indicam que em tempos de 10 minutos, a temperatura do ambiente pode alcançar, aproximadamente, $700^{\circ} \mathrm{C} ; 15$ minutos, $760^{\circ} \mathrm{C} ; 30$ minutos, $840^{\circ} \mathrm{C}$, sendo que níveis acima de $1000^{\circ} \mathrm{C}$, somente seriam obtidos com exposições acima de 120 minutos ${ }^{52}$.

O calor pode ser tão intenso a ponto de produzir a calcinação dos ossos, os quais se transformam em um material branco-acinzentado e friável ${ }^{3,12}$. No estado de carbonização, os elementos dentais podem exibir condições mais preservadas do que outros tecidos, já que representam o tecido corpóreo mais resistente à ação do calor ${ }^{53}$.

No caso específico de cadáveres carbonizados, dependendo da temperatura e do tempo de exposição ao calor, mudanças estruturais nos dentes e nos materiais restauradores odontológicos, que possam estar presentes na cavidade bucal, têm a potencialidade de fornecer dados importantes na estimativa da temperatura atingida ${ }^{54}$.

Dessa forma, os elementos dentais podem ser usados como prova criminal ${ }^{55}$. A literatura pericial relata como plenamente viável a identificação de corpos humanos carbonizados pela análise das particularidades odontológicas, principalmente em razão da resistência dos dentes e materiais restauradores à ação do calor e do fogo 56,57 .

\subsection{Ação das altas temperaturas nos elementos dentais}

Embora os elementos dentais sejam capazes de resistir a temperaturas de aproximadamente $1100^{\circ} \mathrm{C}$, a ação direta do fogo pode destruí-los. Ao atingir $150^{\circ} \mathrm{C}$, surgem linhas de fraturas, predominantemente, na porção coronária. Acima de $270^{\circ} \mathrm{C}$, a porção radicular torna-se enegrecida; por volta de $800^{\circ} \mathrm{C}$, o esmalte sofre carbonização e a dentina ainda mantém parcial integridade, mostrando, assim, maior resistência ao calor em relação ao esmalte dental ${ }^{3,41}$.

Trabalhos dedicados aos efeitos do aumento da temperatura em tecidos dentais têm sido bastante realizados. Yamamoto, et al. ${ }^{58}$ (1990) descobriram que ao 
atingir temperaturas acima de $1000^{\circ} \mathrm{C}$, torna-se difícil diferenciar as estruturas do tecido dental.

Myers, et al.59 (1999) avaliaram, por meio de técnicas histológicas, dentes submetidos a temperaturas de $300^{\circ} \mathrm{C}$ até $1400^{\circ} \mathrm{C}$. No seu estudo, verificaram que o esmalte dental, composto de $96 \%$ de matérias inorgânicas, resiste bem ao calor devido a sua natureza prismática e torna-se friável a temperaturas superiores a $400^{\circ} \mathrm{C}$. Acima de $600^{\circ} \mathrm{C}$, os elementos dentais começam a sofrer desintegração de seus tecidos, o esmalte separa-se da dentina, que apresenta maior resistência ao calor. Em temperaturas maiores do que $1150^{\circ} \mathrm{C}$, análises microscópicas apontaram a separação entre dentina radicular e cemento.

Woisetschläger, et al. ${ }^{44}$ (2011) realizaram testes ao calor e observaram que os dentes apresentam linhas de fraturas mais profundas, atingindo toda a espessura do esmalte e pequena porção da dentina, ao serem submetidos a temperaturas superiores a $400^{\circ} \mathrm{C}$. Próximo aos $1000^{\circ} \mathrm{C}$, os elementos dentais tornam-se, extremamente, frágeis e com aspecto de pulverização.

Fairgrieve $^{60}$ (1994) afirmou que cada acidente e/ou desastre pode se comportar de maneira distinta, da mesma forma que cada incêndio apresenta diferentes temperaturas, devido às mais diversas condições do local do ocorrido. Similarmente, os dentes podem ser submetidos a diferentes temperaturas, a depender dos fatores externos e dos fatores de proteção dos mesmos.

É imprescindível atentarmos que os dentes estão envoltos e protegidos pelos tecidos moles da região da cabeça e pescoço, principalmente, os dentes posteriores, pelos músculos e tecidos adiposos da bochecha ${ }^{48}$, fazendo com que a ação direta do fogo, e por consequência a alta temperatura do ambiente, muitas vezes, atinja a porção externa do corpo e não se verifique no interior da cavidade bucal ${ }^{61}$, possibilitando, por esse motivo, a manutenção da integridade, mesmo que parcial, dos elementos dentais e dos materiais restauradores odontológicos, possivelmente, existentes.

Como o grau de higidez dos elementos dentais de diferentes indivíduos, seguramente, apresenta uma variação individual considerável, pela presença de trincas, fraturas, lesões cariosas ou outras patologias, a análise do comportamento dos materiais restauradores odontológicos pode conduzir a resultados mais satisfatórios e fidedignos 
para comprovação da ocorrência da ação do calor e a provável temperatura na qual foram submetidos.

\subsection{Identificação em corpos congelados}

Além dos acidentes fatais provenientes da ação do calor podem ser constatados acidentes nos quais a ação do frio se faz atuante ${ }^{62}$. Pode-se citar como exemplos: os acidentes em câmaras frias; locais de neve; avalanches, entre outros, que levam à morte em função da hipotermia e, conseguinte, congelamento dos corpos.

A hipotermia é um estado de anormalidade em que a temperatura corporal interna está abaixo do normal. Na exposição ao frio intenso, os mecanismos reguladores cutâneos e nervosos se exaurem e a temperatura corporal cai, entre $10^{\circ} \mathrm{C}$ e $35^{\circ} \mathrm{C}$, resultando na hipotermia. A produção de calor é deprimida e o resfriamento do Sistema Nervoso Central (SNC) leva à supressão dos controles hipotalâmicos. Com a continuidade do processo, ocorre progressiva depressão do SNC, colapso circulatório63, redução no consumo de oxigênio, hipóxia tecidual, bem como produção de ácido lático devido à fadiga muscular decorrida dos tremores estimulados pelo hipotálamo ${ }^{64}$.

Durante o congelamento do corpo, cristais de gelo formam-se dentro das células, resultando em lesão, tecidual e circulatória, permanentes ${ }^{65}$. Ao atingir temperatura corporal entre $10^{\circ} \mathrm{C}$ e $18^{\circ} \mathrm{C}$, dentro de poucos minutos constata-se vasoconstrição periférica, hiperventilação, taquicardia, incapacidade de suspender a respiração, hipertensão e débito cardíaco aumentado.

Essas respostas podem causar síncope ou convulsões e finalmente à morte ${ }^{66}$. A tolerância ao frio depende da duração da exposição a baixas temperaturas e das condições inerentes a cada vítima. Idosos, crianças e pessoas fadigadas têm uma tolerância menor ao frio intenso ${ }^{3,17}$. Em casos de morte, os processos de putrefação são mais lentos do que em temperaturas ambientes normais. 0 frio retarda a autólise celular e quase anula a atividade das bactérias ${ }^{66}$.

Nesses tipos de acidentes, a Odontologia Legal também pode contribuir com a identificação das vítimas, pelo estudo de remanescentes corpóreos envolvendo maxila, mandíbula e seus respectivos elementos dentais e materiais restauradores odontológicos submetidos a baixas temperaturas (ação do frio). 


\subsection{Materiais restauradores odontológicos}

Ao tratarmos dos materiais restauradores odontológicos, devido às múltiplas indicações no uso do amálgama de prata, da resina composta e do cimento de ionômero de vidro, no exercício da prática odontológica, podemos considerar que restaurações confeccionadas com um ou mais desses três compósitos restauradores, possivelmente, serão encontradas em pessoas que passaram por tratamentos odontológicos quando em vida e se vitimaram fatalmente pela ação do calor ou do frio, no momento dos procedimentos de identificação.

O amálgama de prata ainda é um material muito utilizado no Brasil, principalmente nos serviços públicos de atendimento odontológico. Apesar de ser um material antiestético, o seu sucesso clínico é significativo, devido a sua resistência mecânica, durabilidade, capacidade de redução da infiltração marginal na interface dente/restauração, que ocorre com o passar do tempo, e a relativa simplicidade técnica envolvendo sua manipulação, inserção e condensação na cavidade dental 67-70.

Atualmente, os novos princípios restauradores priorizam a manutenção dos tecidos dentinários sadios. A área da Dentística passou a desempenhar importante papel social na busca pela máxima preservação dental e a devolução das características estéticas odontológicas perdidas. Na intenção de reestabelecer ou, pelo menos, manter a estética, e não negligenciar as propriedades físicas e mecânicas, novos materiais restauradores foram introduzidos, posteriormente ao amálgama, na Odontologia ${ }^{71}$.

A resina composta vem sendo um material intensamente pesquisado com o propósito de suprir as exigências estéticas dos pacientes. Na evolução dos compósitos resinosos, alterações na composição, distribuição, formato, quantidade e tamanho das partículas de carga são, periodicamente, testados, objetivando o aprimoramento de suas propriedades mecânicas e estéticas.

Hoje em dia, estão disponíveis no mercado vários tipos de resinas compostas, as quais diferem em sua composição. As resinas híbridas e microhíbridas, que associam as vantagens das resinas de macropartículas e micropartículas, isto é, a união de propriedades mecânicas adequadas e propriedades estéticas com favorável translucidez e lisura superficial, representam o maior contingente de marcas comerciais ${ }^{72}$. 
No estudo das características do cimento de silicato e do policarboxilato de zinco, foi constatado que o primeiro apresentava como características, a presença do flúor e baixa alteração dimensional, responsáveis pelo excelente comportamento do material. Por sua vez, o cimento policarboxilato de zinco possuía como aspecto relevante, adesividade à estrutura dental, produzida, essencialmente, pelo ácido poliacrílico. Tais particularidades benéficas determinaram o surgimento de um cimento híbrido, o cimento de ionômero de vidro. Um material composto de partículas inorgânicas de vidro dispersas numa matriz insolúvel de hidrogel ${ }^{73,74}$.

O cimento de ionômero de vidro é largamente utilizado na Odontologia, em razão de sua biocompatibilidade e eficácia. Desde o seu surgimento, vem sendo aperfeiçoado e, consequentemente, obtendo um número maior de indicações, envolvendo indicações preventivas (selamento de cicatrículas e fissuras), curativas (restaurações de classe I, III e IV, bases e forramentos de cavidades), além de seu uso como agentes de cimentação e em tratamentos endodônticos ${ }^{75}$. 0 cimento de ionômero de vidro têm se destacado cada vez mais como material restaurador de caráter definitivo em decorrência de suas propriedades biológicas e sua boa performance a longo prazo ${ }^{76}$.

\subsection{Exposição dos materiais restauradores a altas e baixas temperaturas}

A temperatura alcançada durante a exposição do corpo humano a altas temperaturas (calor) e a baixas temperaturas (frio) pode levar a transformações nos materiais restauradores presentes nos dentes, das quais o perito odontolegista, durante um processo de identificação humana, deverá ter conhecimento no momento do confronto com a ficha odontológica da vítima ${ }^{77}$.

Dessa maneira, o estudo das propriedades físicas e mecânicas desses materiais restauradores odontológicos, frente ao calor e ao frio, se faz importante no desejo de simular suas possíveis alterações quando encontrados em vítimas carbonizadas ou mortas por congelamento. 
Proposição 



\section{PROPOSIÇÃO}

Este trabalho teve por objetivo avaliar o efeito da ação do calor e do frio, sobre a estabilidade de cor, rugosidade de superfície e microdureza de materiais restauradores odontológicos, na tentativa de simular o comportamento desses materiais, quando presentes nos elementos dentais de vítimas carbonizadas ou mortas por congelamento.

A hipótese nula testada foi que não haveria diferença das propriedades estudadas de cada material, independente das altas ou baixas temperaturas a que foram submetidos. 

Material e Métodos 



\section{MATERIAL E MÉTODOS}

Para realização do estudo foram selecionados 180 incisivos bovinos (Figura 01), hígidos, isentos de trincas ou fraturas. Após remoção dos tecidos moles e tecidos periodontais aderidos a sua porção radicular, os dentes foram armazenados em água destilada e refrigerados até o momento da confecção dos preparos cavitários.

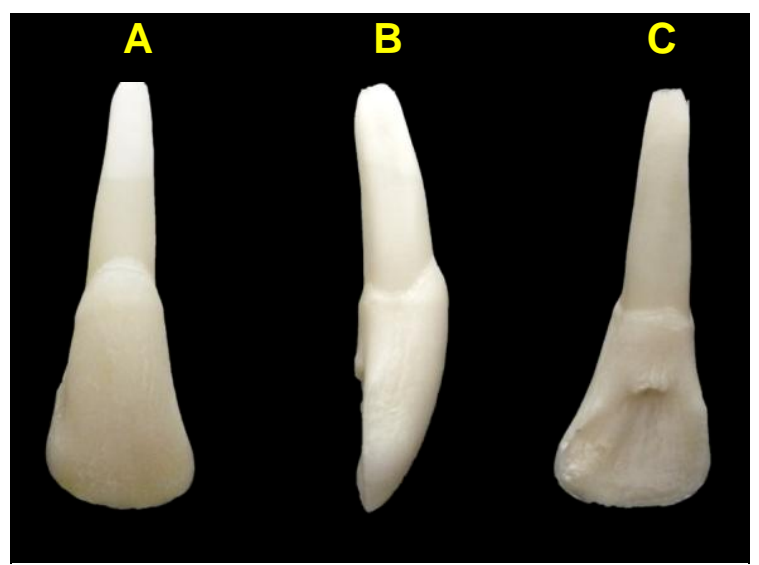

Figura 01 - Dente bovino, do grupo dos incisivos: Face vestibular (A); Face proximal (B); Face palatina/lingual (C)

Os preparos cavitários foram realizados, por um único operador, utilizando-se broca cilíndrica diamantada nำ1343 (KG Sorensen ${ }^{\circledR}$, Cotia, SP, Brasil) (Figura 02) em alta rotação (Dabi Atlante ${ }^{\circledR}$, Ribeirão Preto, SP, Brasil), com dimensões de 6 x $6 \mathrm{~mm}$ (altura x largura), na região central da face vestibular (Figura 03), de cada elemento dental, e profundidade de $2 \mathrm{~mm}$, guiada pelo comprimento da ponta ativa da broca cilíndrica (Figura 04). As medidas foram confirmadas com o uso de um paquímetro digital (Mitutoyo ${ }^{\circledR}$, Kanagawa, Japão) (Figura 05).

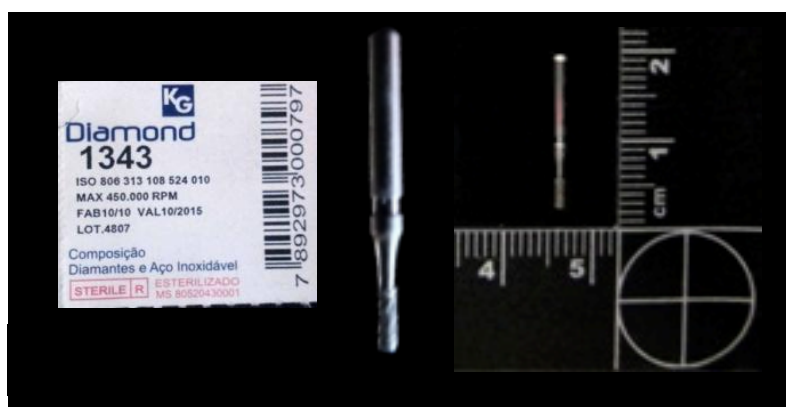

Figura 02 - Broca cilíndrica diamantada nํ1343 

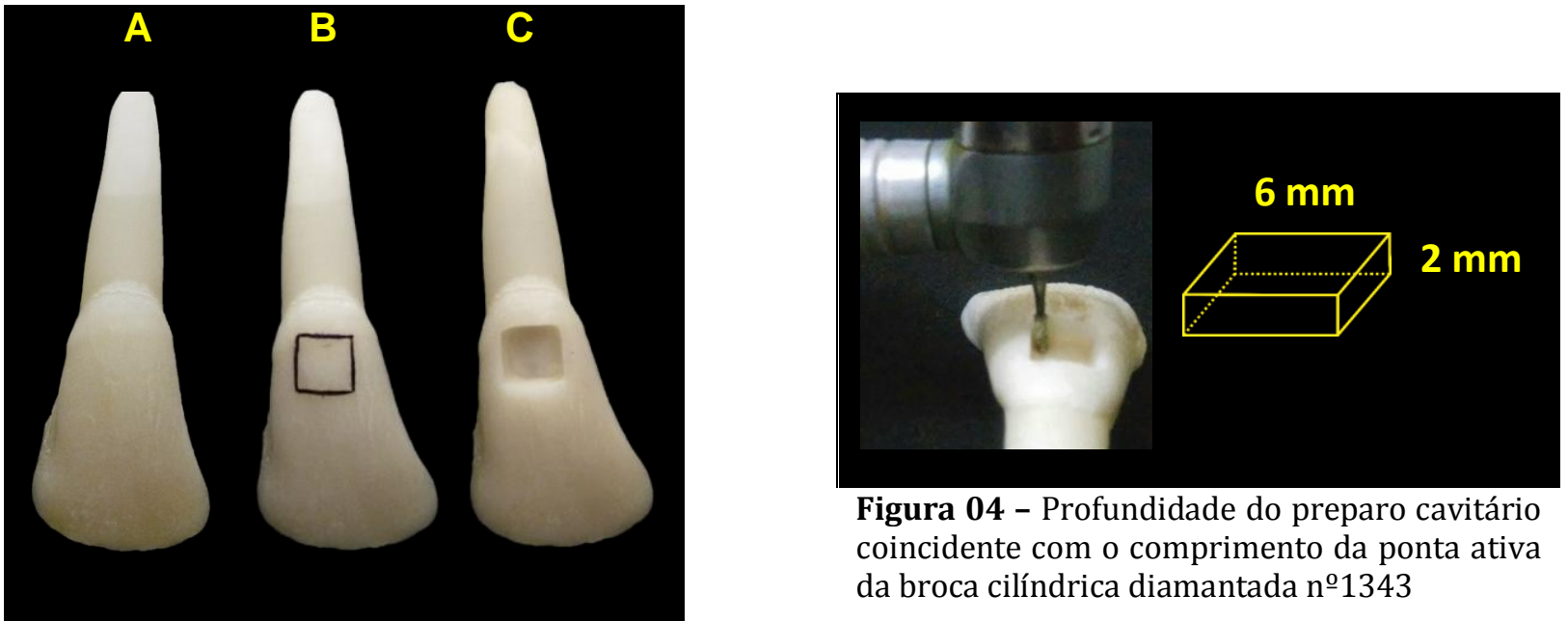

Figura 04 - Profundidade do preparo cavitário coincidente com o comprimento da ponta ativa da broca cilíndrica diamantada nํㅜㄴ 1343

Figura 03 - Incisivo bovino hígido (A);

Delineamento das margens do preparo (B);

Preparo cavitário na face vestibular (C)

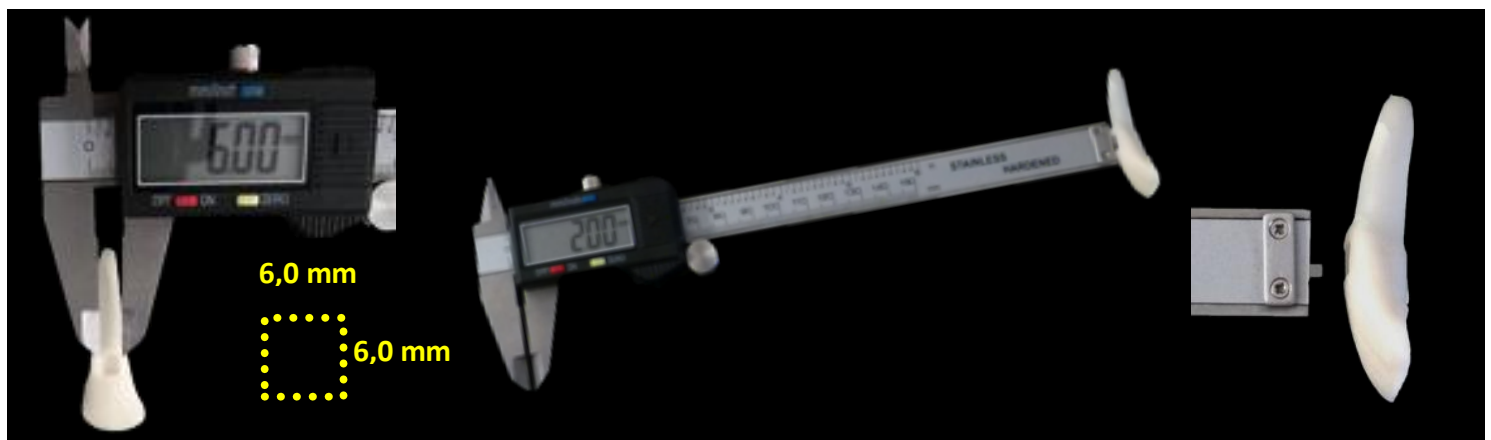

Figura 05 - Mensuração das paredes circundantes $(6 \mathrm{X} 6 \mathrm{~mm})$ e da profundidade do preparo cavitário $(2 \mathrm{~mm})$ com o uso de um paquímetro digital

Nos dentes restaurados com amálgama foram confeccionadas retenções adicionais nos preparos cavitários junto aos ângulos axio-pulpares, com ponta diamantada roda $\mathrm{n}^{\circ} 1052$ (KG Sorensen ${ }^{\circledR}$, Cotia, SP, Brasil) (Figura 06), devido à falta de adesividade desse material restaurador aos tecidos dentinários.

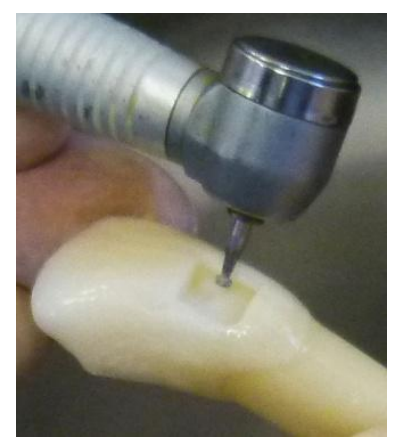

Figura 06 - Retenção adicional com broca diamantada roda nำ1052 
Após a confecção dos preparos cavitários, a superfície dental foi limpa com pedra pomes e água utilizando-se uma escova Robinson (Microdont ${ }^{\circledR}$, Socorro, SP, Brasil), em baixa rotação (Dabi Atlante), enxague e secagem com jatos de ar.

A partir desse momento, os dentes foram separados, aleatoriamente, em três grupos, segundo o tipo de material restaurador utilizado: amálgama de prata, resina composta e cimento de ionômero de vidro (Tabela 1).

Tabela 1 - Materiais utilizados, marcas comerciais, composição e fabricantes

\begin{tabular}{|c|c|c|c|}
\hline Categoria & Nome Comercial & Composição & Fabricante \\
\hline $\begin{array}{c}\text { Amálgama em } \\
\text { cápsulas }\end{array}$ & $\begin{array}{c}\text { Amalgam gs } 80 \\
\text { (2 porções) }\end{array}$ & $\begin{array}{c}1 \text { cápsula: } \\
\text { mercúrio }(540 \mathrm{mg}) \\
+ \\
\text { liga metálica }(600 \mathrm{mg}): \text { prata } \\
(40 \%), \text { estanho }(31,3 \%) \text { e } \\
\text { cobre }(28,7 \%)\end{array}$ & $\begin{array}{l}\text { SDI }{ }^{\circledR}, \\
\text { Bayswater, } \\
\text { Victoria, } \\
\text { Austrália }\end{array}$ \\
\hline Resina composta & Filtek ${ }^{\mathrm{MR}} \mathrm{Z} 250 \mathrm{XT}$ & $\begin{array}{c}\text { resina microhíbrida com } \\
\text { nanopartículas,cerâmica } \\
\text { tratada com silano, Bis-GMA, } \\
\text { Bis-EMA, sílica tratada com } \\
\text { silano, UDMA e TEGDMA }\end{array}$ & $\begin{array}{c}\text { 3M ESPE }{ }^{\circledR}, \\
\text { Sumaré, SP, } \\
\text { Brasil }\end{array}$ \\
\hline $\begin{array}{c}\text { Cimento de } \\
\text { ionômero de vidro }\end{array}$ & Ketac $^{\mathrm{TM}}$ Fil Plus & $\begin{array}{l}\text { Pó: fluorsilicato de alumínio } \\
\text { lantânio e estrôncio, vidro de } \\
\text { fluorsilicato de alumínio e } \\
\text { cálcio e pigmentos } \\
\text { Líquido: água, copolímero de } \\
\text { ácido acrílico e maleico, ácido } \\
\text { tartárico e ácido benzoico }\end{array}$ & $\begin{array}{c}\text { 3M ESPE }{ }^{\circledR}, \\
\text { Sumaré, SP, } \\
\text { Brasil }\end{array}$ \\
\hline
\end{tabular}

\subsection{Amálgama de prata}

Foi utilizado o amálgama de prata em cápsulas de 2 porções (gs-80, SDI ${ }^{\circledR}$, Bayswater, Victoria, Austrália), que foram trituradas em amalgamador Ultramat 2 (SDI ${ }^{\circledR}$, Bayswater, Victoria, Austrália), em 4000 - $4800 \mathrm{rpm}$, pelo tempo de oito segundos por cápsula, segundo as recomendações do fabricante (Figura 07). 


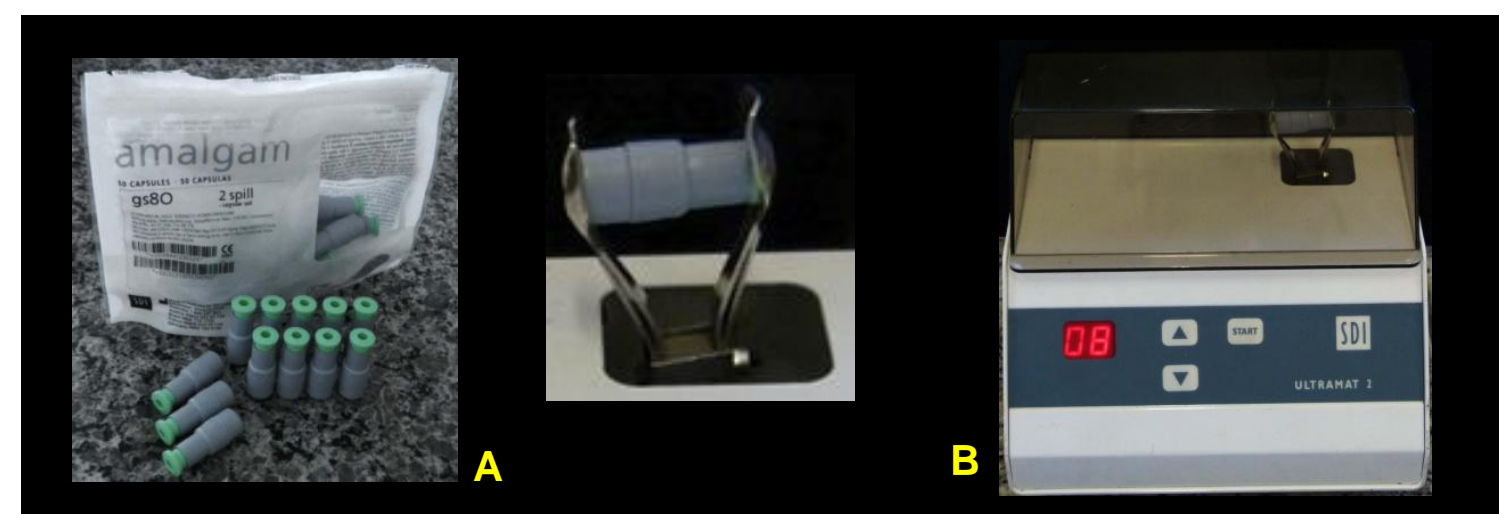

Figura 07 - Amálgama em cápsulas gs80 - 2 porções (A); Trituração no aparelho amalgamador Ultramat 2 (B)

Depois de realizada a trituração e obtenção de uma massa homogênea, o amálgama foi condensado na cavidade preparada, utilizando condensadores para amálgama, seguida de brunidura, com instrumento apropriado, e acabamento da restauração com broca multi-laminada de 12 lâminas FG 7901F (KG Sorensen ${ }^{\circledR}$, Cotia, SP, Brasil).

Passado o intervalo de 48 horas, realizou-se o polimento com taças de borrachas abrasivas em três granulações sequenciais (marrom - granulação grossa; verde granulação média; azul - granulação fina) - Kit polimento de amálgama Viking 8089 (KG Sorensen ${ }^{\circledR}$, Cotia, SP, Brasil) (Figura 08).

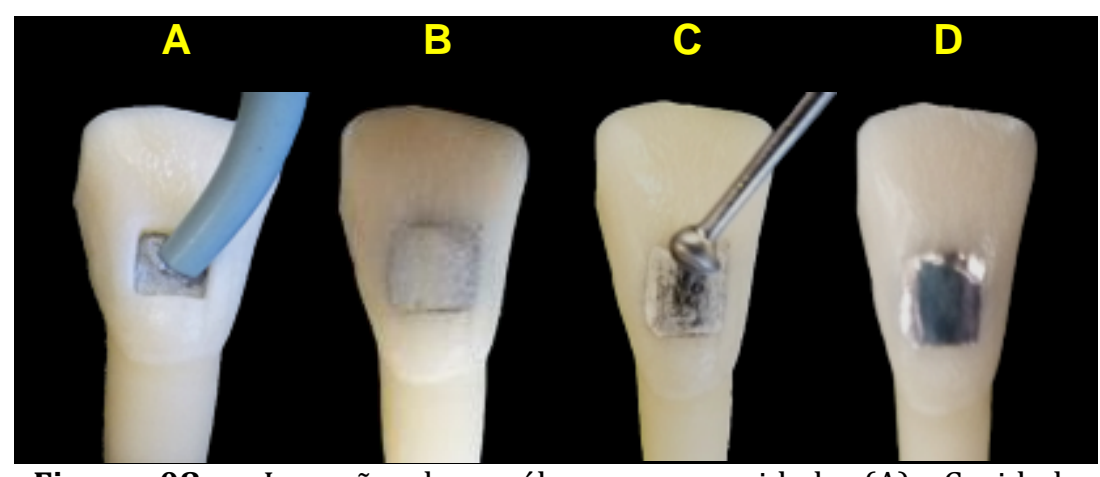

Figura 08 - Inserção do amálgama na cavidade (A); Cavidade preenchida com amálgama sem acabamento (B); Brunidura (C); Restauração em amálgama após o polimento (D)

\subsection{Resina composta}

Para a confecção das restaurações em resina composta, previamente, foi realizada a hibridização do tecido dentinário a partir do uso de condicionamento ácido 
dos tecidos dentais, esmalte e dentina, com ácido fosfórico a 37\% (Alpha Etch $\mathrm{DFL}{ }^{\circledR}$, Rio de Janeiro, RJ, Brasil), aplicado por 15 segundos (Figura 09).

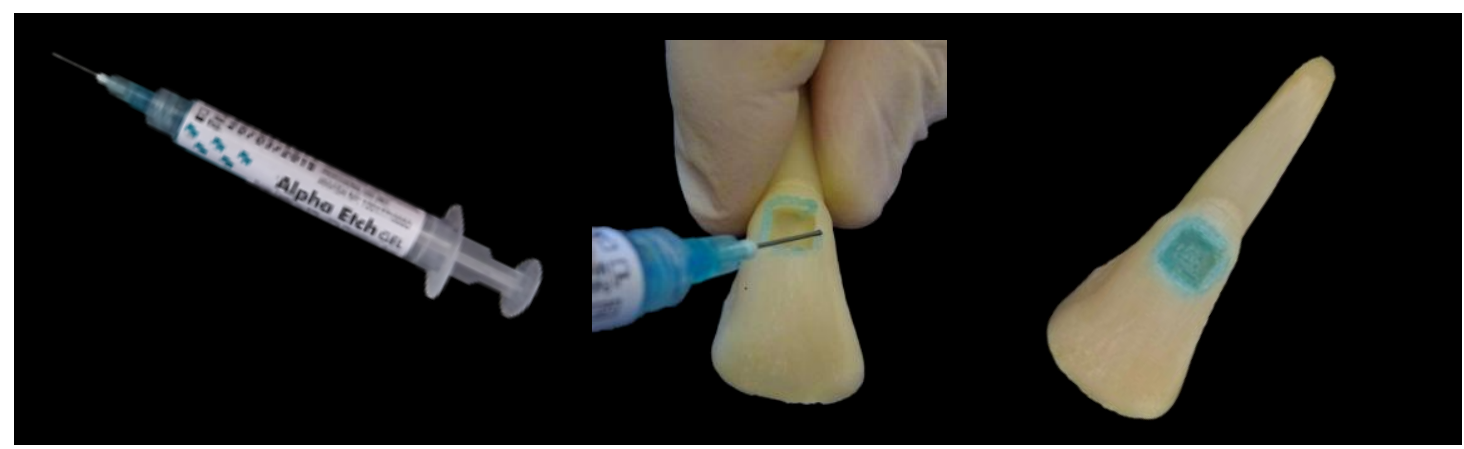

Figura 09 - Aplicação do condicionador para ataque ácido Alpha Etch no preparo cavitário

Em seguida, utilizando microbrush (Applicator Tips - DeTrey/Dentsply ${ }^{\circledR}$, Konstanz, Alemanha), foi aplicado sistema adesivo de dois passos (Adper Single Bond 2, 3M ESPE ${ }^{\circledR}$, Sumaré, SP, Brasil) (Figura 10) que é composto por etanol, Bis-GMA, silano tratado com filler de sílica (10\% de sílica coloidal), 2-hidroxietilmetacrilato, glicerol 1, 3 dimetacrilato, copolímero de ácido acrílico e ácido itacônico e UDMA. Após a evaporação do solvente, foi realizada a fotoativação com fotopolimerizador Ultralux EL (Dabi Atlante) por 10 segundos, conforme recomendação do fabricante.

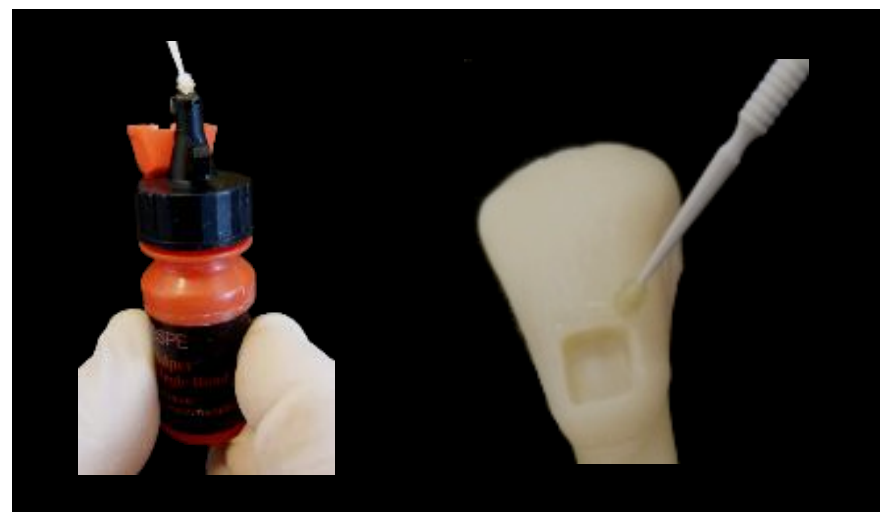

Figura 10 - Aplicação do sistema adesivo Adper Single Bond 2 no preparo cavitário

Sequencialmente, foi inserida na cavidade a resina composta Filtek ${ }^{\mathrm{MR}} \mathrm{Z} 250$ XT (3M ESPE ${ }^{\circledR}$, Sumaré, SP, Brasil), cor A3, segundo a técnica incremental, com incrementos de aproximadamente $2 \mathrm{~mm}$ de espessura e fotopolimerização por 20 segundos, com a ponta do equipamento o mais próximo possível do material restaurador, até o completo preenchimento da cavidade (Figura 11). 
O acabamento das restaurações em resina composta foi feito com a utilização de discos de lixa Sof-Lex ${ }^{\mathrm{TM}}$ Pop-On (3M ESPE ${ }^{\circledR}$, Sumaré, SP, Brasil), em ordem decrescente de abrasividade.

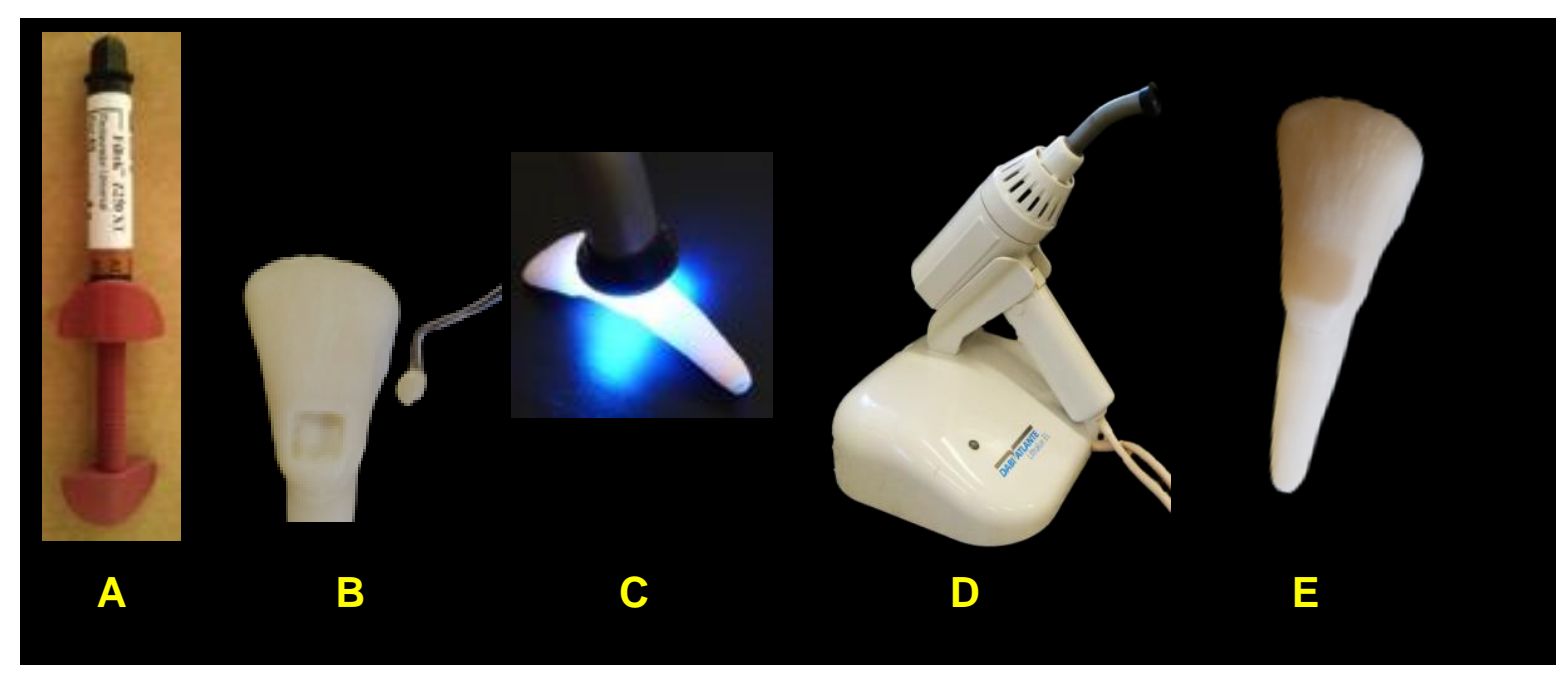

Figura 11 - Confecção da restauração em resina composta Filtek ${ }^{\mathrm{MR}}$ Z250 XT (A); Uso da técnica incremental (B); Fotopolimerização (C); Aparelho fotopolimerizador Ultralux EL (D); Completo preenchimento cavitário (E)

\subsection{Cimento de ionômero de vidro}

Neste estudo, foi utilizado o cimento de ionômero de vidro convencional Ketac ${ }^{\mathrm{TM}}$ Fil Plus (3M ESPE ${ }^{\circledR}$, Sumaré, SP, Brasil), cor A3. Antes da manipulação do material, (pó/líquido), foi aplicada solução de ácido poliacrílico às superfícies preparadas dos dentes durante 10 segundos. Sequencialmente, foi feita lavagem e secagem da cavidade.

A fim de desprender o pó da lateral interna do frasco, este foi agitado e, em seguida, proporcionado segundo as recomendações do fabricante (1:1) utilizando 2 (duas) colheres dosadoras cheia de pó para 2 (duas) gotas do líquido. 0 pó e o líquido foram dispensados lado a lado sobre um bloco de espatulação e aglutinados por meio de uma espátula 22, até a obtenção de uma massa homogênea, com tempo de mistura de um minuto. Em seguida, foi aplicada em camadas, ainda com brilho úmido, na cavidade, visando o total preenchimento do preparo cavitário (Figura 12). 


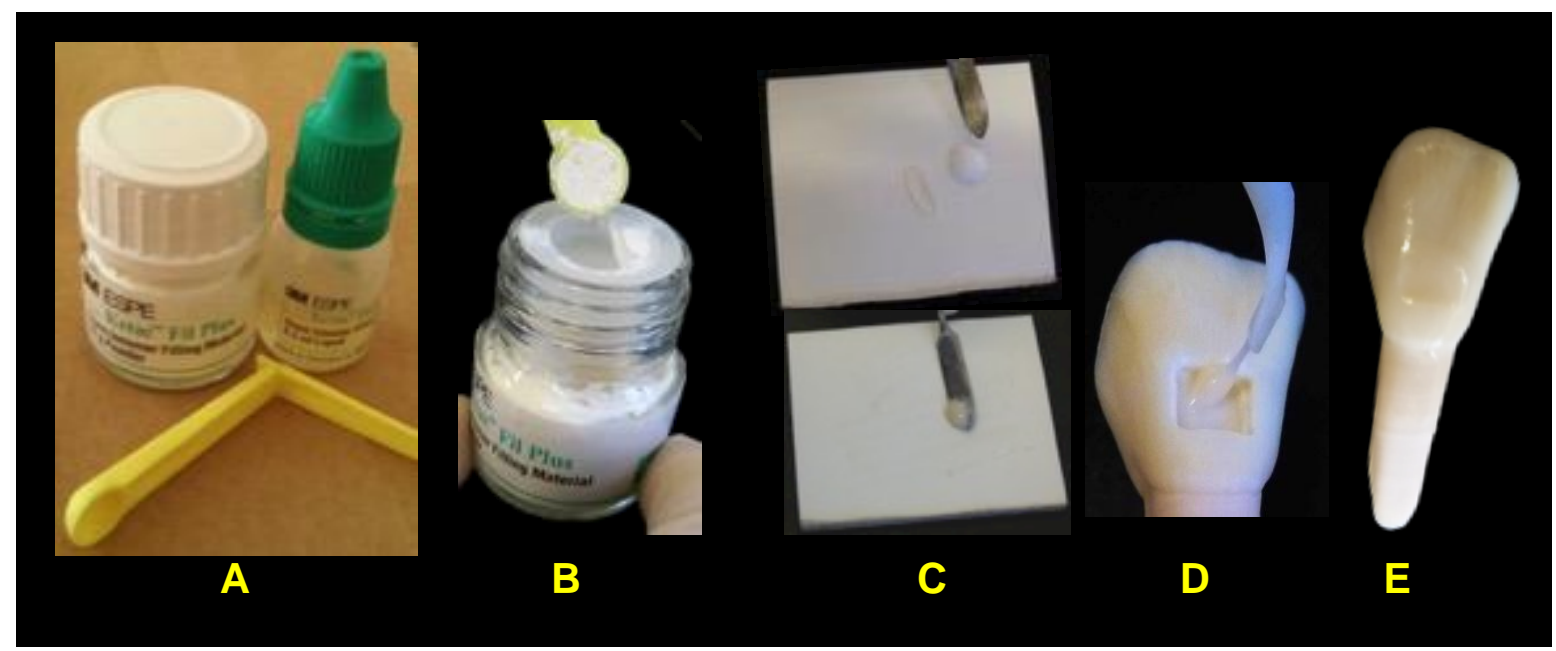

Figura 12 - Confecção da restauração com cimento de ionômero de vidro KetacTM Fil Plus (A): Espatulação da mistura pó/líquido (1:1) (B) e (C); Inserção em camadas do material (D); Completo preenchimento da cavidade (E)

\subsection{Análise das amostras}

Após o término das restaurações, todas as amostras foram fotografadas com câmera digital Lumix DMC-FZ100 (Panasonic Corporation ${ }^{\circledR}$, Kadoma, Osaka, Japão), com a finalidade de adquirir suas imagens antes da realização dos ensaios, obtendo, assim, imagens controle (baseline). Para isso, foi confeccionado um posicionador, em acrílico, formado por duas paredes laterais e uma parede de fundo contendo uma escala milimetrada adaptada às necessidades deste estudo, similar à escala nํㅜㄹ da American Board of Forensic Odontology (ABFO) (Figura 13), onde os dentes bovinos restaurados foram posicionados (Figura 14). Foram padronizadas: angulação, iluminação, tempo de exposição (1/2 segundos), abertura de diafragma (f/2.8), sensibilidade (ISO 800) e distância focal $(4,0 \mathrm{~mm})$ entre a lente da câmera fotográfica e o elemento dental. 


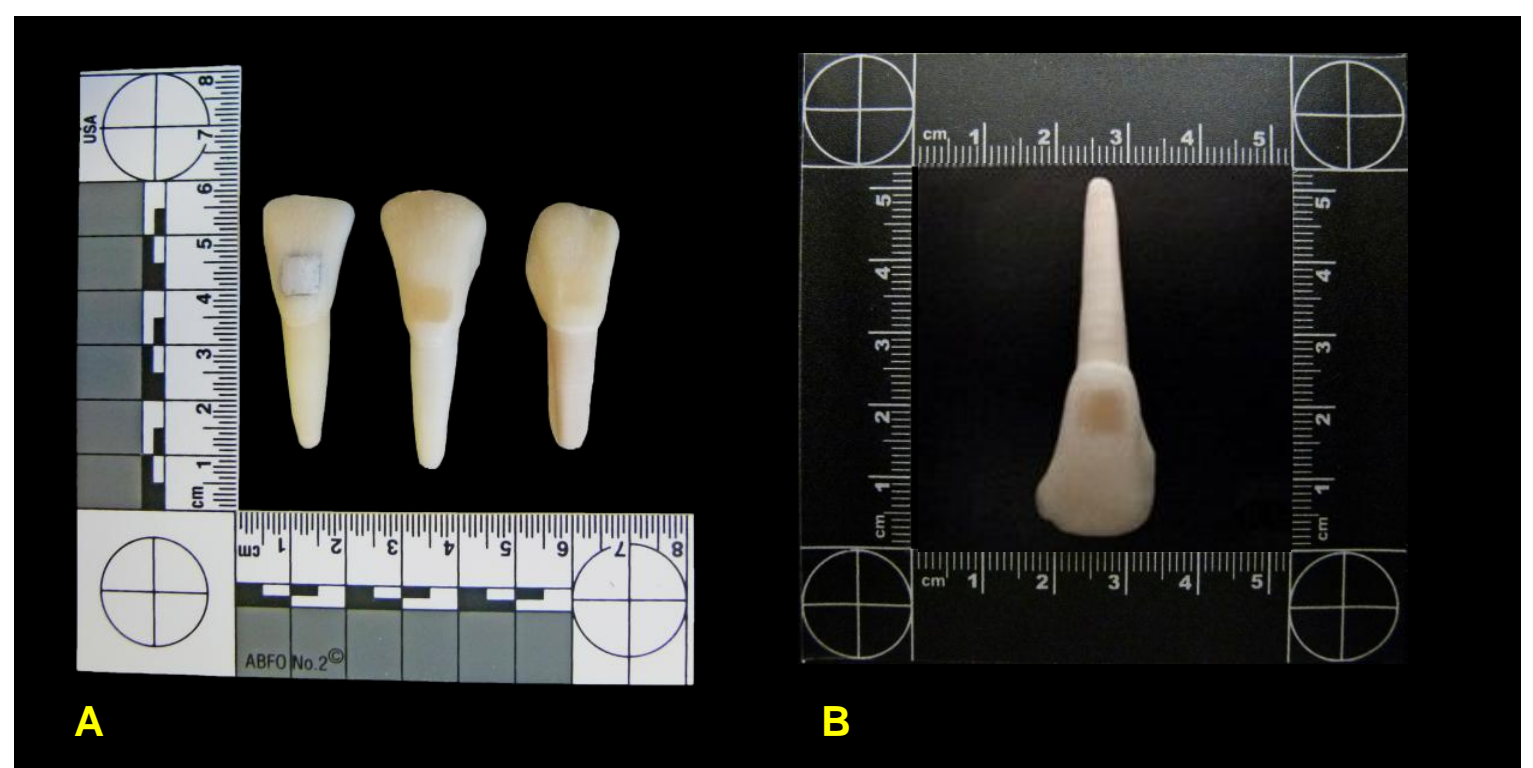

Figura 13 - Escala nํ2 da ABFO (A); Escala milimetrada confeccionada (B)

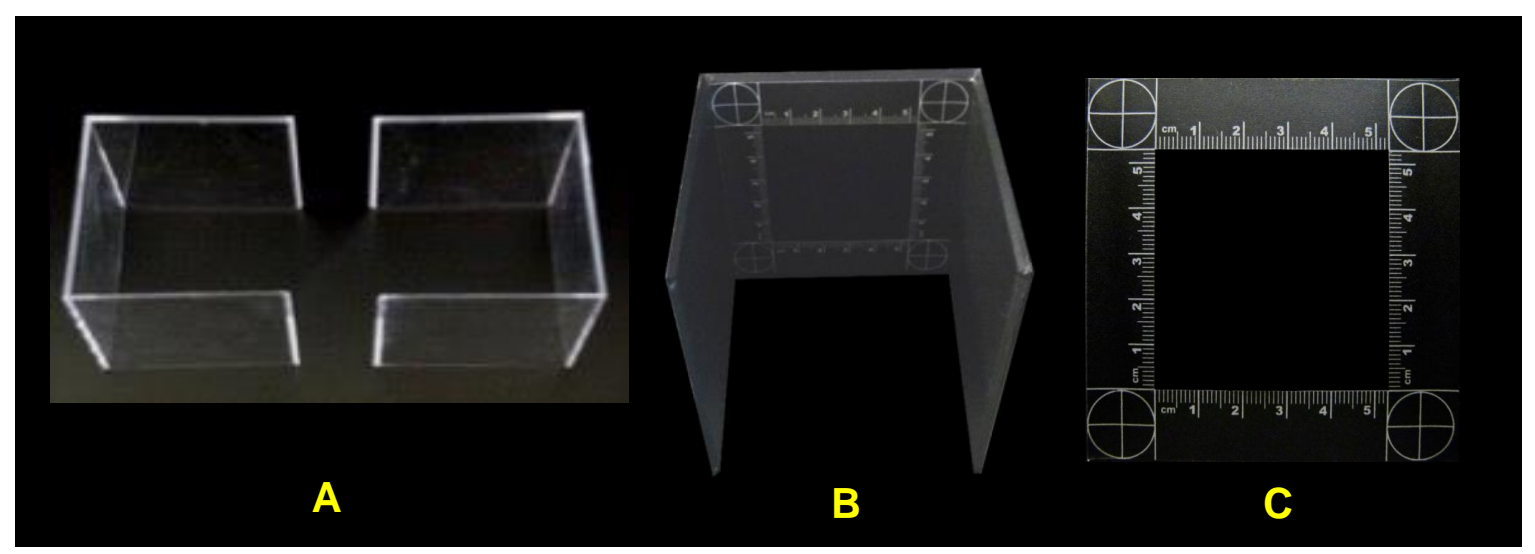

Figura 14 - Dispositivo de acrílico transparente (A); Revestimento por papel contact preto fosco, apresentando a escala milimetrada ao fundo (B); Quatros réguas e quatro círculos nas extremidades da escala (C)

Os registros das imagens foram feitos, em vista frontal do dente, com disparador automático e a câmera acoplada a um tripé. Logo após os disparos, as imagens foram transferidas e armazenadas em um computador (Figuras 15 e 16). 


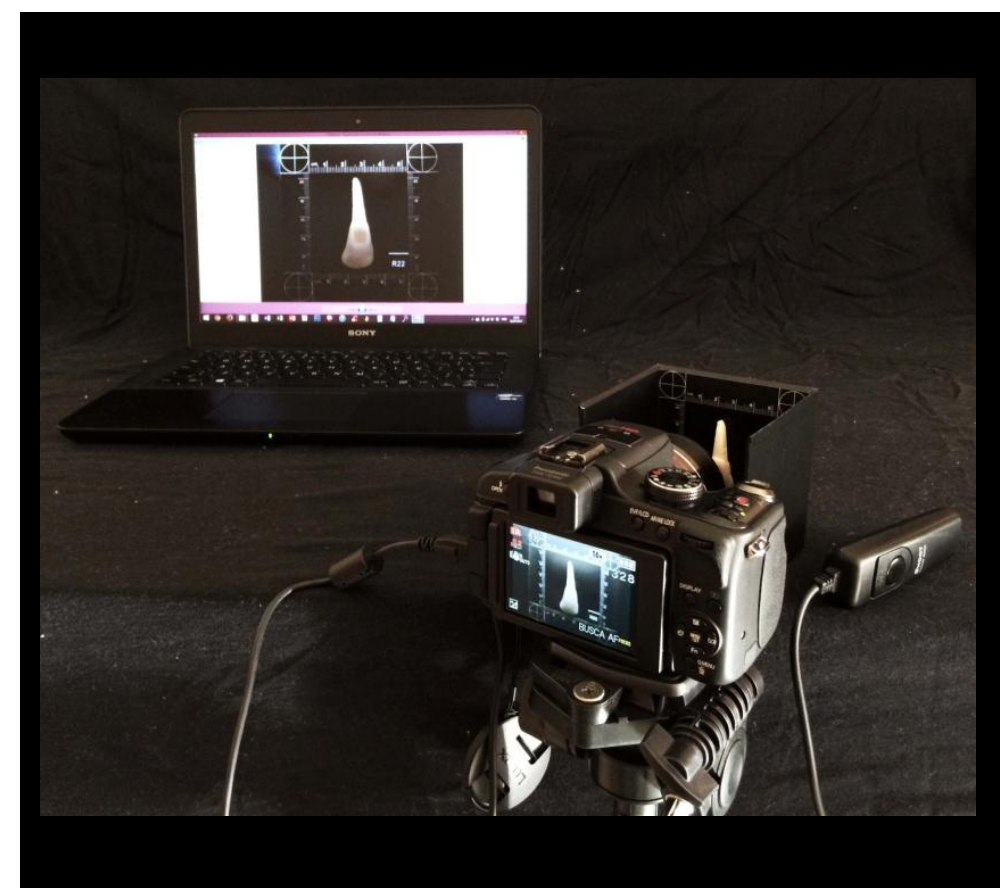

Figura $15 \quad-\quad$ Registros fotográficos realizados com câmera digital Lumix DMC-FZ100, por meio de disparador automático, acoplada a um tripé

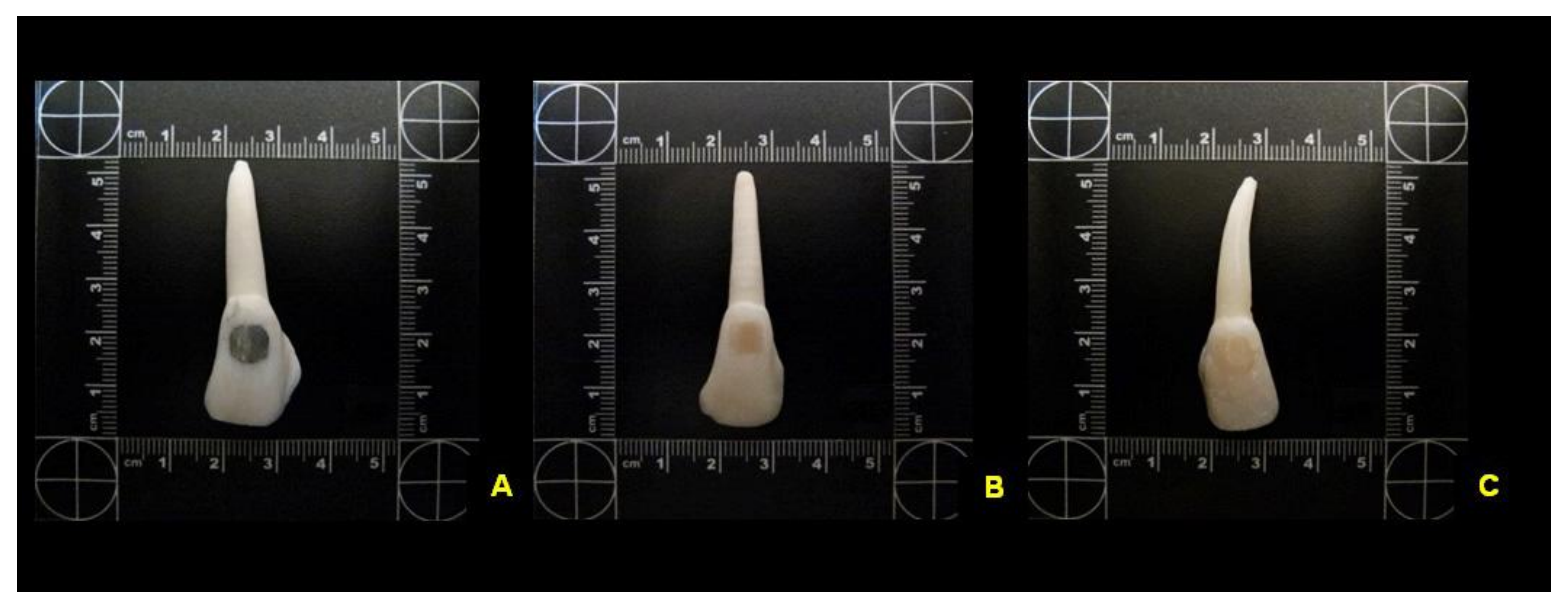

Figura 16 - Fotografias dos dentes bovinos restaurados com amálgama de prata (A); Resina composta (B); Cimento de ionômero de vidro (C)

\subsection{Rugosidade de superfície}

Os dentes restaurados foram submetidos ao estudo da rugosidade de superfície dos materiais restauradores de sua face vestibular com o uso do rugosímetro Surftest SJ201P (Mitutoyo ${ }^{\circledR}$, Kanagawa, Japão), medidor de rugosidade superficial, cuja composição se dá por duas unidades principais:

a) Unidade Programadora de Controle e Registro da Leitura (Figura 17 A): tem a função de selecionar o programa de leitura desejado e acionar o aparelho.

A distância percorrida pela agulha do aparelho rugosímetro e o cut-off utilizado foram programados de acordo com as dimensões apresentadas pelas restaurações. As 
leituras de rugosidade de superfície obtidas das amostras foram expostas em seu display eletrônico.

b) Unidade Transversal Motorizada Precursora de Leitura (Figura 17 B): composta por um motor e uma agulha. 0 motor faz com que a agulha percorra a superfície da restauração, sondando os níveis de rugosidade, de acordo com o programa pré-estabelecido.

A unidade transversal motorizada fica presa a uma haste vertical metálica que, por sua vez, fixa-se a uma base retangular de granito, proporcionando estabilidade ao conjunto (Figura $17 \mathrm{C}$ ). A haste vertical é capaz de propiciar movimentos, nos sentidos vertical e horizontal, da unidade motorizada, oferecendo, dessa maneira, ajustes de posicionamento do motor e agulha para adequada mensuração de rugosidade da superfície da restauração.

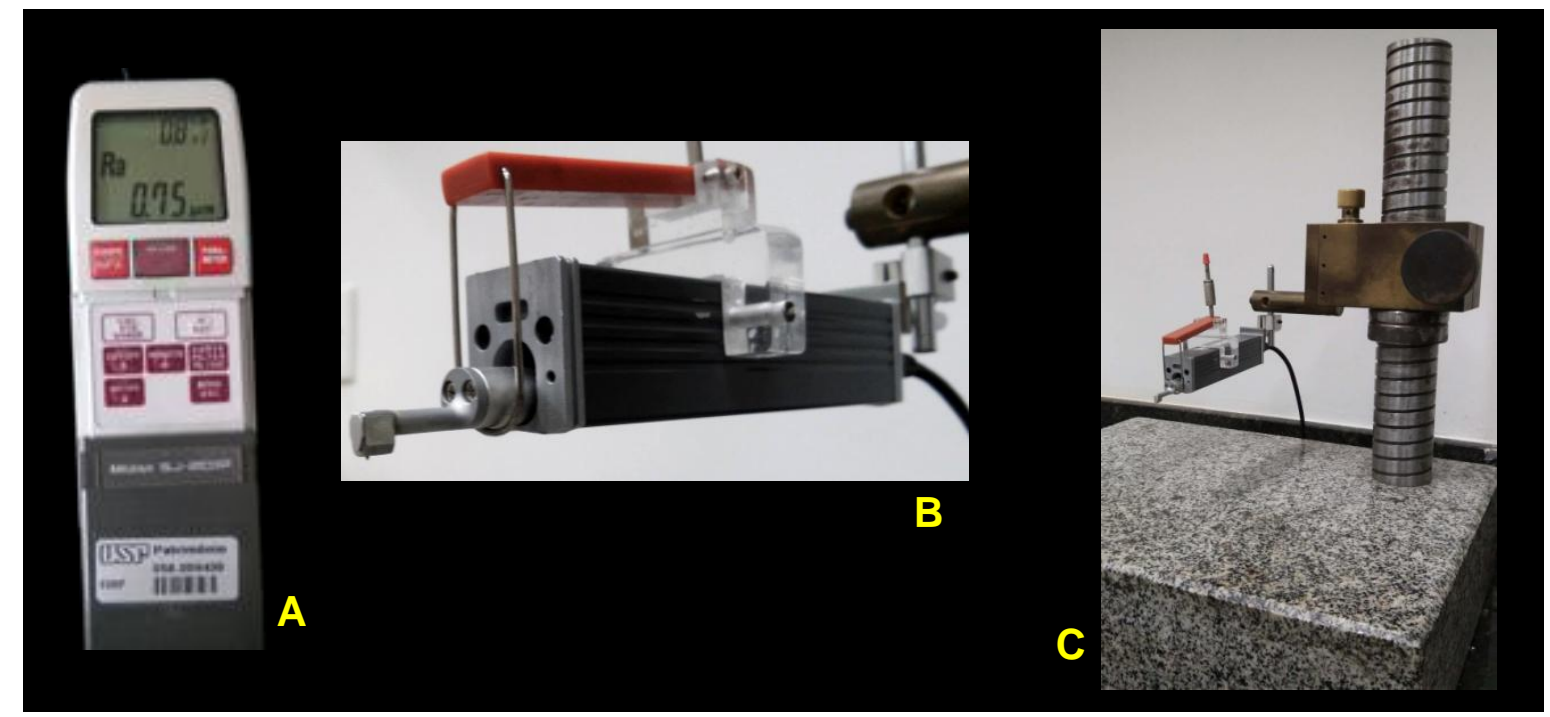

Figura 17 - Unidade Programadora de Controle e Registro da Leitura (A); Unidade Transversal Motorizada Precursora de Leitura (B); Unidade motorizada presa a uma haste vertical que, por sua vez, fixa-se à base de granito $(\mathrm{C})$

Cada elemento dental foi posicionado com a face vestibular voltada para cima, de forma que a porção da restauração ficasse, justamente, abaixo da agulha da unidade transversal motorizada, medidora de rugosidade.

Com o acionamento do aparelho, na unidade programadora de controle e registro da leitura, o motor gerou a movimentação da agulha em uma única direção, sentido inciso-cervical, onde detectou as irregularidades, saliências (picos, vales e ondas) da superfície restaurada dos dentes bovinos (Figura 18). 


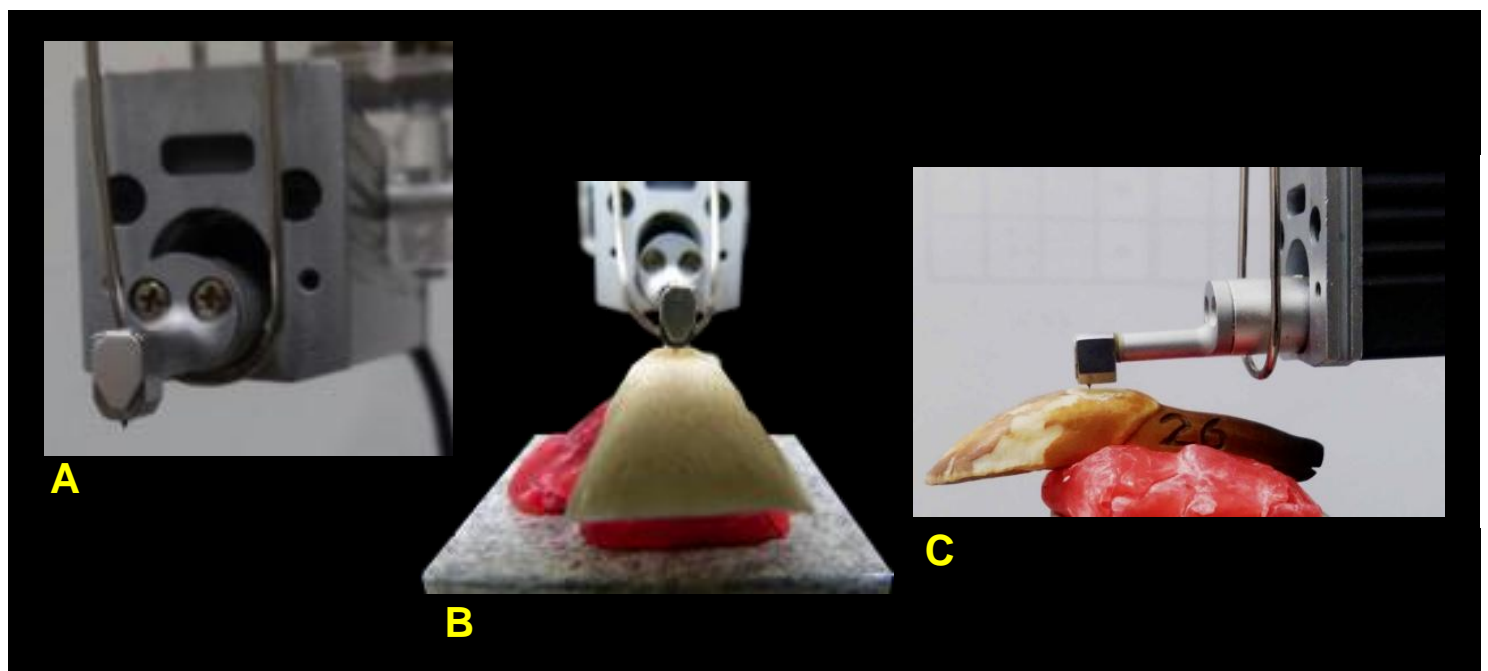

Figura 18 - Unidade transversal, motor e agulha (A); Posicionamento da agulha na superfície da restauração (B); Leitura da rugosidade superficial no sentido inciso-cervical (C)

A agulha percorreu a distância de $3,2 \mathrm{~mm}$, sendo $0,4 \mathrm{~mm}$ para aceleração da agulha, três cut-off de 0,8mm, totalizando um comprimento de leitura de 2,4mm, mais 0,4 $\mathrm{mm}$ para desaceleração da agulha, em velocidade de 0,5 mm/s. Esse valor foi definido como a média dos afastamentos da haste, tanto para cima como para baixo, em relação a uma linha central ${ }^{78}$.

Foram realizadas três leituras em posições distintas da restauração de cada elemento dental: uma leitura central, ou seja, a $3 \mathrm{~mm}$ dos limites proximais e, em outras duas posições; $1 \mathrm{~mm}$ à esquerda e $1 \mathrm{~mm}$ à direita, em relação à primeira marcação central.

Foi considerada como leitura inicial de rugosidade de superfície, a média dessas três leituras, denominada de valor de rugosidade inicial média das superfícies.

\subsection{Microdureza}

Os elementos dentais restaurados passaram por análise da microdureza Knoop do material restaurador pelo microdurômetro Micro Hardness Tester HMV-2 (Shimadzu ${ }^{\circledR}$, Tóquio, Japão) (Figura 19). Para isso, os dentes restaurados foram posicionados com a face vestibular voltada para cima, de maneira que a restauração pudesse ser visualizada e focalizada pelas objetivas do equipamento. Nas restaurações em amálgama e resina composta foi utilizada a objetiva de 40X e nas restaurações com cimento de ionômero de vidro, a objetiva de $10 \mathrm{X}$.

Após a focalização da área, o microdurômetro acionou um penetrador com ponta de diamante de forma piramidal de base losangular, em direção perpendicular à 
superfície da restauração, sob carga vertical estática de $25 \mathrm{~g}$ por 5 segundos, em cada medição (Figura 20).

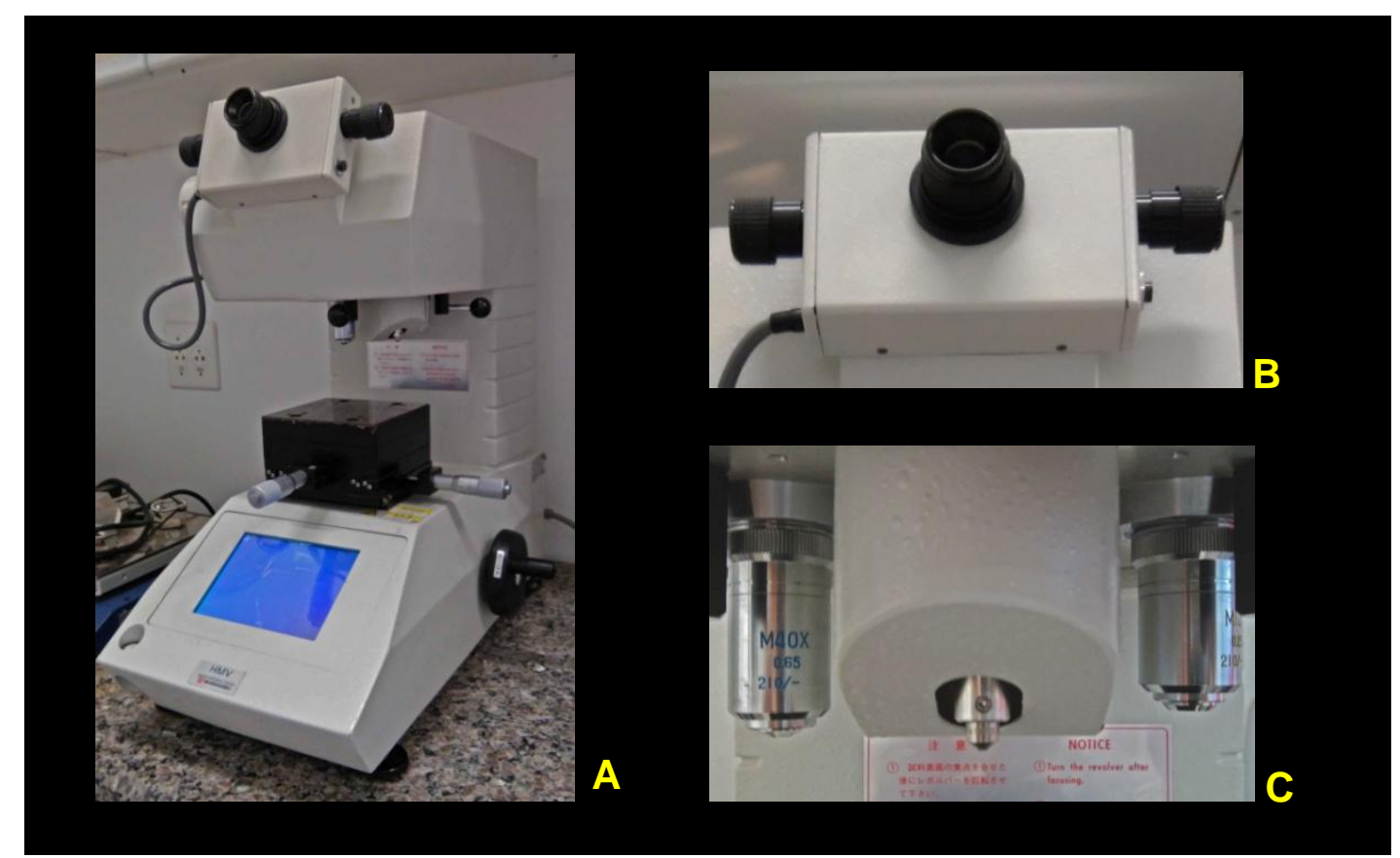

Figura 19 - Microdurômetro HMV-2 (A); Visor acoplado ao aparelho (B); Lentes objetivas nas laterais e ponta penetradora posicionada ao centro (C)

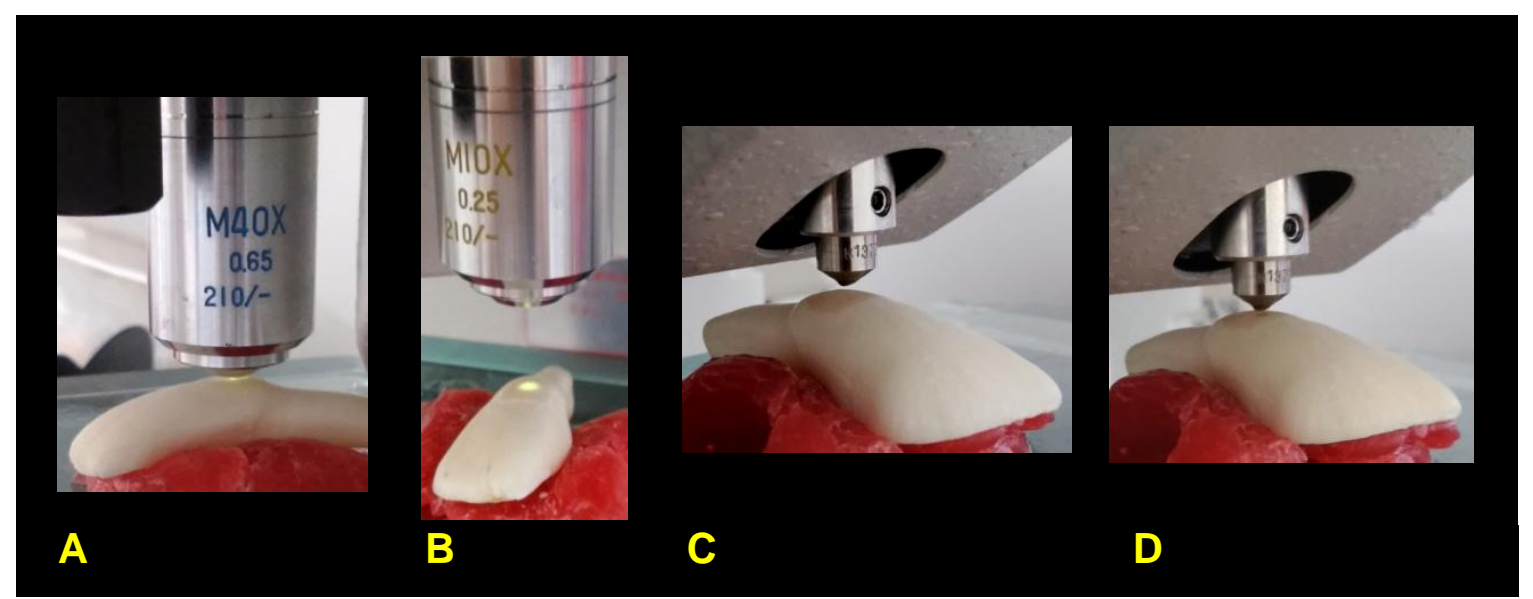

Figura 20 - Focalização da área da restauração, com lente objetiva de 40X (A) e 10X (B); Mensuração da microdureza Knoop por carga exercida pelo penetrador (C e D)

A ponta penetradora comprimiu a superfície restaurada, gerando uma figura geométrica em forma de pirâmide inversa. A visualização da área comprimida foi possível devido ao contraste existente entre a impressão e a superfície da restauração.

A microdureza do material foi determinada pela mensuração da maior diagonal do losango impresso pelo penetrador, a partir da medida obtida por uma régua com duas referências (barras verticais), paralelas entre si, observadas no visor acoplado, as 
quais são interligadas por uma referência horizontal sobreposta à maior diagonal do losango, enquanto as barras verticais são posicionadas nas extremidades da impressão, para determinação do comprimento (Figura 21), cujo valor é aplicado a uma fórmula matemática para aquisição dos resultados:

$\mathrm{KHN}=\frac{1,451 \mathrm{~F}}{\mathrm{~d}^{2}}$

Onde:

KHN = valor de dureza Knoop (Knoop Hardenss Number)

$\mathrm{F}=25 \mathrm{~g}$

$\mathrm{d}=$ comprimento da maior diagonal da endentação

Os cálculos foram realizados pelo software do aparelho, automaticamente, e o resultado, mostrado no display eletrônico (Figura 22).

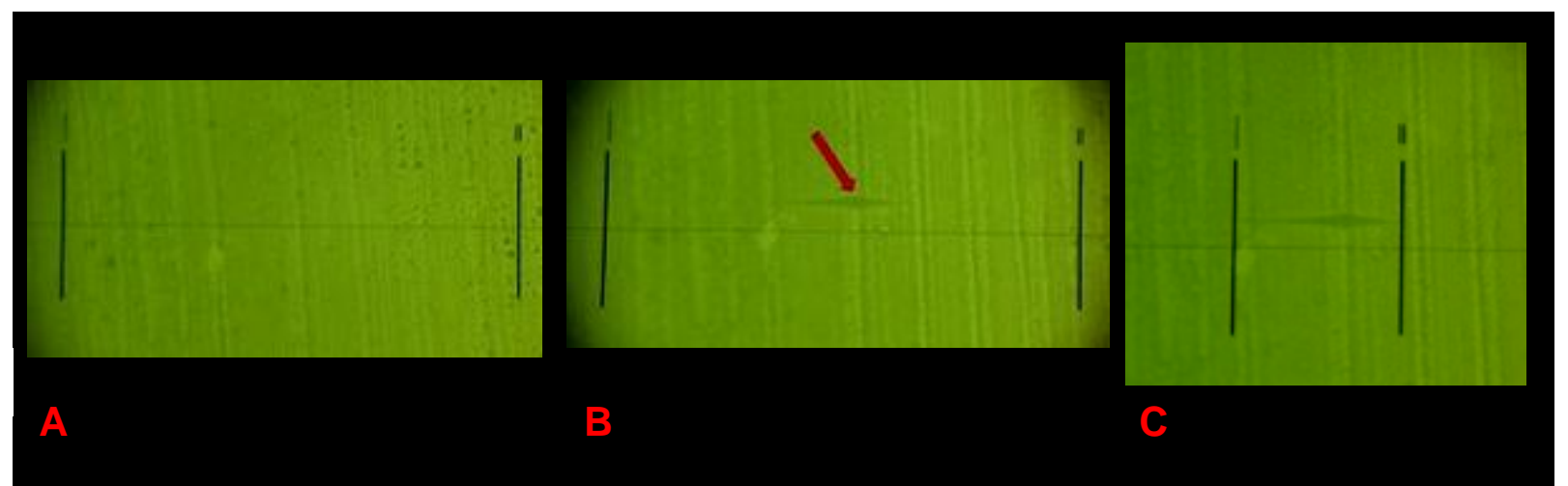

Figura 21 - Área da restauração focalizada pela objetiva e observada no visor acoplado (A); Impressão losangular realizada pela ponta penetradora (B); Mensuração da maior diagonal do losango impresso com o auxílio das barras verticais I e II (C)

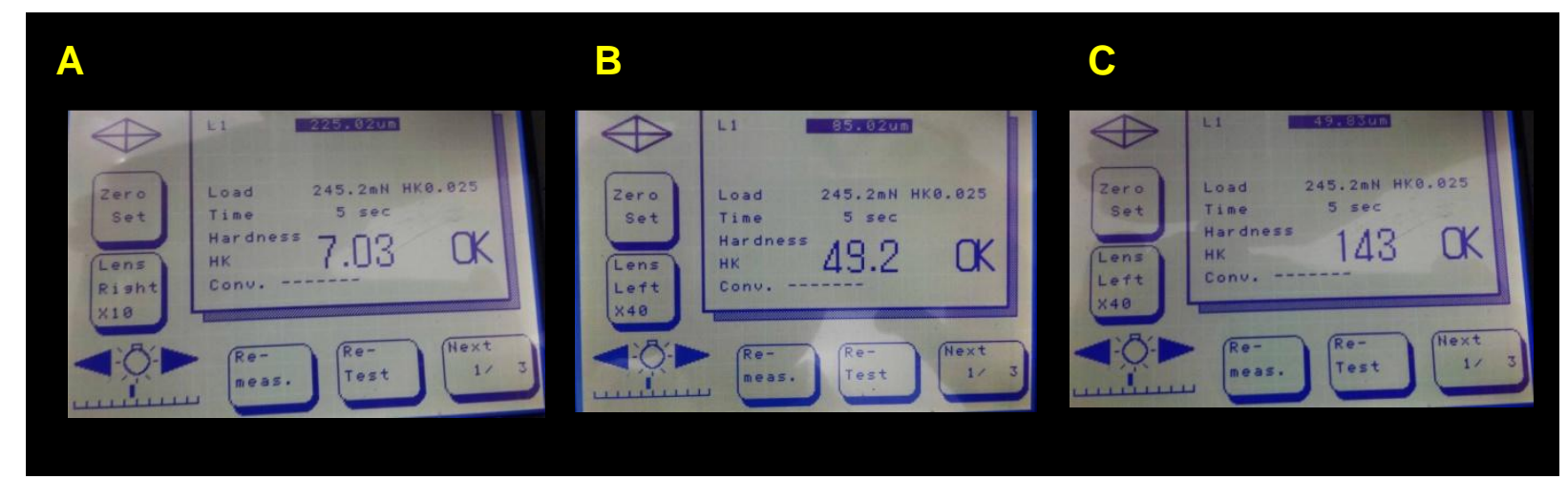

Figura 22 - Valores da microdureza Knoop dos diferentes materiais restauradores: cimento de ionômero de vidro (A); resina composta (B); amálgama (C), mostrados no display eletrônico do aparelho microdurômetro

Foram feitas três penetrações, em posições distintas da restauração: uma central; $1 \mathrm{~mm}$ à esquerda e outra $1 \mathrm{~mm}$ à direita, em relação à primeira marcação central. Foi considerada como leitura inicial de microdureza, em cada dente, a média dessas três leituras de penetração. 


\subsection{Análise de cor}

Foi analisada a cor das restaurações realizadas com materiais estéticos, ou seja, resina composta e cimento de ionômero de vidro. Para isso, utilizou-se um espectrofotômetro (VITA Easyshade ${ }^{\circledR}$, Bad Säckingen, Alemanha), aparelho portátil que contém ponteira digital com $6 \mathrm{~mm}$ de diâmetro, 19 fibras ópticas individuais e sensores espectrofotométricos que emitem feixes de luz. A leitura de cor se dá pela medição da luz refletida pela restauração segundo a escala CIE $\mathrm{L}^{*} \mathrm{a}^{*} \mathrm{~b}^{*}$, normatizado pela CIE (Comission Internationale de L’Éclairage) (Figura 23).

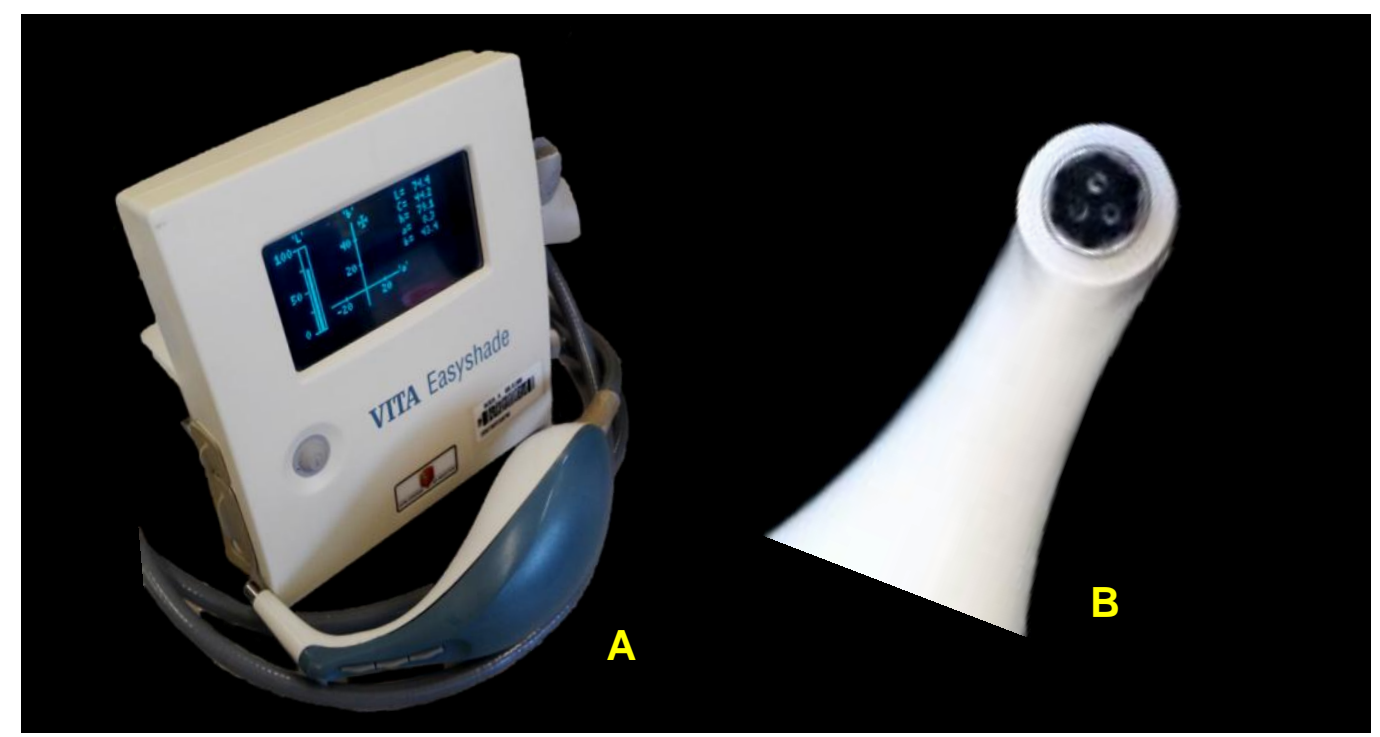

Figura 23 - Espectrofotômetro VITA EasyShade ${ }^{\circledR}(A)$; Extremidade da sonda (B)

O espaço cromático CIE L*a*b* conta com três eixos de coordenadas cartesianas onde um ponto está associado a uma cor única. 0 eixo $L^{*}$, expressa a claridade ou escuridão relativas e os eixos $\mathrm{a}^{*}$ e $\mathrm{b}^{*}$ indicam os componentes de vermelho/verde e amarelo/azul respectivamente.

Nesse espaço cromático, o eixo $L^{*}$ (escala de cinza) é conhecido como coordenada de luminosidade, representando a medida de claridade do objeto, que vai desde 0 (negro) até 100 (branco).

Os eixos a* e b* são as coordenadas de cromaticidade e apresentam valores que variam de -80 a +80 . 0 eixo $a^{*}$ representa a medida para a qualidade, saturação, de vermelho $(a>0)$ ou de verde $(a<0)$ e o eixo $b^{*}$, a medida para qualidade, saturação, de amarelo ( $b>0$ ) ou de azul $(b<0)$ (Figura 24). 


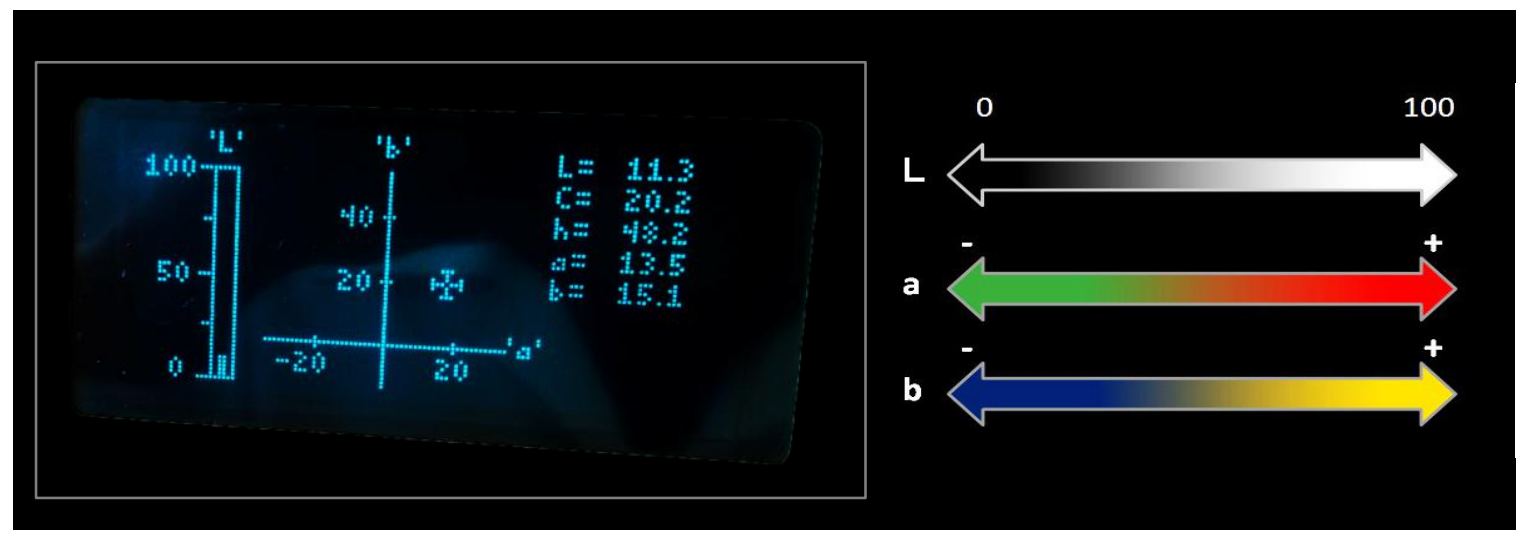

Figura 24 - Leitura numérica de cor (CIE L*a*b*) mostrada no display do aparelho EasyShade ${ }^{\circledR}$

Para a leitura de cor, os dentes restaurados foram posicionados sobre um bloco com fundo padrão branco (White Standard Sphere for $45^{\circ}, 0^{\circ}$ Reflectance and Color Gardner Laboratory Inc. Bethesda, Geretsried, Alemanha). Após calibragem, a ponta do equipamento foi mantida em posição perpendicular à superfície da restauração e em contato com a mesma (Figura 25).

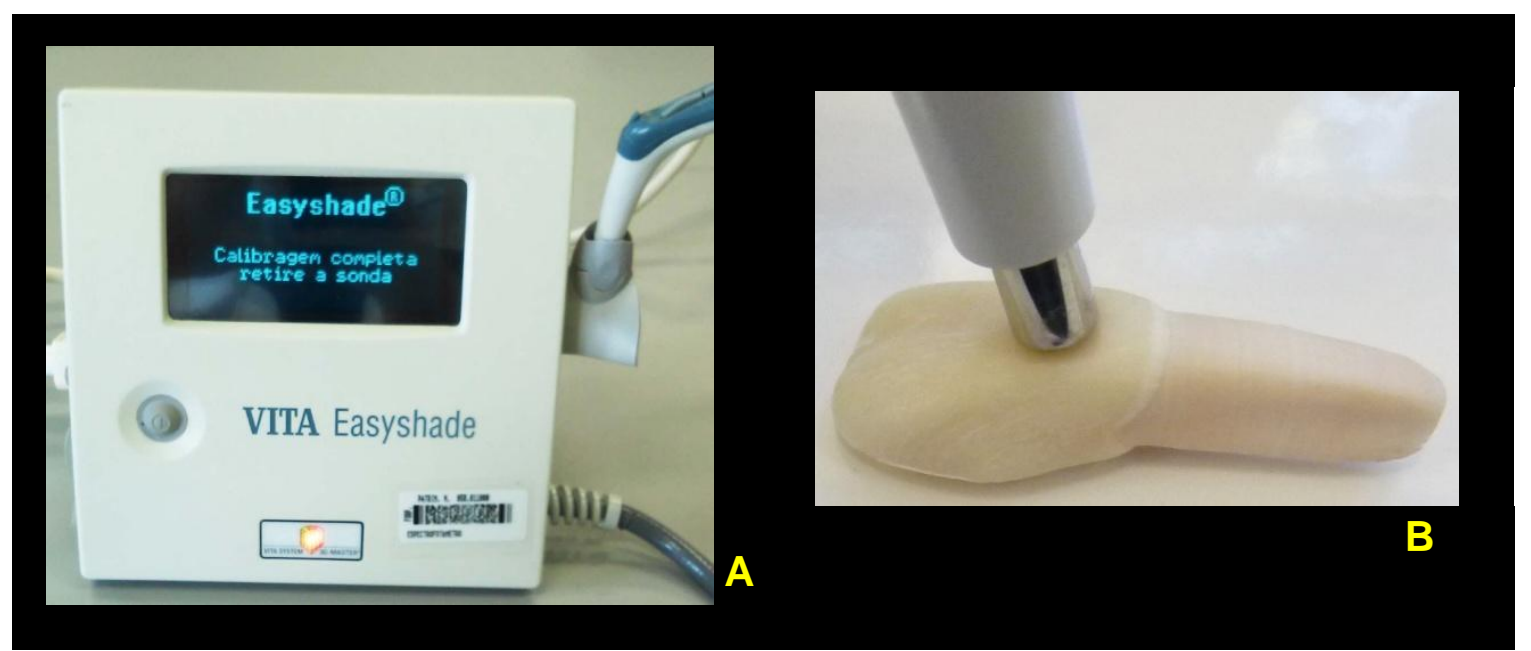

Figura 25 - Extremidade da sonda na conexão de calibragem (A); Posição da sonda, perpendicular à superfície da restauração, para leitura numérica da cor (B)

Para a mensuração da cor, após o acionamento do equipamento, 30 lâmpadas LED com 10 cores diferentes dispostas de forma circular acendem e incidem o feixe de luz em $45^{\circ}$ com a superfície do material, utilizando o iluminante padrão primário D65, que apresenta temperatura de cor de 6.500 Kelvin, simulando, dessa maneira, o espectro da luz do dia. Esse feixe de luz é refletido em $0^{\circ}$ de volta ao aparelho, captando e registrando os valores de $L^{*}, a^{*}$ e b* de cada restauração. 
Foram realizadas três leituras iniciais em cada restauração de resina composta e de cimento de ionômero de vidro. 0 valor de leitura de cor inicial considerado foi a média desses três valores obtidos.

Todos os dentes bovinos foram numerados, sendo assim identificados, individualmente, em sua porção radicular, com broca esférica diamantada no1012 (KG Sorensen ${ }^{\circledR}$, Cotia, SP, Brasil), em alta rotação (Dabi Atlante), para possibilitar as análises comparativas, de um mesmo elemento dental, antes e após a submissão às diferentes temperaturas.

Após a realização das leituras iniciais, de todas as propriedades analisadas, os dentes restaurados por cada material foram separados, aleatoriamente, em grupos $(\mathrm{n}=10)$ segundo a temperatura a que foi submetido de $-80^{\circ} \mathrm{C},-20^{\circ} \mathrm{C}, 2,5^{\circ} \mathrm{C}, 100^{\circ} \mathrm{C}, 200^{\circ} \mathrm{C}$ e $300^{\circ} \mathrm{C}$ (Figura 26).

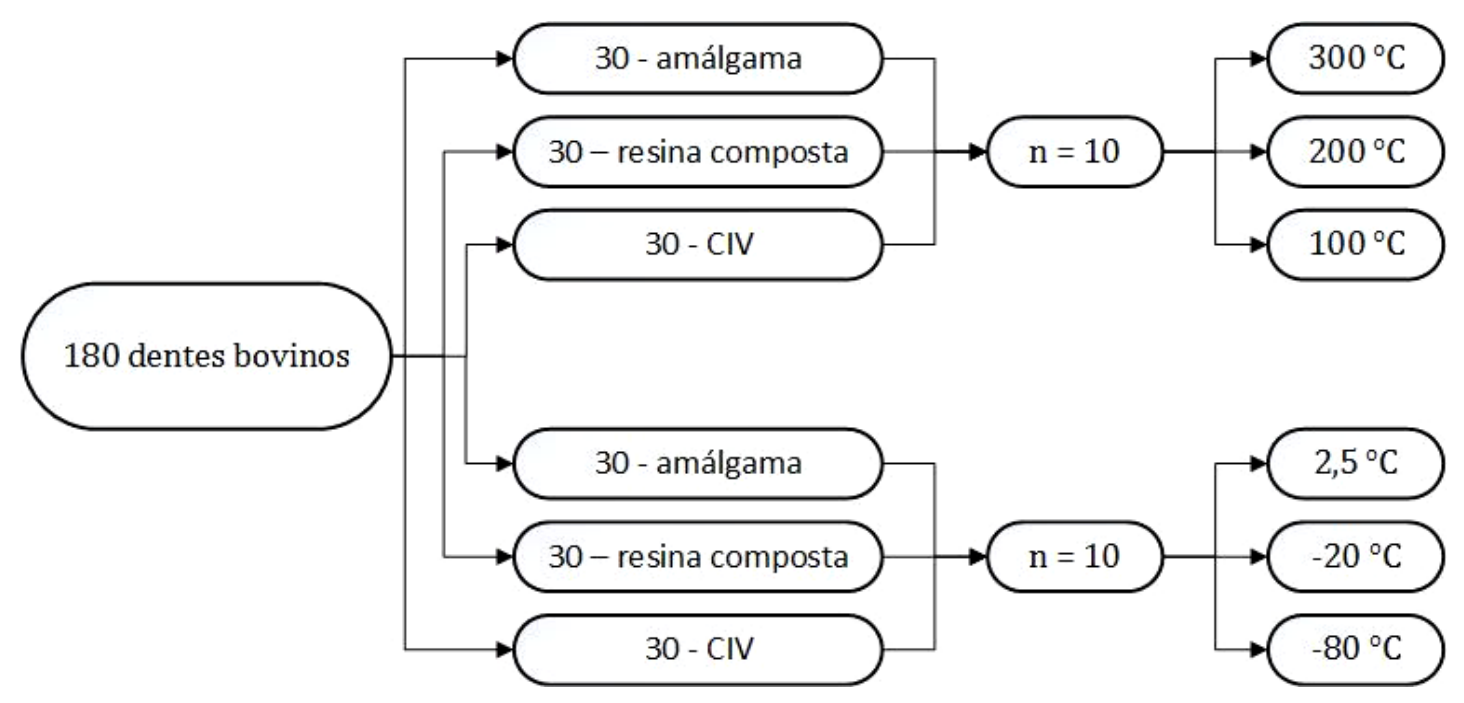

Figura 26 - Distribuição amostral segundo a temperatura de submissão

Para determinação das temperaturas a que os materiais seriam submetidos, foi realizado um teste piloto partindo da temperatura de $100^{\circ} \mathrm{C}$ até $1000^{\circ} \mathrm{C}$, com aumentos de $100^{\circ} \mathrm{C}$, a fim de verificar a que temperaturas os materiais suportariam e que permitiriam as análises propostas. 


\subsection{Condições Térmicas}

\subsubsection{Baixas temperaturas (Frio)}

No intuito de realizar os testes ao frio, cada um desses grupos foi submetido às temperaturas de $2,5^{\circ} \mathrm{C},\left(-20^{\circ} \mathrm{C}\right)$ e $\left(-80^{\circ} \mathrm{C}\right)$. Para que as amostras permanecessem à temperatura de $2,5^{\circ} \mathrm{C}$, foram colocadas em recipientes plásticos com tampa em refrigerador frost free, modelo RFGE 700 (GE ${ }^{\circledR} /$ Mabe Brasil Eletrodomésticos Ltda, Campinas, SP, Brasil); para a temperatura de $\left(-20^{\circ} \mathrm{C}\right)$, foi utilizado congelador vertical, modelo CVU18 (Consul ${ }^{\circledR}$, Joinville, SC, Brasil) e, por fim, a $\left(-80^{\circ} \mathrm{C}\right)$, um freezer Ultra Freezer AL 374 - 80V (American Lab ${ }^{\circledR}$, Charqueada, SP, Brasil) (Figura 27).

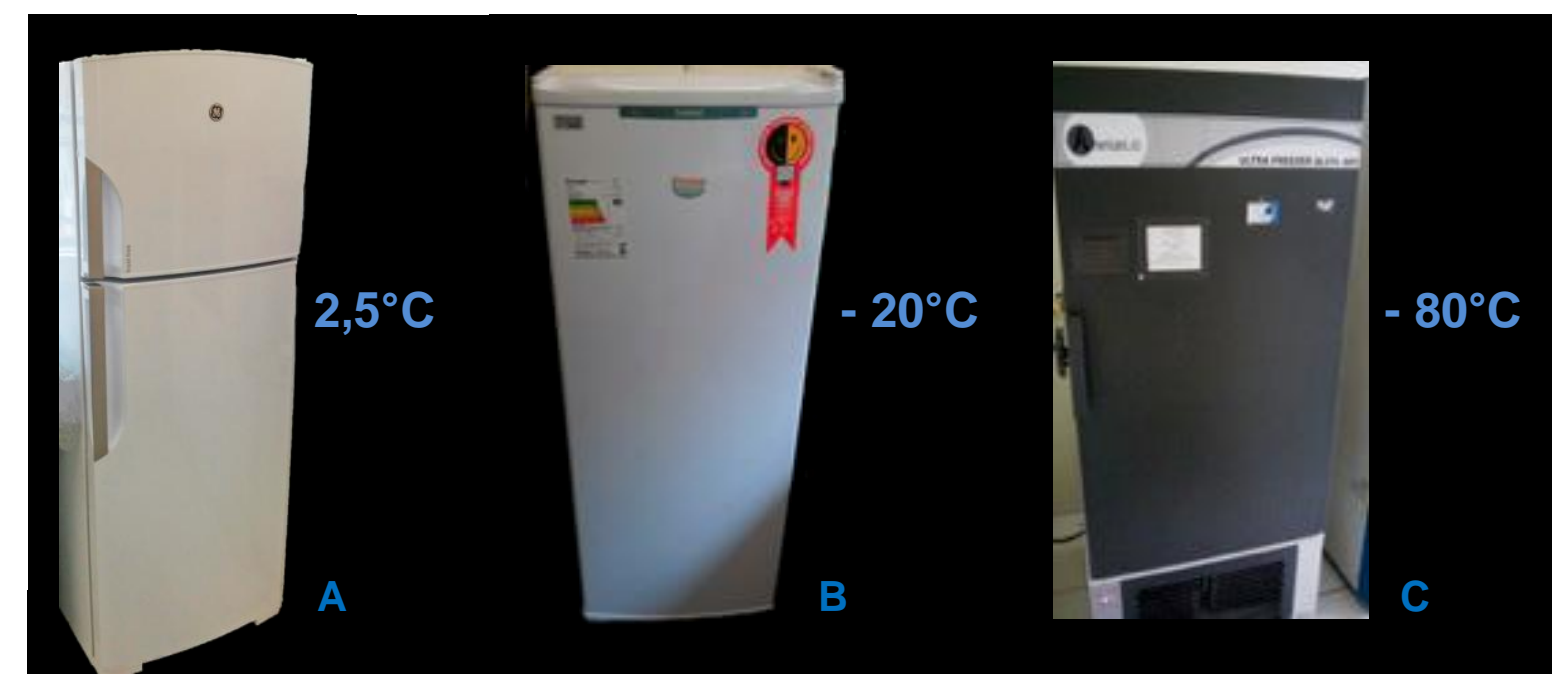

Figura 27 - Refrigerador para os testes a $2,5^{\circ} \mathrm{C}(\mathrm{A})$; Congelador vertical para os testes a - $20^{\circ} \mathrm{C}(\mathrm{B})$; Freezer para os testes a $-80^{\circ} \mathrm{C}(\mathrm{C})$

As baixas temperaturas internas geradas pelo refrigerador $\left(2,5^{\circ} \mathrm{C}\right)$ e congelador $\left(-20^{\circ} \mathrm{C}\right)$ foram aferidas com o uso de um termômetro infravermelho portátil digital, modelo MT-360 (Minipa ${ }^{\circledR}$, São Paulo, SP, Brasil), que realiza medições de temperatura sem contato, com auxílio de mira laser para identificação do local de medida (Figura 28). No caso do grupo exposto a $\left(-80^{\circ} \mathrm{C}\right)$, o termostato do próprio freezer controlou a manutenção desta temperatura (Figura 29). 


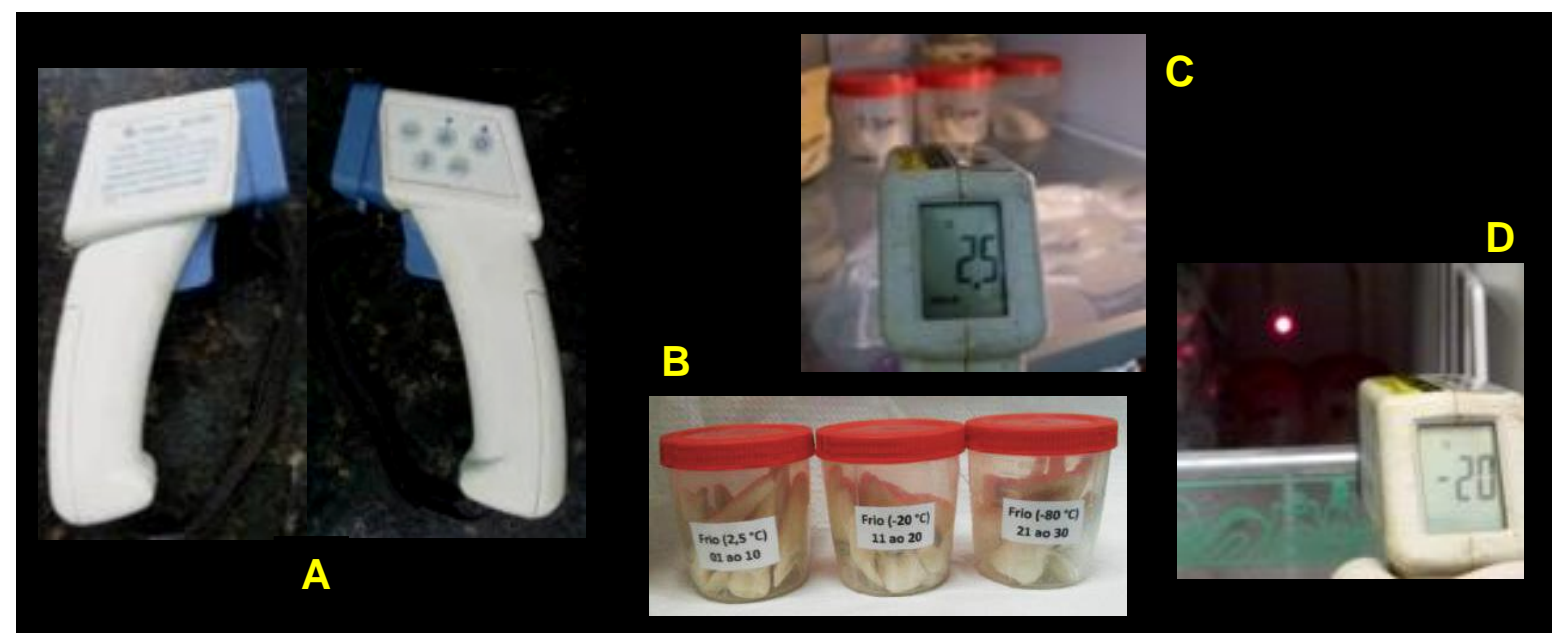

Figura 28 - Termômetro infravermelho portátil (A); Recipientes plásticos com tampa contendo os dentes bovinos (B); Aferição das temperaturas internas no refrigerador (C) e no congelador (D)

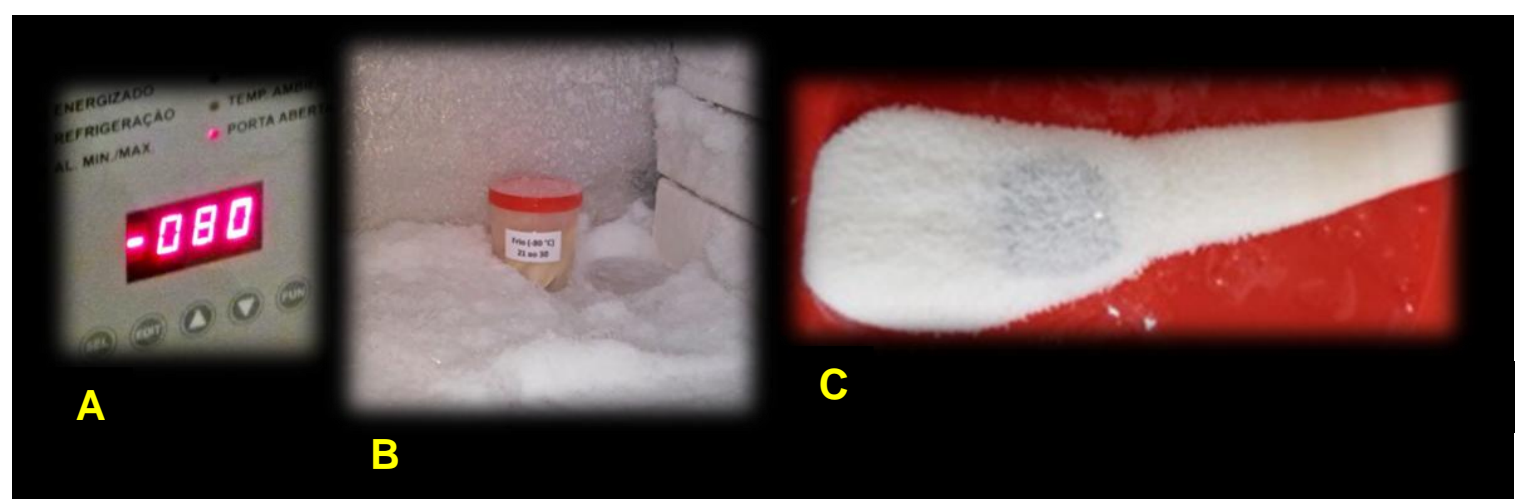

Figura 29 - Indicador de temperatura do Ultra Freezer (A); Recipiente com dentes bovinos no interior do freezer (B); Dente retirado após 30 dias de exposição a $\left(-80^{\circ} \mathrm{C}\right)$

Após 7 e 30 dias, os dentes foram removidos do interior dos aparelhos, foram novamente fotografados e analisados, conforme metodologia anteriormente descrita, quanto à rugosidade superficial, microdureza e cor, esta última análise realizada apenas para materiais restauradores estéticos.

\subsubsection{Altas temperaturas (Calor)}

Para realização dos testes ao calor foi utilizado o forno ALUMINI - Sinter Press (EDG ${ }^{\circledR}$ Equipamentos e Controle Ltda, São Carlos, SP, Brasil), no qual cada um dos dentes dos três grupos foi colocado e submetido, separadamente, às temperaturas de $100^{\circ} \mathrm{C}, 200^{\circ} \mathrm{C}$ e $300^{\circ} \mathrm{C}$ pelo tempo de 15 minutos. Para isso, os dentes foram posicionados sobre manta de queima de cerâmica e dispostos sobre a plataforma do forno que ao ser acionado iniciou a queima (Figura 30). 
No grupo restaurado com amálgama, os dentes foram colocados no forno, juntamente, com um bloco de carvão ativado a fim de que fosse evitada a dispersão do vapor de mercúrio constituinte da composição do amálgama.

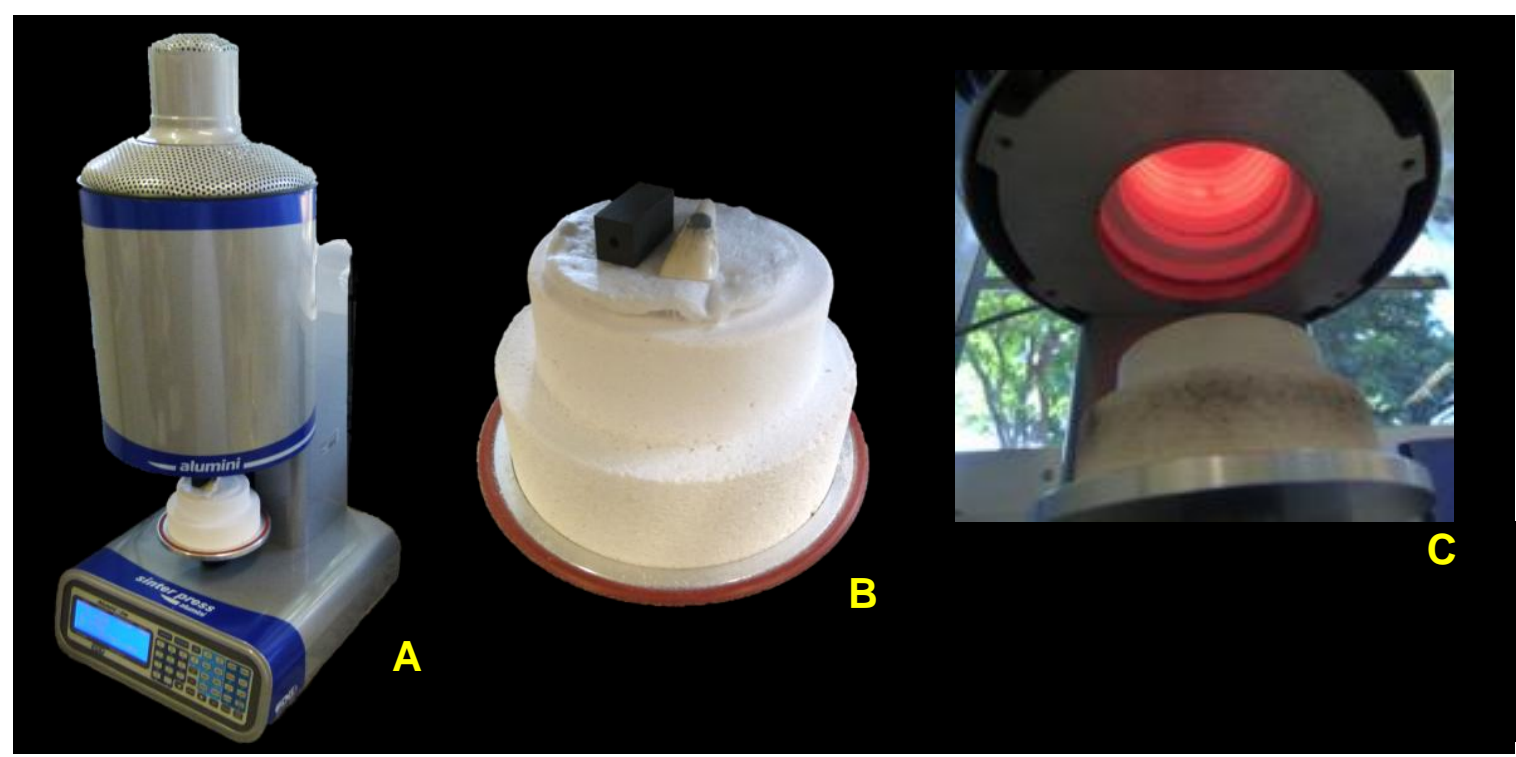

Figura 30 - Forno ALUMINI Sinter-Press (A); Dente bovino restaurado com amálgama e carvão ativado, apoiados sobre a plataforma rígida e posicionados na bandeja auxiliar do forno (B); Acionamento do forno para início da queima (C)

Após a realização das queimas às diferentes temperaturas, todos os dentes foram novamente fotografados e analisados, conforme metodologia anteriormente descrita, quanto à rugosidade superficial, microdureza e cor, esta realizada apenas para materiais restauradores estéticos.

As variações de rugosidade de superfície $(\Delta \mathrm{Ra})$, antes e após submissão ao frio e ao calor, foram calculadas a partir da seguinte fórmula:

$\Delta \mathrm{Ra}=\mathrm{Ra}_{\mathrm{f}}-\mathrm{Ra}_{\mathrm{i}}$

Onde:

$\mathrm{Ra}$ i é referido como medida inicial e Ra f como medida final da rugosidade de superfície.

As alterações de microdureza Knoop $(\Delta \mathrm{KHN})$, antes e após exposição ao frio e ao calor, foram calculadas a partir da seguinte fórmula:

$\Delta \mathrm{KHN}=\mathrm{KHN}_{\mathrm{f}}-\mathrm{KHN}_{\mathrm{i}}$

Onde:

$\mathrm{KHN}_{\mathrm{i}}$ é referido como medida inicial e $\mathrm{KHN}_{\mathrm{f}}$ como medida final da microdureza. 
A alteração de cor $(\Delta \mathrm{E})$, dos materiais restauradores estéticos, ocorrida após submissão ao frio e ao calor, foi calculada a partir da seguinte fórmula79:

$\Delta \mathrm{E}=\left[\left(\Delta \mathrm{L}^{*}\right)^{2}+\left(\Delta \mathrm{a}^{*}\right)^{2}+\left(\Delta \mathrm{b}^{*}\right)^{2}\right]^{1 / 2}$

Onde:

$\Delta \mathrm{E}=$ alteração de cor

$\Delta \mathrm{L}^{*}=$ diferença na luminosidade $\left(\mathrm{L}^{*}\right)$

$\Delta \mathrm{a}^{*}=$ diferença no eixo $\mathrm{a}^{*}$

$\Delta \mathrm{b}^{*}=$ diferença no eixo $\mathrm{b}^{*}$

A direção da diferença de cor é descrita pelas magnitudes e sinais algébricos dos componentes $\Delta \mathrm{L}^{*}, \Delta \mathrm{a}^{*}$ e $\Delta \mathrm{b}^{*}$ :

$$
\begin{aligned}
& \Delta \mathrm{L}^{*}=\mathrm{L}_{\mathrm{f}}-\mathrm{L}^{*}{ }_{\mathrm{i}} \\
& \Delta \mathrm{a}^{*}=\mathrm{a}_{\mathrm{f}}{ }_{\mathrm{f}}-\mathrm{a}^{*}{ }_{\mathrm{i}} \\
& \Delta \mathrm{b}^{*}=\mathrm{b}^{*_{\mathrm{f}}}-\mathrm{b}^{*}{ }_{\mathrm{i}}
\end{aligned}
$$

Onde:

$\mathrm{L}_{\mathrm{i}} \mathrm{a}^{*_{\mathrm{i}}}$ e $\mathrm{b}^{*_{i}}$ são referidos como medidas iniciais e $\mathrm{L}_{\mathrm{f}}^{*_{\mathrm{f}}} \mathrm{a}_{\mathrm{f}}^{*_{\mathrm{f}}}$ e $\mathrm{b}_{\mathrm{f}}^{*_{\mathrm{f}}}$ como medidas finais das coordenadas da cor.

\subsection{Análise estatística}

Após os ensaios às altas temperaturas, os valores de $\Delta \mathrm{E}$ e das coordenadas $\Delta \mathrm{L}^{*}$, $\Delta \mathrm{a}^{*}$ e $\Delta \mathrm{b}^{*}$, das restaurações de resina composta e cimento de ionômero de vidro, e os valores de $\Delta$ Ra e $\Delta$ KHN foram submetidos à análise estatística One-way ANOVA, teste de Tukey, p<0,05 (fator de variação: temperatura). A análise dos dados de todas as variações após os ensaios às baixas temperaturas foi realizada por Two-way ANOVA, Bonferroni, $\mathrm{p}<0,05$ (fatores de variação: temperatura e tempo). 
Resultados 



\section{RESULTADOS}

\subsection{Altas temperaturas (Ação do calor)}

As amostras de resina composta e cimento de ionômero de vidro (CIV) foram analisadas em alteração de cor, alteração de rugosidade de superfície e microdureza Knoop, enquanto as amostras de amálgama foram analisadas somente para as duas últimas propriedades estudadas.

\subsubsection{Teste piloto}

Os materiais restauradores foram analisados, antes e após a queima, nas temperaturas finais de $100^{\circ} \mathrm{C}, 200^{\circ} \mathrm{C}, 300^{\circ} \mathrm{C}, 400^{\circ} \mathrm{C}, 500^{\circ} \mathrm{C}, 600^{\circ} \mathrm{C}, 700^{\circ} \mathrm{C}, 800^{\circ} \mathrm{C}, 900^{\circ} \mathrm{C} \mathrm{e}$ $1000^{\circ} \mathrm{C}$, pelo período de 15 minutos.

Para a resina composta e CIV, ocorreu um total enegrecimento desses materiais a partir de $400^{\circ} \mathrm{C}$ (Figura 31), o que impossibilitou a análise de cor. Para o amálgama, a partir de $400^{\circ} \mathrm{C}$, não foi possível a realização dos testes de microdureza (Figura 32).

Todas as análises (leitura de cor, alteração de rugosidade de superfície e alteração de microdureza Knoop), nos três materiais restauradores estudados, somente foram possíveis de serem realizadas nas temperaturas de $100^{\circ} \mathrm{C}, 200^{\circ} \mathrm{C} \mathrm{e} 300^{\circ} \mathrm{C}$.

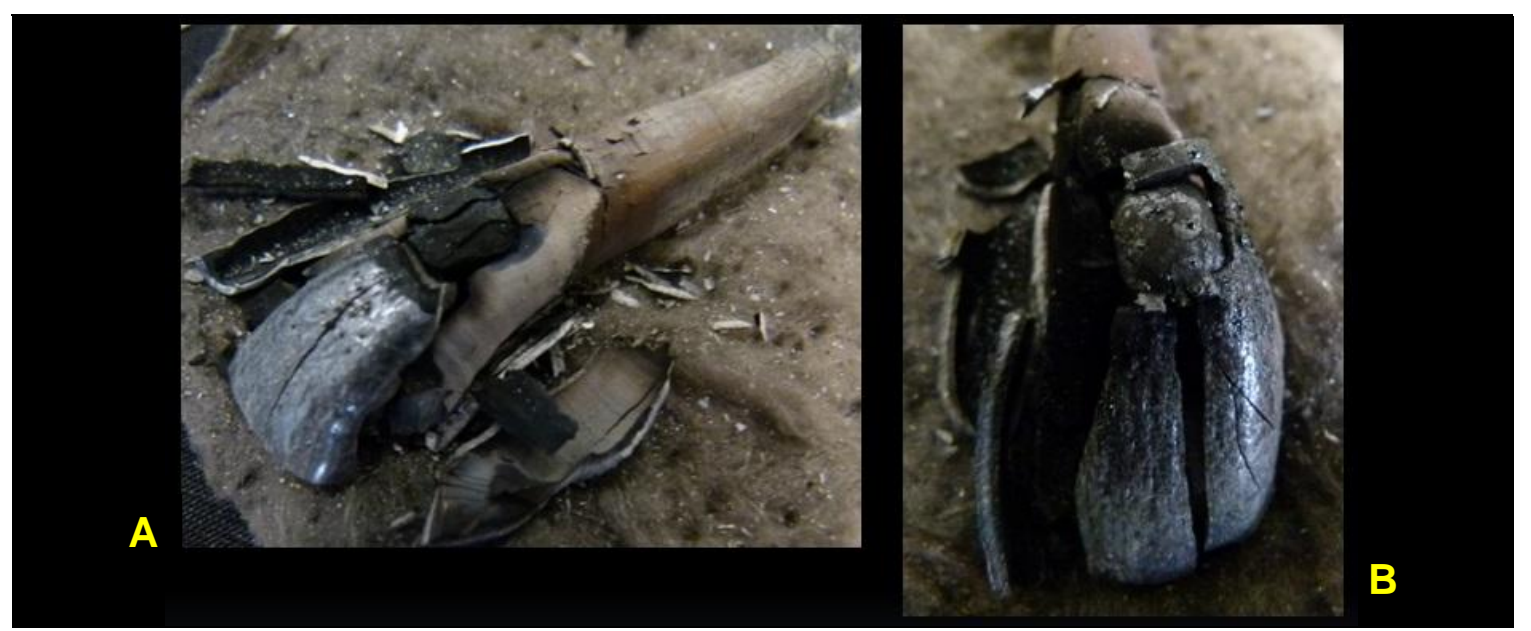

Figura 31 - Total enegrecimento das restaurações em resina composta (A) e CIV (B) submetidas a $400^{\circ} \mathrm{C}$. 


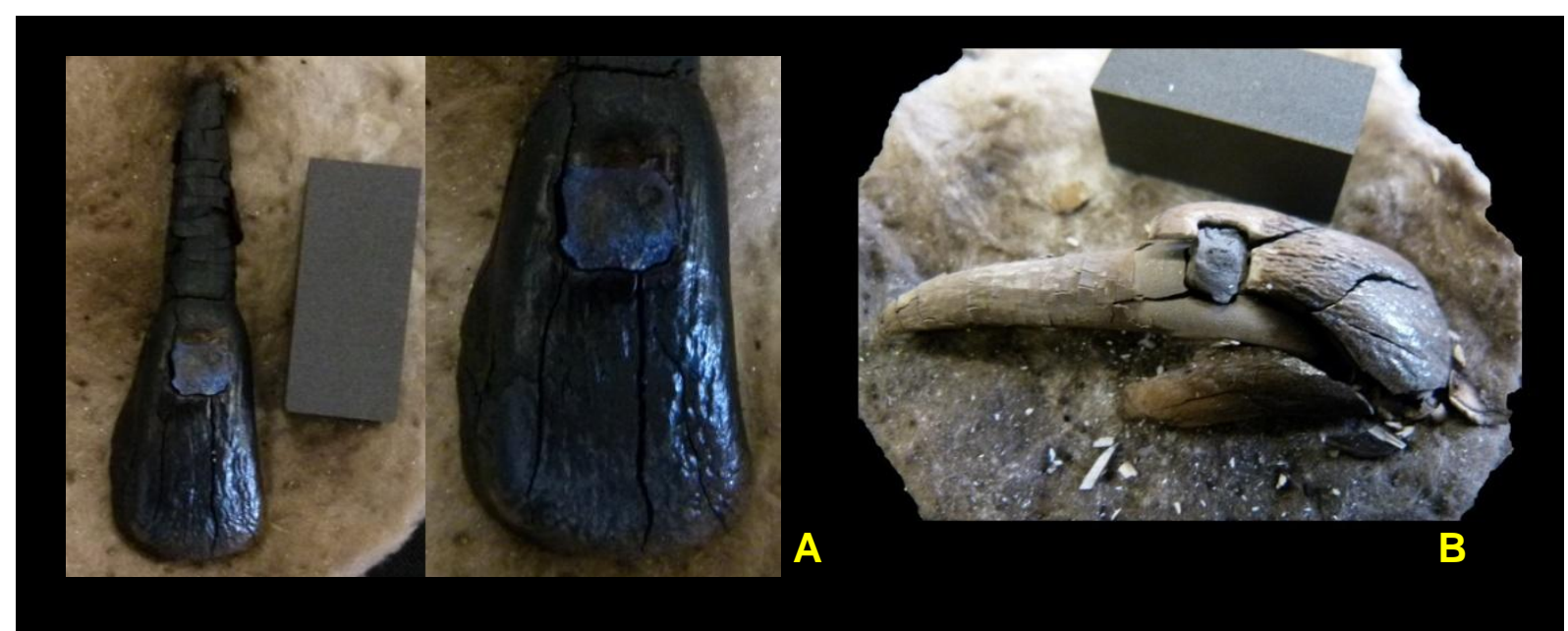

Figura 32 - Restauração em amálgama submetida a $400^{\circ} \mathrm{C}$ (A); Restauração em amálgama submetida a $500^{\circ} \mathrm{C}(\mathrm{B})$.

\subsubsection{Análise de cor}

A leitura de cor dos materiais restauradores estéticos (resina composta e CIV) foi analisada antes da exposição às altas temperaturas (inicial) e após a queima (final), nas temperaturas finais de $100^{\circ} \mathrm{C}, 200^{\circ} \mathrm{C}$ e $300^{\circ} \mathrm{C}$. Os valores das leituras de cor nas coordenadas $\mathrm{L}^{*}, \mathrm{a}^{*}$ e b*, das respectivas médias, antes e após ação do calor, e as alterações de cor $\left(\Delta \mathrm{L}^{*}, \Delta \mathrm{a}^{*}, \Delta \mathrm{b}^{*}\right.$ e $\left.\Delta \mathrm{E}\right)$ ocorridas; para a resina composta; estão apresentados nas Tabelas 02, 03 e 04; e para o CIV nas Tabelas 05, 06 e 07. 
Tabela 02 - Valores das coordenadas $\mathrm{L}^{*}, \mathrm{a}^{*}, \mathrm{~b}^{*}$, das respectivas médias e (desvio-padrão) antes (inicial) e após (final) exposição ao calor e das alterações de cor nas coordenadas $\left(\Delta \mathrm{L}^{*}, \Delta \mathrm{a}^{*}, \Delta \mathrm{b}^{*} \mathrm{e} \Delta \mathrm{E}\right)$ ocorridas após a submissão da resina composta a $100^{\circ} \mathrm{C}$.

\section{Resina Composta}

$100^{\circ} \mathrm{C}$

\begin{tabular}{ccccccccccc}
\hline & \multicolumn{3}{c}{ Inicial } & \multicolumn{4}{c}{ Final } & \multicolumn{4}{c}{$\boldsymbol{\Delta}$ (Delta) } \\
\hline $\mathbf{L}$ & $\mathbf{a}$ & $\mathbf{b}$ & $\mathbf{L}$ & $\mathbf{a}$ & $\mathbf{b}$ & $\mathbf{\Delta L}$ & $\boldsymbol{\Delta a}$ & $\boldsymbol{\Delta b}$ & $\boldsymbol{\Delta E}$ \\
\hline 74,83 & 3,83 & 28,70 & 82,00 & 7,50 & 36,13 & 7,17 & 3,67 & 7,43 & 10,96 \\
& 76,70 & 3,90 & 29,53 & 84,90 & 7,20 & 36,90 & 8,20 & 3,30 & 7,37 & 11,51 \\
& 75,20 & 3,87 & 28,40 & 81,80 & 7,07 & 34,97 & 6,60 & 3,20 & 6,57 & 9,84 \\
& 68,33 & 5,50 & 28,27 & 73,70 & 8,93 & 34,07 & 5,37 & 3,43 & 5,80 & 8,62 \\
& 75,00 & 4,20 & 28,80 & 81,90 & 7,53 & 35,70 & 6,90 & 3,33 & 6,90 & 10,31 \\
& 70,97 & 4,47 & 29,70 & 76,40 & 8,20 & 35,63 & 5,43 & 3,73 & 5,93 & 8,87 \\
& 76,10 & 3,37 & 28,90 & 84,40 & 7,40 & 37,53 & 8,30 & 4,03 & 8,63 & 12,64 \\
& 68,70 & 4,30 & 30,50 & 73,50 & 7,00 & 35,60 & 4,80 & 2,70 & 5,10 & 7,51 \\
& $\mathbf{6 7 , 6 0}$ & 5,20 & 27,67 & 71,80 & 7,80 & 31,87 & 4,20 & 2,60 & 4,20 & 6,48 \\
& 72,50 & 4,30 & 30,83 & 79,43 & 7,60 & 37,27 & 6,93 & 3,30 & 6,43 & 10,02 \\
\hline Média & $\mathbf{7 2 , 5 9}$ & $\mathbf{4 , 2 9}$ & $\mathbf{2 9 , 1 3}$ & $\mathbf{7 8 , 9 8}$ & $\mathbf{7 , 6 2}$ & $\mathbf{3 5 , 5 7}$ & $\mathbf{6 , 3 9}$ & $\mathbf{3 , 3 3}$ & $\mathbf{6 , 4 4}$ & $\mathbf{9 , 6 7}$ \\
Desvio \\
padrão & $\mathbf{( 3 , 4 6 )}$ & $\mathbf{( 0 , 6 4 )}$ & $\mathbf{( 1 , 0 0 )}$ & $\mathbf{( 4 , 7 9 )}$ & $\mathbf{( 0 , 5 8 )}$ & $\mathbf{( 1 , 1 1 )}$ & $\mathbf{( 1 , 3 9 )}$ & $\mathbf{( 0 , 4 4 )}$ & $\mathbf{( 1 , 2 6 )}$ & $\mathbf{( 1 , 8 6 )}$
\end{tabular}

Tabela 03 - Valores das coordenadas $\mathrm{L}^{*}, \mathrm{a}^{*}, \mathrm{~b}^{*}$, das respectivas médias e (desvio-padrão) antes (inicial) e após (final) exposição ao calor e das alterações de cor nas coordenadas $\left(\Delta \mathrm{L}^{*}, \Delta \mathrm{a}^{*}, \Delta \mathrm{b}^{*} \mathrm{e} \Delta \mathrm{E}\right)$ ocorridas após a submissão da resina composta a $200^{\circ} \mathrm{C}$.

\section{Resina Composta}

$200^{\circ} \mathrm{C}$

\begin{tabular}{ccccccccccc}
\hline & \multicolumn{3}{c}{ Inicial } & \multicolumn{4}{c}{ Final } & \multicolumn{4}{c}{$\boldsymbol{\Delta}$ (Delta) } \\
\hline $\mathbf{L}$ & $\mathbf{a}$ & $\mathbf{b}$ & $\mathbf{L}$ & $\mathbf{a}$ & $\mathbf{b}$ & $\mathbf{\Delta L}$ & $\mathbf{\Delta a}$ & $\boldsymbol{\Delta b}$ & $\boldsymbol{\Delta E}$ \\
\hline 77,20 & 3,00 & 29,90 & 86,23 & 6,27 & 36,80 & 9,03 & 3,27 & 6,90 & 11,83 \\
& 64,90 & 4,77 & 26,60 & 73,10 & 8,90 & 35,67 & 8,20 & 4,13 & 9,07 & 12,90 \\
& 76,03 & 3,10 & 30,00 & 83,70 & 7,30 & 38,57 & 7,67 & 4,20 & 8,57 & 12,24 \\
& 71,40 & 3,80 & 27,83 & 77,17 & 8,20 & 35,27 & 5,77 & 4,40 & 7,43 & 10,39 \\
& 63,90 & 4,80 & 27,60 & 71,47 & 9,37 & 36,33 & 7,57 & 4,57 & 8,73 & 12,42 \\
& 64,50 & 4,70 & 25,60 & 71,27 & 8,10 & 33,00 & 6,77 & 3,40 & 7,40 & 10,59 \\
& 66,60 & 4,80 & 27,73 & 74,70 & 9,30 & 37,77 & 8,10 & 4,50 & 10,03 & 13,66 \\
& 76,30 & 4,00 & 29,97 & 86,30 & 7,20 & 36,73 & 10,00 & 3,20 & 6,77 & 12,49 \\
& 76,40 & 3,70 & 29,73 & 82,93 & 7,60 & 37,47 & 6,53 & 3,90 & 7,73 & 10,85 \\
& 69,10 & 4,50 & 29,00 & 75,90 & 9,20 & 37,93 & 6,80 & 4,70 & 8,93 & 12,17 \\
\hline Média & $\mathbf{7 0 , 6 3}$ & $\mathbf{4 , 1 2}$ & $\mathbf{2 8 , 4 0}$ & $\mathbf{7 8 , 2 8}$ & $\mathbf{8 , 1 4}$ & $\mathbf{3 6 , 5 5}$ & $\mathbf{7 , 6 4}$ & $\mathbf{4 , 0 3}$ & $\mathbf{8 , 1 6}$ & $\mathbf{1 1 , 9 5}$ \\
Desvio \\
padrão & $\mathbf{( 5 , 5 0 )}$ & $\mathbf{( 0 , 7 0 )}$ & $\mathbf{( 1 , 5 6 )}$ & $\mathbf{( 5 , 9 7 )}$ & $\mathbf{( 1 , 0 5 )}$ & $\mathbf{( 1 , 6 1 )}$ & $\mathbf{( 1 , 2 6 )}$ & $\mathbf{( 0 , 5 6 )}$ & $\mathbf{( 1 , 0 7 )}$ & $\mathbf{( 1 , 0 5 )}$
\end{tabular}


Tabela 04 - Valores das coordenadas $\mathrm{L}^{*}, \mathrm{a}^{*}, \mathrm{~b}^{*}$, das respectivas médias e (desvio-padrão) antes (inicial) e após (final) exposição ao calor e das alterações de cor nas coordenadas $\left(\Delta \mathrm{L}^{*}, \Delta \mathrm{a}^{*}, \Delta \mathrm{b}^{*} \mathrm{e} \Delta \mathrm{E}\right)$ ocorridas após a submissão da resina composta a $300^{\circ} \mathrm{C}$.

\section{Resina Composta} $300^{\circ} \mathrm{C}$

\begin{tabular}{ccccccccccc}
\hline & \multicolumn{3}{c}{ Inicial } & \multicolumn{4}{c}{ Final } & \multicolumn{3}{c}{$\boldsymbol{\Delta}$ (Delta) } \\
\hline $\mathbf{L}$ & $\mathbf{a}$ & $\mathbf{b}$ & $\mathbf{L}$ & $\mathbf{a}$ & $\mathbf{b}$ & $\mathbf{\Delta L}$ & $\boldsymbol{\Delta a}$ & $\boldsymbol{\Delta b}$ & $\boldsymbol{\Delta E}$ \\
\hline 64,20 & 5,43 & 28,30 & 67,73 & 11,93 & 43,67 & 3,53 & 6,50 & 15,37 & 17,05 \\
& 77,00 & 3,20 & 30,80 & 79,43 & 11,37 & 47,50 & 2,43 & 8,17 & 16,70 & 18,75 \\
& 77,00 & 3,60 & 29,50 & 76,67 & 11,03 & 54,20 & $-0,33$ & 7,43 & 24,70 & 25,80 \\
& 68,67 & 4,63 & 29,43 & 73,20 & 13,73 & 45,63 & 4,53 & 9,10 & 16,20 & 19,13 \\
& 62,67 & 5,50 & 25,83 & 65,60 & 13,60 & 47,40 & 2,93 & 8,10 & 21,57 & 23,22 \\
& 78,90 & 3,37 & 30,67 & 76,43 & 11,10 & 53,63 & $-2,47$ & 7,73 & 22,97 & 24,36 \\
& 70,60 & 4,43 & 29,53 & 67,57 & 13,03 & 55,47 & $-3,03$ & 8,60 & 25,93 & 27,49 \\
& 67,23 & 5,80 & 28,37 & 70,90 & 13,63 & 45,57 & 3,67 & 7,83 & 17,20 & 19,25 \\
& 76,10 & 3,20 & 28,37 & 79,13 & 8,80 & 45,30 & 3,03 & 5,60 & 16,93 & 18,09 \\
& 69,80 & 5,30 & 29,07 & 68,50 & 15,60 & 60,00 & $-1,30$ & 10,30 & 30,93 & 32,63 \\
\hline Média & $\mathbf{7 1 , 2 2}$ & $\mathbf{4 , 4 4}$ & $\mathbf{2 8 , 9 9}$ & $\mathbf{7 2 , 5 2}$ & $\mathbf{1 2 , 3 8}$ & $\mathbf{4 9 , 8 4}$ & $\mathbf{1 , 3 0}$ & $\mathbf{7 , 9 4}$ & $\mathbf{2 0 , 8 5}$ & $\mathbf{2 2 , 5 8}$ \\
Desvio \\
padrão & $\mathbf{5 , 7 4 )}$ & $\mathbf{( 1 , 0 4 )}$ & $\mathbf{( 1 , 4 2 )}$ & $\mathbf{( 5 , 1 5 )}$ & $\mathbf{( 1 , 9 2 )}$ & $\mathbf{( 5 , 5 2 )}$ & $\mathbf{( 2 , 8 0 )}$ & $\mathbf{( 1 , 3 0 )}$ & $\mathbf{( 5 , 2 2 )}$ & $\mathbf{( 5 , 0 3 )}$
\end{tabular}

Tabela 05 - Valores das coordenadas $\mathrm{L}^{*}, \mathrm{a}^{*}, \mathrm{~b}^{*}$, das respectivas médias e (desvio-padrão) antes (inicial) e após (final) exposição ao calor e das alterações de cor nas coordenadas $\left(\Delta \mathrm{L}^{*}, \Delta \mathrm{a}^{*}, \Delta \mathrm{b}^{*} \mathrm{e} \Delta \mathrm{E}\right)$ ocorridas após a submissão do $\mathrm{CIV}$ a $100^{\circ} \mathrm{C}$.

\section{Cimento de Ionômero de Vidro}

\section{$100^{\circ} \mathrm{C}$}

\begin{tabular}{|c|c|c|c|c|c|c|c|c|c|c|}
\hline & \multicolumn{3}{|c|}{ Inicial } & \multicolumn{3}{|c|}{ Final } & \multicolumn{4}{|c|}{$\Delta$ (Delta) } \\
\hline & $\mathbf{L}$ & $\mathbf{a}$ & b & $\mathbf{L}$ & $\mathbf{a}$ & b & $\Delta \mathrm{L}$ & $\Delta \mathbf{a}$ & $\Delta \mathbf{b}$ & $\Delta \mathrm{E}$ \\
\hline & 86,83 & 1,10 & 30,13 & 77,53 & 5,60 & 39,67 & $-9,30$ & 4,50 & 9,53 & 14,06 \\
\hline & 87,13 & 2,00 & 31,60 & 74,40 & 6,37 & 39,27 & $-12,73$ & 4,37 & 7,67 & 15,49 \\
\hline & 84,47 & 0,73 & 27,33 & 78,50 & 4,80 & 37,60 & $-5,97$ & 4,07 & 10,27 & 12,55 \\
\hline & 86,10 & 0,90 & 29,00 & 76,67 & 5,50 & 38,83 & $-9,43$ & 4,60 & 9,83 & 14,38 \\
\hline & 85,60 & 1,10 & 29,03 & 72,73 & 6,50 & 39,77 & $-12,87$ & 5,40 & 10,73 & 17,60 \\
\hline & 81,90 & 3,20 & 36,77 & 71,50 & 8,50 & 44,30 & $-10,40$ & 5,30 & 7,53 & 13,89 \\
\hline & 86,03 & 1,40 & 29,80 & 75,23 & 6,10 & 39,77 & $-10,80$ & 4,70 & 9,97 & 15,43 \\
\hline & 87,97 & 1,70 & 32,20 & 73,50 & 7,33 & 41,80 & $-14,47$ & 5,63 & 9,60 & 18,25 \\
\hline & 85,60 & 2,40 & 32,23 & 75,97 & 7,63 & 43,20 & $-9,63$ & 5,23 & 10,97 & 15,51 \\
\hline & 84,20 & 2,30 & 33,10 & 74,50 & 8,30 & 43,37 & $-9,70$ & 6,00 & 10,27 & 15,35 \\
\hline Média & 85,58 & 1,68 & 31,12 & 75,05 & 6,66 & 40,76 & $-10,53$ & 4,98 & 9,64 & 15,25 \\
\hline $\begin{array}{l}\text { Desvio } \\
\text { padrão }\end{array}$ & $(1,73)$ & $(0,79)$ & $(2,68)$ & $(2,18)$ & $(1,24)$ & $(2,25)$ & $(2,38)$ & $(0,62)$ & $(1,17)$ & $(1,70)$ \\
\hline
\end{tabular}


Tabela 06 - Valores das coordenadas $\mathrm{L}^{*}, \mathrm{a}^{*}, \mathrm{~b}^{*}$, das respectivas médias e (desvio-padrão) antes (inicial) e após (final) exposição ao calor e das alterações de cor nas coordenadas $\left(\Delta \mathrm{L}^{*}, \Delta \mathrm{a}^{*}, \Delta \mathrm{b}^{*}\right.$ e $\left.\Delta \mathrm{E}\right)$ ocorridas após a submissão do CIV a $200^{\circ} \mathrm{C}$.

\section{Cimento de Ionômero de Vidro}

$200^{\circ} \mathrm{C}$

\begin{tabular}{ccccccccccc}
\hline & \multicolumn{3}{c}{ Inicial } & \multicolumn{4}{c}{ Final } & \multicolumn{4}{c}{$\boldsymbol{\Delta}$ (Delta) } \\
\hline $\mathbf{L}$ & $\mathbf{a}$ & $\mathbf{b}$ & $\mathbf{L}$ & $\mathbf{a}$ & $\mathbf{b}$ & $\mathbf{\Delta L}$ & $\mathbf{\Delta a}$ & $\mathbf{\Delta b}$ & $\mathbf{\Delta E}$ \\
\hline 71,63 & 4,07 & 33,70 & 43,00 & 14,47 & 38,23 & $-28,63$ & 10,40 & 4,53 & 30,80 \\
& 87,07 & 0,80 & 29,10 & 53,77 & 11,80 & 40,40 & $-33,30$ & 11,00 & 11,30 & 36,85 \\
& 87,30 & 2,90 & 36,37 & 30,00 & 12,93 & 28,00 & $-57,30$ & 10,03 & $-8,37$ & 58,77 \\
& 85,03 & 1,80 & 32,53 & 43,23 & 12,60 & 34,77 & $-41,80$ & 10,80 & 2,23 & 43,23 \\
& 85,70 & 1,10 & 30,50 & 39,07 & 13,30 & 35,73 & $-46,63$ & 12,20 & 5,23 & 48,49 \\
& 87,13 & 1,70 & 33,30 & 39,30 & 13,70 & 37,10 & $-47,83$ & 12,00 & 3,80 & 49,46 \\
& 83,40 & 1,30 & 31,40 & 31,43 & 13,77 & 31,27 & $-51,97$ & 12,47 & $-0,13$ & 53,44 \\
& 91,20 & 1,00 & 29,03 & 56,10 & 10,10 & 37,50 & $-35,10$ & 9,10 & 8,47 & 37,24 \\
& 86,10 & 1,00 & 27,70 & 62,30 & 9,93 & 38,93 & $-23,80$ & 8,93 & 11,23 & 27,79 \\
& 86,47 & 1,80 & 33,50 & 38,17 & 13,93 & 34,93 & $-48,30$ & 12,13 & 1,43 & 49,82 \\
\hline Média & $\mathbf{8 5 , 1 0}$ & $\mathbf{1 , 7 5}$ & $\mathbf{3 1 , 7 1}$ & $\mathbf{4 3 , 6 4}$ & $\mathbf{1 2 , 6 5}$ & $\mathbf{3 5 , 6 9}$ & $\mathbf{- 4 1 , 4 7}$ & $\mathbf{1 0 , 9 1}$ & $\mathbf{3 , 9 7}$ & $\mathbf{4 3 , 5 9}$ \\
Desvio \\
padrão & $\mathbf{( 5 , 1 4 )}$ & $\mathbf{( 1 , 0 2 )}$ & $\mathbf{( 2 , 6 6 )}$ & $\mathbf{( 1 0 , 6 0 )}$ & $\mathbf{( 1 , 5 8 )}$ & $\mathbf{( 3 , 7 2 )}$ & $\mathbf{( 1 0 , 8 5 )}$ & $\mathbf{( 1 , 2 9 )}$ & $\mathbf{( 5 , 8 4 )}$ & $\mathbf{( 1 0 , 1 3 )}$
\end{tabular}

Tabela 07 - Valores das coordenadas $\mathrm{L}^{*}, \mathrm{a}^{*}, \mathrm{~b}^{*}$, das respectivas médias e (desvio-padrão) antes (inicial) e após (final) exposição ao calor e das alterações de cor nas coordenadas $\left(\Delta \mathrm{L}^{*}, \Delta \mathrm{a}^{*}, \Delta \mathrm{b}^{*} \mathrm{e} \Delta \mathrm{E}\right)$ ocorridas após a submissão do CIV a $300^{\circ} \mathrm{C}$.

\section{Cimento de Ionômero de Vidro}

$300^{\circ} \mathrm{C}$

\begin{tabular}{|c|c|c|c|c|c|c|c|c|c|c|}
\hline & \multicolumn{3}{|c|}{ Inicial } & \multicolumn{3}{|c|}{ Final } & \multicolumn{4}{|c|}{$\Delta$ (Delta) } \\
\hline & $\mathbf{L}$ & $\mathbf{a}$ & b & $\mathbf{L}$ & $\mathbf{a}$ & b & $\Delta \mathbf{L}$ & $\Delta \mathbf{a}$ & $\Delta \mathbf{b}$ & $\Delta \mathrm{E}$ \\
\hline & 92,37 & 0,70 & 28,97 & 9,97 & 10,33 & 13,07 & $-82,40$ & 9,63 & $-15,90$ & 84,47 \\
\hline & 83,20 & 2,00 & 33,47 & 9,63 & 5,07 & 9,13 & $-73,57$ & 3,07 & $-24,33$ & 77,55 \\
\hline & 88,47 & 0,60 & 26,90 & 10,00 & 13,03 & 12,53 & $-78,47$ & 12,43 & $-14,37$ & 80,73 \\
\hline & 91,60 & 1,70 & 31,73 & 17,63 & 16,27 & 19,40 & $-73,97$ & 14,57 & $-12,33$ & 76,39 \\
\hline & 82,10 & 2,90 & 32,83 & 12,60 & 17,47 & 16,87 & $-69,50$ & 14,57 & $-15,97$ & 72,78 \\
\hline & 81,27 & 2,30 & 31,60 & 14,87 & 17,97 & 18,37 & $-66,40$ & 15,67 & $-13,23$ & 69,49 \\
\hline & 76,57 & 4,00 & 35,43 & 8,47 & 10,50 & 11,40 & $-68,10$ & 6,50 & $-24,03$ & 72,51 \\
\hline & 83,83 & 2,00 & 32,40 & 16,97 & 15,43 & 17,97 & $-66,87$ & 13,43 & $-14,43$ & 69,71 \\
\hline & 85,17 & 3,20 & 35,50 & 12,40 & 13,31 & 14,84 & $-72,76$ & 10,11 & $-20,66$ & 76,31 \\
\hline & 89,83 & 1,90 & 32,10 & 11,50 & 13,70 & 14,83 & $-78,33$ & 11,80 & $-17,27$ & 81,08 \\
\hline & 85,44 & 2,13 & 32,10 & 12,40 & 13,31 & 14,84 & $-73,04$ & 12,08 & $-17,25$ & 76,10 \\
\hline $\begin{array}{l}\text { Desvio } \\
\text { padrão }\end{array}$ & $(5,05)$ & $(1,05)$ & $(2,63)$ & $(3,16)$ & $(3,90)$ & $(3,33)$ & $(5,43)$ & $(2,75)$ & $(4,32)$ & $(5,02)$ \\
\hline
\end{tabular}




\section{Delta E}

As comparações das médias de Delta E (One-way ANOVA, Tukey, p<0,05) podem ser vistas nas Tabelas 08, 09 e Gráfico 01.

Tabela 08 - Comparação das alterações de cor $(\Delta \mathrm{E})$ e desvio padrão, da resina composta e do CIV nas submissões a $100^{\circ} \mathrm{C}, 200^{\circ} \mathrm{C}$ e $300^{\circ} \mathrm{C}$ e entre os materiais, nas mesmas temperaturas, analisadas segundo One-way ANOVA, teste de Tukey, $\mathrm{p}<0,05$.

\section{Delta E}

\begin{tabular}{ccc}
\hline Temperaturas & Resina & CIV \\
\hline $100^{\circ} \mathrm{C}$ & $9,67 \pm 1,86 \mathrm{aB}$ & $15,25 \pm 1,70 \mathrm{aB}$ \\
$200^{\circ} \mathrm{C}$ & $11,95 \pm 1,05 \mathrm{bB}$ & $43,59 \pm 10,13 \mathrm{aC}$ \\
$300^{\circ} \mathrm{C}$ & $22,58 \pm 5,03 \mathrm{bA}$ & $76,10 \pm 5,02 \mathrm{Aa}$ \\
\hline
\end{tabular}

Letras diferentes, minúsculas na linha, entre os materiais, e maiúsculas na coluna, para o mesmo material, indicam diferença estatisticamente significante $(\mathrm{p}<0,05)$.

Tabela 09 - Comparação das alterações de cor $(\Delta \mathrm{E})$ e desvio padrão, da resina composta e do $\mathrm{CIV}$ nas submissões a $100^{\circ} \mathrm{C}, 200^{\circ} \mathrm{C}$ e $300^{\circ} \mathrm{C}$ e entre os materiais, em diferentes temperaturas, analisadas segundo One-way ANOVA, teste de Tukey, $\mathrm{p}<0,05$.

\section{Delta E}

Material

Temperatura

CIV

\begin{tabular}{cccccc} 
& Temperatura & & $100^{\circ} \mathrm{C}$ & $200^{\circ} \mathrm{C}$ & $300^{\circ} \mathrm{C}$ \\
& & & $15,25 \pm 1,70$ & $43,59 \pm 10,13$ & $76,10 \pm 5,02$ \\
Resina & $100^{\circ} \mathrm{C}$ & $9,67 \pm 1,86$ & & $* * * *$ & $* * * *$ \\
Composta & $200^{\circ} \mathrm{C}$ & $11,95 \pm 1,05$ & ns & $* * *$ \\
\hline & $300^{\circ} \mathrm{C}$ & $22,58 \pm 5,03$ & $*$ & $* * * *$
\end{tabular}

* = Diferença estatisticamente significante $(\mathrm{p}<0,05)$. Quanto maior o número de * nas células, maior a significância da diferença. ns = Não houve diferença estatisticamente significante $(p>0,05)$. 
Gráfico 01 - Representação gráfica da comparação de Delta E entre os materiais restauradores estéticos submetidos à ação do calor.

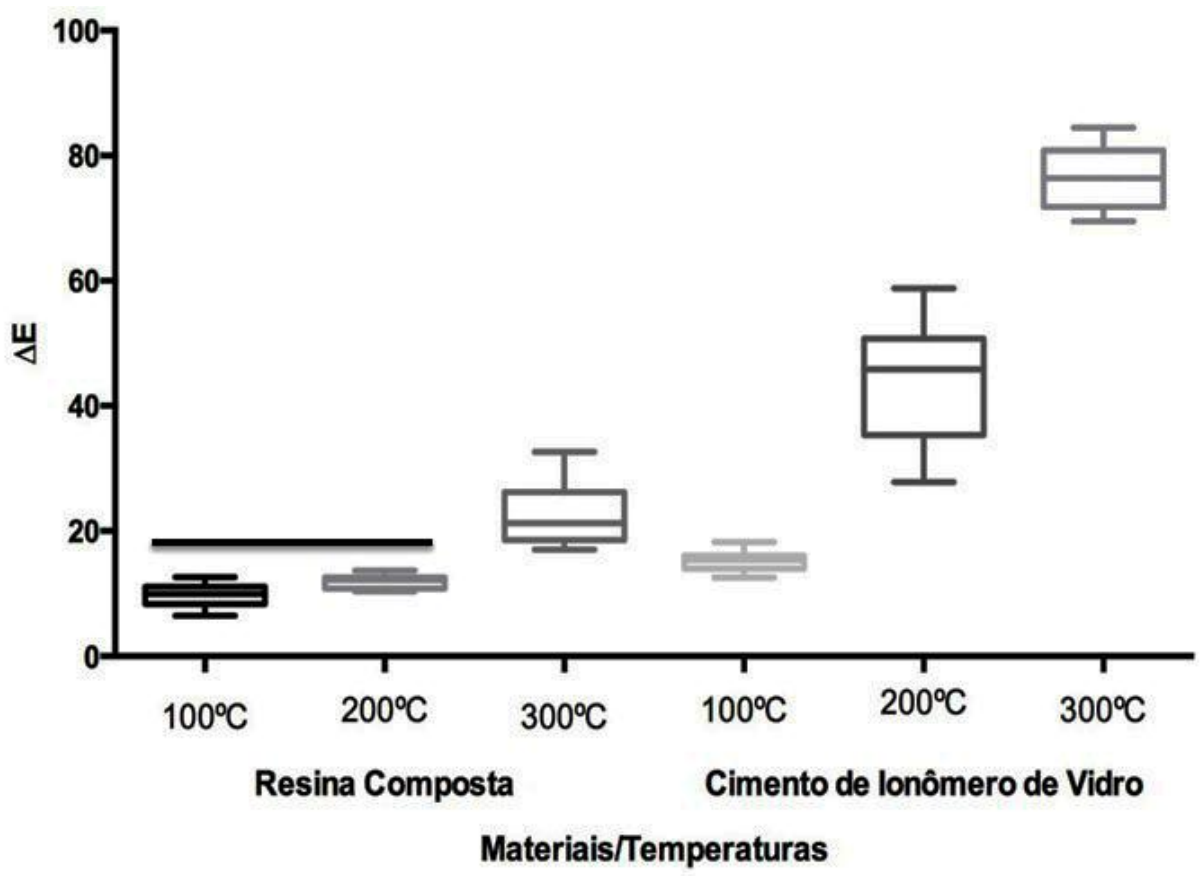

Para a resina composta, grupos amostrais sob linha horizontal, indicam ausência de diferença significante $(p>0,05)$. Para o CIV, em todas as comparações, $p<0,05$.

Pela análise do $\Delta \mathrm{E}$, pôde-se verificar que, para a resina composta; houve alteração de cor nas três temperaturas analisadas, sendo mais intensa quanto maior a temperatura de exposição, até $300^{\circ} \mathrm{C}$, resultado diferente estatisticamente $(\mathrm{p}<0,05)$ em relação às duas temperaturas menores $\left(100^{\circ} \mathrm{C}\right.$ e $\left.200^{\circ} \mathrm{C}\right)$, que não apresentaram diferença $(p>0,05)$ entre si.

Para o CIV, da mesma maneira, ocorreu aumento no valor médio de $\Delta \mathrm{E}$ quanto maior a temperatura a que o material foi submetido, com diferença estatisticamente significante $(p<0,05)$ entre todos os grupos testados.

Nas Tabelas 08 e 09 e no Gráfico 01, podemos observar o aumento do $\Delta \mathrm{E}$ nas três temperaturas analisadas para os dois materiais estéticos avaliados, sendo que a alteração de cor no CIV foi significantemente maior $(\mathrm{p}<0,05)$ do que na resina composta, apesar de ambos apresentarem modificações em sua cor pela ação do calor até $300^{\circ} \mathrm{C}$.

Comparando a alteração de cor dos materiais estéticos, verificou-se que houve diferença estatisticamente significante $(\mathrm{p}<0,05)$ entre todas as temperaturas testadas, 
sendo semelhantes $(\mathrm{p}>0,05)$, apenas o CIV após $100^{\circ} \mathrm{C}$ e a resina composta após $100^{\circ} \mathrm{C}$ e $200^{\circ} \mathrm{C}$ (Tabelas 08 e 09).

\section{Delta L}

As comparações das médias de Delta L* (One-way ANOVA, Tukey, p<0,05) podem ser vistas nas Tabelas 10 e 11 e Gráfico 02.

Tabela 10 - Comparação das alterações de cor, na coordenada $L^{*}\left(\Delta \mathrm{L}^{*}\right)$ e desvio padrão, da resina composta e do CIV nas submissões a $100^{\circ} \mathrm{C}, 200^{\circ} \mathrm{C}$ e $300^{\circ} \mathrm{C}$ e entre os materiais, nas mesmas temperaturas, analisadas segundo One-way ANOVA, teste de Tukey, $\mathrm{p}<0,05$.

\section{Delta L}

\begin{tabular}{ccc}
\hline Temperaturas & Resina & CIV \\
\hline $100^{\circ} \mathrm{C}$ & $6,39 \pm 1,39 \mathrm{bA}$ & $-10,53 \pm 2,38 \mathrm{aB}$ \\
$200^{\circ} \mathrm{C}$ & $7,64 \pm 1,26 \mathrm{bA}$ & $-41,47 \pm 10,85 \mathrm{aC}$ \\
$300^{\circ} \mathrm{C}$ & $1,30 \pm 2,80 \mathrm{bA}$ & $-73,04 \pm 5,43 \mathrm{aA}$ \\
\hline
\end{tabular}

Letras diferentes, minúsculas na linha e maiúsculas na coluna, para cada material, indicam diferença estatisticamente significante $(\mathrm{p}<0,05)$.

Tabela 11 - Comparação das alterações de cor, na coordenada $L^{*}\left(\Delta \mathrm{L}^{*}\right)$ e desvio padrão, da resina composta e do CIV nas submissões a $100^{\circ} \mathrm{C}, 200^{\circ} \mathrm{C}$ e $300^{\circ} \mathrm{C}$ e entre os materiais, em diferentes temperaturas, analisadas segundo One-way ANOVA, teste de Tukey, $\mathrm{p}<0,05$.

\section{Delta L}

\begin{tabular}{|c|c|c|c|c|c|}
\hline \multirow[t]{3}{*}{ Material } & & & \multicolumn{3}{|c|}{ CIV } \\
\hline & \multirow{2}{*}{\multicolumn{2}{|c|}{ Temperatura }} & $100^{\circ} \mathrm{C}$ & $200^{\circ} \mathrm{C}$ & $300^{\circ} \mathrm{C}$ \\
\hline & & & $-10,53 \pm 2,38$ & $-41,47 \pm 10,85$ & $-73,04 \pm 5,43$ \\
\hline \multirow{3}{*}{$\begin{array}{c}\text { Resina } \\
\text { Composta }\end{array}$} & $100^{\circ} \mathrm{C}$ & $6,39 \pm 1,39$ & & $* * * *$ & $* * * *$ \\
\hline & $200^{\circ} \mathrm{C}$ & $7,64 \pm 1,26$ & $* * * *$ & & $* * * *$ \\
\hline & $300^{\circ} \mathrm{C}$ & $1,30 \pm 2,80$ & $* * * *$ & $* * * *$ & \\
\hline
\end{tabular}

$* * * *=$ Diferença estatisticamente significante $(\mathrm{p}<0,05)$. 
Gráfico 02 - Representação gráfica da comparação de Delta L* entre os materiais restauradores estéticos submetidos à ação do calor.

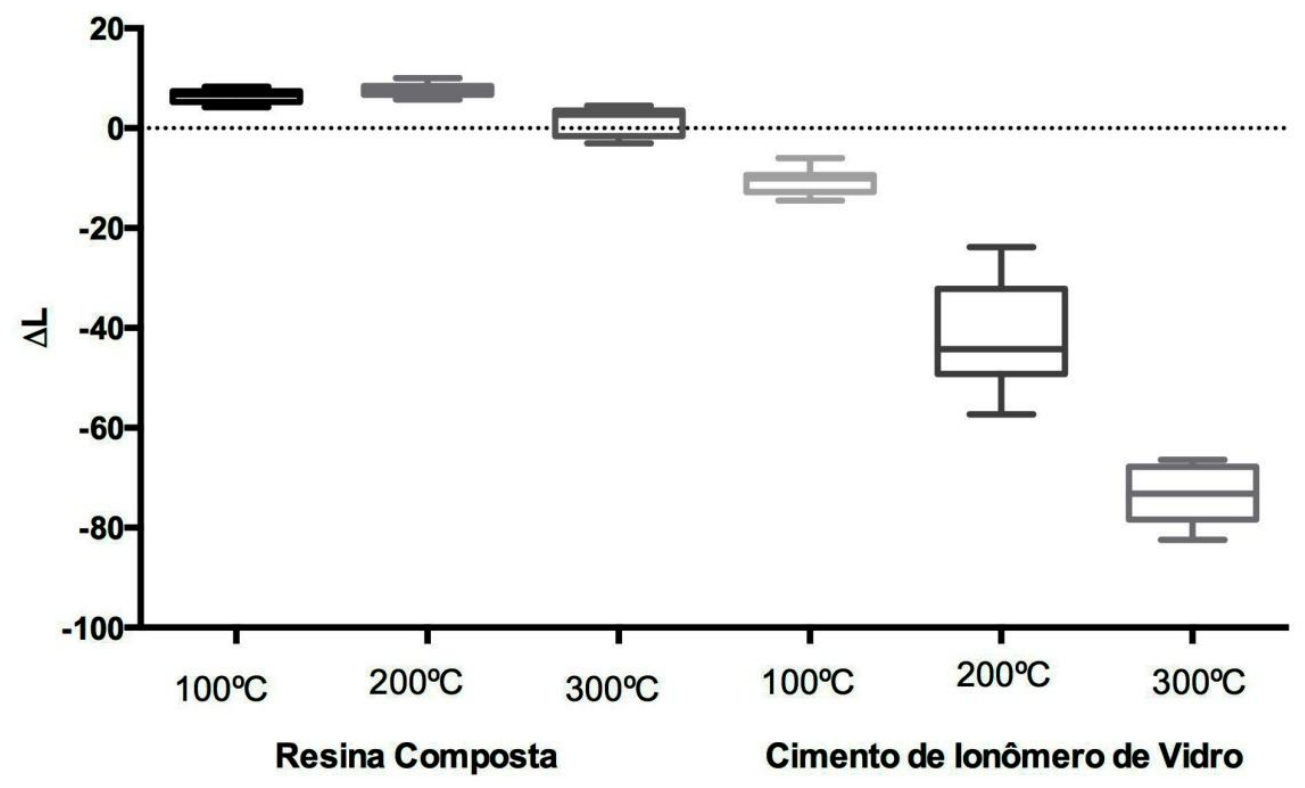

Materiais/Temperaturas

Para todas as comparações entre os grupos amostrais das resinas compostas, $p>0,05$. Para todas as comparações entre os grupos amostrais do CIV, $\mathrm{p}<0,05$.

Os resultados demonstram que nos grupos restaurados com resina composta não ocorreram alterações significativas nos valores da coordenada $L^{*}(p>0,05)$, pela ação do calor, em nenhuma das três temperaturas avaliadas.

Nos dentes restaurados com CIV, verificou-se diminuição na coordenada L*, com maior alteração de Delta $L^{*}$ quanto maior a temperatura a que o material foi submetido, com resultados diferentes estatisticamente entre todos os grupos testados $(\mathrm{p}<0,05)$.

A alteração de Delta $L^{*}$ sempre foi maior para o CIV do que para resina composta, com diferença estatisticamente significante $(\mathrm{p}<0,05)$ para todas as temperaturas testadas. (Tabelas 10 e 11).

\section{Delta a}

As comparações das médias de Delta a* (One-way ANOVA, Tukey, p<0,05) podem ser visualizadas nas Tabelas 12 e 13 e Gráfico 03. 
Tabela 12 - Comparação das alterações de cor, na coordenada $\mathrm{a}^{*}\left(\Delta \mathrm{a}^{*}\right)$ e desvio padrão, da resina composta e do $\mathrm{CIV}$ nas submissões a $100^{\circ} \mathrm{C}, 200^{\circ} \mathrm{C}$ e $300^{\circ} \mathrm{C}$ e entre os materiais, nas mesmas temperaturas, analisadas segundo One-way ANOVA, teste de Tukey, $\mathrm{p}<0,05$.

\section{Delta a}

\begin{tabular}{ccc}
\hline Temperaturas & Resina & CIV \\
\hline $100^{\circ} \mathrm{C}$ & $3,33 \pm 0,44 \mathrm{aB}$ & $4,98 \pm 0,62 \mathrm{aB}$ \\
$200^{\circ} \mathrm{C}$ & $4,03 \pm 0,56 \mathrm{bB}$ & $10,91 \pm 1,29 \mathrm{aA}$ \\
$300^{\circ} \mathrm{C}$ & $7,94 \pm 1,30 \mathrm{bA}$ & $12,08 \pm 2,75 \mathrm{aA}$ \\
\hline
\end{tabular}

Letras diferentes, minúsculas na linha, entre os materiais, e maiúsculas na coluna, para o mesmo material, indicam diferença estatisticamente significante $(\mathrm{p}<0,05)$.

Tabela 13 - Comparação das alterações de cor, na coordenada $\mathrm{a}^{*}\left(\Delta \mathrm{a}^{*}\right)$ e desvio padrão, da resina composta e do CIV nas submissões a $100^{\circ} \mathrm{C}, 200^{\circ} \mathrm{C}$ e $300^{\circ} \mathrm{C}$ e entre os materiais, em diferentes temperaturas, analisadas segundo One-way ANOVA, teste de Tukey, $\mathrm{p}<0,05$.

\section{Delta a}

\begin{tabular}{|c|c|c|c|c|c|}
\hline \multirow[t]{3}{*}{ Material } & & & \multicolumn{3}{|c|}{ CIV } \\
\hline & \multirow[t]{2}{*}{ Temperatura } & & $100^{\circ} \mathrm{C}$ & $200^{\circ} \mathrm{C}$ & $300^{\circ} \mathrm{C}$ \\
\hline & & & $4,98 \pm 0,62$ & $10,91 \pm 1,29$ & $12,08 \pm 2,75$ \\
\hline \multirow{3}{*}{$\begin{array}{c}\text { Resina } \\
\text { Composta }\end{array}$} & $100^{\circ} \mathrm{C}$ & $3,33 \pm 0,44$ & & $* * * *$ & $* * * *$ \\
\hline & $200^{\circ} \mathrm{C}$ & $4,03 \pm 0,56$ & ns & & $* * * *$ \\
\hline & $300^{\circ} \mathrm{C}$ & $7,94 \pm 1,30$ & $* * *$ & $* * *$ & \\
\hline
\end{tabular}

* = Diferença estatisticamente significante $(\mathrm{p}<0,05)$. Quanto maior o número de * nas células, maior a significância da diferença. ns = Não houve diferença estatisticamente significante $(\mathrm{p}>0,05)$. 
Gráfico 03 - Representação gráfica da comparação de Delta a* entre os materiais restauradores estéticos submetidos à ação do calor.

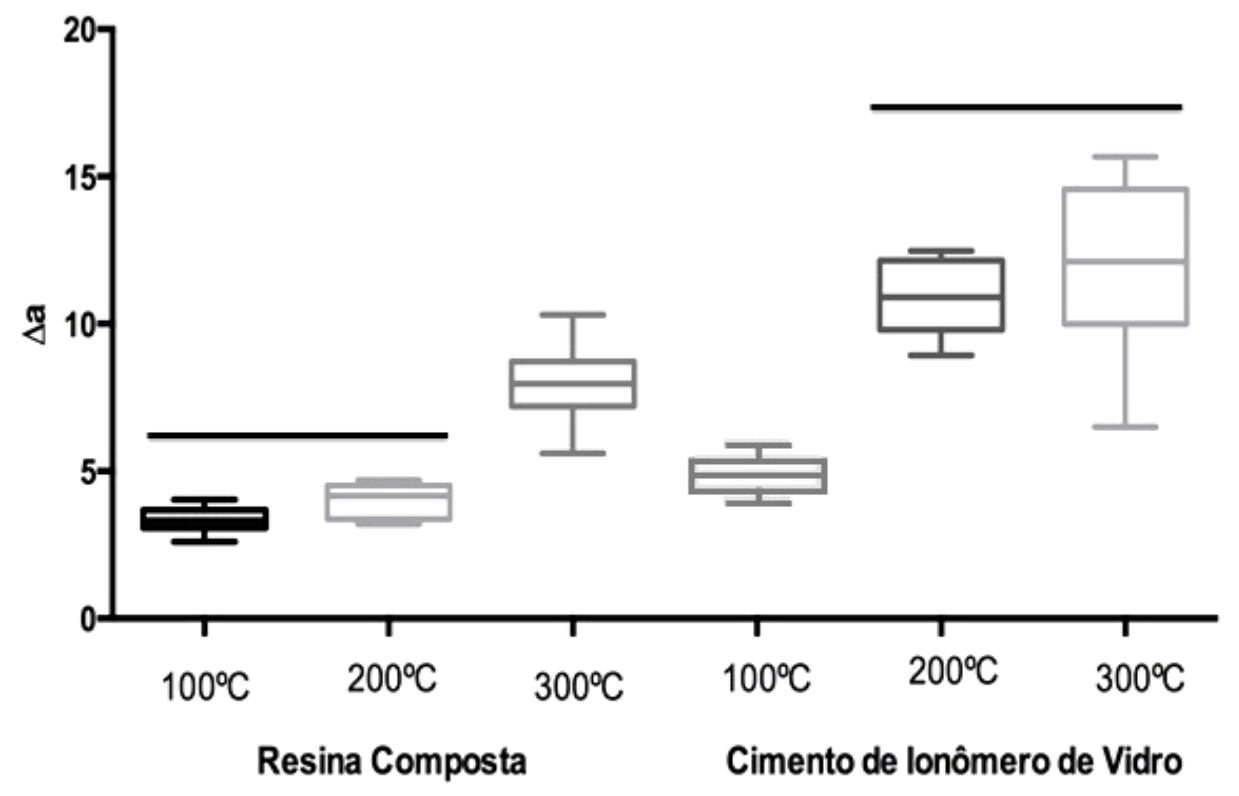

Materiais/Temperaturas

Grupos amostrais sob linha horizontal, indicam ausência de diferença significante $(p>0,05)$.

$\mathrm{Na}$ resina composta, verificou-se aumento na coordenada $\mathrm{a}^{*}$, nas três temperaturas avaliadas. A maior alteração ocorreu à temperatura de $300^{\circ} \mathrm{C}$, resultado estatisticamente significante $(p<0,05)$ em relação aos demais grupos de resina composta, que não apresentaram diferença entre si $(p>0,05)$. Para o CIV, também houve aumento na coordenada $\mathrm{a}^{*}$ com maior alteração à temperatura de $300^{\circ} \mathrm{C}$, resultado estatisticamente semelhante $(p>0,05)$ à temperatura de $200^{\circ} \mathrm{C}$ e diferente significativamente $(\mathrm{p}<0,05)$ de $100^{\circ} \mathrm{C}$.

A análise comparativa entre os materiais estéticos demonstra que houve diferença estatisticamente significante $(p<0,05)$ entre todas as temperaturas nas quais os materiais foram submetidos, com exceção quando comparada a resina composta a $100^{\circ} \mathrm{C}$ e $200^{\circ} \mathrm{C}$ e o $\mathrm{CIV}$ a $100^{\circ} \mathrm{C}$ que não apresentaram diferença significativa $(\mathrm{p}<0,05)$ (Tabelas 12 e 13). 


\section{Delta b}

As comparações das médias de Delta b* (One-way ANOVA, Tukey, $p<0,05$ ) podem ser vistas nas Tabelas 14 e 15 e Gráfico 04.

Tabela 14 - Comparação das alterações de cor, na coordenada $b^{*}\left(\Delta b^{*}\right)$ e desvio padrão, da resina composta e do CIV nas submissões a $100^{\circ} \mathrm{C}, 200^{\circ} \mathrm{C}$ e $300^{\circ} \mathrm{C}$ e entre os materiais, nas mesmas temperaturas, analisadas segundo One-way ANOVA, teste de Tukey, $\mathrm{p}<0,05$.

\section{Delta b}

\begin{tabular}{ccc}
\hline Temperaturas & Resina & CIV \\
\hline $100^{\circ} \mathrm{C}$ & $6,44 \pm 1,26 \mathrm{aB}$ & $9,64 \pm 1,17 \mathrm{aB}$ \\
$200^{\circ} \mathrm{C}$ & $8,16 \pm 1,07 \mathrm{aB}$ & $3,97 \pm 5,84 \mathrm{aC}$ \\
$300^{\circ} \mathrm{C}$ & $20,85 \pm 5,22^{\mathrm{aA}}$ & $-17,25 \pm 4,32 \mathrm{bA}$ \\
\hline
\end{tabular}

Letras diferentes, minúsculas na linha e maiúsculas na coluna, para cada material, indicam diferença estatisticamente significante $(\mathrm{p}<0,05)$.

Tabela 15 - Comparação das alterações de cor, na coordenada $\mathrm{b}^{*}\left(\Delta \mathrm{b}^{*}\right)$ e desvio padrão, da resina composta e do CIV nas submissões a $100^{\circ} \mathrm{C}, 200^{\circ} \mathrm{C}$ e $300^{\circ} \mathrm{C}$ e entre os materiais, em diferentes temperaturas, analisadas segundo One-way ANOVA, teste de Tukey, $\mathrm{p}<0,05$.

\section{Delta b}

\begin{tabular}{|c|c|c|c|c|c|}
\hline \multirow[t]{3}{*}{ Material } & \multirow{3}{*}{ Temperatura } & & \multicolumn{3}{|c|}{ CIV } \\
\hline & & & $100^{\circ} \mathrm{C}$ & $200^{\circ} \mathrm{C}$ & $300^{\circ} \mathrm{C}$ \\
\hline & & & $9,64 \pm 1,17$ & $3,97 \pm 5,84$ & $-17,25 \pm 4,32$ \\
\hline \multirow{3}{*}{$\begin{array}{l}\text { Resina } \\
\text { Composta }\end{array}$} & $100^{\circ} \mathrm{C}$ & $6,44 \pm 1,26$ & & ns & $* * * *$ \\
\hline & $200^{\circ} \mathrm{C}$ & $8,16 \pm 1,07$ & ns & & $* * * *$ \\
\hline & $300^{\circ} \mathrm{C}$ & $20,85 \pm 5,22$ & $* * * *$ & $* * * *$ & \\
\hline
\end{tabular}


Gráfico 04 - Representação gráfica da comparação de Delta b* entre os materiais restauradores estéticos submetidos à ação do calor.

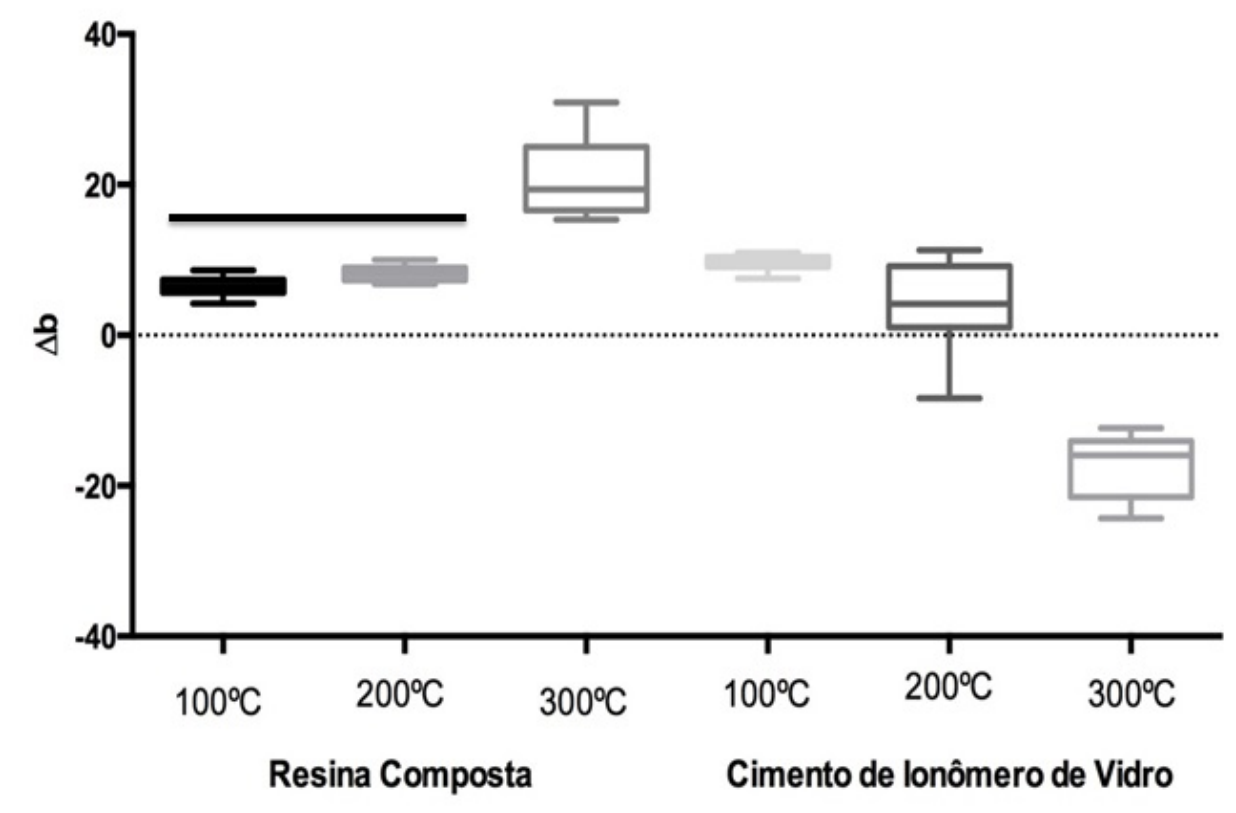

\section{Materiais/Temperaturas}

Para a resina composta, grupos amostrais sob linha horizontal indicam ausência de diferença significante $(p>0,05)$. Para todas as comparações no CIV, $p<0,05$.

Pelas leituras de cor na coordenada $b^{*}$, para a resina composta, verificou-se que a ação do calor promoveu aumento nesta coordenada, nas três temperaturas avaliadas. A maior alteração ocorreu após submissão à temperatura de $300^{\circ} \mathrm{C}$, resultado estatisticamente significante $(\mathrm{p}<0,05)$ em relação aos demais grupos testados, que não apresentaram diferença entre si $(p>0,05)$.

Quanto ao CIV, todos os grupos apresentaram diferenças estatisticamente significantes $(\mathrm{p}<005)$ entre $\mathrm{si}$, ocorrendo maior aumento a $100^{\circ} \mathrm{C}$, aumento mais discreto a $200^{\circ} \mathrm{C}$ e diminuição nesta coordenada em $300^{\circ} \mathrm{C}$.

Comparando os resultados entre todas as temperaturas testadas, verificou-se que o comportamento dos materiais restauradores estéticos foi diferente $(\mathrm{p}<0,05)$ à temperatura de $300^{\circ} \mathrm{C}$ em relação às demais temperaturas testadas. 0 Delta $\mathrm{b}^{*}$ negativo no CIV foi responsável por diferença estatisticamente significante $(\mathrm{p}<0,05)$ em relação à resina composta a $300^{\circ} \mathrm{C}$. Nas demais temperaturas testadas, não houve diferença estatisticamente significante ( $p>0,05)$ entre os mesmos (Tabelas 14 e 15). 


\subsubsection{Rugosidade de superfície}

Nos testes ao calor, a rugosidade de superfície (Ra) dos materiais restauradores foi analisada antes ( $\mathrm{Ra}$ inicial) e após ( $\mathrm{Ra}$ final) exposição às altas temperaturas $\left(100^{\circ} \mathrm{C}, 200^{\circ} \mathrm{C}\right.$ e $\left.300^{\circ} \mathrm{C}\right)$. Os valores das leituras da rugosidade de superfície, das respectivas médias, antes e após a ação do calor, além das alterações de rugosidade $(\Delta \mathrm{Ra})$, obtidos para a resina composta, CIV e amálgama estão apresentados respectivamente nas Tabelas 16, 17 e 18.

Tabela 16 - Valores da rugosidade de superfície (Ra), das respectivas médias e (desvio padrão) antes (Ra inicial) e após (Ra final) exposição ao calor e das alterações de rugosidade $(\Delta \mathrm{Ra})$ ocorridas após submissão da resina composta a $100^{\circ} \mathrm{C}, 200^{\circ} \mathrm{C}$ e $300^{\circ} \mathrm{C}$.

\begin{tabular}{|c|c|c|c|c|c|c|c|c|c|}
\hline & \multicolumn{9}{|c|}{ Resina Composta } \\
\hline & \multicolumn{3}{|c|}{$100^{\circ} \mathrm{C}$} & \multicolumn{3}{|c|}{$200^{\circ} \mathrm{C}$} & \multicolumn{3}{|c|}{$300^{\circ} \mathrm{C}$} \\
\hline & Inicial & Final & $\Delta \mathbf{R a}$ & Inicial & Final & $\Delta \mathbf{R a}$ & Inicial & Final & $\Delta \mathbf{R a}$ \\
\hline & 0,62 & 0,70 & 0,08 & 0,77 & 1,03 & 0,27 & 0,26 & 0,39 & 0,13 \\
\hline & 0,62 & 0,60 & $-0,02$ & 1,16 & 1,14 & $-0,02$ & 0,58 & 0,63 & 0,05 \\
\hline & 1,03 & 0,85 & $-0,18$ & 0,76 & 1,01 & 0,25 & 1,44 & 1,30 & $-0,14$ \\
\hline & 0,40 & 0,53 & 0,13 & 0,67 & 0,64 & $-0,02$ & 0,84 & 0,77 & $-0,07$ \\
\hline & 1,31 & 0,99 & $-0,32$ & 0,49 & 0,55 & 0,06 & 0,83 & 0,94 & 0,11 \\
\hline & 0,60 & 0,50 & $-0,10$ & 0,33 & 0,41 & 0,09 & 0,87 & 0,91 & 0,03 \\
\hline & 1,55 & 1,74 & 0,19 & 0,70 & 0,91 & 0,21 & 0,85 & 0,76 & $-0,09$ \\
\hline & 0,84 & 0,82 & $-0,02$ & 0,89 & 0,73 & $-0,17$ & 0,94 & 0,86 & $-0,07$ \\
\hline & 0,60 & 0,52 & $-0,08$ & 0,55 & 0,83 & 0,28 & 1,32 & 0,97 & $-0,35$ \\
\hline & 1,11 & 1,06 & $-0,04$ & 0,37 & 0,50 & 0,12 & 0,65 & 0,66 & 0,01 \\
\hline Média & 0,87 & 0,83 & $-0,04$ & 0,67 & 0,78 & 0,11 & 0,86 & 0,82 & $-0,04$ \\
\hline $\begin{array}{l}\text { Desvio } \\
\text { padrão }\end{array}$ & $(0,37)$ & $(0,38)$ & $(0,15)$ & $(0,25)$ & $(0,25)$ & $(0,15)$ & $(0,34)$ & $(0,24)$ & $(0,14)$ \\
\hline
\end{tabular}


Tabela 17 - Valores da rugosidade de superfície (Ra), das respectivas médias e (desvio padrão) antes (Ra inicial) e após (Ra final) exposição ao calor e das alterações de rugosidade $(\Delta \mathrm{Ra})$ ocorridas após submissão do $\mathrm{CIV}$ a $100^{\circ} \mathrm{C}, 200^{\circ} \mathrm{C}$ e $300^{\circ} \mathrm{C}$.

\begin{tabular}{|c|c|c|c|c|c|c|c|c|c|}
\hline & \multicolumn{9}{|c|}{ Cimento de Ionômero de Vidro } \\
\hline & \multicolumn{3}{|c|}{$100^{\circ} \mathrm{C}$} & \multicolumn{3}{|c|}{$200^{\circ} \mathrm{C}$} & \multicolumn{3}{|c|}{$300^{\circ} \mathrm{C}$} \\
\hline & Inicial & Final & $\Delta \mathbf{R a}$ & Inicial & Final & $\Delta \mathbf{R a}$ & Inicial & Final & $\Delta \mathbf{R a}$ \\
\hline & 1,00 & 2,32 & 1,32 & 1,20 & 1,72 & 0,52 & 0,93 & 2,28 & 1,35 \\
\hline & 2,03 & 1,87 & $-0,16$ & 1,41 & 1,81 & 0,41 & 1,29 & 1,92 & 0,63 \\
\hline & 0,81 & 1,80 & 0,98 & 1,62 & 2,59 & 0,98 & 1,80 & 2,13 & 0,33 \\
\hline & 1,17 & 1,46 & 0,29 & 1,89 & 2,24 & 0,35 & 1,14 & 1,94 & 0,80 \\
\hline & 1,16 & 1,99 & 0,83 & 1,22 & 2,04 & 0,83 & 1,94 & 2,81 & 0,87 \\
\hline & 0,89 & 1,82 & 0,93 & 1,03 & 2,24 & 1,21 & 1,89 & 3,09 & 1,20 \\
\hline & 1,54 & 1,92 & 0,38 & 0,91 & 1,65 & 0,74 & 1,38 & 2,64 & 1,26 \\
\hline & 1,72 & 2,11 & 0,39 & 1,45 & 3,00 & 1,55 & 1,14 & 1,94 & 0,80 \\
\hline & 0,99 & 1,54 & 0,55 & 1,34 & 2,24 & 0,90 & 1,28 & 3,19 & 1,91 \\
\hline & 0,90 & 1,48 & 0,58 & 1,07 & 2,61 & 1,54 & 1,28 & 2,59 & 1,31 \\
\hline Média & 1,22 & 1,83 & 0,61 & 1,31 & 2,21 & 0,90 & 1,41 & 2,45 & 1,05 \\
\hline $\begin{array}{l}\text { Desvio } \\
\text { padrão }\end{array}$ & $(0,41)$ & $(0,28)$ & $(0,42)$ & $(0,29)$ & $(0,43)$ & $(0,43)$ & $(0,35)$ & $(0,48)$ & $(0,45)$ \\
\hline
\end{tabular}

Tabela 18 - Valores da rugosidade de superfície (Ra), das respectivas médias e (desvio padrão) antes (Ra inicial) e após (Ra final) exposição ao calor e das alterações de rugosidade $(\Delta \mathrm{Ra})$ ocorridas após submissão do amálgama a $100^{\circ} \mathrm{C}, 200^{\circ} \mathrm{C}$ e $300^{\circ} \mathrm{C}$.

\section{Amálgama}

\begin{tabular}{ccccccccc}
\hline & $\mathbf{1 0 0}{ }^{\circ} \mathbf{C}$ & \multicolumn{3}{c}{$\mathbf{2 0 0}^{\circ} \mathbf{C}$} & \multicolumn{3}{c}{$\mathbf{3 0 0}^{\circ} \mathbf{C}$} \\
\hline Inicial & Final & $\mathbf{\Delta R a}$ & Inicial & Final & $\mathbf{\Delta R a}$ & Inicial & Final & $\mathbf{\Delta R a}$ \\
\hline 0,98 & 0,64 & $-0,34$ & 0,74 & 0,70 & $-0,04$ & 0,41 & 1,95 & 1,54 \\
0,64 & 0,51 & $-0,12$ & 0,76 & 0,91 & 0,15 & 1,14 & 1,52 & 0,38 \\
0,51 & 0,81 & 0,30 & 0,76 & 0,89 & 0,13 & 0,48 & 2,52 & 2,03 \\
0,68 & 0,66 & $-0,02$ & 0,60 & 1,00 & 0,39 & 0,70 & 1,05 & 0,35 \\
0,37 & 0,34 & $-0,04$ & 0,50 & 1,00 & 0,51 & 0,94 & 2,03 & 1,08 \\
0,79 & 0,62 & $-0,17$ & 0,43 & 0,93 & 0,50 & 0,29 & 2,57 & 2,28 \\
0,70 & 0,65 & $-0,05$ & 0,78 & 0,94 & 0,16 & 0,97 & 2,77 & 1,80 \\
0,64 & 0,56 & $-0,08$ & 0,67 & 0,88 & 0,21 & 0,94 & 3,83 & 2,89 \\
0,71 & 0,76 & 0,06 & 0,50 & 0,86 & 0,36 & 0,81 & 1,53 & 0,72 \\
0,58 & 0,48 & $-0,10$ & 1,34 & 1,60 & 0,26 & 1,05 & 1,73 & 0,68 \\
\hline $\mathbf{0 , 6 6}$ & $\mathbf{0 , 6 0}$ & $\mathbf{- 0 , 0 6}$ & $\mathbf{0 , 7 1}$ & $\mathbf{0 , 9 7}$ & $\mathbf{0 , 2 6}$ & $\mathbf{0 , 7 7}$ & $\mathbf{2 , 1 5}$ & $\mathbf{1 , 3 7}$ \\
$\mathbf{( 0 , 1 6 )}$ & $\mathbf{( 0 , 1 4 )}$ & $\mathbf{( 0 , 1 6 )}$ & $\mathbf{( 0 , 2 6 )}$ & $\mathbf{( 0 , 2 4 )}$ & $\mathbf{( 0 , 1 8 )}$ & $\mathbf{( 0 , 2 9 )}$ & $\mathbf{( 0 , 8 0 )}$ & $\mathbf{( 0 , 8 7 )}$
\end{tabular}


As comparações das médias de alteração de rugosidade (One-way ANOVA, Tukey, $p<0,05$ ) entre resina composta e CIV podem ser vistas nas Tabelas 19 e 20 e Gráfico 05.

Tabela 19 - Comparação das alterações de rugosidade de superfície $(\Delta \mathrm{Ra})$ e desvio padrão, da resina composta e do $\mathrm{CIV}$ nas submissões a $100^{\circ} \mathrm{C}, 200^{\circ} \mathrm{C}$ e $300^{\circ} \mathrm{C}$ e entre os materiais, nas mesmas temperaturas, analisadas segundo One-way ANOVA, teste de Tukey, $\mathrm{p}<0,05$.

\begin{tabular}{ccc}
\multicolumn{3}{c}{ Rugosidade de superfície } \\
\hline Temperaturas & Resina & CIV \\
\hline $100^{\circ} \mathrm{C}$ & $-0,04 \pm 0,15 \mathrm{bA}$ & $0,61 \pm 0,42^{\mathrm{aB}}$ \\
$200^{\circ} \mathrm{C}$ & $0,11 \pm 0,15 \mathrm{bA}$ & $0,90 \pm 0,43 \mathrm{aAB}$ \\
$300^{\circ} \mathrm{C}$ & $-0,04 \pm 0,14 \mathrm{bA}$ & $1,05 \pm 0,45 \mathrm{aA}$ \\
\hline
\end{tabular}

Letras diferentes, minúsculas na linha, entre os materiais, e maiúsculas na coluna, para o mesmo material, indicam diferença estatisticamente significante $(\mathrm{p}<0,05)$.

Tabela 20 - Comparação das alterações de rugosidade de superfície $(\Delta \mathrm{Ra})$ e desvio padrão, da resina composta e do CIV nas submissões a $100^{\circ} \mathrm{C}, 200^{\circ} \mathrm{C}$ e $300^{\circ} \mathrm{C}$ e entre os materiais, em diferentes temperaturas, analisadas segundo One-way ANOVA, teste de Tukey, $\mathrm{p}<0,05$.

\section{Rugosidade de superfície}

\begin{tabular}{cccccc}
\hline Material & & & \multicolumn{3}{c}{$\mathrm{CIV}$} \\
& Temperatura & & $100^{\circ} \mathrm{C}$ & $200^{\circ} \mathrm{C}$ & $300^{\circ} \mathrm{C}$ \\
& & & $0,61 \pm 0,42$ & $0,90 \pm 0,43$ & $1,05 \pm 0,45$ \\
& & & & $* * * *$ & $* * * *$ \\
Resina & $100^{\circ} \mathrm{C}$ & $-0,04 \pm 0,15$ & & & $* * * *$ \\
Composta & $200^{\circ} \mathrm{C}$ & $0,11 \pm 0,15$ & $*$ & $* * * *$ & \\
& $300^{\circ} \mathrm{C}$ & $-0,04 \pm 0,14$ & $* * *$ & $*{ }^{*}$ & \\
\hline
\end{tabular}

* = Diferença estatisticamente significante $(\mathrm{p}<0,05)$. Quanto maior o número de * nas células, maior a significância da diferença. 
Gráfico 05 - Representação gráfica da comparação das alterações de rugosidade de superfície $(\Delta \mathrm{Ra})$ dos materiais restauradores estéticos submetidos à ação do calor.

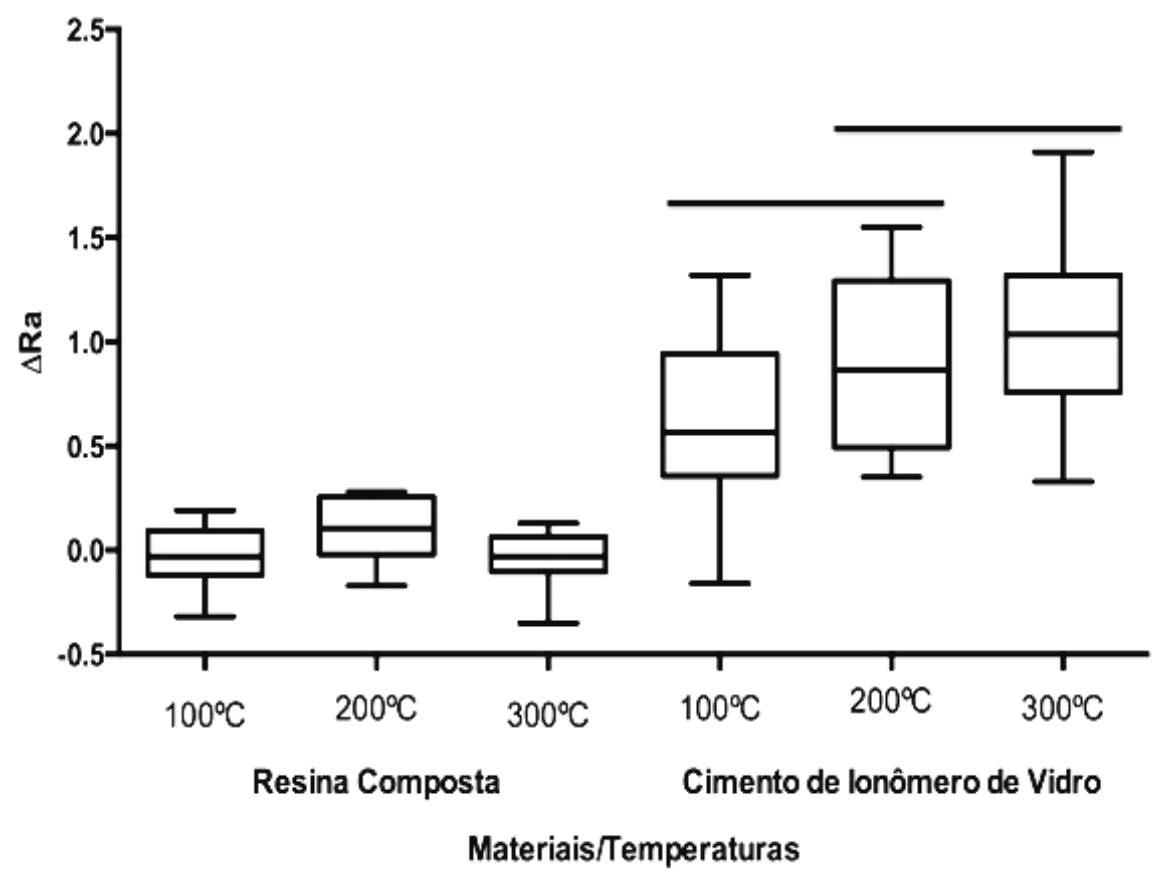

Para todas as comparações entre os grupos amostrais da resina composta, $p>0,05$. Para o CIV, grupos amostrais sob linhas horizontais, indicam ausência de diferença significante $(p>0,05)$.

Os resultados obtidos com as restaurações em resina composta após submissão ao calor demonstraram que não houve diferença estatisticamente significante $(p>0,05)$ na alteração de rugosidade de superfície entre as três temperaturas testadas. Quanto ao CIV, o grupo submetido a $300^{\circ} \mathrm{C}$ apresentou diferença estatisticamente significante $(\mathrm{p}<0,05)$ em relação ao grupo submetido a $100^{\circ} \mathrm{C}$. Ambos não apresentaram diferença $(p>0,05)$ em relação ao grupo submetido a $200^{\circ} \mathrm{C}$.

Comparando a resina composta ao CIV, verificou-se que houve maior alteração de rugosidade do último, com diferença estatisticamente significante $(p<0,05)$ para todos os grupos em todas as temperaturas (Tabela 19). Verificou-se também que para o CIV, ocorreu aumento de rugosidade com a ação do calor, quanto maior a temperatura de submissão, até $300^{\circ} \mathrm{C}$.

As comparações das médias de alteração de rugosidade (One-way ANOVA, Tukey, p<0,05) do amálgama podem ser vistas na Tabela 21 e Gráfico 06. 
Tabela 21 - Comparação das alterações de rugosidade de superfície $(\Delta \mathrm{Ra})$ e desvio padrão, do amálgama, nas submissões a $100^{\circ} \mathrm{C}, 200^{\circ} \mathrm{C}$ e $300^{\circ} \mathrm{C}$, analisadas segundo One-way ANOVA, teste de Tukey, $\mathrm{p}<0,05$.

\begin{tabular}{cc}
\hline \multicolumn{2}{c}{ Rugosidade de superfície } \\
\hline Temperaturas & Amálgama \\
\hline $100^{\circ} \mathrm{C}$ & $-0,06 \pm 0,16^{\mathrm{B}}$ \\
$200^{\circ} \mathrm{C}$ & $0,26 \pm 0,18^{\mathrm{B}}$ \\
$300^{\circ} \mathrm{C}$ & $1,37 \pm 0,87^{\mathrm{A}}$ \\
\hline
\end{tabular}

Letras diferentes, maiúsculas na coluna, indicam diferença estatisticamente significante $(\mathrm{p}<0,05)$.

Gráfico 06 - Representação gráfica das alterações de rugosidade de superfície $(\Delta \mathrm{Ra})$ das restaurações de amálgama submetidas à ação do calor.

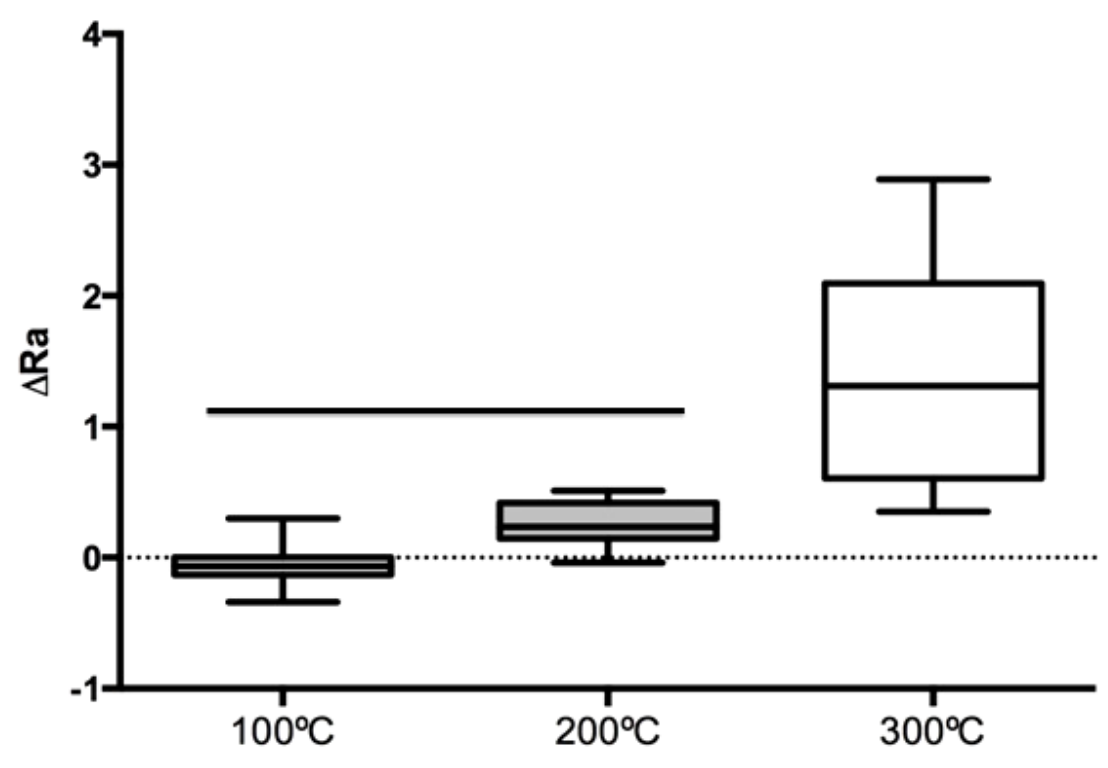

Amálgama

Grupos amostrais sob linha horizontal, indicam ausência de diferença significante $(p>0,05)$. Na comparação entre $100^{\circ} \mathrm{C}$ e $300^{\circ} \mathrm{C}$ e entre $200^{\circ} \mathrm{C}$ e $300^{\circ} \mathrm{C}$, p<0,05.

Nos dentes restaurados com o amálgama de prata, a maior alteração de rugosidade $(\Delta \mathrm{Ra})$ ocorreu após submissão a $300^{\circ} \mathrm{C}$. Resultados estes diferentes estatisticamente $(p<0,05)$ comparados aos grupos submetidos a temperaturas menores, que não apresentaram diferença $(p>0,05)$ entre si. 


\subsubsection{Microdureza}

A microdureza Knoop (KHN) dos materiais restauradores foi analisada antes da exposição às altas temperaturas (KHN inicial) e após a ação do calor (KHN final), nas temperaturas finais de $100^{\circ} \mathrm{C}, 200^{\circ} \mathrm{C}$ e $300^{\circ} \mathrm{C}$. Os valores das leituras da microdureza, das respectivas médias, antes e após a ação do calor, além das alterações da microdureza Knoop $(\Delta \mathrm{KHN})$, obtidos para a resina composta, CIV e amálgama estão apresentados nas Tabelas 22, 23 e 24.

Tabela 22 - Valores da microdureza Knoop (KHN), das respectivas médias e (desvio padrão) antes (KHN inicial) e após (KHN final) exposição ao calor e das alterações da microdureza $(\Delta K H N)$ ocorridas após submissão da resina composta a $100^{\circ} \mathrm{C}, 200^{\circ} \mathrm{C}$ e $300^{\circ} \mathrm{C}$.

\begin{tabular}{|c|c|c|c|c|c|c|c|c|c|}
\hline & \multicolumn{9}{|c|}{ Resina Composta } \\
\hline & \multicolumn{3}{|c|}{$100^{\circ} \mathrm{C}$} & \multicolumn{3}{|c|}{$200^{\circ} \mathrm{C}$} & \multicolumn{3}{|c|}{$300^{\circ} \mathrm{C}$} \\
\hline & Inicial & Final & $\Delta \mathrm{KHN}$ & Inicial & Final & $\Delta \mathrm{KHN}$ & Inicial & Final & $\Delta \mathrm{KHN}$ \\
\hline & 73,00 & 87,67 & 14,67 & 46,57 & 112,57 & 66,00 & 40,13 & 28,10 & $-12,03$ \\
\hline & 107,40 & 53,33 & $-54,07$ & 80,37 & 63,73 & $-16,63$ & 73,97 & 70,87 & $-3,10$ \\
\hline & 54,60 & 93,37 & 38,77 & 91,33 & 92,63 & 2,30 & 73,37 & 120,33 & 46,97 \\
\hline & 28,00 & 28,53 & 0,53 & 31,67 & 39,27 & 7,60 & 68,83 & 44,57 & $-24,27$ \\
\hline & 103,83 & 127,00 & 23,17 & 41,40 & 65,10 & 23,70 & 31,33 & 47,10 & 15,77 \\
\hline & 55,87 & 53,40 & $-2,47$ & 39,87 & 39,63 & $-0,23$ & 77,27 & 93,87 & 16,60 \\
\hline & 121,33 & 147,73 & 26,4 & 87,53 & 118,50 & 30,97 & 43,70 & 44,83 & 1,13 \\
\hline & 40,67 & 40,83 & 0,17 & 88,73 & 87,67 & $-1,07$ & 42,13 & 65,17 & 23,03 \\
\hline & 47,47 & 49,67 & 2,20 & 96,93 & 97,17 & 0,23 & 97,10 & 93,43 & $-3,67$ \\
\hline & 37,30 & 46,30 & 9,00 & 38,67 & 40,97 & 2,30 & 24,53 & 42,93 & 18,40 \\
\hline Média & 66,95 & 72,78 & 5,84 & 64,31 & 75,82 & 11,52 & 57,24 & 65,12 & 7,88 \\
\hline $\begin{array}{l}\text { Desvio } \\
\text { padrão }\end{array}$ & $(32,88)$ & $(39,68)$ & $(25,00)$ & $(26,56)$ & $(30,20)$ & $(23,33)$ & $(23,83)$ & $(29,31)$ & $(20,37)$ \\
\hline
\end{tabular}


Tabela 23 - Valores da microdureza Knoop (KHN), das respectivas médias e (desvio padrão) antes (KHN inicial) e após (KHN final) exposição ao calor e das alterações da microdureza $(\Delta \mathrm{KHN})$ ocorridas após submissão do $\mathrm{CIV}$ a $100^{\circ} \mathrm{C}, 200^{\circ} \mathrm{C}$ e $300^{\circ} \mathrm{C}$.

\begin{tabular}{|c|c|c|c|c|c|c|c|c|c|}
\hline & \multicolumn{9}{|c|}{ Cimento de Ionômero de Vidro } \\
\hline & \multicolumn{3}{|c|}{$100^{\circ} \mathrm{C}$} & \multicolumn{3}{|c|}{$200^{\circ} \mathrm{C}$} & \multicolumn{3}{|c|}{$300^{\circ} \mathrm{C}$} \\
\hline & Inicial & Final & $\Delta \mathrm{KHN}$ & Inicial & Final & $\Delta \mathrm{KHN}$ & Inicial & Final & $\Delta \mathrm{KHN}$ \\
\hline & 6,12 & 27,86 & 21,74 & 11,06 & 118,33 & 107,28 & 10,59 & 260,50 & 249,91 \\
\hline & 13,87 & 52,00 & 38,13 & 4,58 & 139,37 & 134,79 & 8,94 & 157,00 & 148,06 \\
\hline & 6,99 & 26,27 & 19,27 & 9,58 & 156,00 & 146,42 & 6,24 & 264,67 & 258,43 \\
\hline & 6,99 & 31,30 & 24,31 & 6,44 & 154,00 & 147,56 & 5,84 & 222,50 & 216,66 \\
\hline & 7,85 & 50,57 & 42,72 & 3,89 & 188,50 & 184,61 & 14,27 & 235,00 & 220,73 \\
\hline & 6,03 & 78,40 & 72,37 & 11,67 & 131,23 & 119,57 & 13,07 & 257,33 & 244,27 \\
\hline & 6,82 & 36,57 & 29,75 & 2,16 & 103,30 & 101,14 & 10,91 & 247,33 & 236,42 \\
\hline & 6,79 & 25,90 & 19,11 & 11,35 & 151,27 & 139,92 & 13,08 & 245,50 & 232,42 \\
\hline & 6,23 & 40,00 & 33,77 & 8,06 & 117,00 & 108,94 & 13,20 & 171,00 & 157,80 \\
\hline & 11,42 & 27,43 & 16,02 & 2,75 & 149,50 & 146,75 & 9,70 & 271,00 & 261,30 \\
\hline Média & 7,91 & 39,63 & 31,72 & 7,15 & 140,85 & 133,68 & 10,58 & 233,18 & 222,60 \\
\hline $\begin{array}{l}\text { Desvio } \\
\text { padrão }\end{array}$ & $(2,61)$ & $(16,70)$ & $(16,79)$ & $(3,68)$ & $(24,58)$ & $(25,23)$ & $(2,94)$ & $(39,29)$ & $(39,55)$ \\
\hline
\end{tabular}

Tabela 24 - Valores da microdureza Knoop (KHN), das respectivas médias e (desvio padrão) antes (KHN inicial) e após (KHN final) exposição ao calor e das alterações da microdureza $(\Delta \mathrm{KHN})$ ocorridas após submissão do amálgama a $100^{\circ} \mathrm{C}, 200^{\circ} \mathrm{C}$ e $300^{\circ} \mathrm{C}$.

Amálgama

\begin{tabular}{|c|c|c|c|c|c|c|c|c|c|}
\hline & \multicolumn{3}{|c|}{$100^{\circ} \mathrm{C}$} & \multicolumn{3}{|c|}{$200^{\circ} \mathrm{C}$} & \multicolumn{3}{|c|}{$300^{\circ} \mathrm{C}$} \\
\hline & Inicial & Final & $\Delta \mathrm{KHN}$ & Inicial & Final & $\Delta \mathrm{KHN}$ & Inicial & Final & $\Delta \mathrm{KHN}$ \\
\hline & 77,10 & 71,07 & $-6,03$ & 90,63 & 128,33 & 37,70 & 130,00 & 199,00 & 69,00 \\
\hline & 90,97 & 160,33 & 69,37 & 51,87 & 88,60 & 36,73 & 117,70 & 118,00 & 0,30 \\
\hline & 92,87 & 160,00 & 67,13 & 154,67 & 145,00 & $-9,67$ & 133,63 & 139,33 & 5,70 \\
\hline & 157,87 & 161,67 & 3,80 & 87,43 & 131,00 & 43,57 & 134,67 & 175,33 & 40,67 \\
\hline & 131,00 & 144,00 & 13,00 & 121,03 & 127,67 & 6,63 & 82,17 & 50,53 & $-31,63$ \\
\hline & 100,00 & 57,43 & $-42,57$ & 87,53 & 68,67 & $-18,87$ & 188,00 & 362,50 & 174,50 \\
\hline & 118,80 & 105,20 & $-13,60$ & 124,40 & 100,10 & $-24,30$ & 86,20 & 53,37 & $-32,83$ \\
\hline & 144,67 & 91,97 & $-52,70$ & 119,33 & 101,73 & $-17,60$ & 171,67 & 140,50 & $-31,17$ \\
\hline & 104,90 & 115,23 & 10,33 & 89,13 & 113,17 & 24,03 & 136,33 & 52,80 & $-83,53$ \\
\hline & 114,80 & 125,10 & 10,30 & 135,27 & 143,47 & 8,20 & 184,33 & 90,27 & $-94,07$ \\
\hline Média & 113,30 & 119,20 & 5,90 & 106,13 & 114,77 & 8,64 & 136,47 & 138,16 & 1,69 \\
\hline $\begin{array}{l}\text { Desvio } \\
\text { padrão }\end{array}$ & $(25,36)$ & $(37,85)$ & $(39,69)$ & $(30,01)$ & $(24,83)$ & $(25,73)$ & $(36,62)$ & $(94,44)$ & $(78,70)$ \\
\hline
\end{tabular}


As comparações das médias de alteração de microdureza Knoop (One-way ANOVA, Tukey, $\mathrm{p}<0,05$ ) de resina composta e CIV podem ser vistas nas Tabelas 25 e 26 e Gráfico 07.

Tabela 25 - Comparação das alterações da microdureza Knoop ( $\Delta \mathrm{KHN}$ ) e desvio padrão, da resina composta e do CIV nas submissões a $100^{\circ} \mathrm{C}, 200^{\circ} \mathrm{C}$ e $300^{\circ} \mathrm{C}$ e entre os materiais, nas mesmas temperaturas, analisadas segundo One-way ANOVA, teste de Tukey, $\mathrm{p}<0,05$.

\section{Microdureza}

\begin{tabular}{ccc}
\hline Temperaturas & Resina & CIV \\
\hline $100^{\circ} \mathrm{C}$ & $5,84 \pm 25,00 \mathrm{aA}$ & $31,72 \pm 16,79 \mathrm{aC}$ \\
$200^{\circ} \mathrm{C}$ & $11,52 \pm 23,33 \mathrm{bA}$ & $133,70 \pm 25,23 \mathrm{aB}$ \\
$300^{\circ} \mathrm{C}$ & $7,88 \pm 20,37 \mathrm{bA}$ & $222,60 \pm 39,55 \mathrm{aA}$ \\
\hline
\end{tabular}

Letras diferentes, minúsculas na linha, entre os materiais, e maiúsculas na coluna, para o mesmo material, indicam diferença estatisticamente significante $(\mathrm{p}<0,05)$.

Tabela 26 - Comparação das alterações de rugosidade de superfície ( $\Delta \mathrm{Ra})$ e desvio padrão, da resina composta e do CIV nas submissões a $100^{\circ} \mathrm{C}, 200^{\circ} \mathrm{C}$ e $300^{\circ} \mathrm{C}$ e entre os materiais, em diferentes temperaturas, analisadas segundo One-way ANOVA, teste de Tukey, $\mathrm{p}<0,05$.

\section{Microdureza}

\begin{tabular}{|c|c|c|c|c|c|}
\hline \multirow[t]{3}{*}{ Material } & & & \multicolumn{3}{|c|}{ CIV } \\
\hline & \multirow{2}{*}{\multicolumn{2}{|c|}{ Temperatura }} & $100^{\circ} \mathrm{C}$ & $200^{\circ} \mathrm{C}$ & $300^{\circ} \mathrm{C}$ \\
\hline & & & $31,72 \pm 16,79$ & $133,70 \pm 25,23$ & $222,60 \pm 39,55$ \\
\hline \multirow{3}{*}{$\begin{array}{c}\text { Resina } \\
\text { Composta }\end{array}$} & $100^{\circ} \mathrm{C}$ & $5,84 \pm 25,00$ & & $* * * *$ & $* * * *$ \\
\hline & $200^{\circ} \mathrm{C}$ & $11,52 \pm 23,33$ & ns & & $* * * *$ \\
\hline & $300^{\circ} \mathrm{C}$ & $7,88 \pm 20,37$ & ns & $* * * *$ & \\
\hline
\end{tabular}

**** = Diferença estatisticamente significante $(\mathrm{p}<0,05) . \mathrm{ns}=$ Não houve diferença estatisticamente significante $(p>0,05)$. 
Gráfico 07 - Representação gráfica da comparação das alterações da microdureza Knoop $(\triangle \mathrm{KHN})$ dos materiais restauradores estéticos submetidos à ação do calor.

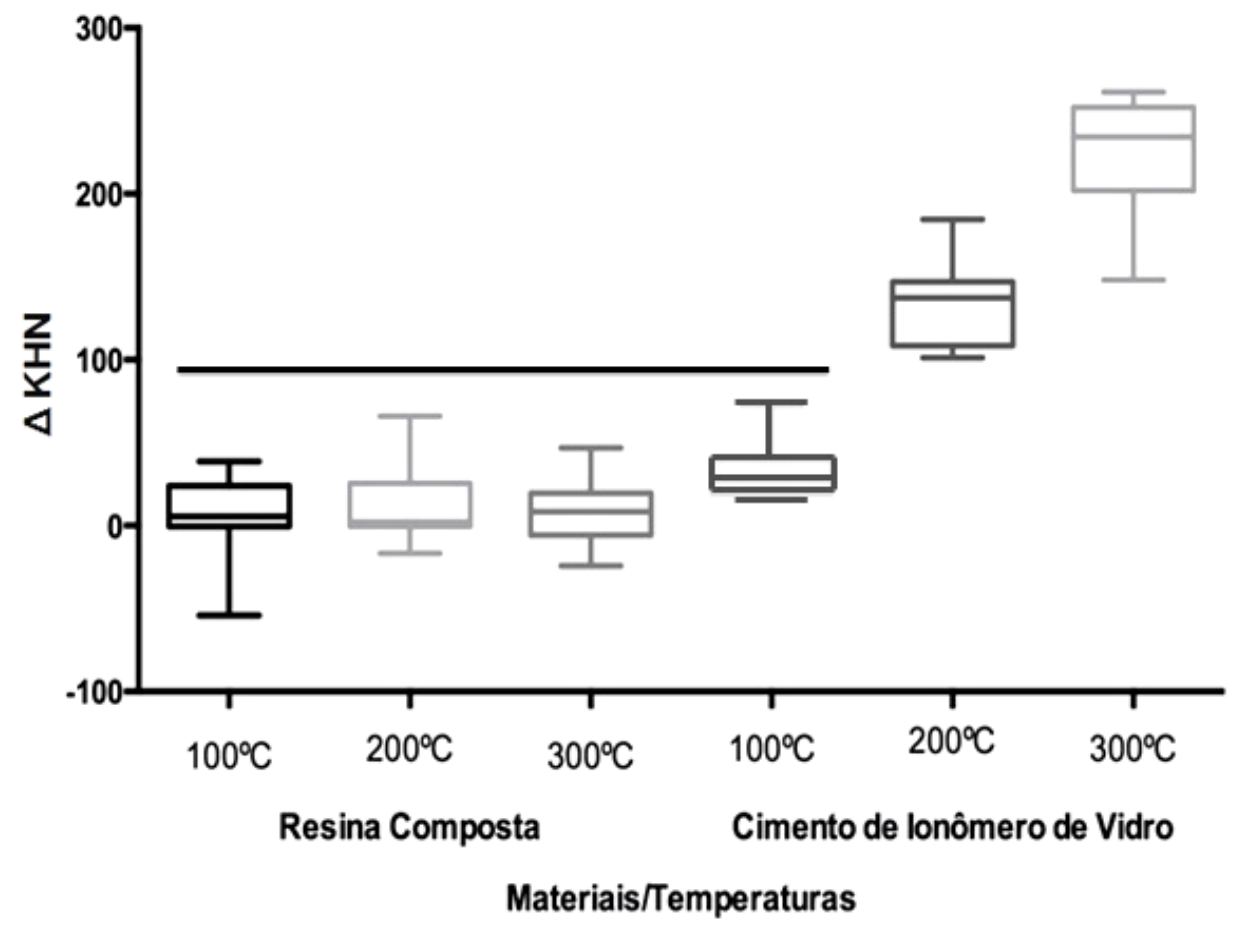

Para todas as comparações entre os grupos amostrais da resina composta, $p>0,05$. Para todas as comparações entre os grupos amostrais do CIV, $\mathrm{p}<0,05$. Grupos amostrais sob linha horizontal, indicam ausência de diferença significante $(p>0,05)$.

Não houve diferença significativa $(p>0,05)$ de alteração de microdureza quando a resina composta foi submetida às diferentes temperaturas. Quanto ao CIV, houve maior alteração de microdureza quanto maior a temperatura a que foi submetido, com resultados diferentes estatisticamente $(p<0,05)$ entre os grupos.

Comparando os resultados entre os materiais, verificou-se que o CIV apresenta maior alteração de microdureza $(\mathrm{p}<0,05)$ que a resina composta, após submissão a $200^{\circ} \mathrm{C}$, permanecendo a diferença $(p<0,05)$ em $300^{\circ} \mathrm{C}$. Após $100^{\circ} \mathrm{C}$, a alteração de microdureza do CIV foi semelhante $(p>0,05)$ aos resultados encontrados para resina composta após $100^{\circ} \mathrm{C}, 200^{\circ} \mathrm{C}$ e $300^{\circ} \mathrm{C}$. Para todas as outras comparações entre as diferentes temperaturas, houve diferenças estatisticamente significantes $(\mathrm{p}<0,05)$.

As comparações das médias de alteração de microdureza (One-way ANOVA, Tukey, p<.05) de amálgama podem ser vistas na Tabela 27 e Gráfico 08. 
Tabela 27 - Comparação das alterações da microdureza Knoop ( $\Delta \mathrm{KHN}$ ) e desvio padrão, do amálgama, analisadas segundo One-way ANOVA, teste de Tukey, $\mathrm{p}<0,05$.

\section{Microdureza}

\begin{tabular}{cc}
\hline Temperaturas & Amálgama \\
\hline $100^{\circ} \mathrm{C}$ & $5,90 \pm 39,69 \mathrm{~A}$ \\
$200^{\circ} \mathrm{C}$ & $8,64 \pm 25,73 \mathrm{~A}$ \\
$300^{\circ} \mathrm{C}$ & $1,69 \pm 78,70 \mathrm{~A}$ \\
\hline
\end{tabular}

Para todas as comparações, na coluna, $\mathrm{p}>0,05$.

Gráfico 08 - Representação gráfica das alterações da microdureza Knoop ( $\Delta \mathrm{KHN}$ ) das restaurações de amálgama submetidas à ação do calor.

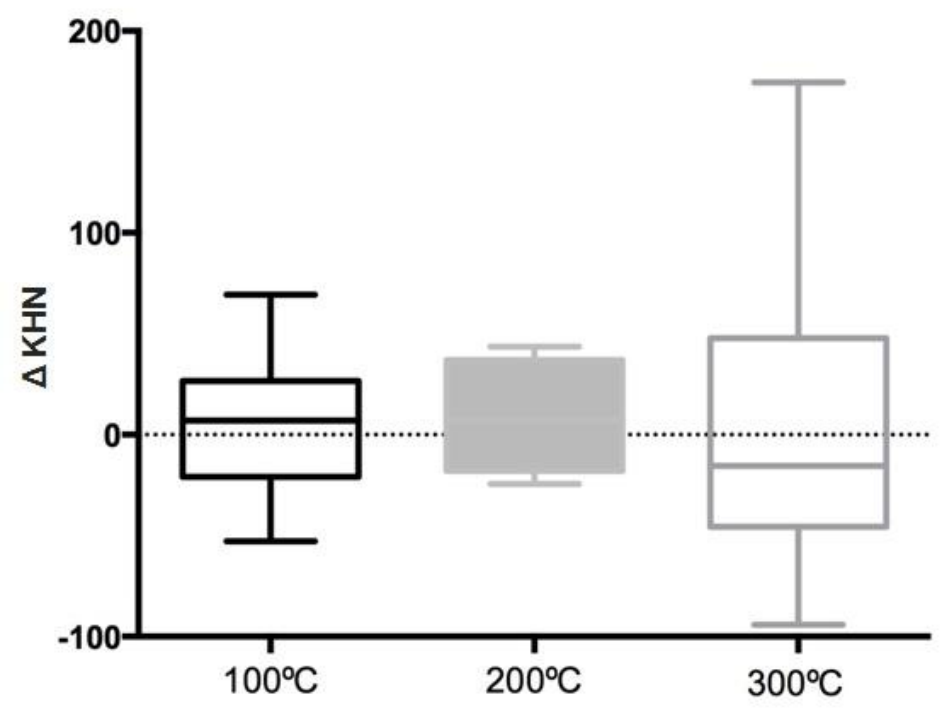

Amálgama

Para todas as comparações, $\mathrm{p}>0,05$.

A análise dos valores médios de alteração de microdureza Knoop $(\Delta \mathrm{KHN})$ encontrados para amálgama demonstrou que não houve diferença estatisticamente significante $(p>0,05)$ entre as temperaturas nas quais as amostras foram submetidas. 


\subsubsection{Análise visual}

As imagens fotográficas realizadas, representativas do grupo amostral da resina composta, do CIV e do amálgama, antes e após submissão às altas temperaturas de $100^{\circ} \mathrm{C}, 200^{\circ} \mathrm{C}$ e $300^{\circ} \mathrm{C}$, por um período de tempo de 15 minutos de ação do calor, são observadas, respectivamente, nas Figuras 33, 34 e 35.

Figura 33 - Comparação visual das restaurações de resina composta, antes e após a submissão ao calor, nas temperaturas referidas, por um período de tempo de 15 minutos.

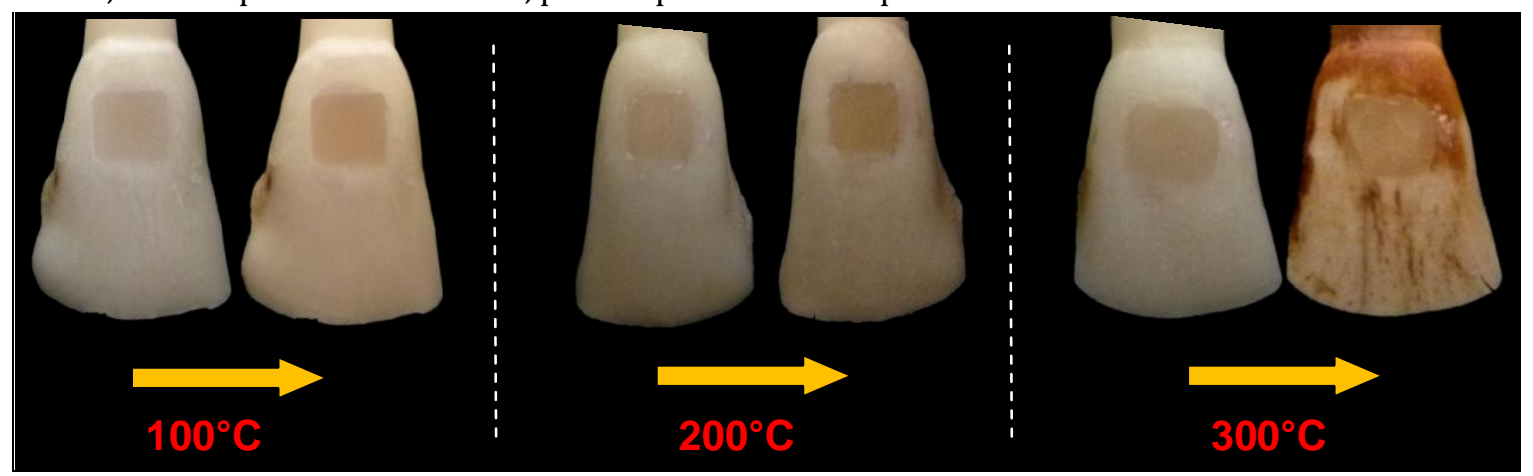

Figura 34 - Comparação visual das restaurações de CIV, antes e após a submissão ao calor, nas temperaturas referidas, por um período de tempo de 15 minutos.

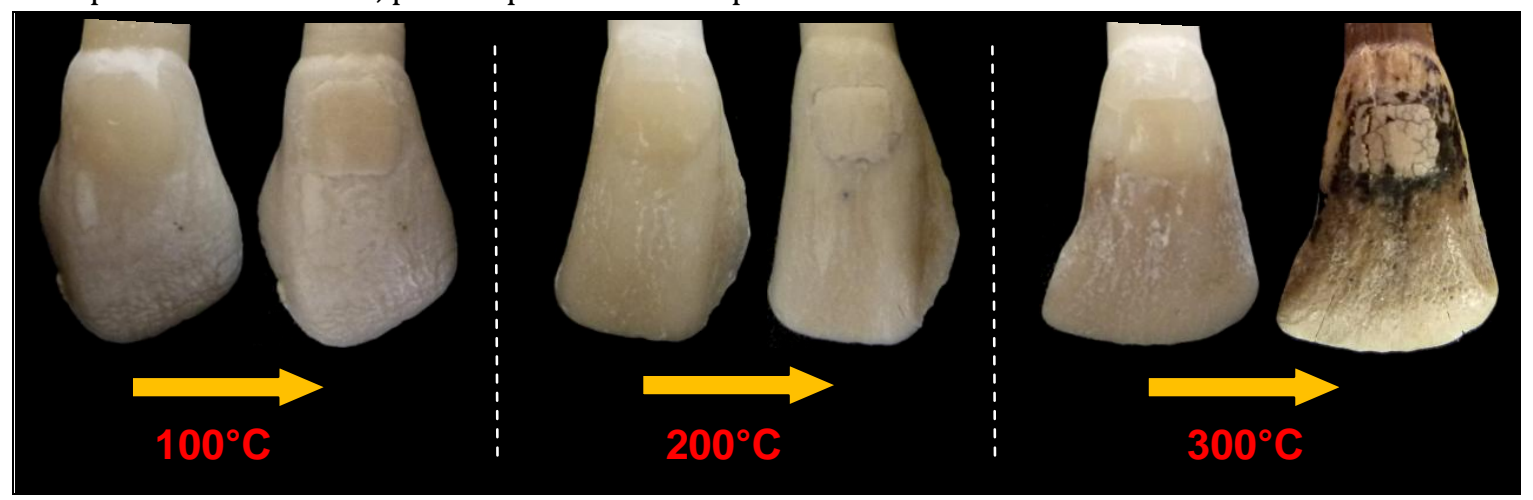

Figura 35 - Comparação visual das restaurações de amálgama, antes e após a ação do calor, nas temperaturas referidas, por um período de tempo de 15 minutos.

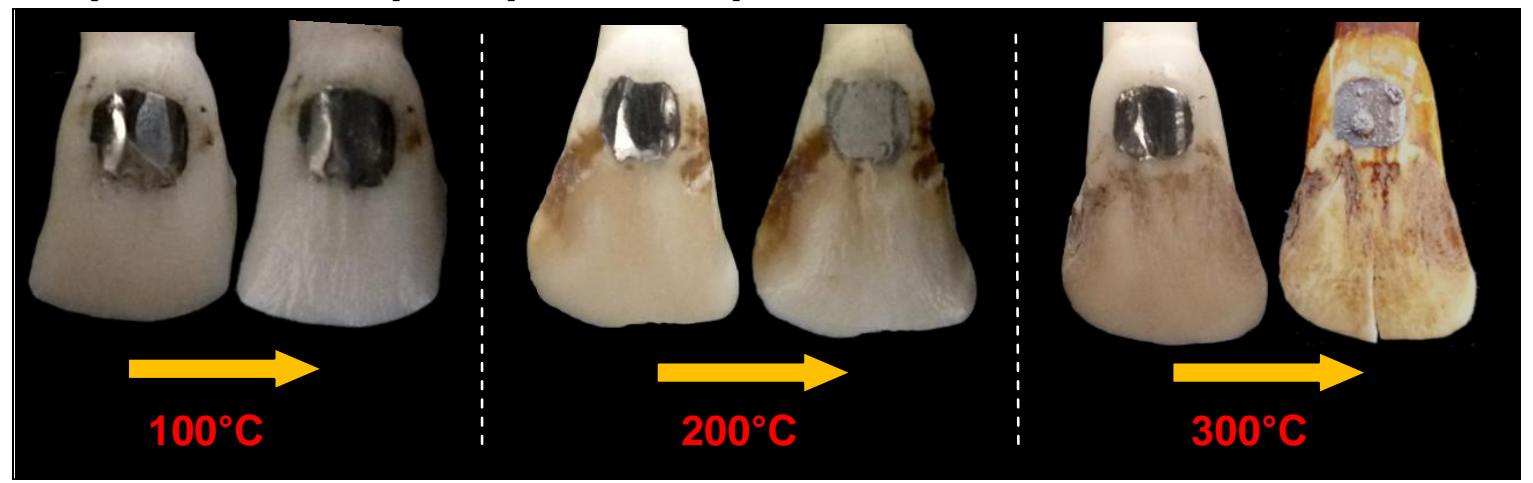


Nas restaurações em resina composta, pelas imagens fotográficas, pôde ser observado que a ação do calor provocou aparente escurecimento do material, sendo discreto em $100^{\circ} \mathrm{C}$ e mais evidente com a elevação da temperatura. A resina composta manteve-se unida ao elemento dental nas três temperaturas avaliadas.

No CIV, verificou-se que o material apresentou uma aparência mais branca e opaca com o aumento da temperatura. Em $200^{\circ} \mathrm{C}$, houve pequena perda de adesividade do CIV à estrutura dental, observada pela formação de uma discreta fenda entre o material restaurador e a parede do preparo cavitário (Figura 36 A). No grupo submetido a $300^{\circ} \mathrm{C}$, o CIV apresentou-se, totalmente, desprovido de adesividade ao esmalte e dentina, de forma que a interface entre o material e o dente ficou degradada. Nesta temperatura, o material passou a apresentar várias pequenas rachaduras, porém, ainda, mantendo-se como um bloco unido (Figura 36 B).

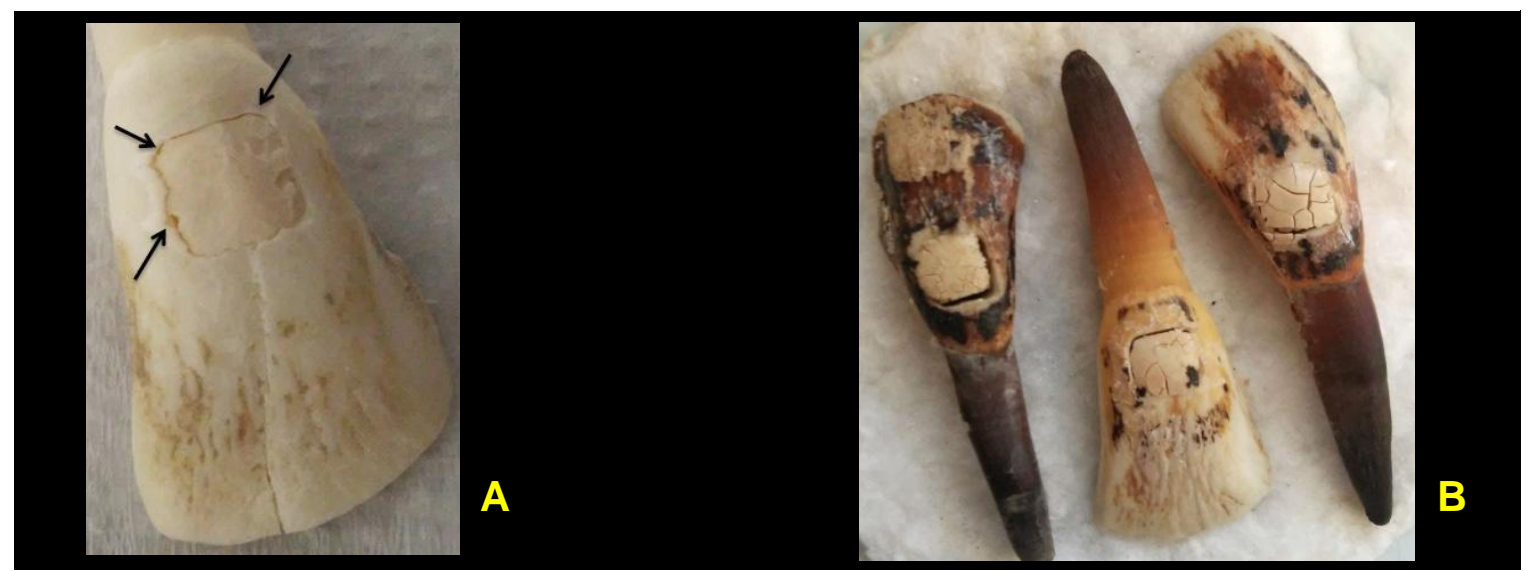

Figura 36 - Formação de discreta fenda entre o CIV e o dente, na submissão a $200^{\circ} \mathrm{C}$ (A) Surgimento de pequenas rachaduras no CIV e interface dente/restauração degradada a $300^{\circ} \mathrm{C}(\mathrm{B})$

Para o amálgama, observou-se perda de brilho do material quanto maior a temperatura a que foi submetido. Em $300^{\circ} \mathrm{C}$, além da grande perda de brilho e maior aspereza do material, verificou-se a presença de pequenas bolhas positivas formadas em sua superfície (Figura 37). 0 amálgama manteve-se unido ao dente nas três temperaturas avaliadas. 


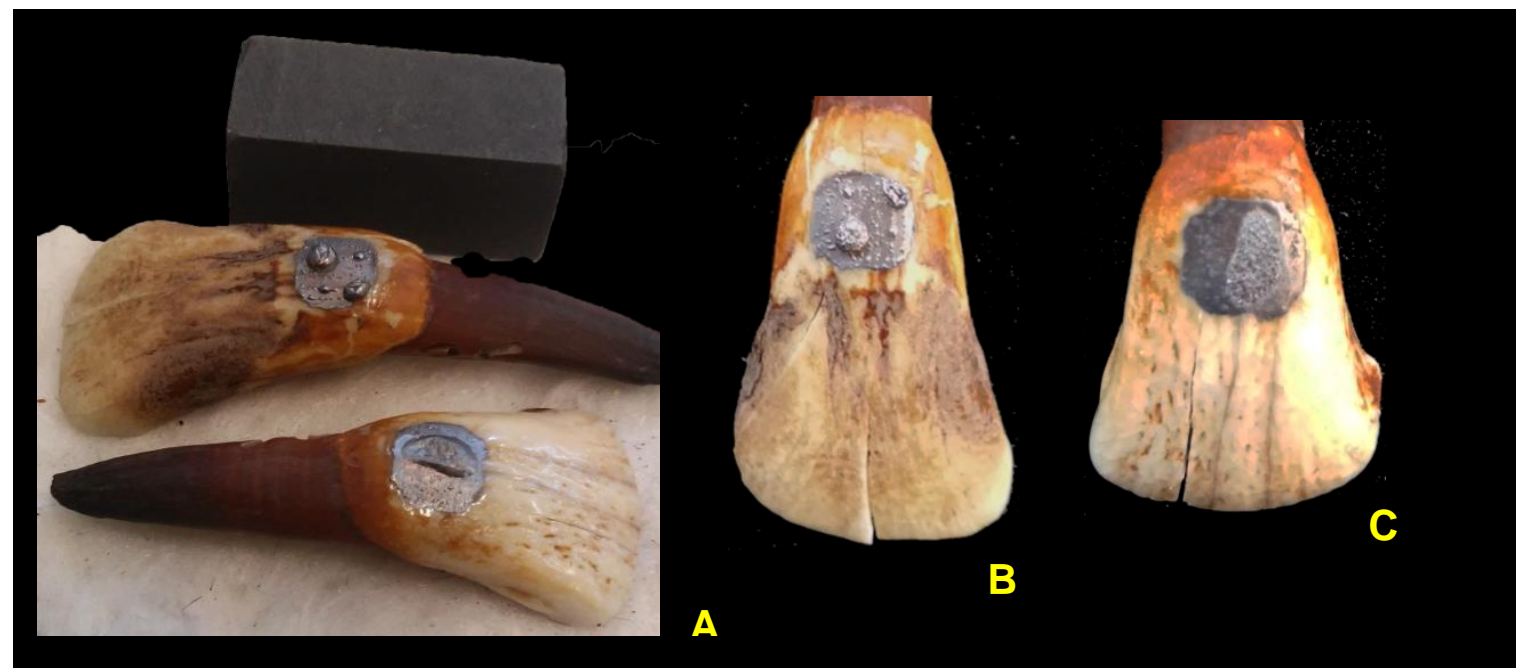

Figura 37 - Restaurações em amálgama, submetidas a $300^{\circ} \mathrm{C}$, com formação de bolhas de mercúrio, imediatamente, após a retirada do forno (A) Amálgama após o resfriamento (B e C)

\subsection{Baixas temperaturas (Ação do frio)}

As amostras de resina composta e cimento de ionômero de vidro (CIV) foram analisadas em alteração de cor, alteração de rugosidade de superfície e microdureza Knoop, enquanto que as amostras de amálgama foram analisadas somente para as duas últimas propriedades estudadas.

\subsubsection{Análise de cor}

A leitura de cor dos materiais restauradores estéticos (resina composta e CIV) foi analisada antes da exposição às baixas temperaturas (inicial), após 7 dias e 30 dias de submissão às temperaturas de $2,5^{\circ} \mathrm{C},\left(-20^{\circ} \mathrm{C}\right)$ e $\left(-80^{\circ} \mathrm{C}\right)$.

Os valores das leituras de cor nas coordenadas $\mathrm{L}^{*}, \mathrm{a}^{*}$ e $\mathrm{b}^{*}$, das respectivas médias, antes e após a ação do frio, e as alterações de cor $\left(\Delta \mathrm{L}^{*}, \Delta \mathrm{a}^{*}, \Delta \mathrm{b}^{*}\right.$ e $\left.\Delta \mathrm{E}\right)$ ocorridas após 7 dias e 30 dias de submissão às baixas temperaturas; estão apresentados nas Tabelas 28 a 33; e para o CIV nas Tabelas 34 a 39. 
Tabela 28 - Valores das leituras de cor nas coordenadas $\mathrm{L}^{*}, \mathrm{a}^{*}, \mathrm{~b}^{*}$, das respectivas médias e (desvio padrão), antes (inicial) e após 7 dias de exposição ao frio e das alterações de cor $\left(\Delta \mathrm{L}^{*}, \Delta \mathrm{a}^{*}, \Delta \mathrm{b}^{*} \mathrm{e} \Delta \mathrm{E}\right)$ após submissão da resina composta a $2,5^{\circ} \mathrm{C}$.

\section{Resina Composta}

$2,5^{\circ} \mathrm{C}$

\begin{tabular}{ccccccccccc}
\hline & \multicolumn{3}{c}{ Inicial } & \multicolumn{7}{c}{$\mathbf{7}$ dias } \\
& $\mathbf{L}$ & $\mathbf{a}$ & $\mathbf{b}$ & $\mathbf{L}$ & $\mathbf{a}$ & $\mathbf{b}$ & $\mathbf{\Delta L}$ & $\mathbf{\Delta a}$ & $\mathbf{\Delta b}$ & $\boldsymbol{\Delta} \mathbf{E}$ \\
\hline & 77,03 & 2,70 & 30,97 & 79,80 & 4,60 & 34,30 & 2,77 & 1,90 & 3,33 & 4,73 \\
& 78,90 & 2,30 & 31,33 & 81,27 & 4,07 & 34,53 & 2,37 & 1,77 & 3,20 & 4,35 \\
& 78,90 & 2,60 & 32,10 & 81,50 & 4,53 & 35,47 & 2,60 & 1,93 & 3,37 & 4,67 \\
& 78,23 & 2,30 & 31,63 & 80,30 & 3,53 & 33,63 & 2,07 & 1,23 & 2,00 & 3,13 \\
& 77,20 & 2,50 & 31,37 & 79,50 & 4,37 & 34,53 & 2,30 & 1,87 & 3,17 & 4,34 \\
& 79,07 & 2,20 & 31,67 & 81,40 & 4,20 & 35,53 & 2,33 & 2,00 & 3,87 & 4,94 \\
& 79,17 & 2,00 & 32,07 & 81,90 & 4,00 & 35,53 & 2,73 & 2,00 & 3,47 & 4,85 \\
& 80,00 & 2,33 & 32,43 & 82,83 & 4,43 & 36,40 & 2,83 & 2,10 & 3,97 & 5,31 \\
& 77,80 & 2,70 & 32,30 & 81,67 & 4,90 & 36,30 & 3,87 & 2,20 & 4,00 & 5,98 \\
Média & $\mathbf{7 8 , 5 1}$ & $\mathbf{2 , 3 9}$ & $\mathbf{3 1 , 8 0}$ & $\mathbf{8 1 , 1 4}$ & $\mathbf{4 , 2 2}$ & $\mathbf{3 5 , 0 7}$ & $\mathbf{2 , 6 3}$ & $\mathbf{1 , 8 3}$ & $\mathbf{3 , 2 8}$ & $\mathbf{4 , 5 9}$ \\
Desvio & $\mathbf{( 0 , 9 3 )}$ & $\mathbf{( 0 , 2 3 )}$ & $\mathbf{( 0 , 4 8 )}$ & $\mathbf{( 1 , 0 0 )}$ & $\mathbf{( 0 , 4 3 )}$ & $\mathbf{( 0 , 9 1 )}$ & $\mathbf{( 0 , 5 0 )}$ & $\mathbf{( 0 , 3 2 )}$ & $\mathbf{( 0 , 6 5 )}$ & $\mathbf{( 0 , 8 1 )}$
\end{tabular}

Tabela 29 - Valores das leituras de cor nas coordenadas $\mathrm{L}^{*}, \mathrm{a}^{*}, \mathrm{~b}^{*}$, das respectivas médias e (desvio padrão), antes (inicial) e após 30 dias de exposição ao frio e das alterações de cor $\left(\Delta \mathrm{L}^{*}, \Delta \mathrm{a}^{*}, \Delta \mathrm{b}^{*} \mathrm{e} \Delta \mathrm{E}\right)$ após submissão da resina composta a $2,5^{\circ} \mathrm{C}$.

\section{Resina Composta}

$$
2,5^{\circ} \mathrm{C}
$$

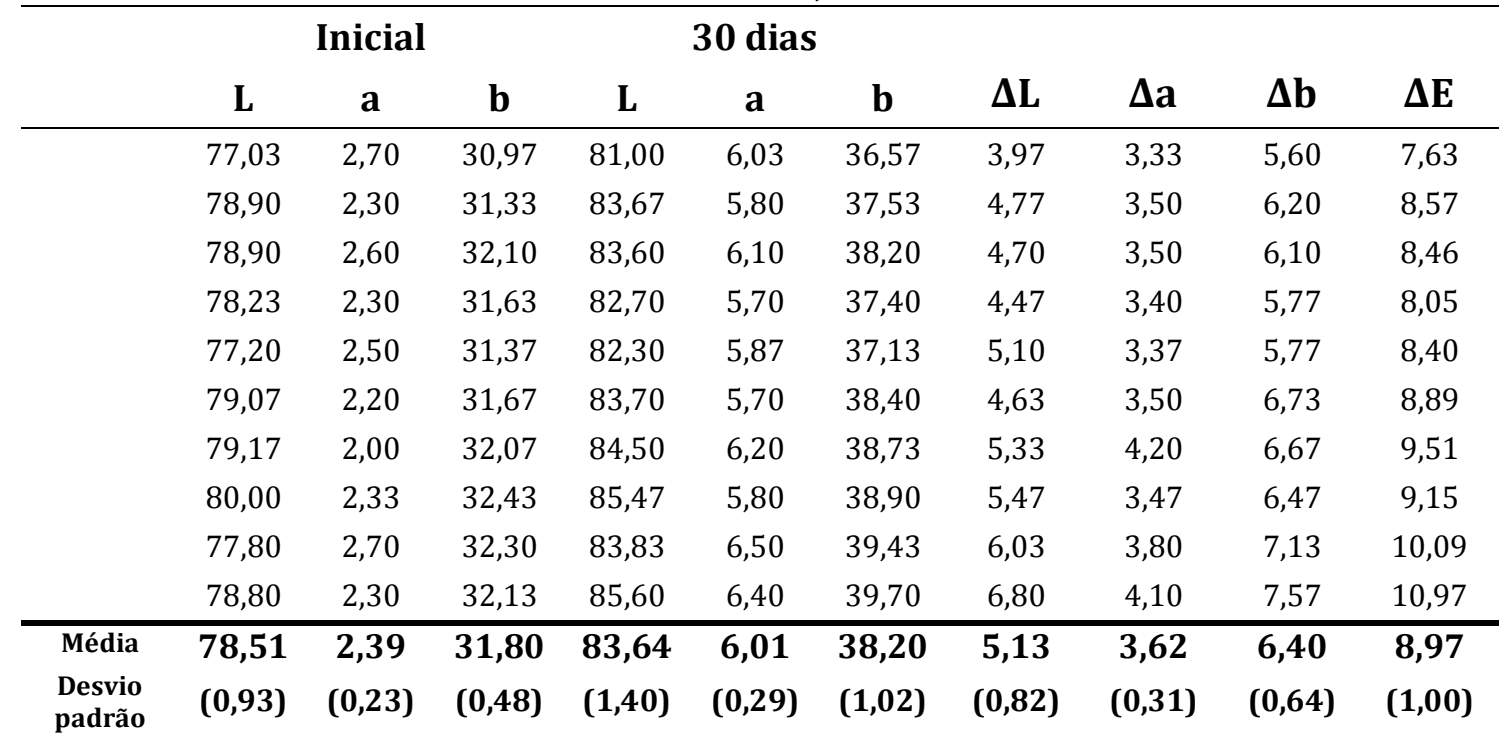


Tabela 30 - Valores das leituras de cor nas coordenadas $\mathrm{L}^{*}, \mathrm{a}^{*}, \mathrm{~b}^{*}$, das respectivas médias e (desvio padrão), antes (inicial) e após 7 dias de exposição ao frio e das alterações de cor $\left(\Delta \mathrm{L}^{*}, \Delta \mathrm{a}^{*}, \Delta \mathrm{b}^{*} \mathrm{e} \Delta \mathrm{E}\right)$ após submissão da resina composta a $-20^{\circ} \mathrm{C}$.

\section{Resina Composta}

$-20^{\circ} \mathrm{C}$

\begin{tabular}{|c|c|c|c|c|c|c|c|c|c|c|}
\hline & \multicolumn{3}{|c|}{ Inicial } & \multicolumn{3}{|c|}{7 dias } & \multirow[b]{2}{*}{$\Delta \mathbf{L}$} & \multirow[b]{2}{*}{$\Delta \mathbf{a}$} & \multirow[b]{2}{*}{$\Delta \mathbf{b}$} & \multirow[b]{2}{*}{$\Delta \mathrm{E}$} \\
\hline & $\mathbf{L}$ & $\mathbf{a}$ & $\mathbf{b}$ & $\mathbf{L}$ & $\mathbf{a}$ & $\mathbf{b}$ & & & & \\
\hline & 75,83 & 2,87 & 31,93 & 78,37 & 3,93 & 33,53 & 2,53 & 1,07 & 1,60 & 3,18 \\
\hline & 75,97 & 3,80 & 33,23 & 78,93 & 6,20 & 36,47 & 2,97 & 2,40 & 3,23 & 5,00 \\
\hline & 78,40 & 3,40 & 33,10 & 80,10 & 4,80 & 35,03 & 1,70 & 1,40 & 1,93 & 2,93 \\
\hline & 76,13 & 3,30 & 31,90 & 77,43 & 4,10 & 33,00 & 1,30 & 0,80 & 1,10 & 1,88 \\
\hline & 76,63 & 4,43 & 33,63 & 76,30 & 4,70 & 33,57 & $-0,33$ & 0,27 & $-0,07$ & 0,43 \\
\hline & 75,70 & 3,60 & 32,50 & 77,73 & 5,00 & 34,80 & 2,03 & 1,40 & 2,30 & 3,37 \\
\hline & 76,93 & 4,33 & 34,10 & 77,93 & 4,80 & 34,13 & 1,00 & 0,47 & 0,03 & 1,10 \\
\hline & 79,80 & 2,60 & 32,30 & 82,10 & 4,40 & 35,80 & 2,30 & 1,80 & 3,50 & 4,56 \\
\hline & 79,57 & 2,40 & 32,00 & 82,33 & 4,30 & 35,60 & 2,77 & 1,90 & 3,60 & 4,92 \\
\hline & 67,33 & 4,20 & 28,07 & 69,07 & 4,20 & 28,13 & 1,73 & 0,00 & 0,07 & 1,73 \\
\hline Média & 76,23 & 3,49 & 32,28 & 78,03 & 4,64 & 34,00 & 1,80 & 1,15 & 1,73 & 2,91 \\
\hline $\begin{array}{l}\text { Desvio } \\
\text { padrão }\end{array}$ & $(3,48)$ & $(0,72)$ & $(1,66)$ & $(3,71)$ & $(0,65)$ & $(2,34)$ & $(0,98)$ & $(0,77)$ & $(1,44)$ & $(1,61)$ \\
\hline
\end{tabular}

Tabela 31 - Valores das leituras de cor nas coordenadas $\mathrm{L}^{*}, \mathrm{a}^{*}, \mathrm{~b}^{*}$, das respectivas médias e (desvio padrão), antes (inicial) e após 30 dias de exposição ao frio e das alterações de cor $\left(\Delta \mathrm{L}^{*}, \Delta \mathrm{a}^{*}, \Delta \mathrm{b}^{*} \mathrm{e} \Delta \mathrm{E}\right)$ após submissão da resina composta a $-20^{\circ} \mathrm{C}$.

\section{Resina Composta} $-20^{\circ} \mathrm{C}$

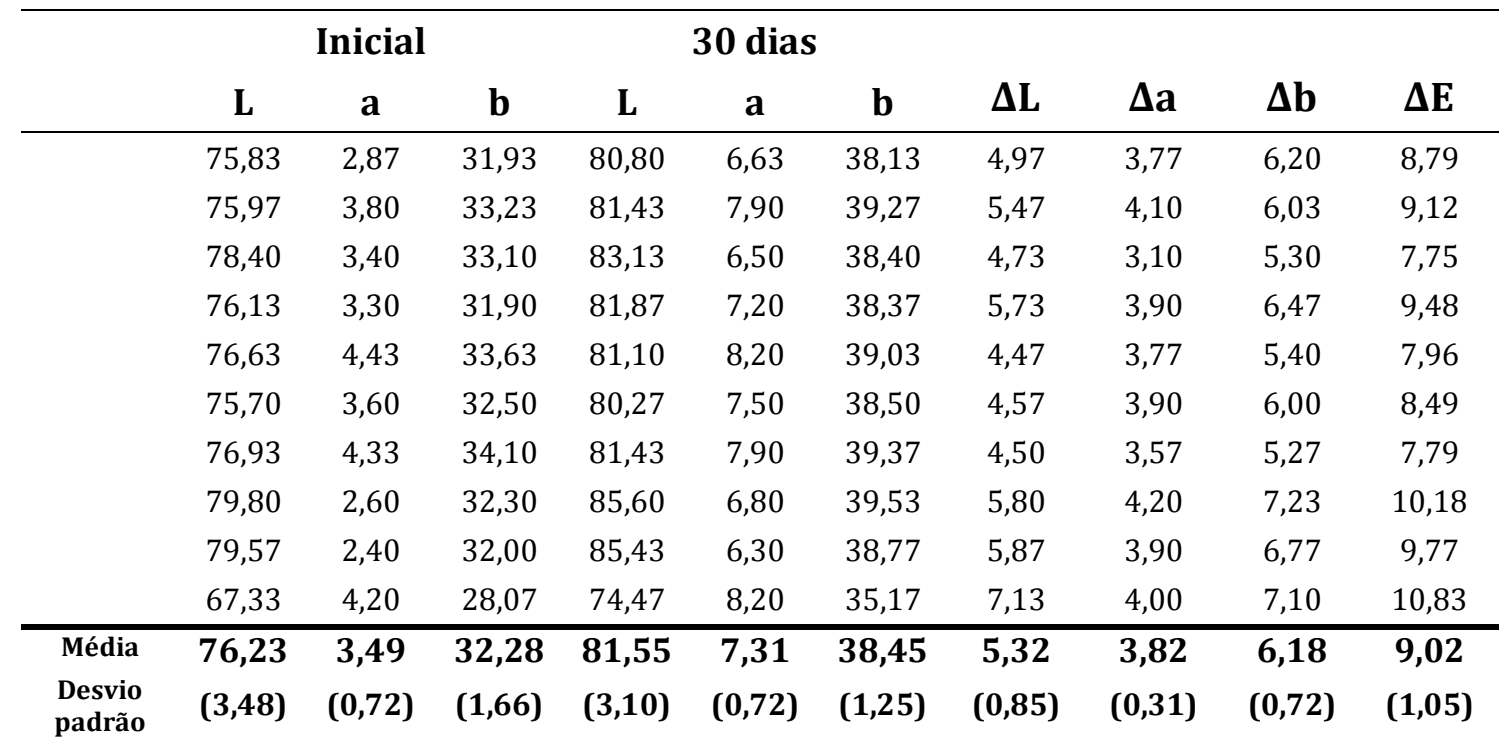


Tabela 32 - Valores das leituras de cor nas coordenadas $\mathrm{L}^{*}, \mathrm{a}^{*}, \mathrm{~b}^{*}$, das respectivas médias e (desvio padrão), antes (inicial) e após 7 dias de exposição ao frio e das alterações de cor $\left(\Delta \mathrm{L}^{*}, \Delta \mathrm{a}^{*}, \Delta \mathrm{b}^{*} \mathrm{e} \Delta \mathrm{E}\right)$ após submissão da resina composta a $-80^{\circ} \mathrm{C}$.

\section{Resina Composta}

$-80^{\circ} \mathrm{C}$

\begin{tabular}{|c|c|c|c|c|c|c|c|c|c|c|}
\hline & \multicolumn{3}{|c|}{ Inicial } & \multicolumn{3}{|c|}{7 dias } & \multirow[b]{2}{*}{$\Delta \mathbf{L}$} & \multirow[b]{2}{*}{$\Delta \mathbf{a}$} & \multirow[b]{2}{*}{$\Delta \mathbf{b}$} & \multirow[b]{2}{*}{$\Delta \mathbf{E}$} \\
\hline & $\mathbf{L}$ & $\mathbf{a}$ & $\mathbf{b}$ & $\mathbf{L}$ & $\mathbf{a}$ & $\mathbf{b}$ & & & & \\
\hline & 76,97 & 2,70 & 33,03 & 78,20 & 2,50 & 32,60 & 1,23 & $-0,20$ & $-0,43$ & 1,32 \\
\hline & 75,37 & 4,07 & 30,03 & 76,53 & 4,20 & 30,57 & 1,17 & 0,13 & 0,53 & 1,29 \\
\hline & 72,57 & 3,03 & 31,37 & 73,00 & 3,10 & 30,00 & 0,43 & 0,07 & $-1,37$ & 1,44 \\
\hline & 75,00 & 2,20 & 29,80 & 76,57 & 3,20 & 30,80 & 1,57 & 1,00 & 1,00 & 2,11 \\
\hline & 64,23 & 4,70 & 27,37 & 70,93 & 4,60 & 30,03 & 6,70 & $-0,10$ & 2,67 & 7,21 \\
\hline & 75,47 & 3,23 & 28,73 & 76,97 & 4,17 & 29,73 & 1,50 & 0,93 & 1,00 & 2,03 \\
\hline & 70,70 & 4,27 & 29,23 & 76,97 & 3,40 & 30,47 & 5,87 & $-0,87$ & 1,23 & 6,06 \\
\hline & 70,13 & 0,90 & 25,83 & 70,50 & 1,40 & 26,23 & 0,37 & 0,50 & 0,40 & 0,74 \\
\hline & 69,27 & 4,20 & 29,60 & 70,10 & 4,20 & 29,17 & 0,83 & 0,00 & $-0,43$ & 0,94 \\
\hline & 68,40 & 4,90 & 27,70 & 73,00 & 4,50 & 28,53 & 4,60 & $-0,40$ & 0,83 & 4,69 \\
\hline Média & 71,81 & 3,42 & 29,27 & 74,28 & 3,53 & 29,81 & 2,43 & 0,11 & 0,54 & 2,78 \\
\hline $\begin{array}{l}\text { Desvio } \\
\text { padrão }\end{array}$ & $(3,99)$ & $(1,25)$ & $(2,05)$ & $(3,10)$ & $(1,02)$ & $(1,66)$ & $(2,36)$ & $(0,58)$ & $(1,11)$ & $(2,33)$ \\
\hline
\end{tabular}

Tabela 33 - Valores das leituras de cor nas coordenadas $\mathrm{L}^{*}, \mathrm{a}^{*}, \mathrm{~b}^{*}$, das respectivas médias e (desvio padrão), antes (inicial) e após 30 dias de exposição ao frio e das alterações de cor $\left(\Delta \mathrm{L}^{*}, \Delta \mathrm{a}^{*}, \Delta \mathrm{b}^{*} \mathrm{e} \Delta \mathrm{E}\right)$ após submissão da resina composta a $-80^{\circ} \mathrm{C}$.

\section{Resina Composta} $-80^{\circ} \mathrm{C}$

\begin{tabular}{|c|c|c|c|c|c|c|c|c|c|c|}
\hline & \multicolumn{3}{|c|}{ Inicial } & \multicolumn{3}{|c|}{30 dias } & \multirow[b]{2}{*}{$\Delta \mathbf{L}$} & \multirow[b]{2}{*}{$\Delta \mathbf{a}$} & \multirow[b]{2}{*}{$\Delta \mathbf{b}$} & \multirow[b]{2}{*}{$\Delta \mathbf{E}$} \\
\hline & $\mathbf{L}$ & $\mathbf{a}$ & b & $\mathbf{L}$ & $\mathbf{a}$ & b & & & & \\
\hline & 76,97 & 2,70 & 33,03 & 83,10 & 5,60 & 38,50 & 6,13 & 2,90 & 5,47 & 8,71 \\
\hline & 75,37 & 4,07 & 30,03 & 81,53 & 6,77 & 35,77 & 6,17 & 2,70 & 5,73 & 8,84 \\
\hline & 72,57 & 3,03 & 31,37 & 76,40 & 4,90 & 33,40 & 3,83 & 1,87 & 2,03 & 4,72 \\
\hline & 75,00 & 2,20 & 29,80 & 80,33 & 5,40 & 35,07 & 5,33 & 3,20 & 5,27 & 8,15 \\
\hline & 64,23 & 4,70 & 27,37 & 74,57 & 6,10 & 33,40 & 10,33 & 1,40 & 6,03 & 12,05 \\
\hline & 75,47 & 3,23 & 28,73 & 80,70 & 6,57 & 34,00 & 5,23 & 3,33 & 5,27 & 8,14 \\
\hline & 70,70 & 4,27 & 29,23 & 79,70 & 5,60 & 34,40 & 9,00 & 1,33 & 5,17 & 10,46 \\
\hline & 70,13 & 0,90 & 25,83 & 73,50 & 3,20 & 29,57 & 3,37 & 2,30 & 3,73 & 5,53 \\
\hline & 69,27 & 4,20 & 29,60 & 75,10 & 7,70 & 34,97 & 5,83 & 3,50 & 5,37 & 8,66 \\
\hline & 68,40 & 4,90 & 27,70 & 77,21 & 7,33 & 33,47 & 8,81 & 2,43 & 5,77 & 10,80 \\
\hline Média & 71,81 & 3,42 & 29,27 & 78,21 & 5,92 & 34,25 & 6,40 & 2,50 & 4,98 & 8,61 \\
\hline $\begin{array}{l}\text { Desvio } \\
\text { padrão }\end{array}$ & $(3,99)$ & $(1,25)$ & $(2,05)$ & $(3,29)$ & $(1,30)$ & $(2,25)$ & $(2,28)$ & $(0,77)$ & $(1,21)$ & $(2,24)$ \\
\hline
\end{tabular}


Tabela 34 - Valores das leituras de cor nas coordenadas $\mathrm{L}^{*}, \mathrm{a}^{*}, \mathrm{~b}^{*}$, das respectivas médias e (desvio padrão), antes (inicial) e após 7 dias de exposição ao frio e das alterações de cor $\left(\Delta \mathrm{L}^{*}, \Delta \mathrm{a}^{*}, \Delta \mathrm{b}^{*} \mathrm{e} \Delta \mathrm{E}\right)$ após submissão do CIV a $2,5^{\circ} \mathrm{C}$.

\section{Cimento de Ionômero de Vidro}

\section{$2,5^{\circ} \mathrm{C}$}

\begin{tabular}{|c|c|c|c|c|c|c|c|c|c|c|}
\hline & \multicolumn{3}{|c|}{ Inicial } & \multicolumn{3}{|c|}{7 dias } & \multirow[b]{2}{*}{$\Delta \mathbf{L}$} & \multirow[b]{2}{*}{$\Delta \mathbf{a}$} & \multirow[b]{2}{*}{$\Delta \mathbf{b}$} & \multirow[b]{2}{*}{$\Delta \mathbf{E}$} \\
\hline & $\mathbf{L}$ & $\mathbf{a}$ & $\mathbf{b}$ & $\mathbf{L}$ & $\mathbf{a}$ & $\mathbf{b}$ & & & & \\
\hline & 68,83 & 5,50 & 36,27 & 71,80 & 3,10 & 33,80 & 2,97 & $-2,40$ & $-2,47$ & 4,54 \\
\hline & 86,43 & 6,30 & 41,43 & 84,63 & 3,23 & 36,17 & $-1,80$ & $-3,07$ & $-5,27$ & 6,35 \\
\hline & 86,47 & 3,77 & 33,53 & 87,37 & 2,50 & 32,03 & 0,90 & $-1,27$ & $-1,50$ & 2,16 \\
\hline & 86,53 & 5,30 & 39,30 & 87,70 & 2,60 & 34,13 & 1,17 & $-2,70$ & $-5,17$ & 5,95 \\
\hline & 89,63 & 4,80 & 39,93 & 89,40 & 3,60 & 38,17 & $-0,23$ & $-1,20$ & $-1,77$ & 2,15 \\
\hline & 83,77 & 5,70 & 40,17 & 84,43 & 3,60 & 36,97 & 0,67 & $-2,10$ & 3,20 & 3,89 \\
\hline & 86,53 & 4,60 & 37,20 & 85,70 & 2,50 & 33,77 & $-0,83$ & $-2,10$ & 3,43 & 4,11 \\
\hline & 76,70 & 5,27 & 35,73 & 74,70 & 3,30 & 32,40 & $-2,00$ & $-1,97$ & $-3,33$ & 4,36 \\
\hline & 87,13 & 2,80 & 32,27 & 87,37 & 2,20 & 32,57 & 0,23 & $-0,60$ & 0,30 & 0,71 \\
\hline & 81,70 & 6,60 & 42,13 & 78,10 & 3,80 & 36,40 & $-3,60$ & $-2,80$ & $-5,73$ & 7,33 \\
\hline Média & 83,37 & 5,06 & 37,80 & 83,12 & 3,04 & 34,64 & $-0,25$ & $-2,02$ & $-3,16$ & 4,15 \\
\hline $\begin{array}{l}\text { Desvio } \\
\text { padrão }\end{array}$ & $(6,25)$ & $(1,14)$ & $(3,33)$ & $(6,07)$ & $(0,56)$ & $(2,14)$ & $(1,88)$ & $(0,79)$ & $(1,90)$ & $(2,06)$ \\
\hline
\end{tabular}

Tabela 35 - Valores das leituras de cor nas coordenadas $\mathrm{L}^{*}, \mathrm{a}^{*}, \mathrm{~b}^{*}$, das respectivas médias e (desvio padrão), antes (inicial) e após 30 dias de exposição ao frio e das alterações de cor $\left(\Delta \mathrm{L}^{*}, \Delta \mathrm{a}^{*}, \Delta \mathrm{b}^{*} \mathrm{e} \Delta \mathrm{E}\right)$ após submissão do $\mathrm{CIV}$ a $2,5^{\circ} \mathrm{C}$.

\section{Cimento de Ionômero de Vidro}

$$
2,5^{\circ} \mathrm{C}
$$

\begin{tabular}{|c|c|c|c|c|c|c|c|c|c|c|}
\hline & \multicolumn{3}{|c|}{ Inicial } & \multicolumn{3}{|c|}{30 dias } & \multirow[b]{2}{*}{$\Delta \mathbf{L}$} & \multirow[b]{2}{*}{$\Delta \mathbf{a}$} & \multirow[b]{2}{*}{$\Delta \mathbf{b}$} & \multirow[b]{2}{*}{$\Delta \mathrm{E}$} \\
\hline & $\mathbf{L}$ & $\mathbf{a}$ & $\mathbf{b}$ & $\mathbf{L}$ & $\mathbf{a}$ & $\mathbf{b}$ & & & & \\
\hline & 68,83 & 5,50 & 36,27 & 71,80 & 7,47 & 41,33 & 2,97 & 1,97 & 5,07 & 6,19 \\
\hline & 86,43 & 6,30 & 41,43 & 87,27 & 6,27 & 43,30 & 0,83 & $-0,03$ & 1,87 & 2,04 \\
\hline & 86,47 & 3,77 & 33,53 & 87,30 & 4,10 & 36,83 & 0,83 & 0,33 & 3,30 & 3,42 \\
\hline & 86,53 & 5,30 & 39,30 & 86,87 & 5,10 & 40,00 & 0,33 & $-0,20$ & 0,70 & 0,80 \\
\hline & 89,63 & 4,80 & 39,93 & 93,07 & 5,70 & 43,80 & 3,43 & 0,90 & 3,87 & 5,25 \\
\hline & 83,77 & 5,70 & 40,17 & 83,77 & 6,40 & 42,97 & 0,00 & 0,70 & 2,80 & 2,89 \\
\hline & 86,53 & 4,60 & 37,20 & 87,00 & 5,00 & 39,80 & 0,47 & 0,40 & 2,60 & 2,67 \\
\hline & 76,70 & 5,27 & 35,73 & 72,67 & 6,60 & 39,13 & $-4,03$ & 1,33 & 3,40 & 5,44 \\
\hline & 87,13 & 2,80 & 32,27 & 89,60 & 4,10 & 37,60 & 2,47 & 1,30 & 5,33 & 6,02 \\
\hline & 81,70 & 6,60 & 42,13 & 81,27 & 6,60 & 42,80 & $-0,43$ & 0,00 & 0,67 & 0,80 \\
\hline Média & 83,37 & 5,06 & 37,80 & 84,06 & 5,73 & 40,76 & 0,69 & 0,67 & 2,96 & 3,55 \\
\hline $\begin{array}{l}\text { Desvio } \\
\text { padrão }\end{array}$ & $(6,25)$ & $(1,14)$ & $(3,33)$ & $(6,97)$ & $(1,13)$ & $(2,46)$ & $(2,11)$ & $(0,70)$ & $(1,60)$ & $(2,06)$ \\
\hline
\end{tabular}


Tabela 36 - Valores das leituras de cor nas coordenadas $\mathrm{L}^{*}, \mathrm{a}^{*}, \mathrm{~b}^{*}$, das respectivas médias e (desvio padrão), antes (inicial) e após 7 dias de exposição ao frio e das alterações de cor $\left(\Delta \mathrm{L}^{*}, \Delta \mathrm{a}^{*}, \Delta \mathrm{b}^{*} \mathrm{e} \Delta \mathrm{E}\right)$ após submissão do CIV a $-20^{\circ} \mathrm{C}$.

\section{Cimento de Ionômero de Vidro} $-20^{\circ} \mathrm{C}$

\begin{tabular}{|c|c|c|c|c|c|c|c|c|c|c|}
\hline & \multicolumn{3}{|c|}{ Inicial } & \multicolumn{3}{|c|}{7 dias } & \multirow[b]{2}{*}{$\Delta \mathbf{L}$} & \multirow[b]{2}{*}{$\Delta \mathbf{a}$} & \multirow[b]{2}{*}{$\Delta \mathbf{b}$} & \multirow[b]{2}{*}{$\Delta \mathrm{E}$} \\
\hline & $\mathbf{L}$ & $\mathbf{a}$ & $\mathbf{b}$ & $\mathbf{L}$ & $\mathbf{a}$ & $\mathbf{b}$ & & & & \\
\hline & 83,10 & 7,20 & 42,93 & 80,97 & 5,70 & 40,00 & $-2,13$ & $-1,50$ & $-2,93$ & 3,92 \\
\hline & 82,50 & 4,27 & 36,40 & 83,90 & 4,50 & 37,73 & 1,40 & 0,23 & 1,33 & 1,95 \\
\hline & 87,57 & 4,50 & 36,63 & 85,50 & 3,13 & 34,83 & $-2,07$ & $-1,37$ & $-1,80$ & 3,06 \\
\hline & 89,23 & 5,50 & 40,43 & 86,53 & 4,17 & 37,13 & $-2,70$ & $-1,33$ & $-3,30$ & 4,47 \\
\hline & 86,73 & 4,90 & 39,53 & 84,63 & 2,83 & 35,60 & $-2,10$ & $-2,07$ & $-3,93$ & 4,91 \\
\hline & 94,20 & 2,63 & 36,30 & 91,00 & 2,50 & 36,13 & $-3,20$ & $-0,13$ & $-0,17$ & 3,21 \\
\hline & 85,20 & 4,10 & 36,27 & 86,33 & 4,83 & 38,50 & 1,13 & 0,73 & 2,23 & 2,61 \\
\hline & 90,70 & 5,70 & 41,27 & 87,27 & 4,00 & 38,10 & $-3,43$ & $-1,70$ & $-3,17$ & 4,97 \\
\hline & 82,23 & 7,13 & 42,67 & 82,03 & 5,17 & 38,30 & $-0,20$ & $-1,97$ & $-4,37$ & 4,79 \\
\hline & 86,00 & 5,30 & 40,00 & 85,97 & 5,80 & 41,37 & $-0,03$ & 0,50 & 1,37 & 1,46 \\
\hline Média & 86,75 & 5,12 & 39,24 & 85,41 & 4,26 & 37,77 & $-1,33$ & $-0,86$ & $-1,47$ & 3,54 \\
\hline $\begin{array}{l}\text { Desvio } \\
\text { padrão }\end{array}$ & $(3,84)$ & $(1,38)$ & $(2,66)$ & $(2,81)$ & $(1,16)$ & $(1,98)$ & $(1,77)$ & $(1,07)$ & $(2,46)$ & $(1,27)$ \\
\hline
\end{tabular}

Tabela 37 - Valores das leituras de cor nas coordenadas $\mathrm{L}^{*}, \mathrm{a}^{*}, \mathrm{~b}^{*}$, das respectivas médias e (desvio padrão), antes (inicial) e após 30 dias de exposição ao frio e das alterações de cor $\left(\Delta \mathrm{L}^{*}, \Delta \mathrm{a}^{*}, \Delta \mathrm{b}^{*} \mathrm{e} \Delta \mathrm{E}\right)$ após submissão do $\mathrm{CIV}$ a $-20^{\circ} \mathrm{C}$.

\section{Cimento de Ionômero de Vidro} $-20^{\circ} \mathrm{C}$

\begin{tabular}{ccccccccccc}
\hline & \multicolumn{3}{c}{ Inicial } & \multicolumn{8}{c}{$\mathbf{3 0} \mathbf{d i a s}$} \\
& $\mathbf{L}$ & $\mathbf{a}$ & $\mathbf{b}$ & $\mathbf{L}$ & $\mathbf{a}$ & $\mathbf{b}$ & $\mathbf{\Delta L}$ & $\mathbf{\Delta a}$ & $\boldsymbol{\Delta} \mathbf{b}$ & $\boldsymbol{\Delta} \mathbf{E}$ \\
\hline & 83,10 & 7,20 & 42,93 & 81,33 & 7,20 & 42,90 & $-1,77$ & 0,00 & $-0,03$ & 1,77 \\
& 82,50 & 4,27 & 36,40 & 85,63 & 6,10 & 41,40 & 3,13 & 1,83 & 5,00 & 6,18 \\
& 87,57 & 4,50 & 36,63 & 84,70 & 4,90 & 38,37 & $-2,87$ & 0,40 & 1,73 & 3,37 \\
& 89,23 & 5,50 & 40,43 & 87,40 & 6,00 & 42,00 & $-1,83$ & 0,50 & 1,57 & 2,46 \\
& 86,73 & 4,90 & 39,53 & 86,87 & 5,63 & 42,50 & 0,13 & 0,73 & 2,97 & 3,06 \\
& 94,20 & 2,63 & 36,30 & 91,23 & 4,90 & 42,20 & $-2,97$ & 2,27 & 5,90 & 6,98 \\
& 85,20 & 4,10 & 36,27 & 85,00 & 5,60 & 40,10 & $-0,20$ & 1,50 & 3,83 & 4,12 \\
& 90,70 & 5,70 & 41,27 & 89,83 & 6,00 & 43,00 & $-0,87$ & 0,30 & 1,73 & 1,96 \\
& 82,23 & 7,13 & 42,67 & 80,33 & 7,37 & 43,13 & $-1,90$ & 0,23 & 0,47 & 1,97 \\
\hline Média & $\mathbf{8 6 , 7 5}$ & $\mathbf{5 , 1 2}$ & $\mathbf{3 9 , 2 4}$ & $\mathbf{8 5 , 9 7}$ & $\mathbf{6 , 0 3}$ & $\mathbf{4 1 , 9 4}$ & $\mathbf{- 0 , 7 8}$ & $\mathbf{0 , 9 1}$ & $\mathbf{2 , 6 9}$ & $\mathbf{3 , 6 1}$ \\
Desvio & $\mathbf{( 3 , 8 4 )}$ & $\mathbf{( 1 , 3 8 )}$ & $\mathbf{( 2 , 6 6 )}$ & $\mathbf{( 3 , 3 9 )}$ & $\mathbf{( 0 , 8 4 )}$ & $\mathbf{( 1 , 6 2 )}$ & $\mathbf{( 1 , 9 3 )}$ & $\mathbf{( 0 , 7 7 )}$ & $\mathbf{( 1 , 9 3 )}$ & $\mathbf{( 1 , 8 0 )}$ \\
padrão & & & & & & & & &
\end{tabular}


Tabela 38 - Valores das leituras de cor nas coordenadas $\mathrm{L}^{*}, \mathrm{a}^{*}, \mathrm{~b}^{*}$, das respectivas médias e (desvio padrão), antes (inicial) e após 7 dias de exposição ao frio e das alterações de cor $\left(\Delta \mathrm{L}^{*}, \Delta \mathrm{a}^{*}, \Delta \mathrm{b}^{*} \mathrm{e} \Delta \mathrm{E}\right)$ após submissão do CIV a $-80^{\circ} \mathrm{C}$.

\section{Cimento de Ionômero de Vidro} $-80^{\circ} \mathrm{C}$

\begin{tabular}{|c|c|c|c|c|c|c|c|c|c|c|}
\hline & \multicolumn{3}{|c|}{ Inicial } & \multicolumn{3}{|c|}{7 dias } & \multirow[b]{2}{*}{$\Delta \mathbf{L}$} & \multirow[b]{2}{*}{$\Delta \mathbf{a}$} & \multirow[b]{2}{*}{$\Delta \mathbf{b}$} & \multirow[b]{2}{*}{$\Delta \mathrm{E}$} \\
\hline & $\mathbf{L}$ & $\mathbf{a}$ & $\mathbf{b}$ & $\mathbf{L}$ & $\mathbf{a}$ & $\mathbf{b}$ & & & & \\
\hline & 82,53 & 5,10 & 39,57 & 85,27 & 6,60 & 43,00 & 2,73 & 1,50 & 3,43 & 4,64 \\
\hline & 86,10 & 4,30 & 38,57 & 87,40 & 5,30 & 40,67 & 1,30 & 1,00 & 2,10 & 2,66 \\
\hline & 93,10 & 5,00 & 40,10 & 91,60 & 4,13 & 38,97 & $-1,50$ & $-0,87$ & $-1,13$ & 2,07 \\
\hline & 92,80 & 4,40 & 37,53 & 91,57 & 3,90 & 35,90 & $-1,23$ & $-0,50$ & $-1,63$ & 2,11 \\
\hline & 88,00 & 5,60 & 41,67 & 86,93 & 5,30 & 41,30 & $-1,07$ & $-0,30$ & $-0,37$ & 1,17 \\
\hline & 87,33 & 4,10 & 38,70 & 85,90 & 5,60 & 41,63 & $-1,43$ & 1,50 & 2,93 & 3,59 \\
\hline & 89,60 & 5,93 & 43,73 & 86,73 & 4,47 & 40,07 & $-2,87$ & $-1,47$ & $-3,67$ & 4,88 \\
\hline & 95,80 & 3,83 & 39,03 & 93,73 & 3,50 & 37,93 & $-2,07$ & $-0,33$ & $-1,10$ & 2,36 \\
\hline & 90,67 & 3,60 & 35,20 & 92,93 & 3,60 & 35,70 & 2,27 & 0,00 & 0,50 & 2,32 \\
\hline & 97,00 & 4,97 & 41,73 & 94,63 & 3,00 & 35,63 & $-2,37$ & $-1,97$ & $-6,10$ & 6,83 \\
\hline Média & 90,29 & 4,68 & 39,58 & 89,67 & 4,54 & 39,08 & $-0,62$ & $-0,14$ & $-0,50$ & 3,26 \\
\hline $\begin{array}{l}\text { Desvio } \\
\text { padrão }\end{array}$ & $(4,50)$ & $(0,76)$ & $(2,40)$ & $(3,56)$ & $(1,13)$ & $(2,69)$ & $(1,99)$ & $(1,18)$ & $(2,95)$ & $(1,72)$ \\
\hline
\end{tabular}

Tabela 39 - Valores das leituras de cor nas coordenadas $\mathrm{L}^{*}, \mathrm{a}^{*}, \mathrm{~b}^{*}$, das respectivas médias e (desvio padrão), antes (inicial) e após 30 dias de exposição ao frio e das alterações de cor $\left(\Delta \mathrm{L}^{*}, \Delta \mathrm{a}^{*}, \Delta \mathrm{b}^{*} \mathrm{e} \Delta \mathrm{E}\right)$ após submissão do $\operatorname{CIV}$ a $-80^{\circ} \mathrm{C}$.

\section{Cimento de Ionômero de Vidro} $-80^{\circ} \mathrm{C}$

\begin{tabular}{|c|c|c|c|c|c|c|c|c|c|c|}
\hline & \multicolumn{3}{|c|}{ Inicial } & \multicolumn{3}{|c|}{30 dias } & \multirow[b]{2}{*}{$\Delta \mathbf{L}$} & \multirow[b]{2}{*}{$\Delta \mathbf{a}$} & \multirow[b]{2}{*}{$\Delta \mathbf{b}$} & \multirow[b]{2}{*}{$\Delta E$} \\
\hline & $\mathbf{L}$ & $\mathbf{a}$ & b & $\mathbf{L}$ & $\mathbf{a}$ & $\mathbf{b}$ & & & & \\
\hline & 82,53 & 5,10 & 39,57 & 85,17 & 7,13 & 44,50 & 2,63 & 2,03 & 4,93 & 5,95 \\
\hline & 86,10 & 4,30 & 38,57 & 88,93 & 6,30 & 43,77 & 2,83 & 2,00 & 5,20 & 6,25 \\
\hline & 93,10 & 5,00 & 40,10 & 91,90 & 5,17 & 41,67 & $-1,20$ & 0,17 & 1,57 & 1,98 \\
\hline & 92,80 & 4,40 & 37,53 & 83,53 & 6,27 & 40,63 & $-9,27$ & 1,87 & 3,10 & 9,95 \\
\hline & 88,00 & 5,60 & 41,67 & 87,73 & 6,40 & 44,13 & $-0,27$ & 0,80 & 2,47 & 2,61 \\
\hline & 87,33 & 4,10 & 38,70 & 83,10 & 6,20 & 42,60 & $-4,23$ & 2,10 & 3,90 & 6,13 \\
\hline & 89,60 & 5,93 & 43,73 & 88,90 & 5,90 & 44,20 & $-0,70$ & $-0,03$ & $-0,47$ & 0,84 \\
\hline & 95,80 & 3,83 & 39,03 & 95,90 & 4,50 & 41,83 & 0,10 & 0,67 & 2,80 & 2,88 \\
\hline & 90,67 & 3,60 & 35,20 & 94,20 & 3,43 & 38,13 & 3,53 & $-0,17$ & 2,93 & 4,60 \\
\hline & 97,00 & 4,97 & 41,73 & 96,00 & 4,53 & 41,50 & $-1,00$ & $-0,43$ & $-0,23$ & 1,11 \\
\hline Média & 90,29 & 4,68 & 39,58 & 89,54 & 5,58 & 42,30 & $-0,76$ & 0,90 & 2,71 & 4,23 \\
\hline $\begin{array}{l}\text { Desvio } \\
\text { padrão }\end{array}$ & $(4,50)$ & $(0,76)$ & $(2,40)$ & $(4,83)$ & $(1,14)$ & $(1,99)$ & $(3,78)$ & $(1,01)$ & $(1,76)$ & $(2,87)$ \\
\hline
\end{tabular}




\section{Delta E}

As comparações das médias de Delta E (2-way ANOVA, Bonferroni, $p<0,05$ ), podem ser vistas nas Tabelas 40 a 44 e Gráfico 09.

Tabela 40 - Comparação das alterações de $(\Delta \mathrm{E})$ e desvio padrão, da resina composta e do CIV nas submissões a $2,5^{\circ} \mathrm{C},-20^{\circ} \mathrm{C}$ e $-80^{\circ} \mathrm{C}$, por 7 dias e, entre materiais, nas mesmas temperaturas, analisadas segundo Two-way ANOVA, Bonferroni, $\mathrm{p}<0,05$.

\begin{tabular}{ccc}
\hline \multicolumn{3}{c}{ Delta $\mathbf{E}$} \\
\hline T dias \\
\hline Temperatura & Resina & CIV \\
$2,5^{\circ} \mathrm{C}$ & $4,59 \pm 0,81$ aA & $4,15 \pm 2,06$ aA \\
$-20^{\circ} \mathrm{C}$ & $2,91 \pm 1,61$ aA & $3,54 \pm 1,27$ aA \\
$-80^{\circ} \mathrm{C}$ & $2,78 \pm 2,33$ aA & $3,26 \pm 1,72$ aA \\
\hline
\end{tabular}

Para todas as comparações, em linha, entre os materiais, e na coluna para o mesmo material, não houve diferença estatisticamente significante $(p>0,05)$.

Tabela 41 - Comparação das alterações de cor $(\Delta E)$ e desvio padrão, da resina composta e do CIV nas submissões a $2,5^{\circ} \mathrm{C},-20^{\circ} \mathrm{C}$ e $-80^{\circ} \mathrm{C}$, por 7 dias e, entre os materiais, em diferentes temperaturas, analisadas segundo Two-way ANOVA, Bonferroni, $\mathrm{p}<0,05$.

\section{Delta E}

\begin{tabular}{cccccc}
\hline \multicolumn{5}{c}{7 dias } \\
\hline Material & & & & \\
& Temperatura & & $2,5^{\circ} \mathrm{C}$ & $-20^{\circ} \mathrm{C}$ & $-80^{\circ} \mathrm{C}$ \\
& & & $4,15 \pm 2,06$ & $3,54 \pm 1,27$ & $3,26 \pm 1,72$ \\
& $2,5^{\circ} \mathrm{C}$ & $4,59 \pm 0,81$ & & $n$ ns & ns \\
Resina & $-20^{\circ} \mathrm{C}$ & $2,91 \pm 1,61$ & ns & & ns \\
Composta & $-80^{\circ} \mathrm{C}$ & $2,78 \pm 2,33$ & ns & ns & \\
& & & &
\end{tabular}

ns = Não houve diferença estatisticamente significante $(\mathrm{p}>0,05)$.

Tabela 42 - Comparação das alterações de $(\Delta \mathrm{E})$ e desvio padrão, da resina composta e do CIV nas submissões a $2,5^{\circ} \mathrm{C},-20^{\circ} \mathrm{C} \mathrm{e}-80^{\circ} \mathrm{C}$, por 30 dias e, entre materiais, nas mesmas temperaturas, analisadas segundo Two-way ANOVA, Bonferroni, $\mathrm{p}<0,05$.

\section{Delta E}

\begin{tabular}{ccc}
\hline & 30 dias & \\
\hline Temperatura & Resina & $\mathrm{CIV}$ \\
$2,5^{\circ} \mathrm{C}$ & $8,97 \pm 1,00 \mathrm{aA}$ & $3,55 \pm 2,06 \mathrm{bA}$ \\
$-20^{\circ} \mathrm{C}$ & $9,02 \pm 1,05 \mathrm{aA}$ & $3,61 \pm 1,80 \mathrm{bA}$ \\
$-80^{\circ} \mathrm{C}$ & $8,61 \pm 2,24 \mathrm{aA}$ & $4,23 \pm 2,87 \mathrm{bA}$ \\
\hline
\end{tabular}

Letras diferentes, minúsculas em linha, entre os materiais, indicam diferença estatisticamente significante $(p<0,05)$. Na comparação entre o mesmo material, na coluna, $p>0,05$. 
Tabela 43 - Comparação das alterações de cor $(\Delta \mathrm{E})$ e desvio padrão, da resina composta e do $\mathrm{CIV}$ nas submissões a $2,5^{\circ} \mathrm{C},-20^{\circ} \mathrm{C}$ e $-80^{\circ} \mathrm{C}$, por 30 dias e, entre os materiais, em diferentes temperaturas, analisadas segundo Two-way ANOVA, Bonferroni, $\mathrm{p}<0,05$.

\section{Delta E}

\begin{tabular}{lccccc}
\hline \multicolumn{5}{c}{30 dias } \\
\hline Material & & & & & \\
& Temperatura & & $2,5^{\circ} \mathrm{C}$ & $-20^{\circ} \mathrm{C}$ & $-80^{\circ} \mathrm{C}$ \\
& & & $3,55 \pm 2,06$ & $3,61 \pm 1,80$ & $4,23 \pm 2,87$ \\
& $2,5^{\circ} \mathrm{C}$ & $8,97 \pm 1,00$ & & $* * * *$ & $* * * *$ \\
Resina & $-20^{\circ} \mathrm{C}$ & $9,02 \pm 1,05$ & $* * * *$ & & $* * * *$ \\
Composta & $-80^{\circ} \mathrm{C}$ & $8,61 \pm 2,24$ & $* * * *$ & $* * * *$ & \\
& & & & \\
\hline
\end{tabular}

$* * * *=$ Diferença estatisticamente significante $(\mathrm{p}<0,05)$.

Tabela 44 - Comparação das alterações de cor $(\Delta \mathrm{E})$ e desvio padrão, da resina composta e do $\mathrm{CIV}$, separadamente, nas submissões a $2,5^{\circ} \mathrm{C},-20^{\circ} \mathrm{C}$ e $-80^{\circ} \mathrm{C}$, entre 7 dias e 30 dias, para cada material, analisadas segundo Two-way ANOVA, Bonferroni, $\mathrm{p}<0,05$.

\section{Delta E}

\begin{tabular}{ccc|cc}
\hline & \multicolumn{2}{c|}{ Resina Composta } & \multicolumn{2}{c}{ CIV } \\
\hline Temperaturas & 7 dias & 30 dias & 7 dias & 30 dias \\
\hline $2,5^{\circ} \mathrm{C}$ & $4,59 \pm 0,81^{\mathrm{b}}$ & $8,97 \pm 1,00^{\mathrm{a}}$ & $4,15 \pm 2,06^{\mathrm{a}}$ & $3,55 \pm 2,06^{\mathrm{a}}$ \\
$-20^{\circ} \mathrm{C}$ & $2,91 \pm 1,61^{\mathrm{b}}$ & $9,02 \pm 1,05^{\mathrm{a}}$ & $3,54 \pm 1,27^{\mathrm{a}}$ & $3,61 \pm 1,80^{\mathrm{a}}$ \\
$-80^{\circ} \mathrm{C}$ & $2,78 \pm 2,33^{\mathrm{b}}$ & $8,61 \pm 2,24^{\mathrm{a}}$ & $3,26 \pm 1,72^{\text {a }}$ & $4,23 \pm 2,87^{\mathrm{a}}$ \\
\hline
\end{tabular}

Letras diferentes, minúsculas na linha, para resina composta, indicam diferença estatisticamente significante $(\mathrm{p}<0,05)$. Para o CIV, em linha, $p>0,05$. 
Gráfico 09 - Representação gráfica da comparação de Delta E entre materiais estéticos submetidos à ação do frio.

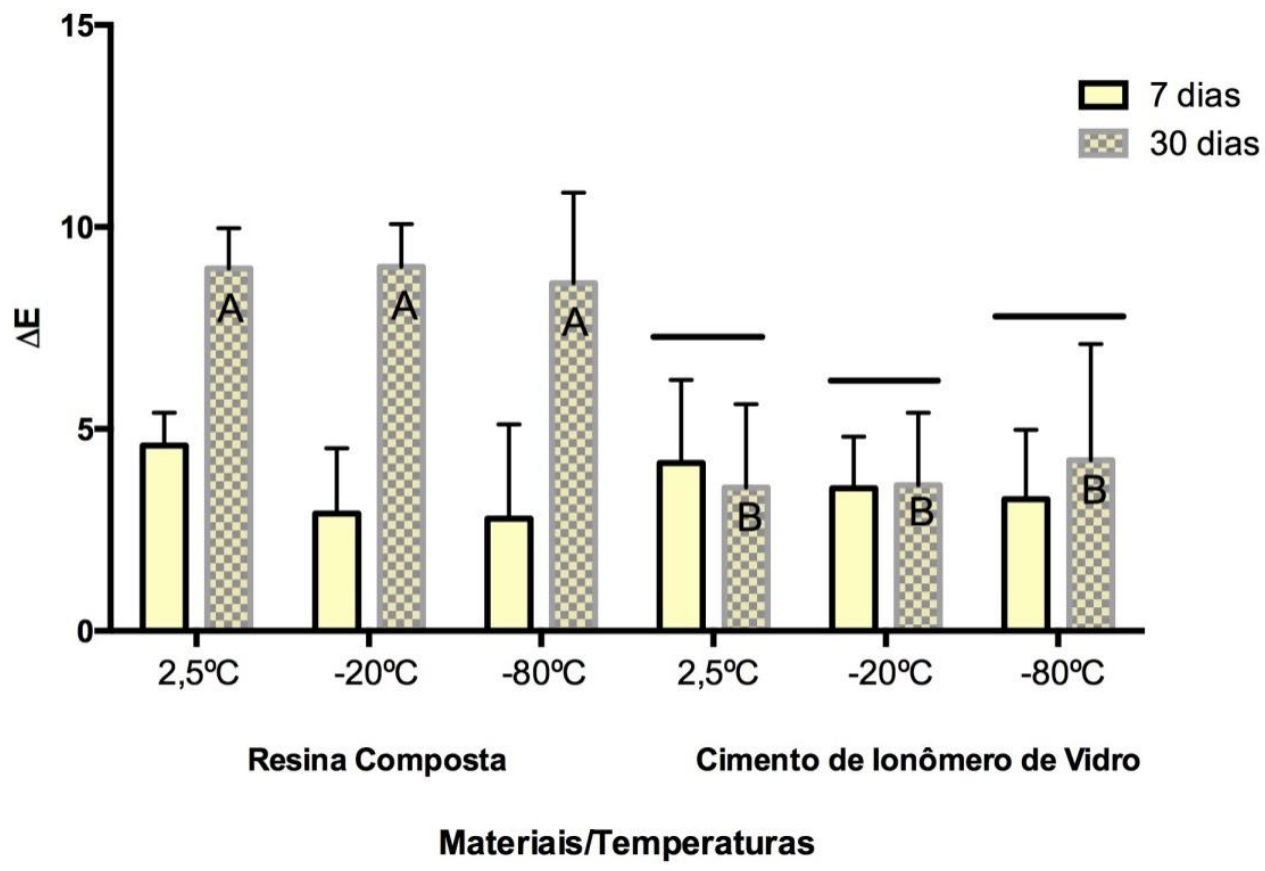

Para as comparações entre 7 dias e 30 dias, na resina composta, $p<0,05$. No CIV, colunas sob linhas horizontais indicam que não houve diferenças estatisticamente significantes $(p>0,05)$. Para todas as comparações entre 7 dias, $p>0,05$. Letras diferentes na comparação entre os materiais após 30 dias, $\mathrm{p}<0,05$.

Não houve diferença estatisticamente significante na alteração de cor $(p>0,05)$ entre as temperaturas testadas quando os materiais estéticos foram submetidos à baixas temperaturas por 7 dias (Tabelas 40 e 41). Após 30 dias, observou-se que a temperatura a que o material foi submetido não foi significante para sua alteração de cor, pois não houve diferença significativa $(p>0,05)$ independente da temperatura a que ambos os materiais foram submetidos. Entretanto, houve maior alteração de cor da resina composta nas três temperaturas testadas, resultado significante $(\mathrm{p}<0,05)$ em relação ao CIV (Tabela 42). Quando analisadas as diferenças entre materiais e temperaturas, verificou-se que a diferença $(\mathrm{p}<0,05)$ entre os materiais também ocorreu, de forma que houve diferença entre os materiais, independente da temperatura testada (Tabela 43).

A análise comparativa entre 7 dias e 30 dias para cada material (Tabela 44), mostrou que houve maior alteração de cor da resina composta após 30 dias, quando submetidas a todas temperaturas testadas, diferente estatisticamente $(p<0,05)$ que quando exposta às temperaturas por 7 dias. Não houve diferença estatisticamente 
significante $(\mathrm{p}>0,05)$ para o CIV, quando comparado o tempo a que foi submetido a baixas temperaturas.

\section{Delta L}

As comparações das médias de Delta L* (2-way ANOVA, Bonferroni, p<0,05), podem ser vistas nas Tabelas 45 a 49 e Gráfico 10 .

Tabela 45 - Comparação das alterações de $\left(\Delta \mathrm{L}^{*}\right)$ e desvio padrão, da resina composta e do CIV nas submissões a $2,5^{\circ} \mathrm{C},-20^{\circ} \mathrm{C}$ e $-80^{\circ} \mathrm{C}$, por 7 dias e, entre materiais, nas mesmas temperaturas, analisadas segundo Two-way ANOVA, Bonferroni, $\mathrm{p}<0,05$.

\section{Delta L}

\begin{tabular}{ccc}
\hline & $\mathbf{7}$ dias & \\
\hline Temperatura & Resina & $\mathrm{CIV}$ \\
$2,5^{\circ} \mathrm{C}$ & $2,63 \pm 0,50 \mathrm{aA}$ & $-0,25 \pm 1,88 \mathrm{aA}$ \\
$-20^{\circ} \mathrm{C}$ & $1,80 \pm 0,98$ aA & $-1,33 \pm 1,77 \mathrm{aA}$ \\
$-80^{\circ} \mathrm{C}$ & $2,43 \pm 2,36$ aA & $-0,62 \pm 1,99$ aA \\
\hline
\end{tabular}

Para todas as comparações, em linha, entre os materiais, e na coluna para o mesmo material, não houve diferença estatisticamente significante $(\mathrm{p}>0,05)$.

Tabela 46 - Comparação das alterações de cor $\left(\Delta \mathrm{L}^{*}\right)$ e desvio padrão, da resina composta e do CIV nas submissões, por 7 dias, a $2,5^{\circ} \mathrm{C},-20^{\circ} \mathrm{C}$ e $-80^{\circ} \mathrm{C}$ e, entre os materiais, em diferentes temperaturas, analisadas segundo Two-way ANOVA, Bonferroni, $\mathrm{p}<0,05$.

\section{Delta L}

\begin{tabular}{cccccc}
\hline & \multicolumn{5}{c}{7 dias } \\
\hline Material & & & $\mathrm{CIV}$ & \\
& Temperatura & & $2,5^{\circ} \mathrm{C}$ & $-20^{\circ} \mathrm{C}$ & $-80^{\circ} \mathrm{C}$ \\
& & & $-0,25 \pm 1,88$ & $-1,33 \pm 1,77$ & $-0,62 \pm 1,99$ \\
& $2,5^{\circ} \mathrm{C}$ & $2,63 \pm 0,50$ & & $n$ ns & ns \\
Resina & $-20^{\circ} \mathrm{C}$ & $1,80 \pm 0,98$ & $\mathrm{~ns}$ & & $\mathrm{~ns}$ \\
Composta & $-80^{\circ} \mathrm{C}$ & $2,43 \pm 2,36$ & $\mathrm{~ns}$ & $\mathrm{~ns}$ & \\
& & &
\end{tabular}

ns = Não houve diferença estatisticamente significante $(p>0,05)$. 
Tabela 47 - Comparação das alterações de $\left(\Delta \mathrm{L}^{*}\right)$ e desvio padrão, da resina composta e do CIV nas submissões a $2,5^{\circ} \mathrm{C},-20^{\circ} \mathrm{C}$ e $-80^{\circ} \mathrm{C}$, por 30 dias e, entre materiais, nas mesmas temperaturas, analisadas segundo Two-way ANOVA, Bonferroni, $\mathrm{p}<0,05$.

Delta L

\begin{tabular}{ccc}
\hline & 30 dias & \\
\hline Temperatura & Resina & $\mathrm{CIV}$ \\
$2,5^{\circ} \mathrm{C}$ & $5,13 \pm 0,82 \mathrm{aB}$ & $0,69 \pm 2,11^{\mathrm{aA}}$ \\
$-20^{\circ} \mathrm{C}$ & $5,32 \pm 0,85^{\mathrm{aB}}$ & $-0,78 \pm 1,93 \mathrm{aA}$ \\
$-80^{\circ} \mathrm{C}$ & $6,40 \pm 2,28 \mathrm{aA}$ & $-0,76 \pm 3,78 \mathrm{bA}$ \\
\hline
\end{tabular}

Letras diferentes, minúsculas em linha, entre os materiais, e maiúsculas na coluna, para o mesmo material, indicam diferença estatisticamente significante $(\mathrm{p}<0,05)$.

Tabela 48 - Comparação das alterações de cor $\left(\Delta \mathrm{L}^{*}\right)$ e desvio padrão, da resina composta e do $\mathrm{CIV}$ nas submissões por 30 dias a $2,5^{\circ} \mathrm{C},-20^{\circ} \mathrm{C}$ e $-80^{\circ} \mathrm{C}$ e, entre os materiais, em diferentes temperaturas, analisadas segundo Two-way ANOVA, Bonferroni, $\mathrm{p}<0,05$.

\section{Delta L}

\begin{tabular}{|c|c|c|c|c|c|}
\hline \multicolumn{6}{|c|}{30 dias } \\
\hline \multirow[t]{3}{*}{ Material } & & & \multicolumn{3}{|c|}{ CIV } \\
\hline & Temperatura & & $2,5^{\circ} \mathrm{C}$ & $-20^{\circ} \mathrm{C}$ & $-80^{\circ} \mathrm{C}$ \\
\hline & & & $0,69 \pm 2,11$ & $-0,78 \pm 1,93$ & $-0,76 \pm 3,78$ \\
\hline \multirow{3}{*}{$\begin{array}{c}\text { Resina } \\
\text { Composta }\end{array}$} & $2,5^{\circ} \mathrm{C}$ & $5,13 \pm 0,82$ & & ns & ns \\
\hline & $-20^{\circ} \mathrm{C}$ & $5,32 \pm 0,85$ & ns & & ns \\
\hline & $-80^{\circ} \mathrm{C}$ & $6,40 \pm 2,28$ & $* * * *$ & $* * * *$ & \\
\hline
\end{tabular}

Tabela 49 - Comparação das alterações de cor $\left(\Delta \mathrm{L}^{*}\right)$ e desvio padrão, da resina composta e do $\mathrm{CIV}$, separadamente, nas submissões a $2,5^{\circ} \mathrm{C},-20^{\circ} \mathrm{C}$ e $-80^{\circ} \mathrm{C}$, entre 7 dias e 30 dias, para cada material, analisadas segundo Two-way ANOVA, Bonferroni, $\mathrm{p}<0,05$.

\section{Delta L}

\begin{tabular}{ccc|cc}
\hline & \multicolumn{2}{c|}{ Resina Composta } & \multicolumn{2}{c}{ CIV } \\
\hline Temperaturas & 7 dias & 30 dias & 7 dias & 30 dias \\
\hline $2,5^{\circ} \mathrm{C}$ & $2,63 \pm 0,50 \mathrm{~b}$ & $5,13 \pm 0,82^{\mathrm{a}}$ & $-0,25 \pm 1,88$ a & $0,69 \pm 2,11^{\mathrm{a}}$ \\
$-20^{\circ} \mathrm{C}$ & $1,80 \pm 0,98 \mathrm{~b}$ & $5,32 \pm 0,85^{\mathrm{a}}$ & $-1,33 \pm 1,77^{\mathrm{a}}$ & $-0,78 \pm 1,93^{\mathrm{a}}$ \\
$-80^{\circ} \mathrm{C}$ & $2,43 \pm 2,36 \mathrm{~b}$ & $6,40 \pm 2,28$ a & $-0,62 \pm 1,99$ a & $-0,76 \pm 3,78$ a \\
\hline
\end{tabular}

Letras diferentes, minúsculas em linha, para resina composta, indicam diferença estatisticamente significante $(p<0,05)$. Para o CIV, em linha, $p>0,05$. 
Gráfico 10 - Representação gráfica da comparação de Delta L* entre materiais estéticos submetidos à ação do frio.

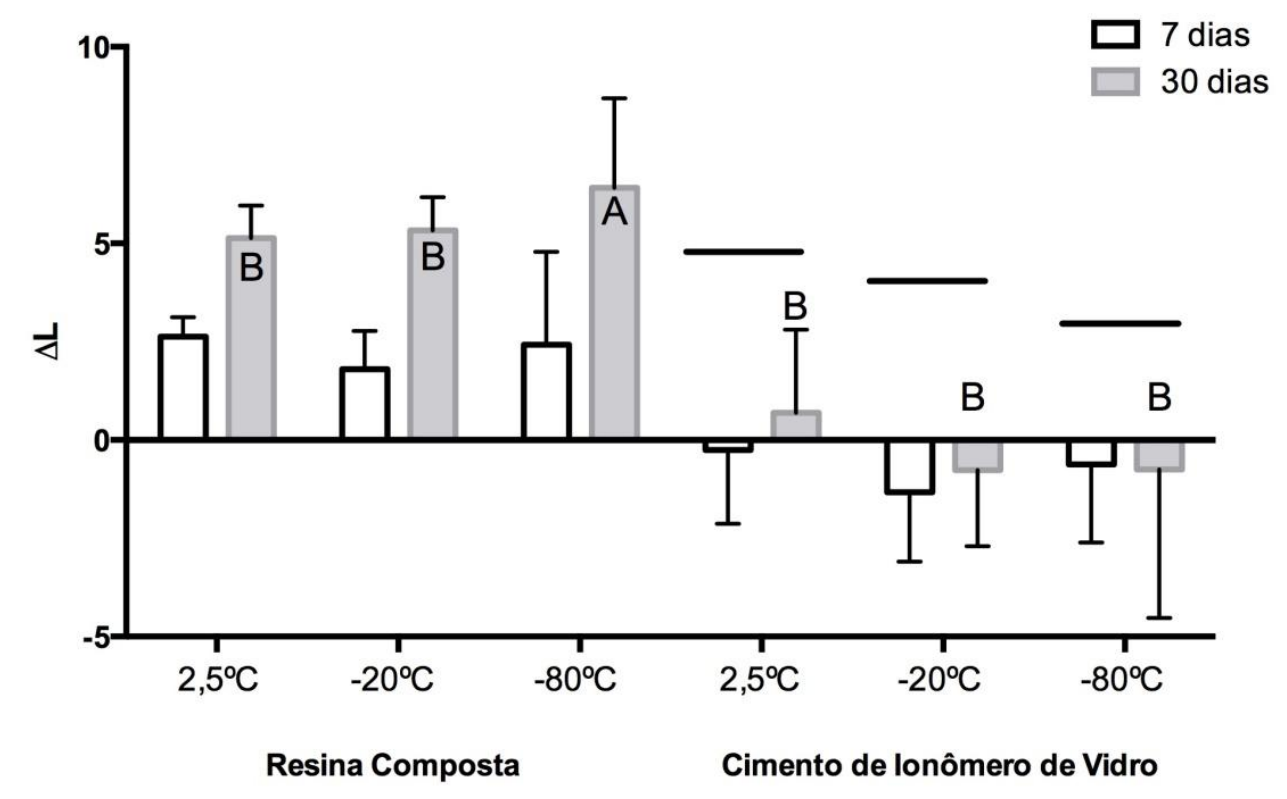

Materiais/Temperaturas

Para as comparações entre 7 dias e 30 dias, na resina composta, $p<0,05$. No CIV, colunas sob linhas horizontais indicam que não houve diferenças estatisticamente significantes $(\mathrm{p}>0,05)$. Para todas as comparações entre 7 dias, $p>0,05$. Letras diferentes na comparação entre os materiais após 30 dias, $\mathrm{p}<0,05$.

Nas restaurações em resina composta, ocorreu um aumento da coordenada $L^{*}$, após 7 e 30 dias, nas três temperaturas estudadas. Não houve diferença significativa ( $>0,05)$ após 7 dias, entretanto, após 30 dias, houve alteração da coordenada em níveis significativos quando submetida a $\left(-80^{\circ} \mathrm{C}\right)$, resultado diferente estatisticamente $(\mathrm{p}<0,05)$ em relação às demais temperaturas testadas, que não apresentaram diferença entre si $(\mathrm{p}>0,05)$.

No CIV, não houve alteração estatisticamente significante $(p>0,05)$ na

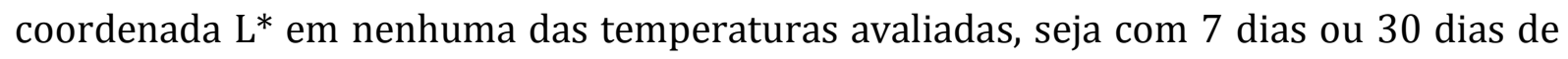
submissão ao frio.

A análise comparativa entre 7 dias e 30 dias para cada material (Tabela 49), indicou que houve maior alteração de cor da resina composta após 30 dias, quando submetidas a todas temperaturas testadas, diferente estatisticamente $(\mathrm{p}<0,05)$ que quando exposta às temperaturas por 7 dias. Não houve diferença estatisticamente significante $(p>0,05)$ para o CIV, quando comparado o tempo a que foi submetido a baixas temperaturas. 


\section{Delta a}

As comparações das médias de Delta a* (2-way ANOVA, Bonferroni, $p<0,05)$, podem ser vistas nas Tabelas 50 a 54 e Gráfico 11.

Tabela 50 - Comparação das alterações de $\left(\Delta \mathrm{a}^{*}\right)$ e desvio padrão, da resina composta e do CIV nas submissões a $2,5^{\circ} \mathrm{C},-20^{\circ} \mathrm{C}$ e $-80^{\circ} \mathrm{C}$, por 7 dias e, entre materiais, nas mesmas temperaturas, analisadas segundo Two-way ANOVA, Bonferroni, $\mathrm{p}<0,05$.

\begin{tabular}{ccc}
\hline \multicolumn{3}{c}{ Delta a } \\
\hline T dias \\
\hline Temperatura & Resina & CIV \\
$2,5^{\circ} \mathrm{C}$ & $1,83 \pm 0,32 \mathrm{bA}$ & $-2,02 \pm 0,79 \mathrm{aA}$ \\
$-20^{\circ} \mathrm{C}$ & $1,15 \pm 0,77 \mathrm{aA}$ & $-0,86 \pm 1,07 \mathrm{bB}$ \\
$-80^{\circ} \mathrm{C}$ & $0,11 \pm 0,58 \mathrm{aB}$ & $-0,14 \pm 1,18 \mathrm{aB}$ \\
\hline
\end{tabular}

Letras diferentes, minúsculas em linha, entre os materiais, e maiúsculas na coluna, para o mesmo material, indicam diferença estatisticamente significante $(\mathrm{p}<0,05)$.

Tabela 51 - Comparação das alterações de cor $\left(\Delta \mathrm{a}^{*}\right)$ e desvio padrão, da resina composta e do CIV nas submissões a $2,5^{\circ} \mathrm{C},-20^{\circ} \mathrm{C}$ e $-80^{\circ} \mathrm{C}$, por 7 dias e, entre os materiais, em diferentes temperaturas, analisadas segundo Two-way ANOVA, Bonferroni $\mathrm{p}<0,05$.

\begin{tabular}{|c|c|c|c|c|c|}
\hline \multicolumn{6}{|c|}{ Delta a } \\
\hline \multicolumn{6}{|c|}{7 dias } \\
\hline \multirow[t]{3}{*}{ Material } & & & \multicolumn{3}{|c|}{ CIV } \\
\hline & \multirow{2}{*}{\multicolumn{2}{|c|}{ Temperatura }} & $2,5^{\circ} \mathrm{C}$ & $-20^{\circ} \mathrm{C}$ & $-80^{\circ} \mathrm{C}$ \\
\hline & & & $-2,02 \pm 0,79$ & $-0,86 \pm 1,07$ & $-0,14 \pm 1,18$ \\
\hline \multirow{3}{*}{$\begin{array}{c}\text { Resina } \\
\text { Composta }\end{array}$} & $2,5^{\circ} \mathrm{C}$ & $1,83 \pm 0,32$ & & $* * * *$ & $* * * *$ \\
\hline & $-20^{\circ} \mathrm{C}$ & $1,15 \pm 0,77$ & $* * * *$ & & $* *$ \\
\hline & $-80^{\circ} \mathrm{C}$ & $0,11 \pm 0,58$ & $* * * *$ & ns & \\
\hline
\end{tabular}

* = Diferença estatisticamente significante $(\mathrm{p}<0,05)$. Quanto maior o número de * nas células, maior a significância da diferença. ns = Não houve diferença estatisticamente significante $(\mathrm{p}>0,05)$. 
Tabela 52 - Comparação das alterações de $\left(\Delta \mathrm{a}^{*}\right)$ e desvio padrão, da resina composta e do CIV nas submissões a $2,5^{\circ} \mathrm{C},-20^{\circ} \mathrm{C}$ e $-80^{\circ} \mathrm{C}$, por 30 dias e, entre materiais, nas mesmas temperaturas, analisadas segundo Two-way ANOVA, Bonferroni, $\mathrm{p}<0,05$.

\begin{tabular}{ccc}
\hline \multicolumn{3}{c}{ Delta a } \\
\hline 30 dias \\
\hline Temperatura & Resina & CIV \\
$2,5^{\circ} \mathrm{C}$ & $3,62 \pm 0,31 \mathrm{aA}$ & $0,67 \pm 0,70 \mathrm{bA}$ \\
$-20^{\circ} \mathrm{C}$ & $3,82 \pm 0,31 \mathrm{aA}$ & $0,91 \pm 0,77 \mathrm{bA}$ \\
$-80^{\circ} \mathrm{C}$ & $2,50 \pm 0,77 \mathrm{aB}$ & $0,90 \pm 1,01 \mathrm{bA}$ \\
\hline
\end{tabular}

Letras diferentes, minúsculas em linha, entre os materiais e, maiúsculas na coluna, para o mesmo material, indicam diferença estatisticamente significante $(\mathrm{p}<0,05)$.

Tabela 53 - Comparação das alterações de cor $\left(\Delta \mathrm{a}^{*}\right)$ e desvio padrão, da resina composta e do CIV nas submissões a $2,5^{\circ} \mathrm{C},-20^{\circ} \mathrm{C}$ e $-80^{\circ} \mathrm{C}$, por 30 dias e, entre os materiais, em diferentes temperaturas, analisadas segundo Two-way ANOVA, Bonferroni $\mathrm{p}<0,05$.

\section{Delta a}

\begin{tabular}{lccccc}
\hline & & \multicolumn{2}{c}{30 dias } & & \\
\hline Material & & & & & \\
& & & & & \\
& Temperatura & & $2,5^{\circ} \mathrm{C}$ & $-20^{\circ} \mathrm{C}$ & $-80^{\circ} \mathrm{C}$ \\
& & & $0,67 \pm 0,70$ & $0,91 \pm 0,77$ & $0,90 \pm 1,01$ \\
Resina & $2,5^{\circ} \mathrm{C}$ & $3,62 \pm 0,31$ & & $* * * *$ & $* * *$ \\
Composta & $-20^{\circ} \mathrm{C}$ & $3,82 \pm 0,31$ & $* * * *$ & & $* * * *$ \\
& $-80^{\circ} \mathrm{C}$ & $2,50 \pm 0,77$ & $* * * *$ & $* * *$ & \\
\hline
\end{tabular}

* = Diferença estatisticamente significante $(\mathrm{p}<0,05)$. Quanto maior o número de * nas células, maior a significância da diferença.

Tabela 54 - Comparação das alterações de cor $\left(\Delta \mathrm{a}^{*}\right)$ e desvio padrão, da resina composta e do CIV, separadamente, nas submissões a $2,5^{\circ} \mathrm{C},-20^{\circ} \mathrm{C}$ e $-80^{\circ} \mathrm{C}$, entre 7 dias e 30 dias, para cada material, analisadas segundo Two-way ANOVA, Bonferroni, $\mathrm{p}<0,05$.

\begin{tabular}{ccc|cc}
\hline \multicolumn{5}{c}{ Delta a } \\
\hline Resina Composta & \multicolumn{2}{c}{ CIV } \\
\hline Temperaturas & 7 dias & 30 dias & 7 dias & 30 dias \\
\hline $2,5^{\circ} \mathrm{C}$ & $1,83 \pm 0,32^{\mathrm{b}}$ & $3,62 \pm 0,31^{\mathrm{a}}$ & $-2,02 \pm 0,79^{\mathrm{a}}$ & $0,67 \pm 0,70^{\mathrm{b}}$ \\
$-20^{\circ} \mathrm{C}$ & $1,15 \pm 0,77^{\mathrm{b}}$ & $3,82 \pm 0,31^{\mathrm{a}}$ & $-0,86 \pm 1,07^{\mathrm{b}}$ & $0,91 \pm 0,77^{\mathrm{a}}$ \\
$-80^{\circ} \mathrm{C}$ & $0,11 \pm 0,58^{\mathrm{b}}$ & $2,50 \pm 0,77^{\mathrm{a}}$ & $-0,14 \pm 1,18^{\mathrm{b}}$ & $0,90 \pm 1,01^{\mathrm{a}}$ \\
\hline
\end{tabular}

Letras diferentes, minúsculas em linha, para cada material, indicam diferença estatisticamente significante $(\mathrm{p}<0,05)$. 
Gráfico 11 - Representação gráfica da comparação de Delta a* entre materiais estéticos submetidos à ação do frio.

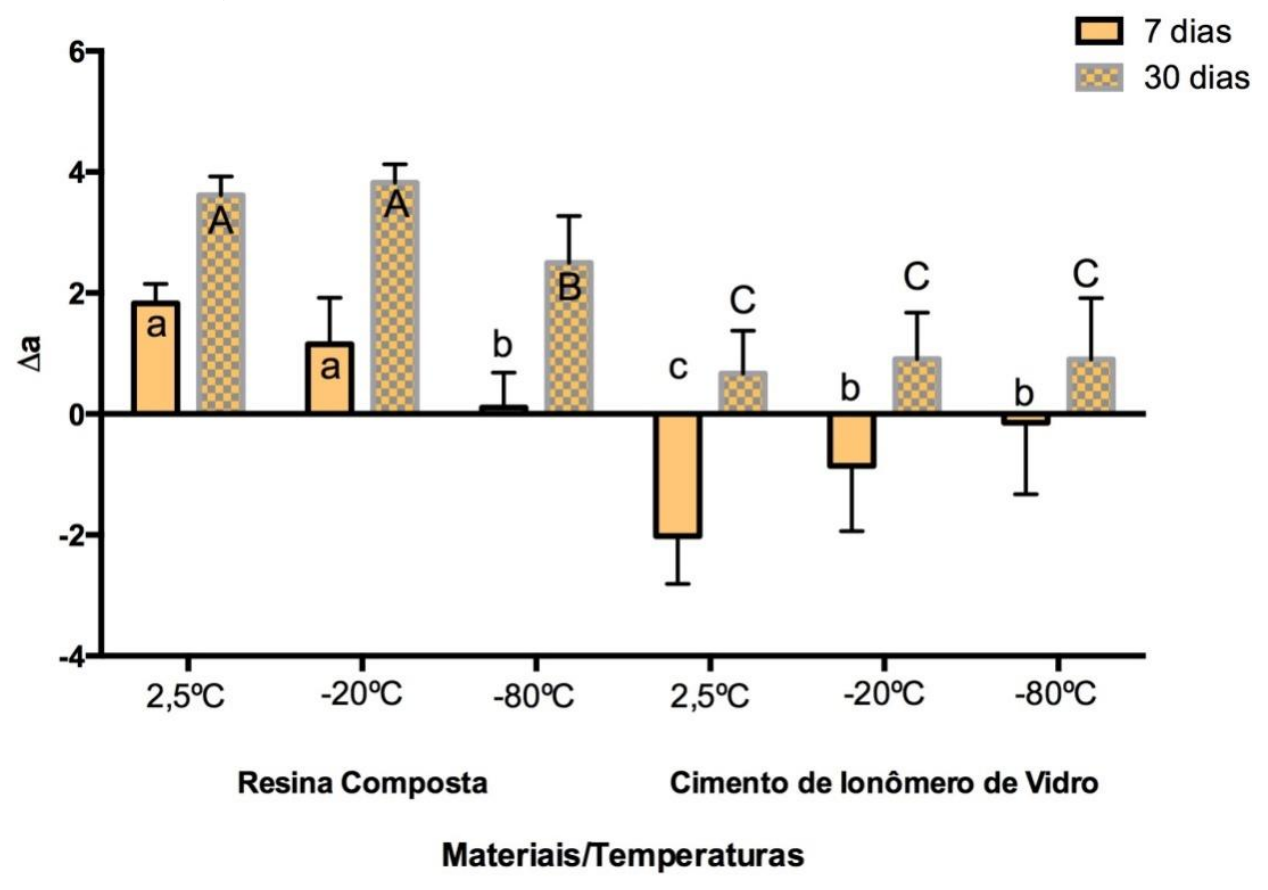

Para todas as comparações entre 7 dias e 30 dias, $p<0,05$. Letras diferentes, minúsculas para 7 dias e maiúsculas para 30 dias, indicam diferença estatisticamente significante $(\mathrm{p}<0,05)$.

Após 7 dias, para a resina composta, a maior alteração da coordenada a* ocorreu após submissão do material a $2,5^{\circ} \mathrm{C}$, resultado diferente $(\mathrm{p}<0,05)$ do ocorrido após submissão a $\left(-80^{\circ} \mathrm{C}\right)$, mas semelhante $(\mathrm{p}>0,05)$ ao observado após $\left(-20^{\circ} \mathrm{C}\right)$. Para o CIV, a maior alteração também ocorreu após $2,5^{\circ} \mathrm{C}$, resultado estatisticamente significante $(\mathrm{p}<0,05)$ em relação às duas outras temperaturas testadas, que não apresentaram diferença $(p>0,05)$ entre si.

A alteração da coordenada $a^{*}$ da resina composta a $\left(-80^{\circ} \mathrm{C}\right)$ foi semelhante $(\mathrm{p}>0,05)$ à ocorrida para o $\mathrm{CIV}$ a $\left(-20^{\circ} \mathrm{C}\right)$ e $\left(-80^{\circ} \mathrm{C}\right)$. Para todas as outras comparações, houve diferença significativa $(\mathrm{p}<0,05)$ nas alterações ocorridas, sendo que a alteração da resina composta foi positiva e do CIV, negativa.

Após 30 dias, não houve diferença significativa $(\mathrm{p}>0,05)$ para CIV em relação às temperaturas a que foi submetido. A resina composta apresentou maior alteração da coordenada a* após submissão a $\left(-20^{\circ} \mathrm{C}\right)$, resultado semelhante $(p>0,05)$ a $2,5^{\circ} \mathrm{C}$, mas diferente de $\left(-80^{\circ} \mathrm{C}\right)$, que apresentou menor alteração da coordenada. 
Quando comparados os comportamentos dos materiais em relação a todas as temperaturas testadas, houve diferença significativa $(\mathrm{p}<0,05)$ para todas as comparações.

Comparando-se os materiais restauradores estéticos em função do tempo a que foram submetidos às baixas temperaturas, observou-se que para ambos, as maiores alterações da coordenada a* ocorreram após 30 dias, para todas as temperaturas testadas, com diferença significativa $(\mathrm{p}<0,05)$ em relação a 7 dias.

\section{Delta b}

As comparações das médias de Delta b* (2-way ANOVA, Bonferroni, p<0,05), podem ser vistas nas Tabelas 55 a 59 e Gráfico 12.

Tabela 55 - Comparação das alterações de $\left(\Delta \mathrm{b}^{*}\right)$ e desvio padrão, da resina composta e do CIV nas submissões a $2,5^{\circ} \mathrm{C},-20^{\circ} \mathrm{C}$ e $-80^{\circ} \mathrm{C}$, por 7 dias e, entre materiais, nas mesmas temperaturas, analisadas segundo Two-way ANOVA, Bonferroni, $\mathrm{p}<0,05$.

\section{Delta b}

\begin{tabular}{ccc}
\hline & $\mathbf{7}$ dias \\
\hline Temperatura & Resina & CIV \\
$2,5^{\circ} \mathrm{C}$ & $3,28 \pm 0,65 \mathrm{aA}$ & $-3,16 \pm 1,90 \mathrm{bA}$ \\
$-20^{\circ} \mathrm{C}$ & $1,73 \pm 1,44 \mathrm{aAB}$ & $-1,47 \pm 2,46 \mathrm{bAB}$ \\
$-80^{\circ} \mathrm{C}$ & $0,54 \pm 1,11^{\mathrm{aB}}$ & $-0,50 \pm 2,95 \mathrm{aB}$ \\
\hline
\end{tabular}

Letras diferentes, minúsculas em linha, entre os materiais, e maiúsculas na coluna, para o mesmo material, indicam diferença estatisticamente significante $(\mathrm{p}<0,05)$.

Tabela 56 - Comparação das alterações de cor $\left(\Delta \mathrm{b}^{*}\right)$ e desvio padrão, da resina composta e do CIV nas submissões a $2,5^{\circ} \mathrm{C},-20^{\circ} \mathrm{C}$ e $-80^{\circ} \mathrm{C}$, por 7 dias e, entre os materiais, em diferentes temperaturas, analisadas segundo Two-way ANOVA, Bonferroni, $\mathrm{p}<0,05$.

\section{Delta b}

\begin{tabular}{cccccc}
\hline \multicolumn{5}{c}{7 dias } \\
\hline Material & & & $\mathrm{CIV}$ & \\
& Temperatura & & $2,5^{\circ} \mathrm{C}$ & $-20^{\circ} \mathrm{C}$ & $-80^{\circ} \mathrm{C}$ \\
& & & $-3,16 \pm 1,90$ & $-1,47 \pm 2,46$ & $-0,50 \pm 2,95$ \\
& $2,5^{\circ} \mathrm{C}$ & $3,28 \pm 0,65$ & & $* * * *$ & $* * *$ \\
Resina & $-20^{\circ} \mathrm{C}$ & $1,73 \pm 1,44$ & $* * * *$ & & $\mathrm{~ns}$ \\
Composta & $-80^{\circ} \mathrm{C}$ & $0,54 \pm 1,11$ & $* * * *$ & $\mathrm{~ns}$ & \\
& & & & \\
\hline
\end{tabular}

**** = Diferença estatisticamente significante $(\mathrm{p}<0,05)$. ns $=$ Não houve diferença estatisticamente significante $(p>0,05)$. 
Tabela 57 - Comparação das alterações de $\left(\Delta \mathrm{b}^{*}\right)$ e desvio padrão, da resina composta e do CIV nas submissões a $2,5^{\circ} \mathrm{C},-20^{\circ} \mathrm{C}$ e $-80^{\circ} \mathrm{C}$, por 30 dias e, entre materiais, nas mesmas temperaturas, analisadas segundo Two-way ANOVA, Bonferroni, $\mathrm{p}<0,05$.

\begin{tabular}{ccc}
\hline & Delta b \\
\hline & $\mathbf{3 0}$ dias \\
\hline Temperatura & Resina & CIV \\
$2,5^{\circ} \mathrm{C}$ & $6,40 \pm 0,64$ aA & $2,96 \pm 1,60 \mathrm{bA}$ \\
$-20{ }^{\circ} \mathrm{C}$ & $6,18 \pm 0,72 \mathrm{aA}$ & $2,69 \pm 1,93 \mathrm{bA}$ \\
$-80^{\circ} \mathrm{C}$ & $4,98 \pm 1,21$ aA & $2,71 \pm 1,76 \mathrm{bA}$ \\
\hline
\end{tabular}

Letras diferentes, minúsculas na linha, entre os materiais, indicam diferença estatisticamente significante $(\mathrm{p}<0,05)$.

Tabela 58 - Comparação das alterações de cor $\left(\Delta \mathrm{b}^{*}\right)$ e desvio padrão, da resina composta e do CIV nas submissões a $2,5^{\circ} \mathrm{C},-20^{\circ} \mathrm{C}$ e $-80^{\circ} \mathrm{C}$, por 30 dias e, entre os materiais, em diferentes temperaturas, analisadas segundo Two-way ANOVA, Bonferroni, $\mathrm{p}<0,05$.

\section{Delta b}

\begin{tabular}{|c|c|c|c|c|c|}
\hline \multicolumn{6}{|c|}{30 dias } \\
\hline \multirow[t]{4}{*}{ Material } & & & & CIV & \\
\hline & Temperatura & & $2,5^{\circ} \mathrm{C}$ & $-20^{\circ} \mathrm{C}$ & $-80^{\circ} \mathrm{C}$ \\
\hline & & & $2,96 \pm 1,60$ & $2,69 \pm 1,93$ & $2,71 \pm 1,76$ \\
\hline & $2,5^{\circ} \mathrm{C}$ & $6,40 \pm 0,64$ & & $* * * *$ & $* * * *$ \\
\hline \multirow[t]{2}{*}{$\begin{array}{c}\text { Resina } \\
\text { Composta }\end{array}$} & $-20^{\circ} \mathrm{C}$ & $6,18 \pm 0,72$ & $* * *$ & & $* * *$ \\
\hline & $-80^{\circ} \mathrm{C}$ & $4,98 \pm 1,21$ & ns & $*$ & \\
\hline
\end{tabular}

* = Diferença estatisticamente significante $(\mathrm{p}<0,05)$. Quanto maior o número de * nas células, maior a significância da diferença. ns = Não houve diferença estatisticamente significante $(p>0,05)$.

Tabela 59 - Comparação das alterações de cor $\left(\Delta \mathrm{b}^{*}\right)$ e desvio padrão, da resina composta e do $\mathrm{CIV}$, separadamente, nas submissões a $2,5^{\circ} \mathrm{C},-20^{\circ} \mathrm{C}$ e $-80^{\circ} \mathrm{C}$, entre 7 dias e 30 dias, para cada material, analisadas segundo Two-way ANOVA, Bonferroni, $\mathrm{p}<0,05$.

\section{Delta b}

\begin{tabular}{ccc|cc}
\hline & \multicolumn{2}{c|}{ Resina Composta } & \multicolumn{2}{c}{ CIV } \\
\hline Temperaturas & 7 dias & 30 dias & 7 dias & 30 dias \\
\hline $2,5^{\circ} \mathrm{C}$ & $3,28 \pm 0,65^{\mathrm{b}}$ & $6,40 \pm 0,64^{\mathrm{a}}$ & $-3,16 \pm 1,90^{\mathrm{a}}$ & $2,96 \pm 1,60^{\mathrm{b}}$ \\
$-20^{\circ} \mathrm{C}$ & $1,73 \pm 1,44^{\mathrm{b}}$ & $6,18 \pm 0,72^{\mathrm{a}}$ & $-1,47 \pm 2,46^{\mathrm{b}}$ & $2,69 \pm 1,93^{\mathrm{a}}$ \\
$-80^{\circ} \mathrm{C}$ & $0,54 \pm 1,11^{\mathrm{b}}$ & $4,98 \pm 1,21^{\mathrm{a}}$ & $-0,50 \pm 2,95^{\mathrm{b}}$ & $2,71 \pm 1,76^{\mathrm{a}}$ \\
\hline
\end{tabular}

Letras diferentes, minúsculas em linha, para cada material, indicam diferença estatisticamente significante $(\mathrm{p}<0,05)$. 
Gráfico 12 - Representação gráfica da comparação de Delta b* entre materiais estéticos submetidos à ação do frio.

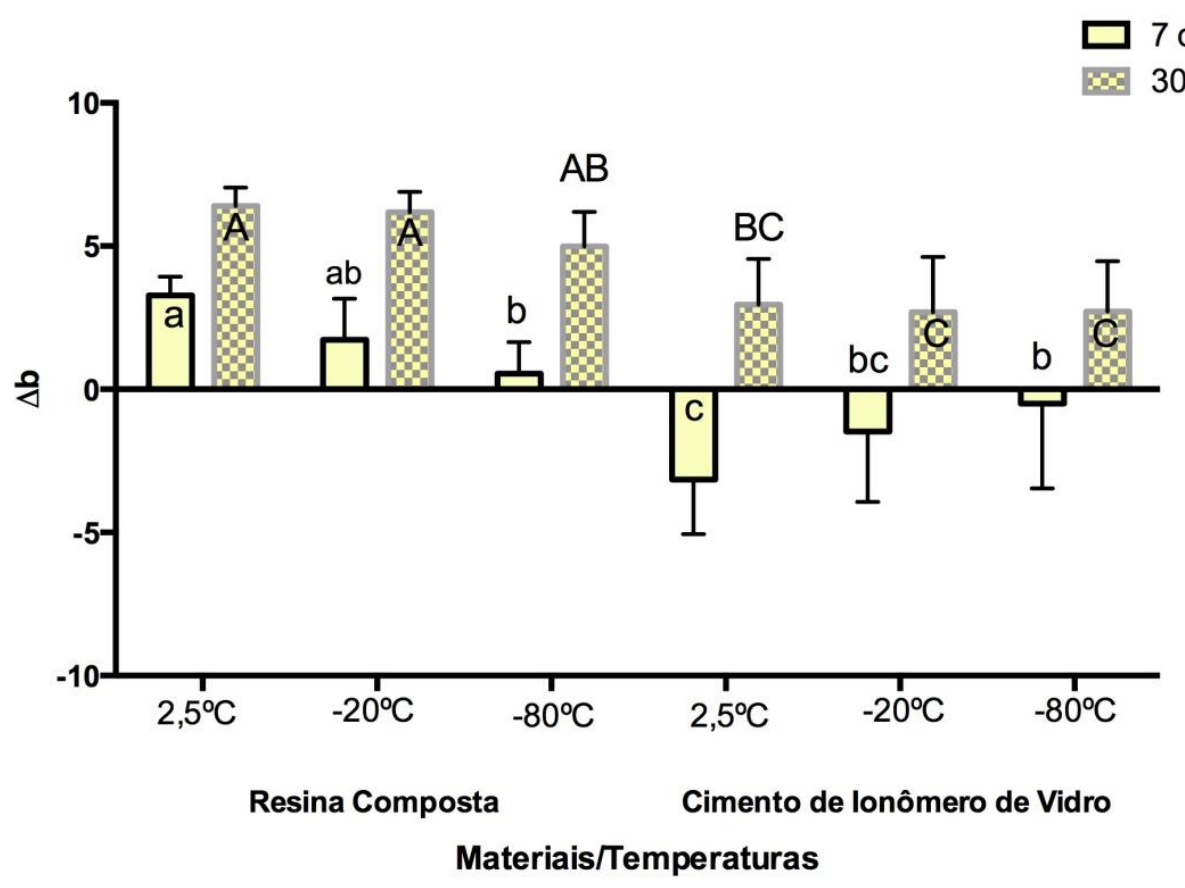

Para todas as comparações entre 7 dias e 30 dias, p<0,05. Letras diferentes, minúsculas para 7 dias e maiúsculas para 30 dias, indicam diferença estatisticamente significante $(\mathrm{p}<0,05)$.

A comparação dos materiais em relação às temperaturas a que foram submetidos permitiu verificar que, após 7 dias, a alteração da coordenada $b^{*}$ foi maior quanto maior a temperatura a que foi submetido, sendo que ambos os materiais apresentaram mais alterações na coordenada ao serem submetidos a $2,5^{\circ} \mathrm{C}$, resultado semelhante $(p>0,05)$ aos encontrados para os materiais submetidos a $\left(-20^{\circ} \mathrm{C}\right)$ e diferente estatisticamente $(\mathrm{p}<0,05)$ em relação aos materiais submetidos a $\left(-80^{\circ} \mathrm{C}\right)$.

Apesar de apresentarem comportamento semelhante em relação às temperaturas a que foram submetidos, a resina composta apresentou alteração da coordenada b* oposta a que o CIV apresentou, ou seja, enquanto para a resina a coordenada teve uma alteração positiva, para o CIV ocorreram valores negativos, resultados estatisticamente significantes $(\mathrm{p}<0,05)$ para todas as temperaturas testadas.

Quando realizada as diversas comparações entre materiais e temperaturas, observou-se que os resultados da resina composta submetida a $\left(-20^{\circ} \mathrm{C}\right)$ não apresenta diferença $(p>0,05)$ em relação ao CIV submetido a $\left(-80^{\circ} \mathrm{C}\right)$. 0 mesmo $(p<0,05)$ ocorre para $\mathrm{CIV}\left(-20^{\circ} \mathrm{C}\right)$ em relação à resina composta $\left(-80^{\circ} \mathrm{C}\right)$ e entre a resina e o $\mathrm{CIV}$ a $\left(-80^{\circ} \mathrm{C}\right)$. 
Após 30 dias, as temperaturas a que os materiais foram submetidos não foram significantes $(p>0,05)$ para alteração da coordenada $b^{*}$; manteve-se, entretanto, a diferença $(p<0,05)$ entre os materiais em todas as temperaturas testadas, sendo maior para resina composta. 0 comportamento da resina composta, quando submetida a $\left(-80^{\circ} \mathrm{C}\right)$ foi semelhante $(\mathrm{p}>0,05)$ ao $\mathrm{CIV}$ submetido a $2,5^{\circ} \mathrm{C}$. Para todas as demais comparações entre as diferentes temperaturas, houve diferença significativa $(p<0,05)$.

Comparando a alteração da coordenada $b^{*}$ para cada material em relação ao tempo a que foram submetidos à baixas temperaturas, verificou-se que, para ambos os materiais, as maiores alterações ocorreram após 30 dias, resultados estatisticamente significante $(p<0,05)$ em relação aos encontrados após 7 dias independente da temperatura a que foram submetidos.

\subsubsection{Rugosidade de superfície}

Os valores das leituras da rugosidade de superfície, das respectivas médias, antes e após a ação do frio, além das alterações de rugosidade $(\Delta \mathrm{Ra})$, transcorridos 7 dias e 30 dias, obtidos para os materiais estéticos (resina composta e CIV) e amálgama, estão apresentados respectivamente nas Tabelas 60 a 68.

Tabela 60 - Valores da rugosidade de superfície $(\mathrm{Ra})$, das respectivas médias e desvio padrão, antes (Ra inicial) e após 7 dias e 30 dias de exposição ao frio e das alterações de rugosidade $(\Delta \mathrm{Ra})$ ocorridas nesses tempos após submissão da resina composta a $2,5^{\circ} \mathrm{C}$.

\section{Resina Composta}

$2,5^{\circ} \mathrm{C}$

\begin{tabular}{|c|c|c|c|c|c|}
\hline & Ra (Inicial) & Ra (7 dias) & Ra (30 dias) & $\Delta \operatorname{Ra}(7$ dias) & $\Delta \mathrm{Ra}$ (30dias) \\
\hline & 0,31 & 0,06 & 0,42 & $-0,25$ & 0,11 \\
\hline & 0,81 & 0,32 & 0,33 & $-0,49$ & $-0,48$ \\
\hline & 1,12 & 0,89 & 0,34 & $-0,23$ & $-0,78$ \\
\hline & 0,29 & 0,26 & 0,34 & $-0,03$ & 0,04 \\
\hline & 0,36 & 0,21 & 0,26 & $-0,15$ & $-0,10$ \\
\hline & 0,08 & 0,20 & 0,03 & 0,11 & $-0,05$ \\
\hline & 0,56 & 0,29 & 0,27 & $-0,27$ & $-0,29$ \\
\hline & 0,30 & 0,24 & 0,41 & $-0,06$ & 0,11 \\
\hline & 0,03 & 0,07 & 0,05 & 0,04 & 0,02 \\
\hline & 0,18 & 0,24 & 0,25 & 0,06 & 0,08 \\
\hline Média & 0,40 & 0,28 & 0,27 & $-0,13$ & $-0,13$ \\
\hline Desvio padrão & $(0,34)$ & $(0,23)$ & $(0,13)$ & $(0,19)$ & $(0,30)$ \\
\hline
\end{tabular}


Tabela 61 - Valores da rugosidade de superfície (Ra), das respectivas médias e desvio padrão, antes (Ra inicial) e após 7 dias e 30 dias de exposição ao frio e das alterações de rugosidade $(\Delta \mathrm{Ra})$ ocorridas nesses tempos após submissão da resina composta a $-20^{\circ} \mathrm{C}$.

\section{Resina Composta}

$-20^{\circ} \mathrm{C}$

\begin{tabular}{cccccc}
\hline & Ra (Inicial) & Ra (7 dias) & Ra (30 dias) & $\boldsymbol{\Delta R a ~ ( 7 ~ d i a s ) ~}$ & $\boldsymbol{\Delta R a ~ ( 3 0 d i a s ) ~}$ \\
\hline 0,24 & 0,19 & 0,27 & $-0,05$ & 0,03 \\
0,03 & 0,07 & 0,10 & 0,04 & 0,07 \\
0,03 & 0,04 & 0,07 & 0,01 & 0,04 \\
0,04 & 0,04 & 0,05 & 0,00 & 0,01 \\
& 0,05 & 0,21 & 0,10 & 0,16 & 0,05 \\
& 0,23 & 0,21 & 0,18 & $-0,03$ & $-0,06$ \\
& 0,13 & 0,06 & 0,06 & $-0,07$ & $-0,07$ \\
& 1,08 & 0,55 & 0,58 & $-0,53$ & $-0,5$ \\
& 1,36 & 0,29 & 0,24 & $-1,07$ & $-1,12$ \\
Média & 0,62 & 0,51 & 0,50 & $-0,12$ & $-0,12$ \\
\hline Desvio padrão & $\mathbf{0 , 3 8}$ & $\mathbf{0 , 2 2}$ & $\mathbf{0 , 2 1}$ & $\mathbf{- 0 , 1 7}$ & $\mathbf{- 0 , 1 7}$ \\
& $\mathbf{0 , 4 8 )}$ & $\mathbf{0 , 1 9}$ & $\mathbf{( 0 , 1 9 )}$ & $\mathbf{( 0 , 3 6 )}$ & $\mathbf{( 0 , 3 7 )}$
\end{tabular}

Tabela 62 - Valores da rugosidade de superfície (Ra), das respectivas médias e desvio padrão, antes (Ra inicial) e após 7 dias e 30 dias de exposição ao frio e das alterações de rugosidade $(\Delta \mathrm{Ra})$ ocorridas nesses tempos após submissão da resina composta a $-80^{\circ} \mathrm{C}$.

$-80^{\circ} \mathrm{C}$

\begin{tabular}{|c|c|c|c|c|c|}
\hline & Ra (Inicial) & Ra (7 dias) & Ra (30 dias) & $\Delta \operatorname{Ra}(7$ dias $)$ & $\Delta \mathrm{Ra}$ (30dias) \\
\hline & 1,63 & 1,24 & 1,68 & $-0,39$ & 0,06 \\
\hline & 0,74 & 0,66 & 0,73 & $-0,08$ & $-0,01$ \\
\hline & 0,81 & 0,71 & 0,78 & $-0,11$ & $-0,03$ \\
\hline & 0,54 & 0,50 & 0,41 & $-0,03$ & $-0,12$ \\
\hline & 0,78 & 0,79 & 0,91 & 0,01 & 0,13 \\
\hline & 0,88 & 0,49 & 0,66 & $-0,39$ & $-0,22$ \\
\hline & 0,59 & 0,54 & 0,50 & $-0,04$ & $-0,08$ \\
\hline & 0,70 & 0,49 & 0,63 & $-0,22$ & $-0,08$ \\
\hline & 0,53 & 0,31 & 0,51 & $-0,23$ & $-0,02$ \\
\hline & 0,77 & 0,74 & 0,64 & $-0,03$ & $-0,13$ \\
\hline Média & 0,80 & 0,65 & 0,75 & $-0,15$ & $-0,05$ \\
\hline Desvio padrão & $(0,31)$ & $(0,25)$ & $(0,36)$ & $(0,15)$ & $(0,10)$ \\
\hline
\end{tabular}


Tabela 63 - Valores da rugosidade de superfície (Ra), das respectivas médias e desvio padrão, antes (Ra inicial) e após 7 dias e 30 dias de exposição ao frio e das alterações de rugosidade $(\Delta \mathrm{Ra})$ ocorridas nesses tempos após submissão do CIV a $2,5^{\circ} \mathrm{C}$.

\section{Cimento de Ionômero de Vidro}

$2,5^{\circ} \mathrm{C}$

\begin{tabular}{|c|c|c|c|c|c|}
\hline & Ra (Inicial) & Ra (7 dias) & Ra (30 dias) & $\Delta \operatorname{Ra}(7$ dias $)$ & $\Delta \operatorname{Ra}(30$ dias) \\
\hline & 1,99 & 2,65 & 2,68 & 0,67 & 0,69 \\
\hline & 1,67 & 2,42 & 2,17 & 0,74 & 0,50 \\
\hline & 1,97 & 2,30 & 2,98 & 0,33 & 1,01 \\
\hline & 1,71 & 1,13 & 1,37 & $-0,58$ & $-0,35$ \\
\hline & 0,96 & 1,23 & 1,24 & 0,27 & 0,28 \\
\hline & 2,08 & 2,10 & 2,11 & 0,02 & 0,03 \\
\hline & 2,01 & 2,16 & 1,85 & 0,15 & $-0,15$ \\
\hline & 3,13 & 2,30 & 2,96 & $-0,83$ & $-0,17$ \\
\hline & 0,73 & 0,86 & 1,05 & 0,12 & 0,32 \\
\hline & 1,67 & 1,49 & 1,37 & $-0,18$ & $-0,30$ \\
\hline Média & 1,79 & 1,86 & 1,98 & 0,07 & 0,19 \\
\hline Desvio padrão & $(0,65)$ & $(0,63)$ & $(0,72)$ & $(0,50)$ & $(0,45)$ \\
\hline
\end{tabular}

Tabela 64 - Valores da rugosidade de superfície (Ra), das respectivas médias e desvio padrão, antes (Ra inicial) e após 7 dias e 30 dias de exposição ao frio e das alterações de rugosidade $(\Delta \mathrm{Ra})$ ocorridas nesses tempos após submissão do CIV a $-20^{\circ} \mathrm{C}$.

\begin{tabular}{|c|c|c|c|c|c|}
\hline & \multicolumn{5}{|c|}{$\begin{array}{l}\text { Cimento de Ionômero de Vidro } \\
\qquad-20^{\circ} \mathrm{C}\end{array}$} \\
\hline & Ra (Inicial) & $\operatorname{Ra}(7$ dias) & Ra (30 dias) & $\Delta \mathrm{Ra}(7$ dias) & $\Delta \operatorname{Ra}(30$ dias) \\
\hline & 1,59 & 1,79 & 1,88 & 0,19 & 0,28 \\
\hline & 0,88 & 0,94 & 0,89 & 0,06 & 0,00 \\
\hline & 1,22 & 1,23 & 1,30 & 0,01 & 0,09 \\
\hline & 1,86 & 2,25 & 2,14 & 0,38 & 0,28 \\
\hline & 1,49 & 1,74 & 1,52 & 0,24 & 0,02 \\
\hline & 1,36 & 1,06 & 1,18 & $-0,30$ & $-0,18$ \\
\hline & 2,18 & 1,76 & 2,02 & $-0,42$ & $-0,16$ \\
\hline & 1,30 & 1,34 & 1,31 & 0,05 & 0,01 \\
\hline & 1,71 & 1,82 & 2,04 & 0,11 & 0,33 \\
\hline & 1,53 & 1,46 & 1,87 & $-0,07$ & 0,35 \\
\hline $\begin{array}{c}\text { Média } \\
\text { Desvio padrão }\end{array}$ & $\begin{array}{c}1,51 \\
(0,36)\end{array}$ & $\begin{array}{l}1,54 \\
(0,40)\end{array}$ & $\begin{array}{c}1,61 \\
(0,43)\end{array}$ & $\begin{array}{c}0,03 \\
(0,24)\end{array}$ & $\begin{array}{c}0,10 \\
(0,20)\end{array}$ \\
\hline
\end{tabular}


Tabela 65 - Valores da rugosidade de superfície (Ra), das respectivas médias e desvio padrão, antes (Ra inicial) e após 7 dias e 30 dias de exposição ao frio e das alterações de rugosidade $(\Delta \mathrm{Ra})$ ocorridas nesses tempos após submissão do CIV a $-80^{\circ} \mathrm{C}$.

\section{Cimento de Ionômero de Vidro}

$-80^{\circ} \mathrm{C}$

\begin{tabular}{cccccc}
\hline & Ra (Inicial) & $\mathbf{R a}(\mathbf{7}$ dias) & $\mathbf{R a}(\mathbf{3 0}$ dias) & $\boldsymbol{\Delta R a ( 7 \text { dias) }}$ & $\boldsymbol{\Delta R a ( 3 0 d i a s )}$ \\
\hline 3,48 & 3,19 & 3,10 & $-0,19$ & $-0,38$ \\
& 0,96 & 0,98 & 0,99 & 0,02 & 0,03 \\
0,97 & 1,27 & 1,26 & 0,30 & 0,29 \\
& 0,60 & 1,97 & 1,61 & 1,37 & 1,01 \\
& 2,30 & 2,27 & 2,26 & $-0,04$ & $-0,04$ \\
& 1,49 & 1,54 & 1,45 & 0,05 & $-0,04$ \\
& 2,51 & 2,49 & 2,45 & $-0,02$ & $-0,06$ \\
& 0,80 & 1,05 & 2,12 & 0,25 & 1,31 \\
& 0,71 & 0,51 & 0,78 & $-0,20$ & 0,07 \\
Mesvídia & 0,63 & 1,03 & 1,04 & 0,40 & 0,41 \\
\hline $\mathbf{1 , 4 5}$ & $\mathbf{1 , 6 3}$ & $\mathbf{1 , 7 1}$ & $\mathbf{0 , 1 8}$ & $\mathbf{0 , 2 6}$ \\
& $\mathbf{0 , 9 9}$ & $\mathbf{0 , 8 3}$ & $\mathbf{0 , 7 5})$ & $\mathbf{0 , 4 7})$ & $\mathbf{( 0 , 5 2 )}$
\end{tabular}

Tabela 66 - Valores da rugosidade de superfície (Ra), das respectivas médias e desvio padrão, antes (Ra inicial) e após 7 dias e 30 dias de exposição ao frio e das alterações de rugosidade $(\Delta \mathrm{Ra})$ ocorridas nesses tempos após submissão do amálgama a $2,5^{\circ} \mathrm{C}$.

\begin{tabular}{|c|c|c|c|c|c|}
\hline & \multicolumn{5}{|c|}{$\begin{array}{c}\text { Amálgama } \\
2,5^{\circ} \mathrm{C}\end{array}$} \\
\hline & Ra (Inicial) & Ra (7 dias) & Ra (30 dias) & $\Delta \operatorname{Ra}(7$ dias $)$ & $\Delta R a(30 d i a s)$ \\
\hline & 1,30 & 1,13 & 1,13 & $-0,17$ & $-0,18$ \\
\hline & 1,86 & 1,60 & 1,96 & $-0,26$ & 0,10 \\
\hline & 2,23 & 2,31 & 2,35 & 0,08 & 0,12 \\
\hline & 1,56 & 1,38 & 1,15 & $-0,18$ & $-0,41$ \\
\hline & 1,35 & 1,38 & 1,50 & 0,03 & 0,15 \\
\hline & 1,19 & 1,34 & 1,20 & 0,15 & 0,01 \\
\hline & 0,94 & 1,05 & 0,95 & 0,11 & 0,01 \\
\hline & 1,83 & 2,22 & 2,21 & 0,40 & 0,39 \\
\hline & 1,24 & 1,04 & 0,94 & 0,16 & $-0,30$ \\
\hline & 1,13 & 1,24 & 1,47 & 0,11 & 0,34 \\
\hline $\begin{array}{c}\text { Média } \\
\text { Doñ }\end{array}$ & 1,46 & 1,51 & 1,49 & 0,04 & 0,02 \\
\hline
\end{tabular}


Tabela 67 - Valores da rugosidade de superfície (Ra), das respectivas médias e desvio padrão, antes (Ra inicial) e após 7 dias e 30 dias de exposição ao frio e das alterações de rugosidade $(\Delta \mathrm{Ra})$ ocorridas nesses tempos após submissão do amálgama a $-20^{\circ} \mathrm{C}$.

\section{Amálgama}

$-20^{\circ} \mathrm{C}$

\begin{tabular}{cccccc}
\hline & Ra (Inicial) & Ra (7 dias) & Ra (30 dias) & $\boldsymbol{\Delta R a ~ ( 7 ~ d i a s ) ~}$ & $\boldsymbol{\Delta R a ~ ( 3 0 d i a s ) ~}$ \\
\hline 1,92 & 2,54 & 1,74 & 0,62 & $-0,17$ \\
1,13 & 1,07 & 1,35 & $-0,06$ & 0,22 \\
1,85 & 1,62 & 1,44 & $-0,23$ & $-0,41$ \\
1,29 & 1,42 & 1,28 & 0,13 & $-0,01$ \\
& 0,93 & 0,94 & 1,06 & 0,01 & 0,14 \\
& 1,51 & 1,31 & 1,34 & $-0,20$ & $-0,17$ \\
& 1,62 & 1,43 & 1,55 & $-0,19$ & $-0,07$ \\
& 1,68 & 1,74 & 1,76 & 0,06 & 0,08 \\
& 1,61 & 1,51 & 1,66 & $-0,09$ & 0,05 \\
Média & 2,67 & 1,61 & 1,76 & $-1,07$ & $-0,91$ \\
\hline Desvio padrão & $\mathbf{1 , 6 2}$ & $\mathbf{1 , 5 2}$ & $\mathbf{1 , 4 9}$ & $\mathbf{- 0 , 1 0}$ & $\mathbf{- 0 , 1 3}$ \\
& $\mathbf{( 0 , 4 8 )}$ & $\mathbf{( 0 , 4 3 )}$ & $\mathbf{( 0 , 2 4 )}$ & $\mathbf{( 0 , 4 2 )}$ & $\mathbf{( 0 , 3 3 )}$
\end{tabular}

Tabela 68 - Valores da rugosidade de superfície (Ra), das respectivas médias e desvio padrão, antes (Ra inicial) e após 7 dias e 30 dias de exposição ao frio e das alterações de rugosidade $(\Delta \mathrm{Ra})$ ocorridas nesses tempos após submissão do amálgama a $-80^{\circ} \mathrm{C}$.

\begin{tabular}{|c|c|c|c|c|c|}
\hline & & & $\begin{array}{c}\text { Amálgama } \\
-80^{\circ} \mathrm{C}\end{array}$ & & \\
\hline & Ra (Inicial) & $\operatorname{Ra}(7$ dias) & Ra (30 dias) & $\Delta \operatorname{Ra}(7$ dias $)$ & $\Delta \mathrm{Ra}(30$ dias) \\
\hline & 2,05 & 1,91 & 1,95 & $-0,13$ & $-0,09$ \\
\hline & 2,01 & 1,80 & 1,92 & $-0,21$ & $-0,09$ \\
\hline & 1,43 & 1,60 & 1,39 & 0,17 & $-0,04$ \\
\hline & 0,83 & 0,67 & 1,10 & $-0,16$ & 0,36 \\
\hline & 0,91 & 1,01 & 1,06 & 0,10 & 0,15 \\
\hline & 0,66 & 0,61 & 0,67 & $-0,05$ & 0,01 \\
\hline & 0,60 & 0,73 & 0,70 & 0,13 & 0,10 \\
\hline & 0,85 & 0,80 & 0,61 & $-0,06$ & $-0,24$ \\
\hline & 0,65 & 0,50 & 0,38 & $-0,15$ & $-0,27$ \\
\hline & 0,68 & 0,51 & 0,53 & $-0,17$ & $-0,16$ \\
\hline Média & 1,07 & 1,02 & 1,04 & $-0,05$ & $-0,03$ \\
\hline Desvio padrão & $(0,56)$ & $(0,55)$ & $(0,57)$ & $(0,14)$ & $(0,19)$ \\
\hline
\end{tabular}

As comparações das médias de alteração de rugosidade (2-way ANOVA, Bonferroni, $\mathrm{p}<0,05$ ) da resina composta e CIV podem ser vistas nas Tabelas 69 a 71 e Gráfico 13. 
Tabela 69 - Comparação das alterações de rugosidade de superfície $(\Delta \mathrm{Ra})$ e desvio padrão, da resina composta e do CIV nas submissões a $2,5^{\circ} \mathrm{C},-20^{\circ} \mathrm{C}$ e $-80^{\circ} \mathrm{C}$, por 7 dias e 30 dias e, entre os materiais, nas mesmas temperaturas, analisadas segundo Two-way ANOVA, Bonferroni, $\mathrm{p}<0,05$.

\section{Rugosidade de superfície}

\begin{tabular}{cccc}
\hline Tempos & Temperaturas & Resina & CIV \\
\hline \multirow{3}{*}{7 dias } & $2,5^{\circ} \mathrm{C}$ & $-0,13 \pm 0,19 \mathrm{aA}$ & $0,07 \pm 0,50 \mathrm{aA}$ \\
& $-20^{\circ} \mathrm{C}$ & $-0,17 \pm 0,36 \mathrm{aA}$ & $0,03 \pm 0,24 \mathrm{aA}$ \\
& $-80^{\circ} \mathrm{C}$ & $-0,15 \pm 0,15 \mathrm{aA}$ & $0,18 \pm 0,47 \mathrm{aA}$ \\
\hline \multirow{3}{*}{30 dias } & $2,5^{\circ} \mathrm{C}$ & $-0,13 \pm 0,30 \mathrm{aA}$ & $0,19 \pm 0,45 \mathrm{aA}$ \\
& $-20^{\circ} \mathrm{C}$ & $-0,17 \pm 0,37 \mathrm{aA}$ & $0,10 \pm 0,20 \mathrm{aA}$ \\
& $-80^{\circ} \mathrm{C}$ & $-0,05 \pm 0,10 \mathrm{aA}$ & $0,26 \pm 0,52 \mathrm{aA}$ \\
\hline
\end{tabular}

Para todas as comparações, em linha, entre os materiais, e na coluna para o mesmo material, não houve diferença estatisticamente significante $(p>0,05)$.

Tabela 70 - Comparação das alterações de rugosidade de superfície ( $\Delta \mathrm{Ra}$ ) e desvio padrão, da resina composta e do CIV nas submissões a $2,5^{\circ} \mathrm{C},-20^{\circ} \mathrm{C}$ e $-80^{\circ} \mathrm{C}$ por 7 dias e, entre os materiais, em diferentes temperaturas, analisadas segundo Two-way ANOVA, Bonferroni, $\mathrm{p}<0,05$.

\section{Rugosidade de superfície}

\begin{tabular}{cccccc}
\hline \multicolumn{5}{c}{7 dias } \\
\hline Material & & & $\mathrm{CIV}$ & \\
& Temperatura & & $2,5^{\circ} \mathrm{C}$ & $-20^{\circ} \mathrm{C}$ & $-80^{\circ} \mathrm{C}$ \\
& & & $0,07 \pm 0,50$ & $0,03 \pm 0,24$ & $0,18 \pm 0,47$ \\
& $2,5^{\circ} \mathrm{C}$ & $-0,13 \pm 0,19$ & & ns & ns \\
Resina & $-20^{\circ} \mathrm{C}$ & $-0,17 \pm 0,36$ & ns & & ns \\
Composta & $-80^{\circ} \mathrm{C}$ & $-0,15 \pm 0,15$ & ns & ns & \\
& & & &
\end{tabular}

ns = Não houve diferença estatisticamente significante $(\mathrm{p}>0,05)$.

Tabela 71 - Comparação das alterações de rugosidade de superfície ( $\Delta \mathrm{Ra}$ ) e desvio padrão, da resina composta e do CIV nas submissões a $2,5^{\circ} \mathrm{C},-20^{\circ} \mathrm{C}$ e $-80^{\circ} \mathrm{C}$ por 30 dias e, entre os materiais, em diferentes temperaturas, analisadas segundo Two-way ANOVA, Bonferroni, $\mathrm{p}<0,05$.

\section{Rugosidade de superfície}

\section{0 dias}

\begin{tabular}{|c|c|c|c|c|c|}
\hline \multirow[t]{3}{*}{ Material } & & & \multicolumn{3}{|c|}{ CIV } \\
\hline & \multirow{2}{*}{\multicolumn{2}{|c|}{ Temperatura }} & $2,5^{\circ} \mathrm{C}$ & $-20^{\circ} \mathrm{C}$ & $-80^{\circ} \mathrm{C}$ \\
\hline & & & $0,19 \pm 0,45$ & $0,10 \pm 0,20$ & $0,26 \pm 0,52$ \\
\hline \multirow{3}{*}{$\begin{array}{c}\text { Resina } \\
\text { Composta }\end{array}$} & $2,5^{\circ} \mathrm{C}$ & $-0,13 \pm 0,30$ & & ns & ns \\
\hline & $-20^{\circ} \mathrm{C}$ & $-0,17 \pm 0,37$ & ns & & ns \\
\hline & $-80^{\circ} \mathrm{C}$ & $-0,05 \pm 0,10$ & ns & ns & \\
\hline
\end{tabular}

ns = Não houve diferença estatisticamente significante $(p>0,05)$. 
Gráfico 13 - Representação gráfica da comparação das alterações de rugosidade de superfície $(\Delta \mathrm{Ra})$ dos materiais restauradores estéticos submetidos à ação do frio.

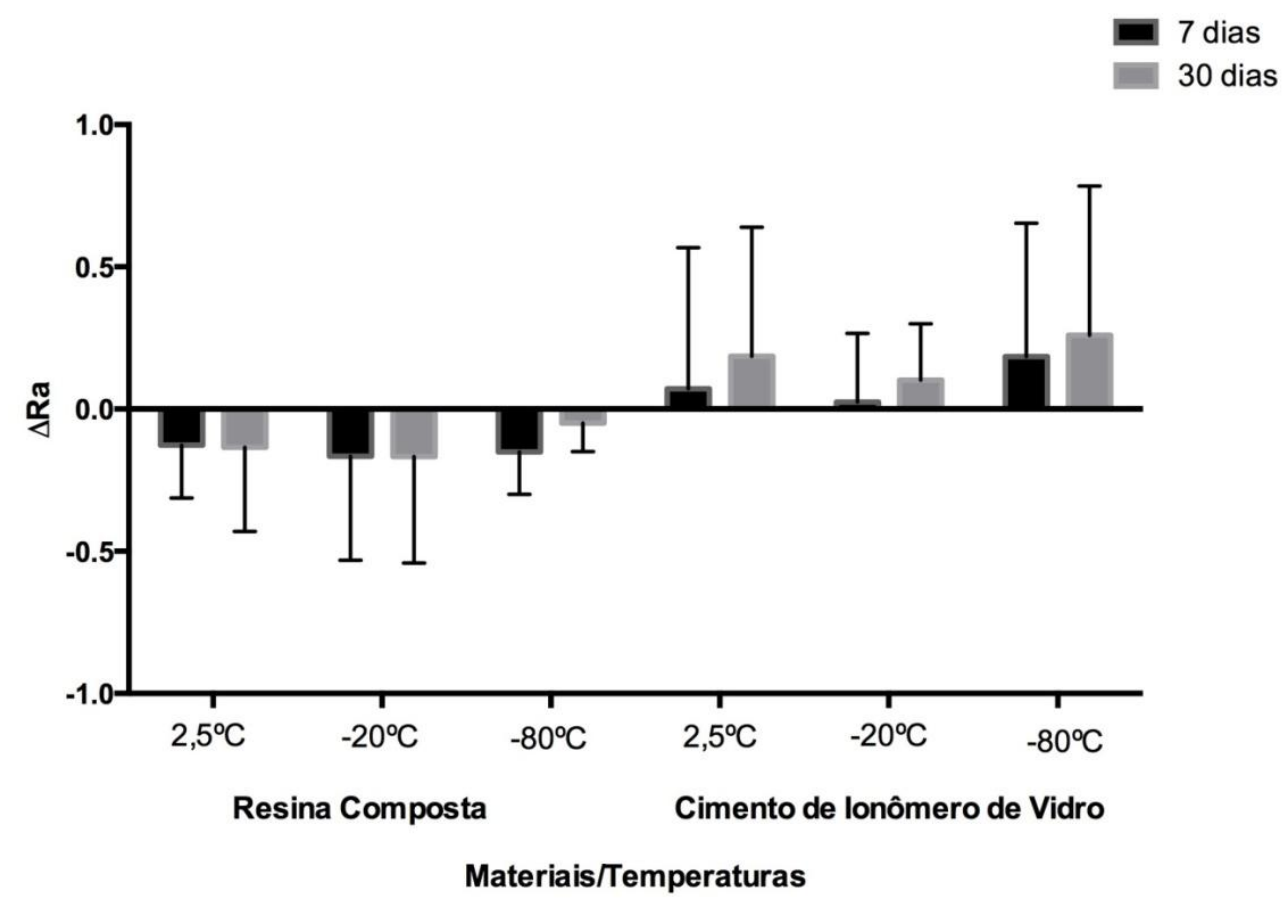

Para todas as comparações, $\mathrm{p}>0,05$.

As comparações das médias de alteração de rugosidade (2-way ANOVA, Bonferroni, p<0,05) do amálgama podem ser vistas na Tabela 72 e Gráfico 14.

Tabela 72 - Comparação das alterações de rugosidade de superfície $(\Delta \mathrm{Ra})$ e desvio padrão, do amálgama nas submissões a $2,5^{\circ} \mathrm{C},-20^{\circ} \mathrm{C}$ e $-80^{\circ} \mathrm{C}$, por 7 dias e 30 dias, analisadas segundo Twoway ANOVA, Bonferroni, $\mathrm{p}<0,05$.

\section{Rugosidade de superfície}

\begin{tabular}{ccc}
\hline & Amálgama \\
\hline Temperaturas & 7 dias & 30 dias \\
\hline $2,5^{\circ} \mathrm{C}$ & $0,04 \pm 0,20 \mathrm{aA}$ & $0,02 \pm 0,26 \mathrm{aA}$ \\
$-20^{\circ} \mathrm{C}$ & $-0,10 \pm 0,42 \mathrm{aA}$ & $-0,13 \pm 0,33 \mathrm{aA}$ \\
$-80^{\circ} \mathrm{C}$ & $-0,05 \pm 0,14 \mathrm{aA}$ & $-0,03 \pm 0,19 \mathrm{aA}$ \\
\hline
\end{tabular}

Para todas as comparações, em linhas e colunas para o amálgama, não houve diferença estatisticamente significante $(\mathrm{p}>0,05)$. 
Gráfico 14 - Representação gráfica das alterações de rugosidade de superfície $(\Delta \mathrm{Ra})$ das restaurações de amálgama submetidas à ação do frio.

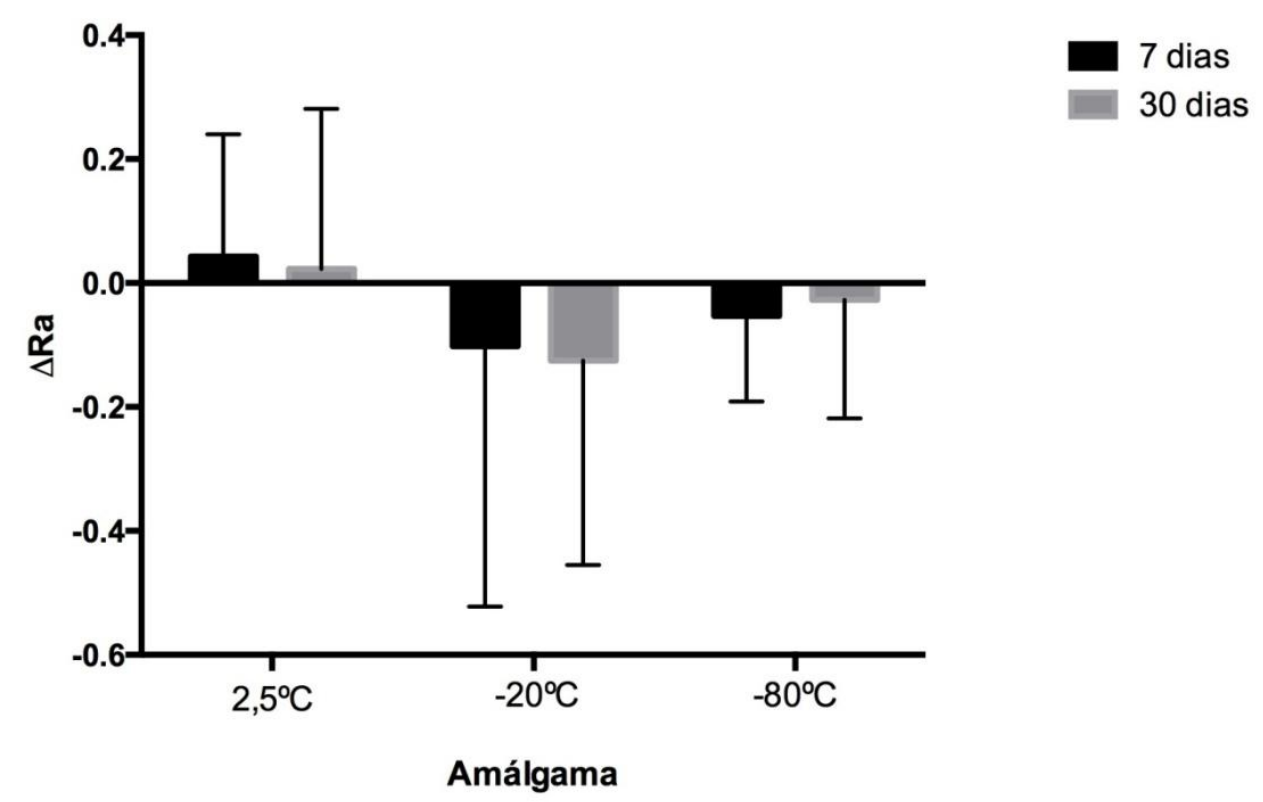

Para todas as comparações, $\mathrm{p}>0,05$.

Os resultados obtidos com as restaurações em resina composta, CIV e amálgama após submissão às baixas temperaturas demonstraram que não ocorreram alterações de rugosidade de superfície estatisticamente significantes $(p>0,05)$ nos três materiais restauradores após 7 e 30 dias, independente da temperatura.

\subsubsection{Microdureza}

Os valores das leituras da microdureza Knoop, das respectivas médias, antes e após a ação do frio, além das alterações da microdureza $(\Delta \mathrm{KHN})$, transcorridos 7 dias e 30 dias, obtidos para os materiais estéticos (resina composta e CIV) e amálgama, estão apresentados respectivamente nas tabelas 73 a 81. 
Tabela 73 - Valores da microdureza Knoop (KHN), das respectivas médias e desvio padrão, antes (KHN inicial) e após 7 dias e 30 dias de exposição ao frio e das alterações da microdureza $(\triangle \mathrm{KHN})$ nesses tempos após submissão da resina composta a $2,5^{\circ} \mathrm{C}$.

\begin{tabular}{|c|c|c|c|c|c|}
\hline & \multicolumn{5}{|c|}{$\begin{array}{c}\text { Resina Composta } \\
2,5^{\circ} \mathrm{C}\end{array}$} \\
\hline & $\begin{array}{c}\text { KHN } \\
\text { (Inicial) }\end{array}$ & $\begin{array}{c}\text { KHN } \\
\text { (7 dias) }\end{array}$ & $\begin{array}{c}\text { KHN } \\
\text { (30 dias) }\end{array}$ & $\begin{array}{l}\Delta \mathrm{KHN} \\
\text { (7 dias) }\end{array}$ & $\begin{array}{c}\Delta \text { KHN } \\
\text { (30dias) }\end{array}$ \\
\hline & 50,83 & 39,70 & 61,57 & $-11,13$ & 10,73 \\
\hline & 27,20 & 51,10 & 49,23 & 23,90 & 22,03 \\
\hline & 47,97 & 66,27 & 78,30 & 18,30 & 30,33 \\
\hline & 70,30 & 60,17 & 63,67 & $-10,13$ & $-6,63$ \\
\hline & 66,10 & 66,13 & 70,80 & 0,03 & 4,70 \\
\hline & 73,00 & 74,87 & 64,00 & 1,87 & $-9,00$ \\
\hline & 40,37 & 53,97 & 65,87 & 13,60 & 25,50 \\
\hline & 69,60 & 59,00 & 43,13 & $-10,60$ & $-26,47$ \\
\hline & 72,40 & 70,77 & 78,43 & $-1,63$ & 6,03 \\
\hline & 65,07 & 58,63 & 68,20 & $-6,43$ & 3,13 \\
\hline $\begin{array}{c}\text { Média } \\
\text { Desvio padrão }\end{array}$ & $\begin{array}{c}58,28 \\
(15,79)\end{array}$ & $\begin{array}{c}60,06 \\
(1024)\end{array}$ & $\begin{array}{c}64,32 \\
(1125)\end{array}$ & $\begin{array}{c}1,78 \\
(12,68)\end{array}$ & $\begin{array}{c}6,04 \\
(17,32)\end{array}$ \\
\hline
\end{tabular}

Tabela 74 - Valores da microdureza Knoop (KHN), das respectivas médias e desvio padrão, antes (KHN inicial) e após 7 dias e 30 dias de exposição ao frio e das alterações da microdureza $(\triangle \mathrm{KHN})$ nesses tempos após submissão da resina composta a $-20^{\circ} \mathrm{C}$.

\begin{tabular}{|c|c|c|c|c|c|}
\hline & \multicolumn{5}{|c|}{$\begin{array}{c}\text { Resina Composta } \\
-20^{\circ} \mathrm{C}\end{array}$} \\
\hline & $\begin{array}{c}\text { KHN } \\
\text { (Inicial) }\end{array}$ & $\begin{array}{c}\text { KHN } \\
\text { (7 dias) }\end{array}$ & $\begin{array}{c}\text { KHN } \\
\text { (30 dias) }\end{array}$ & $\begin{array}{l}\Delta \mathrm{KHN} \\
\text { (7 dias) }\end{array}$ & $\begin{array}{c}\Delta \mathrm{KHN} \\
\text { (30dias) }\end{array}$ \\
\hline & 51,50 & 72,97 & 73,13 & 21,47 & 21,63 \\
\hline & 49,73 & 64,90 & 49,37 & 15,17 & $-0,37$ \\
\hline & 59,80 & 52,60 & 48,43 & $-7,20$ & $-11,37$ \\
\hline & 62,60 & 55,13 & 69,13 & $-7,47$ & 6,53 \\
\hline & 31,87 & 63,00 & 68,50 & 31,13 & 36,63 \\
\hline & 47,07 & 44,57 & 42,67 & $-2,50$ & $-4,40$ \\
\hline & 49,73 & 60,77 & 62,37 & 11,03 & 12,63 \\
\hline & 53,87 & 71,83 & 68,67 & 17,97 & 14,80 \\
\hline & 66,43 & 69,33 & 64,50 & 2,90 & $-1,93$ \\
\hline & 25,67 & 38,07 & 32,70 & 12,40 & 7,03 \\
\hline $\begin{array}{c}\text { Média } \\
\text { Desvio padrão }\end{array}$ & $\begin{array}{c}49,83 \\
(12,79)\end{array}$ & $\begin{array}{c}59,32 \\
(11,65)\end{array}$ & $\begin{array}{c}57,95 \\
(13,66)\end{array}$ & $\begin{array}{c}9,49 \\
(12,82)\end{array}$ & $\begin{array}{c}8,12 \\
(14,04)\end{array}$ \\
\hline
\end{tabular}


Tabela 75 - Valores da microdureza Knoop (KHN), das respectivas médias e desvio padrão, antes (KHN inicial) e após 7 dias e 30 dias de exposição ao frio e das alterações da microdureza $(\triangle \mathrm{KHN})$ nesses tempos após submissão da resina composta a $-80^{\circ} \mathrm{C}$.

\begin{tabular}{|c|c|c|c|c|c|}
\hline & \multicolumn{5}{|c|}{$\begin{array}{c}\text { Resina Composta } \\
-80^{\circ} \mathrm{C}\end{array}$} \\
\hline & $\begin{array}{c}\text { KHN } \\
\text { (Inicial) }\end{array}$ & $\begin{array}{c}\text { KHN } \\
\text { (7 dias) }\end{array}$ & $\begin{array}{c}\text { KHN } \\
\text { (30 dias) } \\
\end{array}$ & $\begin{array}{r}\Delta \mathrm{KHN} \\
\text { (7 dias) }\end{array}$ & $\begin{array}{c}\Delta \text { KHN } \\
\text { (30dias) }\end{array}$ \\
\hline & 97,57 & 94,43 & 67,67 & $-3,13$ & $-29,90$ \\
\hline & 38,60 & 80,00 & 72,13 & 41,40 & 33,53 \\
\hline & 40,23 & 56,67 & 64,10 & 16,43 & 23,87 \\
\hline & 62,00 & 66,20 & 66,40 & 4,20 & 4,40 \\
\hline & 64,83 & 55,37 & 48,77 & $-9,47$ & $-16,07$ \\
\hline & 75,03 & 85,13 & 77,53 & 10,10 & 2,50 \\
\hline & 80,17 & 56,37 & 67,83 & $-23,80$ & $-12,33$ \\
\hline & 58,33 & 73,63 & 61,63 & 15,30 & 3,30 \\
\hline & 34,87 & 37,57 & 29,80 & 2,70 & $-5,07$ \\
\hline & 39,03 & 31,17 & 48,60 & $-7,87$ & 9,57 \\
\hline $\begin{array}{c}\text { Média } \\
\text { Desvio padrão }\end{array}$ & $\begin{array}{l}59,07 \\
(21,04)\end{array}$ & $\begin{array}{c}63,65 \\
(20,24)\end{array}$ & $\begin{array}{c}60,45 \\
(14,15)\end{array}$ & $\begin{array}{c}4,59 \\
(17,83)\end{array}$ & $\begin{array}{c}1,38 \\
(18,66)\end{array}$ \\
\hline
\end{tabular}

Tabela 76 - Valores da microdureza Knoop (KHN), das respectivas médias e desvio padrão, antes (KHN inicial) e após 7 dias e 30 dias de exposição ao frio e das alterações da microdureza $(\Delta \mathrm{KHN})$ nesses tempos após submissão do $\mathrm{CIV}$ a $2,5^{\circ} \mathrm{C}$.

\begin{tabular}{|c|c|c|c|c|c|}
\hline & \multicolumn{5}{|c|}{$\begin{array}{l}\text { Cimento de Ionômero de Vidro } \\
\qquad 2,5^{\circ} \mathrm{C}\end{array}$} \\
\hline & $\begin{array}{c}\text { KHN } \\
\text { (Inicial) }\end{array}$ & $\begin{array}{c}\text { KHN } \\
\text { (7 dias) }\end{array}$ & $\begin{array}{c}\text { KHN } \\
\text { (30 dias) }\end{array}$ & $\begin{array}{l}\Delta \mathrm{KHN} \\
\text { (7 dias) }\end{array}$ & $\begin{array}{c}\Delta \text { KHN } \\
\text { (30dias) }\end{array}$ \\
\hline & 1,37 & 2,91 & 5,52 & 1,54 & 4,15 \\
\hline & 1,42 & 2,64 & 2,06 & 1,22 & 0,64 \\
\hline & 2,90 & 3,03 & 4,74 & 0,13 & 1,84 \\
\hline & 3,42 & 6,01 & 5,88 & 2,59 & 2,46 \\
\hline & 3,21 & 2,83 & 2,06 & $-0,38$ & $-1,14$ \\
\hline & 2,05 & 4,39 & 5,52 & 2,33 & 3,47 \\
\hline & 2,32 & 3,50 & 5,02 & 1,18 & 2,70 \\
\hline & 5,31 & 8,16 & 7,19 & 2,85 & 1,89 \\
\hline & 1,72 & 3,51 & 3,68 & 1,80 & 1,97 \\
\hline & 3,42 & 6,24 & 9,84 & 2,82 & 6,42 \\
\hline $\begin{array}{c}\text { Média } \\
\text { Desvio padrão }\end{array}$ & $\begin{array}{c}2,71 \\
(1,21)\end{array}$ & $\begin{array}{c}4,32 \\
(1,86)\end{array}$ & $\begin{array}{c}5,15 \\
(2,32)\end{array}$ & $\begin{array}{c}1,61 \\
(1,11)\end{array}$ & $\begin{array}{c}2,44 \\
(2,02)\end{array}$ \\
\hline
\end{tabular}


Tabela 77 - Valores da microdureza Knoop (KHN), das respectivas médias e desvio padrão, antes (KHN inicial) e após 7 dias e 30 dias de exposição ao frio e das alterações da microdureza $(\triangle \mathrm{KHN})$ nesses tempos após submissão do CIV a $-20^{\circ} \mathrm{C}$.

\section{Cimento de Ionômero de Vidro}

\begin{tabular}{cccccc} 
& \multicolumn{5}{c}{$\mathbf{- 2 0} \mathbf{C}$} \\
& $\begin{array}{c}\text { KHN } \\
\text { (Inicial) }\end{array}$ & $\begin{array}{c}\text { KHN } \\
\text { (7 dias) }\end{array}$ & $\begin{array}{c}\text { KHN } \\
(\mathbf{3 0} \text { dias })\end{array}$ & $\begin{array}{c}\Delta \text { KHN } \\
\text { (7 dias) }\end{array}$ & $\begin{array}{c}\Delta \text { KHN } \\
\text { (30dias) }\end{array}$ \\
\hline 5,14 & 6,32 & 2,97 & 1,18 & $-2,17$ \\
& 3,19 & 10,07 & 8,57 & 6,88 & 5,38 \\
& 5,15 & 7,31 & 11,46 & 2,16 & 6,31 \\
& 5,21 & 6,17 & 7,28 & 0,96 & 2,07 \\
& 6,36 & 12,63 & 23,57 & 6,27 & 17,21 \\
& 3,82 & 4,01 & 2,27 & 0,19 & $-1,55$ \\
& 7,12 & 3,72 & 7,91 & $-3,40$ & 0,79 \\
& 4,74 & 4,96 & 5,96 & 0,22 & 1,22 \\
Média & 7,27 & 14,00 & 12,33 & 6,73 & 5,06 \\
Desvio padrão & 4,63 & 4,15 & 6,87 & $-0,47$ & 2,24 \\
\hline $\mathbf{5 , 2 6}$ & $\mathbf{( 1 , 3 2 )}$ & $\mathbf{7 , 3 3}$ & $\mathbf{8 , 9 2}$ & $\mathbf{2 , 0 7}$ & $\mathbf{3 , 6 6}$ \\
& & & $\mathbf{( 6 , 0 5 )}$ & $\mathbf{( 3 , 4 6 )}$ & $\mathbf{( 5 , 5 3 )}$
\end{tabular}

Tabela 78 - Valores da microdureza Knoop (KHN), das respectivas médias e desvio padrão, antes (KHN inicial) e após 7 dias e 30 dias de exposição ao frio e das alterações da microdureza $(\triangle \mathrm{KHN})$ nesses tempos após submissão do CIV a $-80^{\circ} \mathrm{C}$.

\begin{tabular}{|c|c|c|c|c|c|}
\hline & \multicolumn{5}{|c|}{$\begin{array}{l}\text { Cimento de Ionômero de Vidro } \\
\qquad-80^{\circ} \mathrm{C}\end{array}$} \\
\hline & $\begin{array}{c}\text { KHN } \\
\text { (Inicial) }\end{array}$ & $\begin{array}{c}\text { KHN } \\
\text { (7 dias) }\end{array}$ & $\begin{array}{c}\text { KHN } \\
\text { (30 dias) }\end{array}$ & $\begin{array}{c}\Delta \mathrm{KHN} \\
\text { (7 dias) }\end{array}$ & $\begin{array}{c}\Delta \mathrm{KHN} \\
\text { (30dias) }\end{array}$ \\
\hline & 3,70 & 6,32 & 12,97 & 2,62 & 9,27 \\
\hline & 2,70 & 6,70 & 6,64 & 4,00 & 3,95 \\
\hline & 1,98 & 3,55 & 4,10 & 1,57 & 2,12 \\
\hline & 1,80 & 2,32 & 3,93 & 0,52 & 2,12 \\
\hline & 3,62 & 12,46 & 11,77 & 8,83 & 8,14 \\
\hline & 2,70 & 5,14 & 10,56 & 2,44 & 7,86 \\
\hline & 3,91 & 11,13 & 19,13 & 7,22 & 15,22 \\
\hline & 2,00 & 6,11 & 9,03 & 4,11 & 7,03 \\
\hline & 0,34 & 1,23 & 2,71 & 0,89 & 2,37 \\
\hline & 1,96 & 2,63 & 4,79 & 0,66 & 2,83 \\
\hline $\begin{array}{c}\text { Média } \\
\text { Desvio padrão }\end{array}$ & $\begin{array}{c}2,47 \\
(1,09)\end{array}$ & $\begin{array}{c}5,76 \\
(2,69)\end{array}$ & $\begin{array}{c}8,56 \\
(5,16)\end{array}$ & $\begin{array}{c}3,29 \\
(2,83)\end{array}$ & $\begin{array}{c}6,09 \\
(4,25)\end{array}$ \\
\hline
\end{tabular}


Tabela 79 - Valores da microdureza Knoop (KHN), das respectivas médias e desvio padrão, antes (KHN inicial) e após 7 dias e 30 dias de exposição ao frio e das alterações da microdureza $(\triangle \mathrm{KHN})$ nesses tempos após submissão do amálgama a $2,5^{\circ} \mathrm{C}$.

\begin{tabular}{|c|c|c|c|c|c|}
\hline & \multicolumn{5}{|c|}{$\begin{array}{c}\text { Amálgama } \\
2,5^{\circ} \mathrm{C}\end{array}$} \\
\hline & $\begin{array}{c}\text { KHN } \\
\text { (Inicial) }\end{array}$ & $\begin{array}{c}\text { KHN } \\
\text { (7 dias) }\end{array}$ & $\begin{array}{c}\text { KHN } \\
\text { (30 dias) }\end{array}$ & $\begin{array}{c}\Delta \mathrm{KHN} \\
\text { (7 dias) }\end{array}$ & $\begin{array}{c}\Delta \text { KHN } \\
\text { (30dias) }\end{array}$ \\
\hline & 95,73 & 106,93 & 101,50 & 11,20 & 5,77 \\
\hline & 73,73 & 127,50 & 125,67 & 53,77 & 51,93 \\
\hline & 131,33 & 120,33 & 133,67 & $-11,00$ & 2,33 \\
\hline & 113,67 & 126,67 & 107,90 & 13,00 & $-5,77$ \\
\hline & 116,67 & 90,87 & 144,00 & $-25,80$ & 27,33 \\
\hline & 117,97 & 98,93 & 112,33 & $-19,03$ & $-5,63$ \\
\hline & 122,67 & 120,00 & 122,33 & $-2,67$ & $-0,33$ \\
\hline & 120,03 & 89,93 & 147,33 & $-30,10$ & 27,30 \\
\hline & 114,63 & 139,33 & 127,00 & 24,70 & 12,37 \\
\hline & 120,33 & 153,00 & 128,00 & 32,67 & 7,67 \\
\hline $\begin{array}{c}\text { Média } \\
\text { Desvio padrão }\end{array}$ & $\begin{array}{l}112,68 \\
(16,37)\end{array}$ & $\begin{array}{l}117,35 \\
(20,71)\end{array}$ & $\begin{array}{l}124,97 \\
(14,76)\end{array}$ & $\begin{array}{c}4,67 \\
(27,30)\end{array}$ & $\begin{array}{c}12,30 \\
(18,24)\end{array}$ \\
\hline
\end{tabular}

Tabela 80 - Valores da microdureza Knoop (KHN), das respectivas médias e desvio padrão, antes (KHN inicial) e após 7 dias e 30 dias de exposição ao frio e das alterações da microdureza $(\triangle \mathrm{KHN})$ nesses tempos após submissão do amálgama a $-20^{\circ} \mathrm{C}$.

\begin{tabular}{cccccc}
\hline \multicolumn{5}{c}{$\begin{array}{c}\text { Amálgama } \\
\mathbf{- 2 0} \mathbf{C}\end{array}$} \\
\hline & KHN & KHN & KHN & $\mathbf{\Delta K H N}$ & $\mathbf{\Delta K H N}$ \\
(Inicial) & $\mathbf{( 7 ~ d i a s )}$ & $\mathbf{( 3 0 \text { dias) }}$ & $\mathbf{( 7 \text { dias) }}$ & (30dias) \\
\hline & 165,00 & 108,33 & 126,33 & $-56,67$ & $-38,67$ \\
& 135,33 & 126,00 & 126,00 & $-9,33$ & $-9,33$ \\
& 118,73 & 144,00 & 125,33 & 25,27 & 6,60 \\
& 142,67 & 144,30 & 140,67 & 1,67 & $-2,00$ \\
& 119,13 & 129,33 & 148,33 & 10,20 & 29,20 \\
& 155,33 & 141,00 & 137,33 & $-14,33$ & $-18,00$ \\
& 119,67 & 103,70 & 127,27 & $-15,97$ & 7,60 \\
& 105,63 & 118,67 & 112,67 & 13,03 & 7,03 \\
& 104,23 & 130,33 & 149,33 & 26,10 & 45,10 \\
Média & $\mathbf{9 7 , 3 0}$ & 84,80 & 132,00 & $-12,50$ & 34,70 \\
\hline Desvio padrão & $\mathbf{1 2 6 , 3 0}$ & $\mathbf{1 2 3 , 0 5}$ & $\mathbf{1 3 2 , 5 3}$ & $\mathbf{- 3 , 2 5}$ & $\mathbf{6 , 2 2}$ \\
& $\mathbf{( 2 2 , 6 0 )}$ & $\mathbf{( 1 9 , 4 0 )}$ & $\mathbf{( 1 1 , 4 3 )}$ & $\mathbf{( 2 4 , 5 1 )}$ & $\mathbf{( 2 5 , 3 1 )}$
\end{tabular}


Tabela 81 - Valores da microdureza Knoop (KHN), das respectivas médias e desvio padrão, antes (KHN inicial) e após 7 dias e 30 dias de exposição ao frio e das alterações da microdureza $(\triangle \mathrm{KHN})$ nesses tempos após submissão do amálgama a $-80^{\circ} \mathrm{C}$.

\begin{tabular}{|c|c|c|c|c|c|}
\hline & \multicolumn{5}{|c|}{$\begin{array}{c}\text { Amálgama } \\
-80^{\circ} \mathrm{C}\end{array}$} \\
\hline & $\begin{array}{c}\text { KHN } \\
\text { (Inicial) }\end{array}$ & $\begin{array}{c}\text { KHN } \\
\text { (7 dias) }\end{array}$ & $\begin{array}{c}\text { KHN } \\
\text { (30 dias) }\end{array}$ & $\begin{array}{c}\Delta \mathrm{KHN} \\
\text { (7 dias) }\end{array}$ & $\begin{array}{c}\Delta \text { KHN } \\
\text { (30dias) }\end{array}$ \\
\hline & 107,60 & 79,80 & 94,97 & $-27,80$ & $-12,63$ \\
\hline & 69,17 & 73,60 & 113,50 & 4,43 & 44,33 \\
\hline & 93,03 & 114,10 & 104,27 & 21,07 & 11,23 \\
\hline & 107,37 & 82,33 & 154,00 & $-25,03$ & 46,63 \\
\hline & 96,67 & 88,07 & 179,00 & $-8,60$ & 82,33 \\
\hline & 102,20 & 88,90 & 120,33 & $-13,30$ & 18,13 \\
\hline & 154,33 & 173,67 & 143,67 & 19,33 & $-10,67$ \\
\hline & 110,30 & 120,83 & 126,67 & 10,53 & 16,37 \\
\hline & 125,40 & 174,33 & 173,00 & 48,93 & 47,60 \\
\hline & 186,33 & 168,67 & 137,33 & $-17,67$ & $-49,00$ \\
\hline $\begin{array}{c}\text { Média } \\
\text { Desvio padrão }\end{array}$ & $\begin{array}{l}115,24 \\
(33,27)\end{array}$ & $\begin{array}{l}116,43 \\
(41,21)\end{array}$ & $\begin{array}{l}134,67 \\
(28,12)\end{array}$ & $\begin{array}{c}1,19 \\
(24,25)\end{array}$ & $\begin{array}{c}19,43 \\
(37,72)\end{array}$ \\
\hline
\end{tabular}

As comparações das médias de alteração de microdureza Knoop (2-way ANOVA, Bonferroni, $\mathrm{p}<0,05$ ) da resina composta e CIV podem ser vistas nas Tabelas 82 a 84 e Gráfico 15.

Tabela 82 - Comparação das alterações da microdureza Knoop $(\Delta \mathrm{KHN})$ e desvio padrão, da resina composta e do CIV nas submissões a $2,5^{\circ} \mathrm{C},-20^{\circ} \mathrm{C}$ e $-80^{\circ} \mathrm{C}$, por 7 dias e 30 dias e, entre os materiais, nas mesmas temperaturas, analisadas segundo Two-way ANOVA, Bonferroni, $\mathrm{p}<0,05$.

\section{Microdureza}

\begin{tabular}{cccc}
\hline Tempos & Temperaturas & Resina & CIV \\
\hline \multirow{3}{*}{7 dias } & $2,5^{\circ} \mathrm{C}$ & $1,78 \pm 12,68 \mathrm{aA}$ & $1,61 \pm 1,11 \mathrm{aA}$ \\
& $-20^{\circ} \mathrm{C}$ & $9,49 \pm 12,82 \mathrm{aA}$ & $2,07 \pm 3,46 \mathrm{aA}$ \\
& $-80^{\circ} \mathrm{C}$ & $4,59 \pm 17,83 \mathrm{aA}$ & $3,29 \pm 2,83 \mathrm{aA}$ \\
\hline \multirow{3}{*}{30 dias } & $2,5^{\circ} \mathrm{C}$ & $6,04 \pm 17,32 \mathrm{aA}$ & $2,44 \pm 2,02 \mathrm{aA}$ \\
& $-20^{\circ} \mathrm{C}$ & $8,12 \pm 14,04 \mathrm{aA}$ & $3,66 \pm 5,53 \mathrm{aA}$ \\
& $-80^{\circ} \mathrm{C}$ & $1,38 \pm 18,66 \mathrm{aA}$ & $6,09 \pm 4,25 \mathrm{aA}$ \\
\hline
\end{tabular}

Para todas as comparações, em linha, entre os materiais, e na coluna para o mesmo material, não houve diferença estatisticamente significante $(p>0,05)$. 
Tabela 83 - Comparação das alterações da microdureza Knoop ( $\Delta$ KHN) e desvio padrão, da resina composta e do CIV nas submissões a $2,5^{\circ} \mathrm{C},-20^{\circ} \mathrm{C}$ e $-80^{\circ} \mathrm{C}$ por 7 dias e, entre os materiais, em diferentes temperaturas, analisadas segundo Two-way ANOVA, Bonferroni, $\mathrm{p}<0,05$.

\begin{tabular}{cccccc}
\hline \multicolumn{5}{c}{ Microdureza } \\
\hline Material & \multicolumn{2}{c}{7 dias } & & \\
& & & & & \\
& Temperatura & & $2,5^{\circ} \mathrm{C}$ & $-20^{\circ} \mathrm{C}$ & $-80^{\circ} \mathrm{C}$ \\
& & & $1,61 \pm 1,11$ & $2,07 \pm 3,46$ & $3,29 \pm 2,83$ \\
Resina & $2,5^{\circ} \mathrm{C}$ & $1,78 \pm 12,68$ & & $\mathrm{~ns}$ & $\mathrm{~ns}$ \\
Composta & $-20^{\circ} \mathrm{C}$ & $9,49 \pm 12,82$ & $\mathrm{~ns}$ & & $\mathrm{~ns}$ \\
& $-80^{\circ} \mathrm{C}$ & $4,59 \pm 17,83$ & $\mathrm{~ns}$ & $\mathrm{~ns}$ & \\
\hline
\end{tabular}

ns = Não houve diferença estatisticamente significante $(\mathrm{p}>0,05)$.

Tabela 84 - Comparação das alterações da microdureza Knoop ( $\Delta$ KHN) e desvio padrão, da resina composta e do CIV nas submissões a $2,5^{\circ} \mathrm{C},-20^{\circ} \mathrm{C}$ e $-80^{\circ} \mathrm{C}$ por 30 dias e, entre os materiais, em diferentes temperaturas, analisadas segundo Two-way ANOVA, Bonferroni, $\mathrm{p}<0,05$.

\begin{tabular}{|c|c|c|c|c|c|}
\hline \multicolumn{6}{|c|}{ Microdureza } \\
\hline \multicolumn{6}{|c|}{30 dias } \\
\hline \multirow[t]{3}{*}{ Material } & & & & CIV & \\
\hline & Temperatura & & $2,5^{\circ} \mathrm{C}$ & $-20^{\circ} \mathrm{C}$ & $-80^{\circ} \mathrm{C}$ \\
\hline & & & $2,44 \pm 2,02$ & $3,66 \pm 5,53$ & $6,09 \pm 4,25$ \\
\hline \multirow{3}{*}{$\begin{array}{c}\text { Resina } \\
\text { Composta }\end{array}$} & $2,5^{\circ} \mathrm{C}$ & $6,04 \pm 17,32$ & & ns & ns \\
\hline & $-20^{\circ} \mathrm{C}$ & $8,12 \pm 14,04$ & ns & & ns \\
\hline & $-80^{\circ} \mathrm{C}$ & $1,38 \pm 18,66$ & ns & ns & \\
\hline
\end{tabular}

ns = Não houve diferença estatisticamente significante $(p>0,05)$. 
Gráfico 15 - Representação gráfica da comparação das alterações da microdureza Knoop $(\Delta \mathrm{KHN})$ dos materiais restauradores estéticos submetidos à ação do frio.

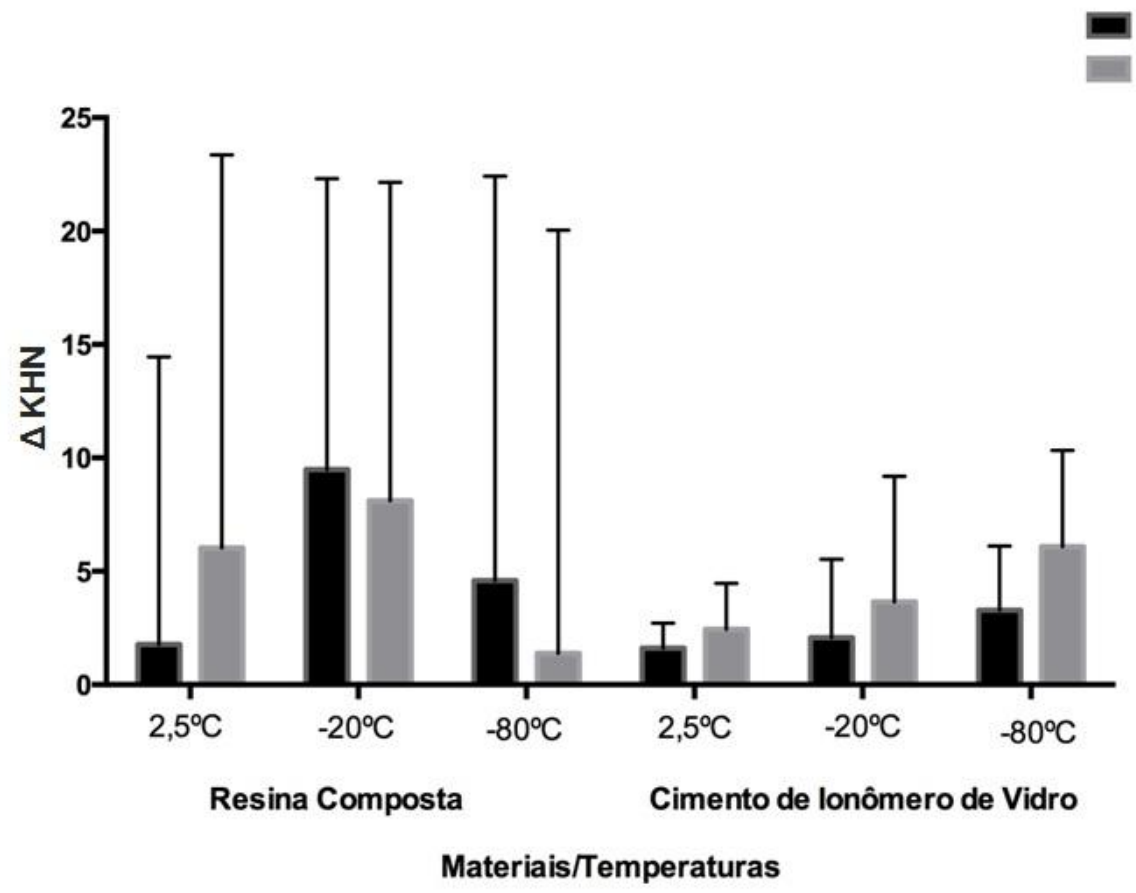

Para todas as comparações, $\mathrm{p}>0,05$

As comparações das médias de alteração de microdureza Knoop (2-way ANOVA, Bonferroni, p<0,05) do amálgama podem ser vistas na Tabela 85 e Gráfico 16.

Tabela 85 - Comparação das alterações da microdureza Knoop $(\Delta \mathrm{KHN})$ e desvio padrão, do amálgama nas submissões a $2,5^{\circ} \mathrm{C},-20^{\circ} \mathrm{C}$ e $-80^{\circ} \mathrm{C}$, por 7 dias e 30 dias, analisadas segundo Twoway ANOVA, Bonferroni, $\mathrm{p}<0,05$.

\section{Microdureza}

\begin{tabular}{ccc}
\hline & Amálgama \\
\hline Temperaturas & 7 dias & 30 dias \\
$2,5^{\circ} \mathrm{C}$ & $4,67 \pm 27,30 \mathrm{aA}$ & $12,30 \pm 18,24 \mathrm{aA}$ \\
$-20^{\circ} \mathrm{C}$ & $-3,25 \pm 24,51 \mathrm{aA}$ & $6,22 \pm 25,31 \mathrm{aA}$ \\
$-80^{\circ} \mathrm{C}$ & $1,19 \pm 24,25 \mathrm{aA}$ & $19,43 \pm 37,72 \mathrm{aA}$ \\
\hline
\end{tabular}

Para todas as comparações, em linhas e colunas para o amálgama, não houve diferença estatisticamente significante $(\mathrm{p}>0,05)$. 
Gráfico 16 - Representação gráfica das alterações da microdureza Knoop ( $\Delta \mathrm{KHN}$ ) das restaurações de amálgama submetidas à ação do frio.

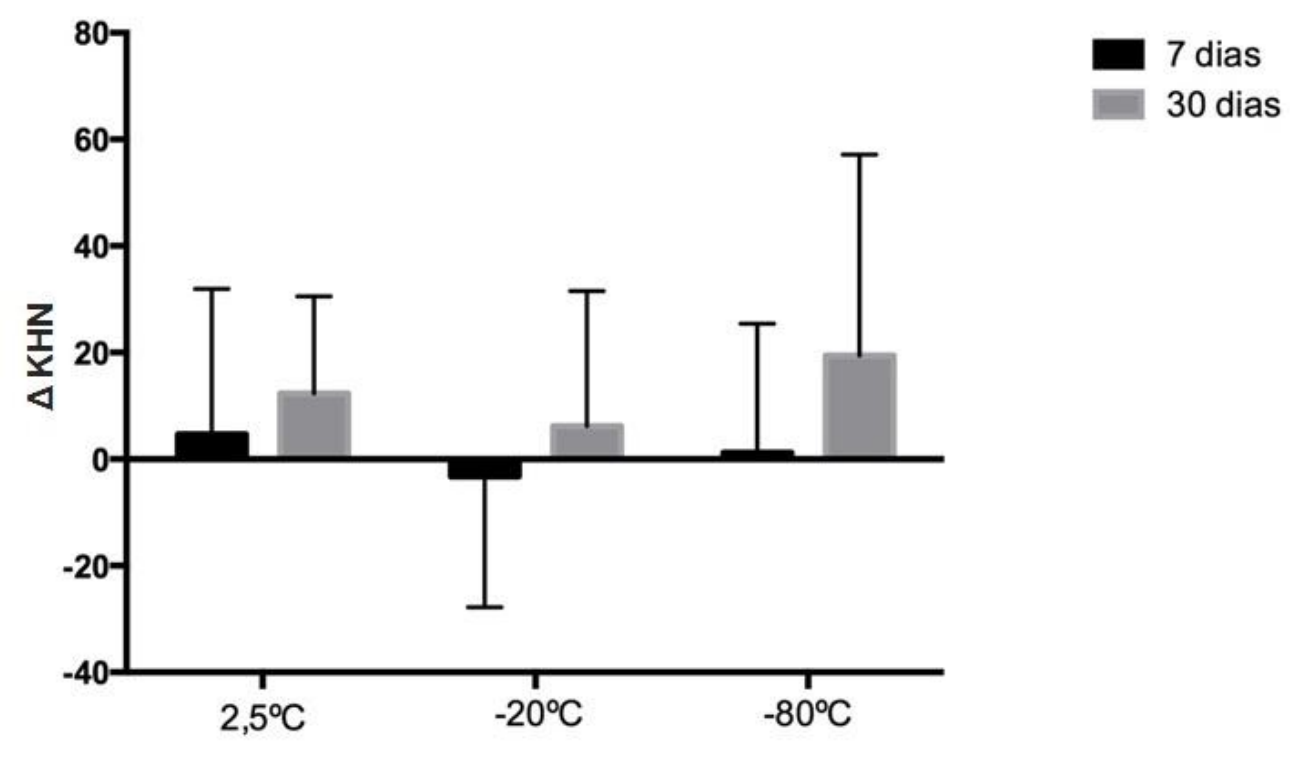

Amálgama

Para todas as comparações, $\mathrm{p}>0,05$.

Os resultados obtidos com as restaurações em resina composta, CIV e amálgama após submissão às baixas temperaturas, nas três temperaturas avaliadas, demonstraram que não ocorreram alterações de microdureza Knoop estatisticamente significantes ( $p>0,05)$ nos três materiais restauradores após 7 e 30 dias.

\subsubsection{Análise visual}

As imagens fotográficas realizadas, representativas do grupo amostral da resina composta, do CIV e do amálgama, antes da exposição ao frio e após 7 dias e 30 dias de submissão às baixas temperaturas de $2,5^{\circ} \mathrm{C},\left(-20^{\circ} \mathrm{C}\right)$ e $\left(-80^{\circ} \mathrm{C}\right)$, são observadas, respectivamente, nas figuras 38,39 e 40. 


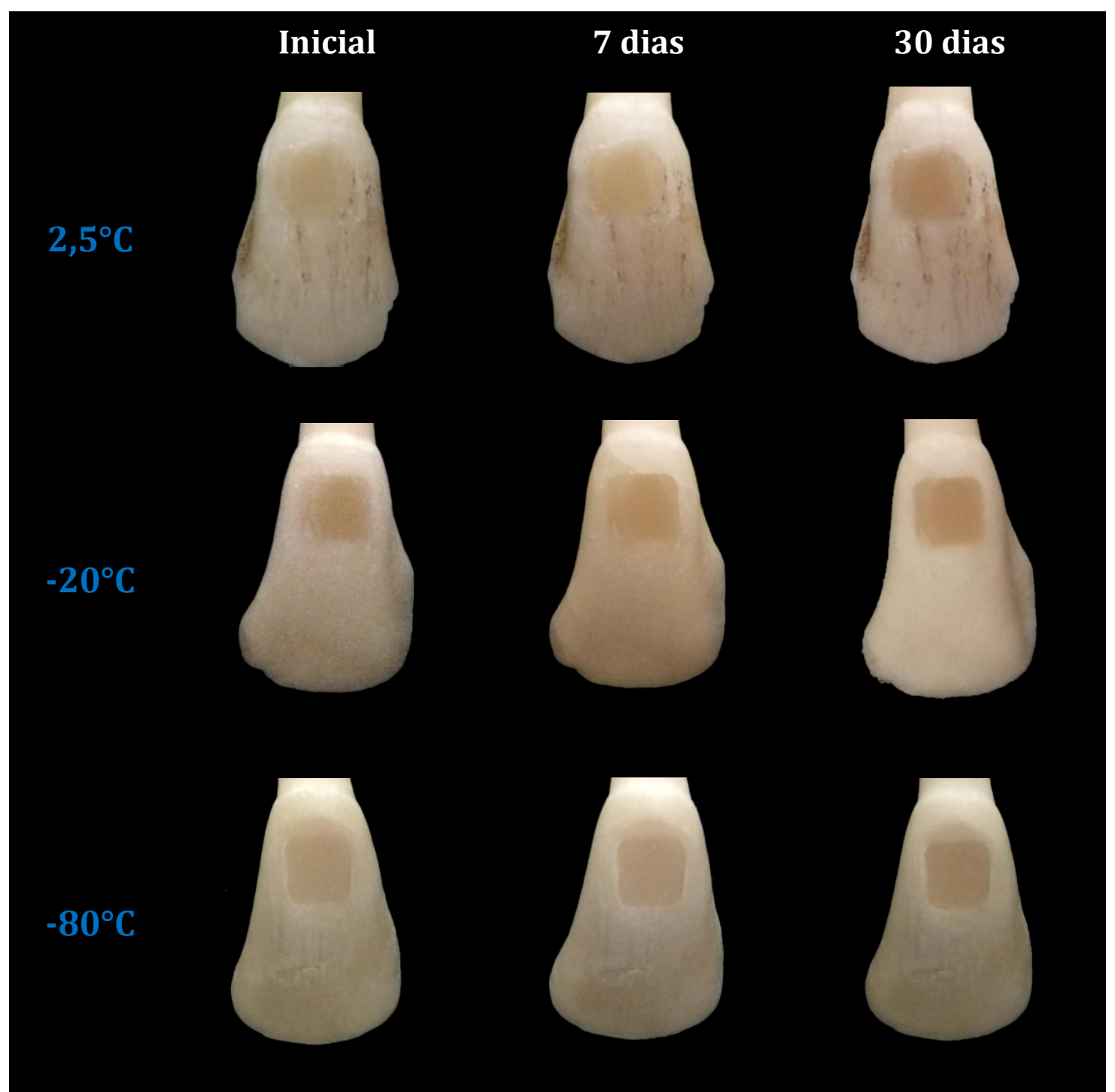

Figura 38 - Comparação visual das restaurações de resina composta, antes e após 7 e 30 dias de submissão ao frio, nas referidas temperaturas. 


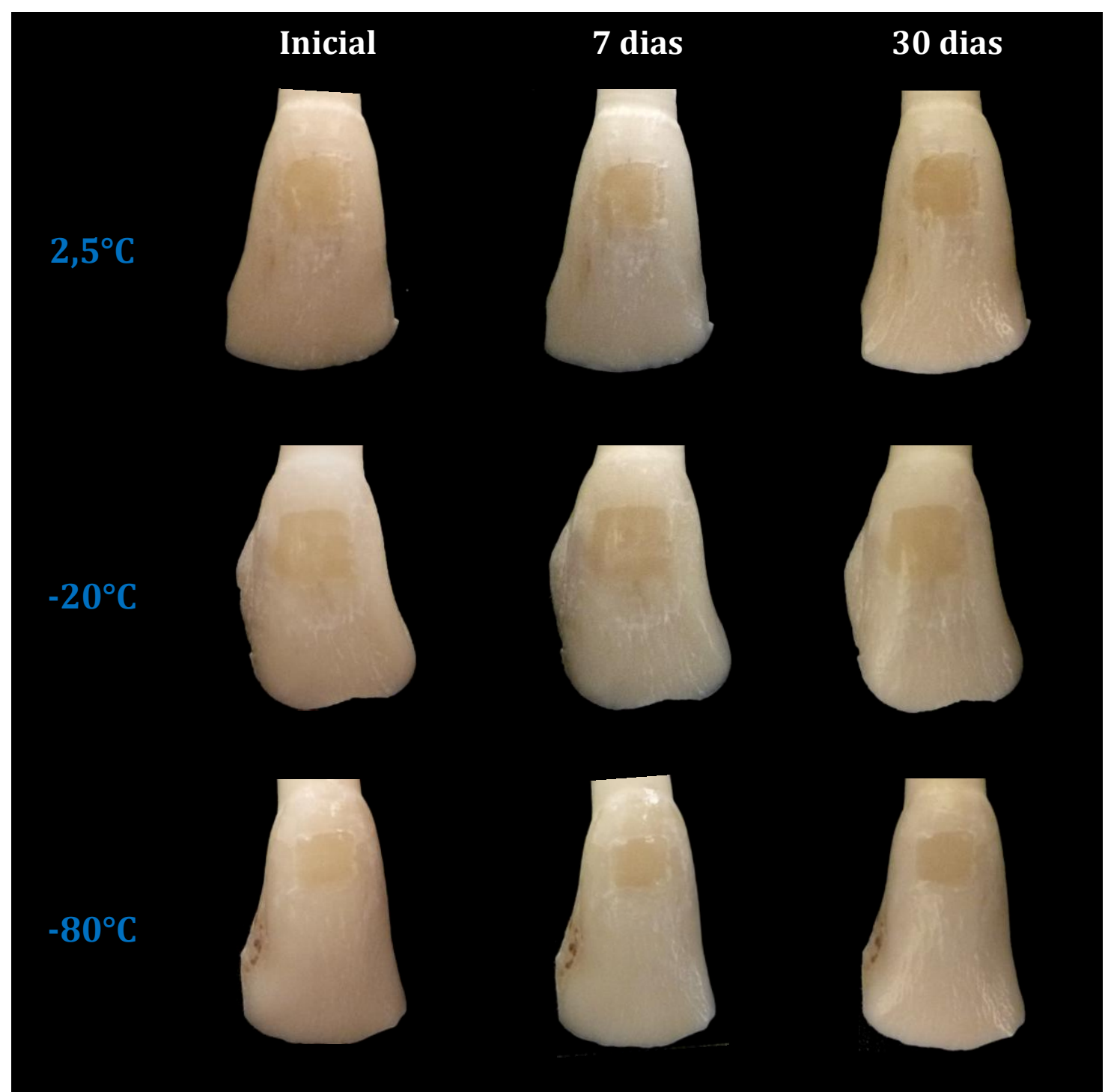

Figura 39 - Comparação visual das restaurações de CIV, antes e após 7 e 30 dias de submissão ao frio, nas referidas temperaturas. 


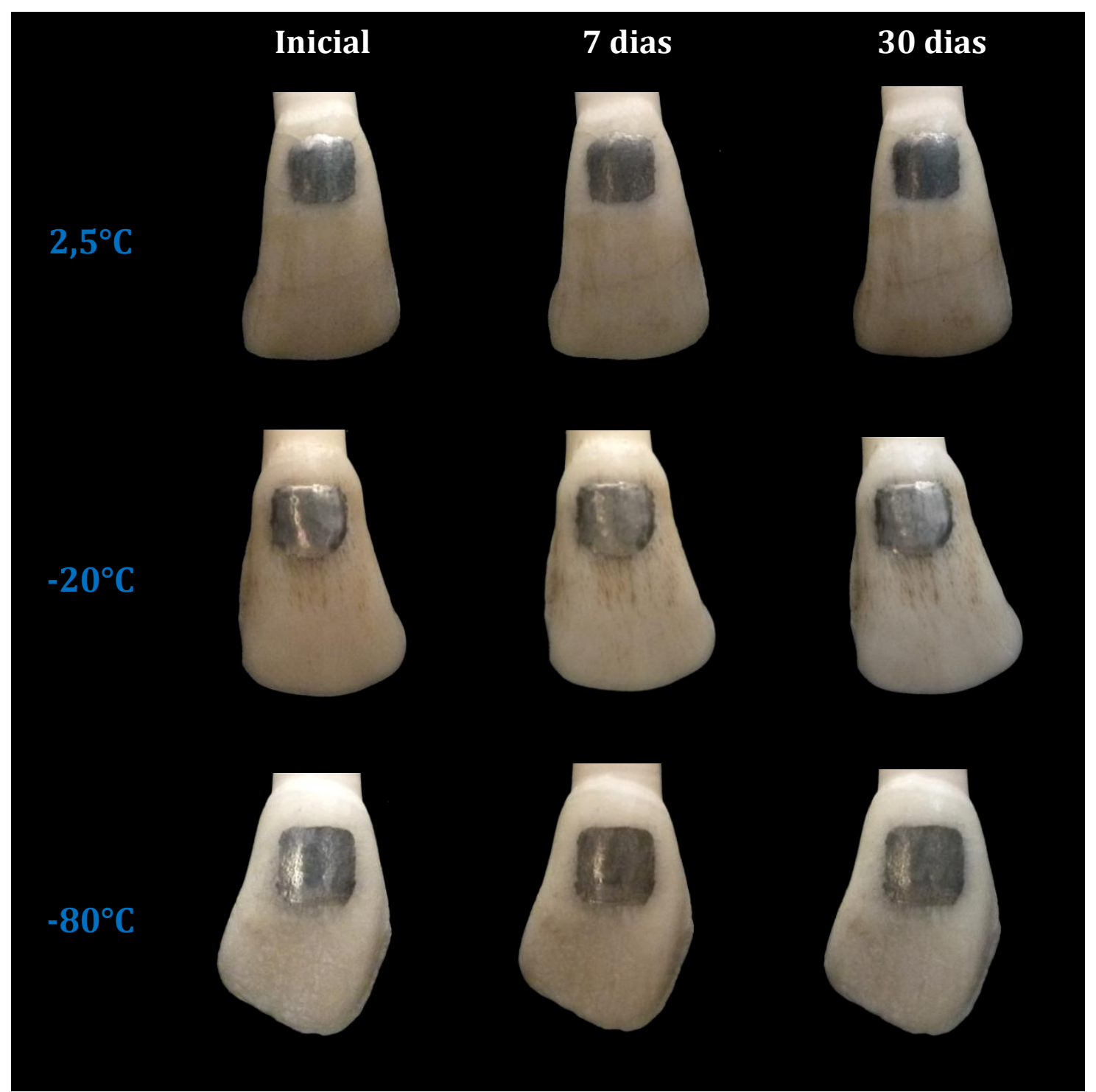

Figura 40 - Comparação visual das restaurações de amálgama, antes e após 7 e 30 dias de submissão ao frio, nas referidas temperaturas.

Na resina composta, observou-se aparente escurecimento das restaurações, sendo mais perceptível após 30 dias de submissão ao frio, nas três temperaturas avaliadas (Figura 38). No CIV, as modificações foram similares à resina composta, com maior escurecimento aparente das restaurações em 30 dias de exposição às baixas temperaturas (Figura 39). Os dois materiais estéticos mantiveram-se unidos ao dente em todos os grupos amostrais. No grupo amostral do amálgama não foram observadas alterações perceptíveis em sua estrutura pela análise visual, apenas discreta perda do brilho da restauração, a qual se deu em todas as temperaturas analisadas (Figura 40). 

Discussãa 



\section{DISCUSSÃO}

Este trabalho teve por objetivo avaliar a ação do calor e do frio, simulando prováveis efeitos de carbonização e congelamento de corpos, sobre a estabilidade de cor, a rugosidade de superfície e a microdureza de materiais restauradores odontológicos usados no cotidiano do exercício profissional da área da Odontologia. Os três materiais selecionados foram: resina composta, cimento de ionômero de vidro (CIV) e amálgama de prata, devido à possibilidade de sua presença nos elementos dentais de vítimas de tais situações.

Partiu-se da hipótese nula de que não haveria diferença das propriedades estudadas de cada material, independente das altas ou baixas temperaturas a que foram submetidos. Os resultados demonstraram que a hipótese testada pode ser aceita parcialmente, pois a ação do calor não promoveu alteração estatisticamente significante $(p>0,05)$ na rugosidade de superfície da resina composta e na microdureza Knoop da resina composta e do amálgama de prata, e a ação do frio não causou alteração estatisticamente significante $(p>0,05)$ na rugosidade de superfície e na microdureza de nenhum dos três materiais restauradores odontológicos avaliados. Contudo, tanto o calor quanto o frio foram capazes de produzir alteração de cor significativa $(p<0,05)$ dos materiais restauradores estéticos.

Como substrato para confecção dos preparos cavitários e posterior inserção dos materiais restauradores odontológicos, foram utilizados dentes bovinos. A seleção de dentes bovinos em detrimento a dentes humanos se deu por: maior facilidade de obtenção, possibilidade de aquisição em quantidade suficiente em condições de higidez e por não gerar qualquer prejuízo aos testes propostos. Dentes bovinos ainda proporcionam maior facilidade na padronização das amostras, menor risco de infecção, além da questão bioética ${ }^{80}$.

Tendo em vista que o objetivo deste estudo foi avaliar as alterações ocorridas nos materiais restauradores odontológicos e não, especificamente, nas estruturas dentais, foi perfeitamente possível o uso de elementos dentais bovinos. Além do mais, é viável a realização de preparos odontológicos em dentes bovinos pelas similaridades 
existentes entre seus tecidos dentinários, principalmente, do esmalte dentário bovino com o esmalte dentário humano ${ }^{81}$.

A composição do esmalte é similar entre ambos; com a orientação dos prismas muito semelhante; porcentagem em peso de cálcio equivalente, tendo uma gradual diminuição à medida que se aproxima da junção amelodentinária, e matriz proteica composta pelos mesmos aminoácidos ${ }^{81}$.

Em relação à estrutura da dentina, Schilke, et al. ${ }^{82}$ (2000) em um estudo de microscopia eletrônica de varredura (MEV), observaram que o número e o diâmetro dos túbulos dentinários em incisivos centrais bovinos eram estatisticamente similares ao de molares decíduos e terceiros molares permanentes humanos. Em contrapartida, Lamosa $^{83}$, em 2001, verificou que a dentina bovina apresentava um maior número de túbulos dentinários próximo ao limite amelodentinário e menor diâmetro junto à polpa comparado à dentina humana. Reeves, et al. ${ }^{84}$ (1995) em estudos anteriores, não verificaram diferenças estatísticas entre esses dois substratos.

Apesar dos resultados controversos, há um consenso na literatura de que em cavidades rasas, com profundidade de $2 \mathrm{~mm}$, isto é, idêntica medida utilizada nos preparos cavitários deste estudo, a dentina bovina mostra-se viável para adesão, proporcionando adequada resistência de união quando comparada à dentina humana $80,85$.

Dentre os dentes bovinos, o grupo dos incisivos é amplamente utilizado em pesquisas ${ }^{81,86-88}$, sendo o grupo de escolha pela similaridade com os dentes humanos em sua espessura de esmalte e de dentina. Para este estudo, os incisivos, pelos seus aspectos anatômicos, ofereceram melhores condições para padronização das amostras, pois a presença de sulcos e cicatrículas, típicas do grupo dos pré-molares e molares, poderia afetar a translucidez dos materiais estéticos e, com isso, ocasionar erros na leitura de cor pelo espectrofotômetro.

Devido ao uso de dentes bovinos, não houve a necessidade de submissão ao Comitê de Ética em Pesquisa com Seres Humanos (CEP) nem à Comissão de Ética no uso de Animais (CEA) da Faculdade de Odontologia de Ribeirão Preto da Universidade de São Paulo (FORP-USP), responsável pela aprovação, controle e vigilância das atividades de criação, ensino e pesquisa científica com animais, bem como da garantia do 
cumprimento das normas de controle da experimentação animal editadas pelo Conselho Nacional de Controle de Experimentação Animal (CONCEA), isto porque, as amostras foram compostas por dentes bovinos obtidos em frigorífico, em caráter de doação, onde a remoção dos elementos dentais se deu após o abate dos animais para outros fins.

\subsection{Altas temperaturas (Ação do calor)}

Há inúmeras situações em que a ação do calor acaba por resultar em vítimas carbonizadas, como a alta incidência de explosões, acidentes automobilísticos, incêndios, quedas de aeronaves, nas quais os procedimentos de identificação humana, pelo confronto dos exames post mortem com fichas odontológicas ante mortem, podem ser importantes para elucidar a identidade de um indivíduo, por meio da análise dos elementos dentais e suas possíveis restaurações odontológicas presentes. Isso torna o estudo da ação de altas temperaturas nos materiais restauradores de grande valia no auxílio à Odontologia Legal ${ }^{89}$.

Com relação às lesões pelo calor, Spitz e Fisher $^{18}$ (2006) afirmaram que a severidade da lesão depende diretamente da intensidade do calor, da duração do tempo de exposição e que as temperaturas do fogo diferem, consideravelmente, na dependência do material queimado.

Alguns incêndios provenientes da combustão de determinadas substâncias químicas atingem, rapidamente, alguns milhares de graus de temperatura, enquanto incêndios domésticos raramente excedem $600^{\circ} \mathrm{C}^{90}$. Nesses acidentes domésticos, se faz necessário um considerável período de tempo para que um corpo humano atinja temperaturas próximas dos $600^{\circ} \mathrm{C}$ até que os ossos sejam expostos. Os ossos dos membros superiores e do crânio somente estarão expostos após, aproximadamente, 25 minutos de ação direta do fogo ${ }^{91}$.

O exame externo de um cadáver atingido diretamente pelo fogo ou exposto ao intenso calor indiretamente, evidencia o estado de carbonização dos tecidos moles e não requer investigações mais apuradas para concluir que a vítima foi, realmente, exposta ao calor, antes ou após sua morte. Entretanto, em muitos casos de acidentes com vítimas carbonizadas, os corpos podem ser encontrados depois de vários dias do fato ocorrido, em tempo suficiente para o desencadeamento da total putrefação dos tecidos moles, 
pela qual é vista a decomposição da matéria orgânica, por bactérias e pela fauna macroscópica ${ }^{42}$.

Ao fim da fase de putrefação, teremos a presença de poucos remanescentes corpóreos ou somente elementos ósseos e dentais dessas vítimas, o que, certamente, levará a dificuldades na identificação, no estabelecimento da causa mortis e, até mesmo, dúvidas sobre a existência ou não da exposição a altas temperaturas, que anteriormente parecia óbvio pela observação externa do cadáver, isto porque a ação do calor pode não ocasionar danos evidentes aos tecidos ósseos ou dentais, pois essas estruturas estão protegidas pelos tecidos dérmicos, musculares e gordurosos da face ${ }^{92}$, mas que podem causar modificações nos materiais restauradores odontológicos existentes, esclarecendo, dessa maneira, a escolha pelas temperaturas utilizadas no estudo.

Em 2003, Pereira61 relatou que durante a ação do fogo, a boca das vítimas tende a se fechar, mantendo por um período maior de tempo a umidade das estruturas intrabucais, e com isso, protegendo-as. A língua aumenta de volume, passa a envolver a região do palato e abrigar parte dos dentes do arco superior, oferecendo proteção a essas estruturas. Dessa maneira, o calor instituído pelo fogo, atinge os elementos dentais, em geral, de forma mais branda, sem destruí-los.

Diversos autores analisaram, por inspeção visual, alterações ocorridas nos elementos dentais ${ }^{41,44,58,59,93,94}$ e nos materiais dentários ${ }^{43,45,77,95-100}$, devido à ação do calor. Em vista disso, buscou-se avaliar neste estudo outros aspectos, ainda não relatados na literatura, como: estabilidade de cor; rugosidade de superfície e microdureza de materiais restauradores utilizados em Odontologia após submissão às altas temperaturas.

Além das justificativas anteriores, ou seja, que os dentes e seus materiais restauradores são protegidos, de certa forma, pelas estruturas moles, a metodologia proposta considerou as temperaturas de $100^{\circ} \mathrm{C}, 200^{\circ} \mathrm{C}$ e $300^{\circ} \mathrm{C}$ como parâmetro para submissão das restaurações às altas temperaturas em razão de estudo piloto realizado anteriormente. $\mathrm{O}$ estudo piloto permitiu estabelecer que os grupos amostrais fossem submetidos até $300^{\circ} \mathrm{C}$, porque até esta temperatura, os três materiais restauradores selecionados poderiam ainda ser analisados em todos os testes laboratoriais sugeridos. 
0 amálgama, submetido às temperaturas de $100^{\circ} \mathrm{C}, 200^{\circ} \mathrm{C}$ e $300^{\circ} \mathrm{C}$, apresentou integridade estrutural, de forma que eram possíveis as análises de rugosidade superficial e microdureza. A partir de $400^{\circ} \mathrm{C}$, isso não era possível devido à formação de uma camada de oxidação superficial no material o que inviabilizou as análises de microdureza, pois impediu a visualização da marcação da ponta penetradora do aparelho microdurômetro, impossibilitando, desse modo, a mensuração do valor da microdureza. A partir de $500^{\circ} \mathrm{C}$, os testes de rugosidade de superfície também não foram passíveis de verificação devido à grande irregularidade apresentada pelo material, prejudicando o adequado movimento da agulha do aparelho rugosímetro para aferição dos valores de rugosidade.

Nos ensaios com resina composta, a partir de $400^{\circ} \mathrm{C}$, não se pôde realizar a leitura de cor, pois ocorreu um total enegrecimento deste material restaurador. No CIV, a partir de $400^{\circ} \mathrm{C}$, o material passou a apresentar-se enegrecido com pequenos pontos acinzentados, impossibilitando, tal como na resina composta, a leitura de cor. Foi observado também o surgimento de várias trincas e perda de adesividade do CIV às paredes do preparo cavitário, o que inviabilizou as aferições de rugosidade e microdureza. Diante disso, a presença de material restaurador enegrecido sugere a ocorrência de ação do calor em temperaturas acima de $400^{\circ} \mathrm{C}$.

Incêndios que atinjam a temperatura de $400^{\circ} \mathrm{C}$, no interior da cavidade bucal das vítimas, somente ocorreriam em casos onde a temperatura ambiente estivesse em torno de $800^{\circ} \mathrm{C}$ a $1000^{\circ} \mathrm{C}$, sendo para isso requerido períodos de tempo prolongados de ação do fogo, por volta de 60 minutos ou mais ${ }^{48,52,61}$. Temperaturas e tempo suficientes para consumir os tecidos que protegem a cavidade bucal das vítimas e possibilitar a ação direta do calor sobre os elementos dentais e materiais restauradores odontológicos.

O tempo a que os dentes bovinos restaurados foram submetidos a altas temperaturas, no presente estudo, foi de 15 minutos, seguindo metodologia anteriormente descrita $45,77,95,97,99$, em que os autores concluíram que nas submissões dos materiais restauradores em tempos de 15 até 60 minutos, as alterações permaneciam as mesmas. 


\subsection{Baixas temperaturas (Ação do frio)}

$\mathrm{Na}$ literatura não há relatos de estudos sobre a influência de baixas temperaturas sobre as propriedades físicas e mecânicas dos materiais restauradores odontológicos, principalmente de sua estabilidade de cor, rugosidade de superfície e microdureza para fins periciais.

Devido aos inúmeros episódios de acidentes em locais de neve, avalanches, acidentes de trabalho em câmaras frias e outras situações nas quais a morte do indivíduo se dá em decorrência do congelamento, torna-se importante o estudo das possíveis alterações ocorridas nos materiais dentários em tais situações, buscando sempre subsídios para maior contribuição na elucidação de uma identificação humana.

Poucas horas após um acidente em baixas temperaturas, muito provavelmente, as características somáticas externas do corpo humano não sofrerão mudanças drásticas e, dessa forma, não ocorrerão maiores dificuldades para a identificação do corpo. Entretanto, corpos descobertos e resgatados após períodos de tempo prolongados podem encontrar-se em avançados estágios de decomposição ${ }^{12,16}$.

É sabido que os elementos dentais são as estruturas mais resistentes do corpo humano a temperaturas extremas ${ }^{27}$; consequentemente, a ação do frio não os destruirá, mas ainda poderia causar modificações nos materiais restauradores odontológicos dessas vítimas de morte por congelamento. As alterações em sua cor, rugosidade e/ou microdureza poderiam contribuir com as investigações para confirmação da submissão à ação do frio, além de oferecer informações quanto à temperatura aproximada na qual foram submetidas e o período de tempo a qual foram expostas sob estas condições.

Tais informações podem auxiliar na cronotanatognose, que estuda os meios de determinação do tempo transcorrido entre a morte e o exame do cadáver ou ossada humana. Todavia, deve-se enfatizar que quase a totalidade das técnicas cronotanatognóticas oferecem dados apenas aproximados do lapso de tempo decorrido entre a morte e o exame necroscópico $3,12,16,17$.

Foram selecionadas as temperaturas de $2,5^{\circ} \mathrm{C},\left(-20^{\circ} \mathrm{C}\right)$ e $\left(-80^{\circ} \mathrm{C}\right)$ para a realização dos testes ao frio, pela possibilidade de manutenção precisa dessas temperaturas por meio de aparelhos refrigeradores. 0 tempo de permanência nesses aparelhos foi no 
máximo de 30 dias, com análises após 7 dias e 30 dias. Buscou-se simular situações em que corpos ou ossadas humanas fossem encontrados em curtos espaços de tempo, de aproximadamente uma semana, até períodos de tempos mais prolongados, em torno de 30 dias, sob condições de frio extremo.

Nos grupos que permaneceram no refrigerador $\left(2,5^{\circ} \mathrm{C}\right)$, devido ao ressecamento, normalmente gerado por este tipo de aparelho, os dentes restaurados com materiais estéticos foram inseridos em potes plásticos com tampa, sendo adicionada água destilada em um terço do volume, não imergindo as restaurações na água, a fim apenas de evitar o ressecamento dos dentes e materiais, além de tentar simular condições mais próximas de um acidente no frio, onde também não haveria perda de umidade com o passar do tempo.

\subsection{Análise de cor}

Os compósitos, principalmente as resinas compostas, vêm sendo aprimorados em suas propriedades físico-químicas, com a finalidade de oferecer maior longevidade e o reestabelecimento da aparência natural dos dentes em relação à cor e translucidez, tornando-os materiais restauradores estéticos de escolha na Odontologia101.

Devido à diversidade de indicações, a resina composta e o CIV, são materiais amplamente utilizados no cotidiano do exercício profissional odontológico. Dessa maneira, durante a análise dos arcos dentais de vítimas de acidentes envolvendo altas ou baixas temperaturas, quando os dentes apresentarem-se restaurados, os materiais estéticos presentes, provavelmente, serão a resina composta ou o CIV. Assim, a análise de cor desses materiais pode indicar a ocorrência da ação do calor ou do frio sobre os mesmos.

A estabilidade de cor de materiais restauradores odontológicos pode ser avaliada pela inspeção visual ${ }^{102}$ ou por análise instrumental ${ }^{103-106}$. Neste estudo, foram utilizados os dois métodos de análise, tanto visual como instrumental, antes a após a ação do calor e do frio.

A análise visual é um método subjetivo de avaliação da cor, pois depende do critério individual de cada observador, gerando diferentes interpretações sobre a alteração de cor ocorrida. Diversos fatores como: posição do objeto observado, 
iluminação do ambiente, fadiga e estado emocional do observador podem interferir na análise visual da cor ${ }^{107,108 .}$

No intuito de evitar possíveis erros de interpretação, devido à inerente percepção inconsistente dos observadores, foi utilizado um aparelho espectrofotômetro para uma leitura numérica e precisa da cor ${ }^{109-112}$. Dessa maneira, o uso de instrumentos são mais confiáveis quando comparados à inspeção visual113-115, e necessários no estudo das alterações de cor de materiais restauradores odontológicos estéticos ${ }^{116}$.

O espectrofotômetro possui uma ponteira com 6,0 $\mathrm{mm}$ de diâmetro, o que corresponde à mesma medida das extensões das paredes dos preparos cavitários confeccionados nos dentes bovinos, proporcionando, desse modo, um adequado posicionamento na superfície das restaurações e registro do espectro de cor. 0 diâmetro efetivo da ponteira é de 5,0 mm, assegurando que a leitura de cor fosse realizada somente dentro da área ocupada pelo material restaurador, não havendo qualquer possibilidade da leitura de cor ter sido aferida fora das margens do material.

O espectrofotômetro utiliza a escala CIE L*a*b* para leitura numérica da cor. Esse sistema é largamente aceito para notificação da cor em compósitos ${ }^{117}$. 0 uso de um instrumento para avaliação da estabilidade de cor elimina a possibilidade de erros subjetivos $^{118}$, transformando os resultados em valores numéricos ${ }^{119}$, e dessa forma, padronizando-os. A quantificação numérica da cor é comparada a uma referência padrão, o que permite calcular a alteração de cor e de luminosidade ${ }^{120}$.

Dentre os sistemas de espaço de cor, podemos citar: Sistema Munsell, Sistema de cor natural, Croma Cosmos 500, e outros. A CIE (Comission Internationale de L’Éclairage), isto é, Comissão Internacional de Iluminação, após estudos e aprimoramentos dos sistemas anteriores, recomenda oficialmente, o uso do espaço de cor CIE L*a*b*, que utiliza um espaço de cor tridimensional ${ }^{121}$.

O espaço cromático CIE L*a*b* é formado por uma combinação de coordenadas cilíndricas e cartesianas, onde um ponto está associado a uma única cor. Nesse sistema de coordenadas, tem-se a coordenada da luminosidade (escala de cinza) ou eixo L*. No eixo $L^{*}$, os valores numéricos da cor variam de 0 "zero" (preto) a "100" (branco). Dessa maneira, objetos escuros apresentam valores próximos a "zero" e objetos claros, próximos a “100”120. 
Os outros dois eixos que compõem o sistema CIE $\mathrm{L}^{*} \mathrm{a}^{*} \mathrm{~b}^{*}$, são denominados de coordenadas de cromaticidade, nas quais os valores numéricos variam de -80 a +80 . A coordenada $a^{*}$ trata do eixo vermelho-verde, onde valores positivos (+) nesta coordenada demonstram desvio no sentido da tonalidade vermelha e valores negativos (-), no sentido do verde ${ }^{121}$. Pela ação do calor ou do frio, aumentos nos valores da coordenada a*, indicam ganhos na saturação do vermelho, e diminuição nos valores de a*, indicam perdas na saturação do vermelho.

A coordenada $b^{*}$, trata do eixo amarelo-azul, no qual valores positivos $(+)$ indicam desvio no sentido da tonalidade amarela e valores negativos ( - ), no sentido da tonalidade azul ${ }^{121}$. Aumentos da coordenada b*, demonstram ganhos na saturação do amarelo e diminuição desses valores, perdas na saturação do amarelo.

A alteração de cor de um compósito pode estar relacionada: às características de suas partículas inorgânicas, como tamanho e distribuição na matriz ${ }^{122,123}$; à rugosidade de superfície, acabamento e polimento das restaurações ${ }^{124}$; fatores extrínsecos, como hábitos alimentares, sorção de corantes $^{125}$, fumaça dos cigarros ${ }^{120}$ e por fatores intrínsecos, como a composição química do material, alteração na matriz orgânica ou interface matriz/partícula de carga ${ }^{122,125}$.

Altas ou baixas temperaturas extremas conduzem ao aparecimento de modificações intrínsecas nos compósitos, visto que a cor intrínseca pode ser alterada pela ação de várias condições físico-químicas, como a luz visível, irradiação UV, alterações de temperatura e umidade ${ }^{126,127}$. As modificações de cor nos compósitos podem sugerir se a resina composta ou o CIV foram, realmente, expostos ao calor ou ao frio, e ainda revelar como distinguir estes materiais estéticos em casos de identificação humana, em vítimas carbonizadas ou mortas por congelamento.

As alterações intrínsecas podem ocorrer devido a reações físico-químicas nas porções profundas da restauração ${ }^{128,129}$. Os aditivos químicos dos compósitos, principalmente, os que sofrem reação, como os iniciadores e filtros ultravioletas, podem degradar os componentes de cor ${ }^{130}$, pela ação de temperaturas extremas. 0 inibidor também pode ser causa da descoloração, de forma que o monômero contendo Bis-GMA e peróxido de benzoíla pode estar relacionado à descoloração interna ${ }^{121}$. 
Alguns estudos ${ }^{130,131}$ avaliaram as diversas causas para alteração de cor das resinas compostas e concluíram que a instabilidade química do sistema da resina pode levar a mudança de cor endógena.

Modificações químicas, como a cisão das cadeias poliméricas e a oxidação de componentes, resultantes da degradação térmica geram instabilidades na coloração ${ }^{132}$. Para a descoloração interna das resinas compostas, constataram que nas resinas quimicamente curadas, a alteração de cor endógena está associada ao tipo e à quantidade de amina envolvida na polimerização ${ }^{130}$.

A alteração de cor induzida termicamente geralmente é atribuída à oxidação das aminas aceleradoras ${ }^{133}$. Dentre elas, temos as aminas terciárias aromáticas e as aminas alifáticas ${ }^{134}$. As aminas alifáticas são mais estáveis em relação à cor, quando comparadas às aminas aromáticas ${ }^{135}$. As aminas são conhecidas por formar produtos de reação durante a fotorreação, que tendem a causar a descoloração do material restaurador pela ação de luz e calor.

A descoloração depende da quantidade e do tipo da amina utilizada como acelerador no sistema de fotopolimerização. A descoloração endógena causada pela ação térmica é irreversível, diferentemente da descoloração exógena causada por absorção de corantes e acúmulo de placa, que são facilmente removidos mecanicamente ${ }^{136}$.

Os monômeros presentes na matriz resinosa são geralmente líquidos, que se solidificam durante o processo de polimerização. A extensão na qual ocorre esse processo é denominada de grau de conversão, que é a medida percentual de ligações duplas de carbono consumidas durante o processo de polimerização, servindo como parâmetro indicativo da qualidade de polimerização do material ${ }^{137,138}$.

Desse modo, a resina polimerizada apresenta macromoléculas de monômeros em ligações covalentes entre si. Com a elevação da temperatura da massa, há aumento, proporcionalmente, das vibrações, por agitação térmica dessas moléculas. A degradação da cadeia polimérica só ocorrerá se a energia for superior à necessária para romper tais ligações covalentes ${ }^{139}$. O rompimento dessas ligações, em que elétrons são compartilhados, resulta em redução na estabilidade $\operatorname{cor}^{140,141}$ e na liberação de subprodutos como formaldeído e ácido metacrílico ${ }^{142-144}$. 
Schulze, et al. ${ }^{145}$ (2003) investigaram a estabilidade de cor e dureza da superfície de cinco compósitos diretos quimicamente ativados e cinco compósitos fotopolimerizáveis onde puderam observar que os compósitos fotopolimerizáveis apresentaram maior resistência à descoloração que as resinas quimicamente ativadas. Verificaram também que não houve correlação entre dureza superficial e alteração de cor dos compósitos, rejeitando a hipótese de que quanto maior a dureza do material resinoso, maior seria a estabilidade de cor.

É importante frisar que a avaliação dos materiais restauradores odontológicos e suas modificações frente às condições de altas ou baixas temperaturas é um método auxiliar, nunca um método primário, sendo assim, capaz de oferecer subsídios na busca de uma identidade positiva ou exclusão na identificação de uma pessoa.

Os resultados encontrados após ação do calor foram submetidos à análise estatística segundo One-way ANOVA, teste de Tukey, com nível de significância de 95\%. O fator de variação considerado foi a temperatura. A seleção deste teste estatístico se deu devido à finalidade do estudo (pericial), de forma que todas as variáveis fossem comparadas para todos os materiais em todas as temperaturas, pois poderia haver semelhanças ou diferenças no comportamento dos materiais em temperaturas diferentes. Por exemplo: o comportamento mecânico da resina composta submetida a $100^{\circ} \mathrm{C}$ poderia ser semelhante ao comportamento do CIV submetido a $200^{\circ} \mathrm{C}$. Assim, devido à similaridade estética, o comportamento de resina composta e CIV foram comparados entre si para todas as propriedades. Como o amálgama não é um material estético e pode ser diferenciado visualmente dos demais materiais estudados, a comparação de suas propriedades foi feita somente em relação às temperaturas a que foi submetido.

Nos testes realizados em baixas temperaturas, os resultados foram submetidos à análise estatística 2-way ANOVA, Bonferroni, com nível de significância de 95\%. Os fatores de variação considerados foram temperatura e tempo. 


\section{Delta E}

Os valores de leitura expressos em unidades de $\Delta \mathrm{E}$, que representam mudanças de cor após a ação das altas e baixas temperaturas selecionadas, foram considerados com os seguintes parâmetros ${ }^{146-148}$ :

$\Delta \mathrm{E}<1$ - Alteração de cor muito discreta, não detectada pelo olho humano;

$1 \leq \Delta \mathrm{E} \leq 3,3$ - Alteração de cor detectada pelo olho humano;

$\Delta \mathrm{E}>3,3$ - Alteração de cor intensa, detectada pelo olho humana, causadora de grande alteração estética, clinicamente inaceitável.

$\mathrm{O}$ valor de $\Delta \mathrm{E}$ é calculado com base nos valores das coordenadas $\mathrm{L}^{*}, \mathrm{a}^{*} \mathrm{e} \mathrm{b}^{*}$, onde: $\Delta \mathrm{L}^{*}$ representa a alteração de luminosidade; $\Delta \mathrm{a}^{*}$ representa mudança de tonalidade ao longo da escala do vermelho $\left(+\mathrm{a}^{*}\right)$ / verde $\left(-\mathrm{a}^{*}\right)$ e $\Delta \mathrm{b}^{*}$, mudança na tonalidade ao longo do amarelo $\left(+\mathrm{b}^{*}\right) /$ azul $\left(-\mathrm{b}^{*}\right)^{149}$.

Nos testes em altas temperaturas, foi observado que a resina composta sofreu alteração significativa $(\mathrm{p}<0,05)$ de cor nas três temperaturas avaliadas $\left(100^{\circ} \mathrm{C}, 200^{\circ} \mathrm{C}\right.$ e $300^{\circ} \mathrm{C}$ ) sendo mais intensa quanto maior a temperatura, até $300^{\circ} \mathrm{C}$. No CIV, também ocorreu alteração de cor com o aumento da temperatura, sendo significativamente maior $(p>0,05)$ do que a resina composta em todas as temperaturas.

Os níveis de alteração de cor da resina composta e, principalmente, do CIV, pela ação do calor nas três temperaturas, foram considerados como "alteração de cor intensa, detectada pelo olho humano, causadora de grande alteração estética, clinicamente inaceitável", isto porque, apresentaram valores de $\Delta \mathrm{E}$ bem acima de 3,3.

Segundo Rodriguez e Pereira ${ }^{150}$ (2008), o tamanho e a distribuição das partículas de carga possuem papel importante na alteração da cor, uma vez que, em materiais com partículas maiores, como o CIV, muitas vezes ocorre um descolamento da matriz, aumento da porosidade da restauração ${ }^{151}$ e maior dispersão de luz no interior do material, tornando-o mais opaco ${ }^{152}$, resultando, dessa maneira, em maior alteração de cor do que em materiais com partículas menores e mais agregadas, como é caso da resina composta. Além disso, segundo Papadopoulos, et al. ${ }^{153}$ (2010) há maior facilidade de degradação do CIV, o que o torna mais suscetível a modificações de cor. 
Nos testes em baixas temperaturas, nos primeiros 7 dias de submissão ao frio, nas três temperaturas estudadas, houve alteração de cor nos dois materiais estéticos. Em 30 dias de exposição ao frio, o CIV apresentou modificação em sua cor semelhante à de 7 dias. Na resina composta houve modificação de cor mais intensa em relação à análise de 7 dias, indicando que o tempo de exposição ao frio foi importante para a alteração de cor neste material.

Usualmente, partículas de carga são unidas na matriz orgânica resinosa por meio do agente de união silano, que forma uma interface matriz/carga. Muitas vezes, o y-metacriloxipropril trimetoxi silano é utilizado como agente de união ${ }^{154}$. Temperaturas extremas (altas ou baixas) podem causar uma reação de degradação desta interface matriz/partículas e provocar alterações na cor ${ }^{155}$, pois tal degradação pode modificar o modo como a luz é dispersa pelas partículas ${ }^{104}$.

Provavelmente, quanto mais alta a temperatura na ação do calor, maior a facilidade e abundância da degradação desta interface. No frio, a ação das baixas temperaturas pode ter causado tal degradação na resina composta que, provavelmente, continuou se desenvolvendo com o passar do tempo, mostrado pela maior alteração de cor em 30 dias.

O monômero TEGDMA, presente na composição da resina composta utilizada neste estudo, tem maior predisposição à sorção de água, aumentando a solubilidade do polímero formado ${ }^{104,156,157}$. A umidade presente, nas submissões ao frio, por períodos de tempo prolongados, como 30 dias, pode ter influenciado na alteração de cor deste compósito mais intensamente, do que em períodos menores de exposição ao ambiente úmido, como em 7 dias.

Como visto anteriormente, na resina composta, a reação dos fotoiniciadores pode causar degradação dos componentes da cor. À medida que a temperatura a que o material é exposto diminui, pode haver uma desaceleração da reação química de degradação ${ }^{130}$, pela diminuição da atividade molecular, o que pode se traduzir em maior alteração de cor quanto maior o tempo a que o material foi exposto a baixas temperaturas. 


\section{Delta L}

A alteração de cor $(\Delta \mathrm{E})$ dos materiais restauradores estéticos é o resultado do efeito conjunto das alterações nas coordenadas $L^{*}, a^{*}$ e $b^{*}$. Por isso, além da análise de cor pelo estudo do Delta E, realizou-se também a análise da leitura de cor, em cada coordenada, e de suas alterações $\left(\Delta \mathrm{L}^{*}, \Delta \mathrm{a}^{*}\right.$ e $\left.\Delta \mathrm{b}^{*}\right)$ frente ao calor e ao frio, separadamente, no intuito de adquirir informações complementares visando uma melhor interpretação dos resultados ${ }^{120}$.

A coordenada $L^{*}$ tem grande importância na análise dos resultados da alteração de cor, pois representa a luminosidade das amostras. 0 olho humano é mais sensível às variações neste eixo do que nos eixos $\mathrm{a}^{*} \mathrm{e} \mathrm{b}^{*}$, isto porque a quantidade de células responsáveis pela visão em preto e branco (bastonetes) é muito maior do que a de células responsáveis pela visão colorida (cones). Diante disso, qualquer perda ou ganho de luminosidade será visualizado e interpretado como alteração de $\operatorname{cor}^{158}$.

Pela ação do calor, a resina composta não apresentou alteração de luminosidade, pois o aumento, na média, do valor na coordenada $L^{*}$ após as queimas foi muito discreto, sem significância estatística $(p>0,05)$. Com isso, apenas pela análise na coordenada $\mathrm{L}^{*}$, não é possível afirmar se a resina composta foi submetida ao calor, nem a qual temperatura, até $300^{\circ} \mathrm{C}$.

No CIV, contrariamente ao ocorrido na resina composta, logo após submissão a $100^{\circ} \mathrm{C}$, já foi percebida diminuição do valor da média na coordenada $\mathrm{L}^{*}$, pela presença de $\Delta \mathrm{L}^{*}$ com valor negativo, ou seja, perda de luminosidade. A perda foi mais intensa, isto é, maior foi o escurecimento do CIV, quanto maior a temperatura de submissão, até $300^{\circ} \mathrm{C}$.

Na comparação entre os materiais estéticos, verificou-se que nas exposições ao calor, em $100^{\circ} \mathrm{C}$, a média do valor de $\mathrm{L}^{*}$ dos materiais tornou-se similar, devido à diminuição no CIV, o que conduziu o seu padrão de luminosidade bem próximo ao da resina composta. Em $200^{\circ} \mathrm{C}$ e $300^{\circ} \mathrm{C}$, a grande perda de luminosidade do CIV, tornou-o distinto da resina composta. Portanto, apenas pelo estudo de cor em sua coordenada L*, a distinção dos materiais só é possível quando submetidos em temperaturas de $200^{\circ} \mathrm{C}$ a $300^{\circ} \mathrm{C}$. 
A alteração de cor pode ter sido influenciada pela perda de água, por evaporação, no $\operatorname{CIV}^{159}$, devido à ação do calor, que foi mais intensa quanto maior a temperatura de exposição. 0 ressecamento do material pode conduzir a uma descoloração de tonalidade para mais branca e opaca ${ }^{160}$, fato demonstrado pela perda de luminosidade do CIV na exposição às altas temperaturas.

Nas submissões ao frio, a resina composta não apresentou alteração de luminosidade significativa ( $p>0,05)$ após 7 dias. Com 30 dias de submissão ao frio, ocorreu aumento na coordenada $L^{*}$ (aumento de luminosidade), que foi mais intensa $(\mathrm{p}<0,05)$ na temperatura de $\left(-80^{\circ} \mathrm{C}\right)$. No CIV ocorreu discreta diminuição de luminosidade com a ação do frio nas três temperaturas, porém sem alteração significante ( $p>0,05)$, mesmo após 30 dias.

Dessa forma, não é possível apenas pelo estudo das leituras de cor na coordenada $\mathrm{L}^{*}$, estimar se a resina composta foi exposta ao frio, nem a qual temperatura, até $\left(-80^{\circ} \mathrm{C}\right)$, nos casos de exposição de até 7 dias ao frio. Maiores períodos de submissão ao frio, entre 7 e 30 dias, promoveram aumentos de luminosidade. No CIV, somente pela análise da luminosidade, não há como definir se este material sofreu ação do frio, pois as baixas temperaturas não provocaram alteração significante $(p>0,05)$ na coordenada $L^{*}$, mesmo em temperaturas extremas de $\left(-80^{\circ} \mathrm{C}\right)$ e por períodos prolongados de até 30 dias.

\section{Delta a}

Alterações na coordenada a* referem-se a aumentos ou diminuições na saturação de matiz vermelho. Com a ação do calor, verificou-se aumento na saturação do vermelho para a resina composta, sendo mais intenso na temperatura de $300^{\circ} \mathrm{C}$. Foi percebido que entre $100^{\circ} \mathrm{C}$ e $200^{\circ} \mathrm{C}$ a saturação do vermelho permaneceu estável e a partir de $200^{\circ} \mathrm{C}$ até $300^{\circ} \mathrm{C}$, o aumento foi bastante significativo.

No CIV, também foi observado aumento na saturação do vermelho, mais intensamente a $200^{\circ} \mathrm{C} \mathrm{e} 300^{\circ} \mathrm{C}$. A coordenada a* teve aumento significativo entre $100^{\circ} \mathrm{C}$ e $200^{\circ} \mathrm{C}$ e permaneceu estável a partir de $200^{\circ} \mathrm{C}$ até $300^{\circ} \mathrm{C}$. Na análise comparativa entre os dois materiais, a resina composta exposta a $100^{\circ} \mathrm{C}$ e $200^{\circ} \mathrm{C}$ apresentou comportamento similar ao $\mathrm{CIV}$ submetido a $100^{\circ} \mathrm{C}$, de forma que não há como diferenciar os materiais somente pela análise da coordenada a*. 
Na ação do frio, pelo período de 7 dias, a resina composta aumentou a saturação do vermelho em $2,5^{\circ} \mathrm{C}$ e $\left(-20^{\circ} \mathrm{C}\right)$, sendo mais intenso $(\mathrm{p}<0,05)$ em $2,5^{\circ} \mathrm{C}$ A saturação do vermelho manteve-se estável quando a resina composta foi submetida a $\left(-80^{\circ} \mathrm{C}\right)$. Quanto mais baixa foi a temperatura de submissão, maior foi a estabilidade da coordenada a*. Após 30 dias, a estabilidade na tonalidade do vermelho também foi maior na temperatura de $\left(-80^{\circ} \mathrm{C}\right)$.

Temperaturas muito baixas, como a $\left(-80^{\circ} \mathrm{C}\right)$, podem ter causado um rápido congelamento da matriz, e assim, um bloqueio ou, no mínimo, diminuição na movimentação dos elétrons, como uma espécie de solidificação das ligações covalentes e enrijecimento das cadeias poliméricas, oferecendo maior estabilidade de cor, comparada às outras temperaturas. Portanto, menor mobilidade das moléculas em sua estrutura proporcionam à matriz um maior grau de organização e menor formação de subprodutos, conduzindo a uma maior estabilidade de cor $^{161}$.

Para o CIV, no período de 7 dias, contrariamente ao ocorrido na resina composta, foi visto diminuição na saturação da tonalidade do vermelho, sendo menos intensa em $\left(-80^{\circ} \mathrm{C}\right)$. Pelos resultados obtidos em 30 dias, verificou-se que com maior período de tempo de exposição, a coordenada a* manteve-se estável, em média, fazendo com que o CIV não perdesse saturação do vermelho.

Após 7 dias, a diminuição na coordenada a* do CIV, pode ter ocorrido devido à sorção de água, e consequente "embranquiçamento" do material, principalmente quando refrigerado a $2,5^{\circ} \mathrm{C}$, gerando a formação de um tom de cor com características de maior palidez. De maneira similar, à resina composta, o congelamento da matriz de hidrogel do $\mathrm{CIV}$, em poucos minutos, quando submetido a $\left(-80^{\circ} \mathrm{C}\right)$, pode ter resultado em menor capacidade de sorção de água e assim maior estabilidade de cor desta coordenada nessa temperatura. Períodos prolongados de exposição ao frio podem ter gerado este mesmo efeito, com menor sorção de água e maior estabilidade nesta coordenada.

As modificações na tonalidade do vermelho foram mais significantes $(\mathrm{p}<0,05)$ após 30 dias, em relação a 7 dias, para a resina composta. Apenas pela análise da coordenada $a^{*}$, não é possível distinguir os dois materiais estéticos, em nenhuma das temperaturas selecionadas no frio. 


\section{Delta b}

Mudanças nos valores da coordenada $b^{*}$, indicam alteração na saturação da tonalidade (matiz) do amarelo. Na resina composta, pela ação do calor, ocorreu aumento na coordenada $b^{*}$, ou seja, aumento na saturação do amarelo, nas três temperaturas testadas, sendo mais intenso o "amarelamento" na submissão a $300^{\circ} \mathrm{C}$. 0 "amarelamento" da resina composta, pelas altas temperaturas, pode ser resultado da degradação do fotoiniciador canforoquinona ${ }^{136,162}$.

No CIV, foi observado maior "amarelamento" do material quando submetido a $100^{\circ} \mathrm{C}$. Na exposição a $200^{\circ} \mathrm{C}$ houve um aumento na tonalidade do amarelo de forma menos intensa e a $300^{\circ} \mathrm{C}$, opostamente, verificou-se a presença de valores negativos de $\Delta \mathrm{b}^{*}$, significando diminuição na saturação do matiz amarelo, tornando-se mais opaco e mostrando aparência mais branca, provavelmente devido ao ressecamento do material.

Diante dessa constatação, quando os materiais estéticos são submetidos à temperatura de $300^{\circ} \mathrm{C}$, os mesmos podem ser facilmente distinguidos devido ao intenso "amarelamento" ocorrido na resina composta e o "embranquiçamento" no CIV. Em submissões até a temperatura de $200^{\circ} \mathrm{C}$, não é possível diferenciá-los somente pela análise da coordenada b*.

Nos testes ao frio, com 7 dias de exposição às baixas temperaturas, a resina composta apresentou um "amarelamento", sendo mais discreto quanto mais baixa foi a temperatura. Com isso, temperaturas extremamente baixas parecem gerar maior estabilidade na saturação da tonalidade do amarelo. No CIV, contrariamente, ocorreu diminuição na saturação do amarelo, o que levou a uma aparência mais opaca da restauração. Da mesma maneira que na resina composta, quanto mais baixa a temperatura de exposição, maior foi a estabilidade na coordenada b* para o CIV.

Para a resina composta, o rápido congelamento das cadeias poliméricas a $\left(-20^{\circ} \mathrm{C}\right)$ e, predominantemente, a $\left(-80^{\circ} \mathrm{C}\right)$, pode ter gerado menor degradação da canforoquinona e resultado em maior estabilidade na coordenada b*. No caso do CIV, mais hidrofílico quando comparado à resina composta, a maior sorção de água pode ter resultado em uma descoloração para a tonalidade branca e opaca, principalmente a $2,5^{\circ} \mathrm{C}$, temperatura esta em que há apenas resfriamento do material, sem atingir o ponto de congelamento ${ }^{129,163}$. 
A presença de água destilada no interior dos potes colocados no refrigerador a $2,5^{\circ} \mathrm{C}$, mesmo que não suficiente para imergir as restaurações em água, acaba por proporcionar maior contato do material com umidade, porém sem ocorrer congelamento, o que leva à alta possibilidade de sorção de água. Nas temperaturas de $\left(-20^{\circ} \mathrm{C}\right)$ e $\left(-80^{\circ} \mathrm{C}\right)$, as alterações do $\mathrm{CIV}$ podem ter sido menos intensas pelo rápido congelamento do material.

Além do mais, no refrigerador $\left(2,5^{\circ} \mathrm{C}\right)$ há maior exposição à luz, em razão da maior frequência de abertura do mesmo, o que resulta em maior exposição do material à luz do ambiente externo e à luz interna do próprio refrigerador, que acende com a abertura da porta, podendo ser fator adicional à maior instabilidade na coordenada b*

Uchida, et al. ${ }^{164}$ (1998) e Buchalla, et al. ${ }^{163}$ (2002) verificaram que a resina composta sofre "amarelamento" quando exposta à luz ultravioleta e que a intensidade da alteração de cor é mais intensa na presença de água. Leibrock, et al. ${ }^{165}$ (1997) citam a hipótese de que a reação com o oxigênio ativado pela energia luminosa ou pelo calor gerado pela mesma, conduz à formação de peróxidos amarelados, promovendo alterações de cor.

Após 30 dias de submissão ao frio, foi vista a ocorrência de um "amarelamento" tanto na resina composta como no CIV. $\mathrm{O}$ aumento na tonalidade do amarelo para a resina composta foi mais intenso do que em 7 dias, mostrando que o maior tempo de ação do frio, até 30 dias, causou maior alteração na coordenada b*.

Na resina composta, com o passar do tempo, pode ser que vá ocorrendo uma gradual degradação da canforoquinona, o que demonstra a maior alteração em 30 dias do que em 7 dias. Porém, temperaturas extremamente baixas parecem estabilizar tal degradação, visto que à $\left(-80^{\circ} \mathrm{C}\right)$, a modificação na coordenada $\mathrm{b}^{*}$ é mais discreta, comparada a $\left(-20^{\circ} \mathrm{C}\right)$ e $2,5^{\circ} \mathrm{C}$.

No CIV, o grau de "amarelamento" foi semelhante nas três temperaturas avaliadas. As menores alterações da coordenada b*, para os dois materiais, nos tempos testados, ocorreram em $\left(-80^{\circ} \mathrm{C}\right)$, confirmando a maior estabilidade desta coordenada quanto menor a temperatura de submissão. 


\subsection{Análise visual}

A análise visual das restaurações foi realizada por imagens fotográficas dos dentes bovinos colocados em um posicionador, confeccionado, exclusivamente, para este estudo, a fim de obter imagens com padronização de posição, angulação e iluminação, possibilitando, assim, a comparação das mesmas restaurações, antes e após a ação do calor e do frio a que foram submetidas.

Nas restaurações em resina composta foi observado que a ação do calor provocou aparente "escurecimento" e "amarelamento" das restaurações em todas as temperaturas avaliadas, sendo mais intensa e perceptível quanto maior a temperatura de exposição, até $300^{\circ} \mathrm{C}$. Como visto na análise de cor pelo método instrumental, a resina não sofreu real escurecimento, isto porque, com a ação do calor não houve diminuição de luminosidade, mas um aumento na saturação do matiz amarelo e do vermelho, propiciando à restauração um tom mais alaranjado, principalmente em $300^{\circ} \mathrm{C}$, dando a impressão visual de escurecimento. Na ação do frio, da mesma forma, o aparente "escurecimento" da resina composta, não se dá por perda de luminosidade, mas sim devido aos aumentos ocorridos nos valores das coordenadas a* e b*.

Miguel e $\operatorname{Sosa}^{96}$ (1996) observaram que em exposições até $120^{\circ} \mathrm{C}$, não ocorria alteração de cor na resina composta pela análise visual, e a $200^{\circ} \mathrm{C}$ iniciava-se a percepção de "escurecimento", tornando-se marrom a 350 C. Steagall e Silva97 (1996) não constataram modificações na cor da resina composta por análise visual em submissões a $200^{\circ} \mathrm{C}$, pelo tempo de 10 minutos, somente percebendo "escurecimento" do material em exposições a $400^{\circ} \mathrm{C}$. Brandão, et al. ${ }^{166}$ (2007) também por inspeção visual, só verificaram "amarelamento" e "escurecimento", significantemente perceptível, em submissões a $400^{\circ} \mathrm{C}$. Entretanto, neste estudo, em exposições ao calor a partir de $400^{\circ} \mathrm{C}$, pelo período de 15 minutos, houve um total enegrecimento da resina composta, o que impossibilitou qualquer análise de cor.

A alteração de cor na resina composta verificada neste estudo, já em exposições a $100^{\circ} \mathrm{C}$, demonstram a maior sensibilidade do método instrumental, por meio do uso do espectrofotômetro, em detrimento ao método visual, pois por inspeção visual, as alterações na cor da resina composta, comumente, só são perceptíveis ao olho humano, em submissões a temperaturas bem superiores, acima de $200^{\circ} \mathrm{C}$. 
Spadácio, et al. ${ }^{77}$ (2011) por análise visual, observaram "embranquiçamento" da resina composta quando exposta a $100^{\circ} \mathrm{C}$, por 15 minutos; "amarelamento" e "escurecimento" a $200^{\circ} \mathrm{C}$ e $300^{\circ} \mathrm{C}$, por 15 minutos. Porém, neste estudo não foi visto "embranquiçamento" em nenhuma das temperaturas testadas.

Para o CIV, as imagens fotográficas revelaram um "embranquiçamento" e opacificação do material, que foram mais intensos à medida que a temperatura de submissão foi mais alta, até $300^{\circ} \mathrm{C}$. No caso do CIV, o aspecto de opacidade ocorreu devido à perda de luminosidade e de água pela ação do calor.

Em relação à cromaticidade, em todas as altas temperaturas avaliadas, verificouse aumento na saturação do vermelho para o CIV. Quanto ao "amarelamento", foi constatado nas exposições a $100^{\circ} \mathrm{C}$, menor em $200^{\circ} \mathrm{C}$ e "embranquiçamento" a $300^{\circ} \mathrm{C}$ devido à diminuição dos valores na coordenada $b^{*}$ a partir desta temperatura, possivelmente, pela maior perda de água.

Merlati, et al. ${ }^{56}$ (2002) por inspeção visual, verificaram que o $\mathrm{CIV}$ a $200^{\circ} \mathrm{C}$ tornouse opaco e com perda de união ao tecido dental. Spadácio, et al. ${ }^{77}$ (2011) observaram "embranquiçamento" do CIV quimicamente ativado a partir de $100^{\circ} \mathrm{C}$; aspecto de desidratação e deslocamento da cavidade a partir de $200^{\circ} \mathrm{C}$. Esses resultados foram similares aos encontrados neste estudo, em que houve perceptível opacificação, perda de adesividade e formação de pequenas fendas entre o CIV e as paredes do preparo cavitário nas exposições a partir de $200^{\circ} \mathrm{C}$.

Nos testes ao frio, o "escurecimento" relatado para a resina composta, predominantemente após 30 dias de exposição às baixas temperaturas, se deve ao aumento na saturação do amarelo e do vermelho e não, propriamente, por diminuição de luminosidade, o que causaria um real escurecimento do material. À instrumentação, verificou-se que houve aumento na coordenada $L^{*}$, ou seja, aumento de luminosidade com o frio e não diminuição nesta coordenada. Dessa maneira, altos valores, acima do padrão, verificados para as coordenadas $a^{*}$ e $b^{*}$, na resina composta, podem sugerir que este material foi exposto ao frio por período prolongado de tempo, provavelmente, maior do que 7 dias.

No CIV, o "escurecimento" relatado pela inspeção visual, ocorreu devido à discreta perda de luminosidade pela ação das baixas temperaturas. A opacificação do 
CIV não foi observada como na submissão ao calor, pois este material não sofreu significativa perda de água durante a exposição às baixas temperaturas, sendo que o meio manteve-se úmido.

Na análise visual das restaurações de amálgama, após a submissão ao calor, foi observada perda de brilho do material em todas as temperaturas, sendo mais intensa e perceptível a $300^{\circ} \mathrm{C}$. Nesta temperatura, iniciou-se a formação de bolhas superficiais devido à evaporação do mercúrio ${ }^{56,98}$, constituinte da composição do amálgama, logo após a retirada do forno. Com o resfriamento do material, os locais anteriormente ocupados pelas bolhas, tornaram-se bastante ásperos e rugosos. Assim, altos valores de rugosidade, acima do padrão, podem indicar que este material foi submetido a temperaturas acima de $300^{\circ} \mathrm{C}$.

Pueyo, et al.167 (1994) avaliaram a temperatura de fusão de diversos materiais odontológicos e verificaram que o amálgama inicia a liberação de vapores de mercúrio em sua superfície ao atingir $200^{\circ} \mathrm{C}$. Entretanto, no presente estudo verificou-se que a liberação de mercúrio e, consequente, formação de bolhas superficiais, ocorreram nas submissões a $300^{\circ} \mathrm{C}$. Até $100^{\circ} \mathrm{C}$ não houve mudanças perceptíveis no amálgama, resultados semelhantes a Miguel e $\operatorname{Sosa}^{96}$ (1996), que encontraram alterações no amálgama apenas após $120^{\circ} \mathrm{C}$ e que exposições a $150^{\circ} \mathrm{C}$ aumentavam o brilho do material. Estes últimos resultados contradizem os encontrados no presente estudo, pois em todas as altas temperaturas analisadas houve perda de brilho da restauração. A diminuição no brilho em restaurações de amálgama também foram constatadas por Spadácio, et al. ${ }^{99}$ (2011).

\subsection{Rugosidade de superfície}

A rugosidade de um material restaurador odontológico refere-se às irregularidades mais finas de sua superfície, quantificada por parâmetros relacionados à altura (amplitude) e largura (espaçamento) ou combinação de ambos ${ }^{168}$, que podem ocorrer devido às características inerentes ao próprio material ${ }^{122}$, pelos procedimentos operatórios utilizados durante a confecção da restauração ${ }^{169}$ e pelo polimento realizado pelo profissional ${ }^{170-174}$. 
Os aspectos estruturais do compósito e as características das partículas de carga têm um impacto direto sobre a rugosidade de superfície e manchamento do compósito ${ }^{175}$.

$\mathrm{Na}$ mensuração da rugosidade de superfície de um material restaurador e detecção de suas alterações, o uso do rugosímetro apresenta-se como um sistema de alta fidelidade176. A leitura da rugosidade é realizada pela ponta ativa (agulha) do equipamento, constituída por uma extremidade de diamante, em formato de triângulo equilátero cujo lado apresenta medida de $5 \mu \mathrm{m}^{177}$.

A ponta ativa desliza sobre as irregularidades (picos, vales e ondas) de um determinado segmento do material, realizando a sondagem de sua superfície e registrando os valores analisados. Nessa análise deve ser aplicado um padrão de filtragem, denominado cut-off, a fim de evitar que irregularidades e possíveis ondulações se sobreponham, interferindo na análise final da rugosidade de superfície ${ }^{177}$.

O parâmetro Ra (roughness average), utilizado neste estudo, retrata a média da rugosidade analisada. A leitura da rugosidade de superfície por este parâmetro limita-se à leitura horizontal $78,178,179$. No entanto, para esse tipo de análise é amplamente utilizado $^{180}$. Por essa razão foi selecionado para este trabalho, por proporcionar adequadas condições comparativas a outros trabalhos similares ${ }^{181,182}$.

Pelos resultados obtidos neste estudo, foi verificado que a ação do calor, até a temperatura de $300^{\circ} \mathrm{C}$, não causou alteração estatisticamente significante $(p>0,05)$ na rugosidade de superfície da resina composta. Dessa maneira, apenas pela análise da alteração de rugosidade, não é possível determinar se a resina composta foi exposta ao calor, nem a qual temperatura, até $300^{\circ} \mathrm{C}$, este material foi submetido.

Em relação ao CIV, a ação do calor provocou um aumento gradual em sua rugosidade, que foi maior quanto mais alta a temperatura de exposição, até $300^{\circ} \mathrm{C}$. Não houve diferença significativa $(p>0,05)$ entre os grupos amostrais submetidos a $100^{\circ} \mathrm{C}$ e $200^{\circ} \mathrm{C}$, da mesma maneira que não ocorreu modificação estatisticamente significante $(\mathrm{p}>0,05)$ entre $200^{\circ} \mathrm{C}$ e $300^{\circ} \mathrm{C}$. Porém, na análise comparativa entre $100^{\circ} \mathrm{C}$ e $300^{\circ} \mathrm{C}$ foi percebida alteração significativa $(\mathrm{p}<0,05)$ na rugosidade de superfície do CIV. 0 ressecamento e surgimento de pequenas trincas no CIV, pela submissão a $300^{\circ} \mathrm{C}$, pode ter gerado maior aumento de sua rugosidade. 
A distinção entre a resina composta e o CIV, pelo estudo da rugosidade de superfície, foi possível porque o padrão de rugosidade destes dois materiais não é similar, independentemente da ação do calor, o qual tornou essa distinção ainda mais evidente à medida que a temperatura de exposição aumentou, até $300^{\circ} \mathrm{C}$, devido à alteração ocorrida no CIV.

Neste estudo, a rugosidade de superfície da resina composta, em média, apresentou-se sempre menor do que o CIV corroborando resultados de Liberman e Geiger $^{183}$ (1994); Araújo, et al. ${ }^{184}$ (1998) e Sasaki, et al. ${ }^{185}$ (2000) segundo os quais, CIVs são mais rugosos que as resinas compostas em razão da própria composição do material.

As resinas compostas e os ionômeros de vidro apresentam componentes inorgânicos em sua composição e com isso podem sofrer alterações em sua rugosidade ${ }^{186,187}$. Em relação ao tamanho das partículas, as resinas compostas possuem as menores partículas inorgânicas ${ }^{188}$, enquanto os CIV convencionais, as maiores ${ }^{189}$. Esse fato proporciona maiores irregularidades na superfície do CIV.

Apesar da dissimilaridade na rugosidade de superfície entre os materiais poder ser atribuída, principalmente, a diferenças no tamanho e volume de partículas de carga, outros fatores são capazes de influenciar na rugosidade como: tipo de carga, grau de conversão da matriz polimérica ${ }^{190}$, composição da matriz orgânica, quantidade da matriz inorgânica, além de fatores relacionados ao paciente (dieta, higiene oral, técnicas de escovação) ${ }^{191}$.

Outra justificativa para a diferença de rugosidade entre resina composta e CIV é que a superfície da primeira é mais lisa, sem irregularidades significativas, quando comparada com a do segundo, que apresenta certa rugosidade inerente ao material em virtude da presença de partículas de vidro de forma irregular que, normalmente, estão expostas $^{192}$. Além do mais, porosidades são evidentes em todos os produtos que requerem para sua aglutinação, uma mistura de pó e líquido ${ }^{193}$.

A resina composta utilizada neste estudo é um compósito microhíbrido de nanopartículas, dessa maneira as partículas de carga são menores e mais homogêneas. Assim, estão mais próximas umas das outras, reduzindo o espaço intersticial das partículas, aumentando a quantidade de carga e melhorando as propriedades mecânicas, 
como a rugosidade de superfície ${ }^{194,195}$. O tamanho menor e a melhor distribuição das partículas na matriz orgânica ${ }^{169}$ reduzem a quantidade de matriz exposta à ação do calor quando comparada ao CIV. Temperaturas até $300^{\circ} \mathrm{C}$, não foram capazes de gerar perdas suficientes na resina composta para a ocorrência de alteração significativa de sua rugosidade.

As altas temperaturas provocaram aumento na rugosidade do CIV, provavelmente, pela evaporação e consequente perda de água (sinérese), expondo suas partículas de carga, o que tornou maior sua rugosidade de superfície. Além disso, após $300^{\circ} \mathrm{C}$ houve o surgimento de pequenas linhas de fratura na superfície do CIV que levaram ao aumento ainda maior em sua rugosidade.

No amálgama, a ação do calor a $100^{\circ} \mathrm{C}$ e $200^{\circ} \mathrm{C}$ não provocou alteração significativa estatisticamente $(p>0,05)$ na rugosidade de superfície do material. Na submissão a $300^{\circ} \mathrm{C}$, foi verificada modificação significante $(\mathrm{p}<0,05)$ quando comparada aos grupos expostos a $100^{\circ} \mathrm{C}$ e $200^{\circ} \mathrm{C}$. Em $300^{\circ} \mathrm{C}$, observou-se a formação de bolhas positivas devido à evaporação do mercúrio constituinte da composição do amálgama, o que gerou aumento da rugosidade de superfície. Portanto, o aumento significativo da rugosidade do amálgama se dá a partir do momento em que ocorre a evaporação do mercúrio 43,45 .

Nos testes realizados ao frio não foi verificada a ocorrência de alterações estatisticamente significantes $(\mathrm{p}<0,05)$ em nenhum dos três materiais restauradores avaliados. Em baixas temperaturas, até $\left(-80^{\circ} \mathrm{C}\right)$, não houve modificações estruturais capazes de alterar a rugosidade dos materiais. Então, apenas pela análise da rugosidade de superfície não é possível afirmar se os materiais restauradores odontológicos estudados sofreram ou não a ação do frio, nem a qual temperatura foram submetidos, até $\left(-80^{\circ} \mathrm{C}\right)$, mesmo que expostos por períodos de tempo prolongados, de até 30 dias.

A distinção entre os materiais estéticos pode ser realizada pela análise da rugosidade de superfície, pois o padrão de rugosidade da resina composta é diferente do CIV, independentemente da ação do frio, até mesmo porque as baixas temperaturas não foram capazes de modificar, de maneira significativa, a rugosidade desses materiais. 


\subsection{Microdureza}

A microdureza é uma das características importantes para compararmos materiais dentários ${ }^{189,196}$, quando submetidos a diversas condições, fornecendo dados a respeito de suas propriedades mecânicas ${ }^{197}$. A análise da microdureza superficial de um material restaurador está comumente relacionada com força mecânica, rigidez e resistência do compósito ${ }^{198}$.

O estudo das propriedades mecânicas implica no exame das relações entre um corpo, constituído de determinado material, e as forças que atuam sobre o mesmo, assim como as consequências dessa relação ${ }^{199}$. A microdureza é uma propriedade mecânica definida como a mensuração da resistência à deformação permanente e é medida por meio da relação da força aplicada pela área de edentação 200 .

Cada material apresenta uma característica de comportamento mecânico mediante a aplicação de uma carga. 0 tempo de edentação pode influenciar nos valores de microdureza, particularmente dos polímeros, como a resina composta, por serem viscoelásticos, ou seja, apresentarem desempenho de um material viscoso, os quais se deformam permanente e progressivamente em função do tempo de aplicação da $\operatorname{carga}^{201}$.

As resinas compostas são polímeros dimetacrilatos que compreendem uma mistura de partículas inorgânicas de elevada resistência, dispersas por uma matriz polimérica. Possuem três componentes principais: a matriz; constituída por um sistema de monômero, um sistema iniciador para polimerização de radicais livres e estabilizadores; partículas inorgânicas e o agente de união, que se une quimicamente, reforçando a ligação da partícula de carga com a matriz $200,202,203$.

A resina microhíbrida usada neste estudo é composta por partículas de zircônia e sílica com tamanho médio de $0,6 \mu \mathrm{m}$ (de $0,01 \mu \mathrm{m}$ a 3,5 $\mu \mathrm{m}$ ); combinação de sílica com tamanho de 20nm não-aglomeradas/não agregadas; zircônia com tamanho de 4-11nm não-aglomeradas/não-agregadas e aglomerados de partículas agregadas de zircônia/sílica (combinação de partículas de sílica com 20nm e zircônia com 4-11 nm), constituindo $60 \%$ do volume total ${ }^{204-206}$. 
Considerando a estrutura do polímero, as partículas de carga poderiam influenciar na rigidez da cadeia polimérica, que é controlada pela facilidade com que ocorrem as mudanças na conformação das ligações químicas ao longo da cadeia. Desse modo, a presença das partículas de carga na cadeia do polímero tenderia a reduzir a mobilidade da cadeia e, consequentemente, enrijecer a cadeia molecular principal ${ }^{207}$.

A microdureza depende basicamente de três variáveis: o material ensaiado, a geometria do penetrador e a força aplicada ${ }^{208}$. 0 edentador Knoop, em virtude da forma assimétrica, apresenta a recuperação elástica da impressão projetada, primariamente, ao longo da diagonal menor. As tensões produzidas no ensaio são distribuídas de tal modo que somente a dimensão do eixo menor da penetração fique sujeita às alterações por relaxamento fazendo com que praticamente independa da ductibilidade do material analisado 209 .

Em vista disso, a vantagem do estudo da microdureza Knoop é a correlação entre a dureza de materiais restauradores distintos ${ }^{198}$, já que o amálgama, diferentemente da resina composta e do CIV, é considerado um material friável, isto é, quando submetido a uma tensão não apenas se deforma, mas sim fratura ${ }^{200,209}$.

Segundo McCabe e Walls ${ }^{210}$ (1998) após a aplicação do edentador, a força aplicada se espalha na superfície do material, a qual responde com uma tensão e uma deformação do local. A extensão da tensão está relacionada com o limite elástico ou limite de proporcionalidade do material testado, que é a capacidade do material voltar à condição anterior sem ocorrer deformação permanente. Qualquer outra deformação de provável natureza elástica, não será computada como parte da mensuração de microdureza por causa da recuperação elástica.

Pelos resultados obtidos, em relação às alterações de microdureza Knoop, foi verificado que a ação do calor, nas temperaturas de $100^{\circ} \mathrm{C}, 200^{\circ} \mathrm{C}$ e $300^{\circ} \mathrm{C}$, não foram capazes de provocar mudanças significativas $(p>0,05)$ na resina composta. Desse modo, apenas pela análise da microdureza, não há possibilidade de definir se a resina composta foi exposta ao calor, nem a qual temperatura foi submetida, até $300^{\circ} \mathrm{C}$, resultados semelhantes aos de Basting et al. ${ }^{211}$ (2002).

Entretanto, há estudos que contradizem os achados do presente estudo, segundo os quais o calor pode levar à degradação da resina composta a temperaturas 
próximas de $150^{\circ} \mathrm{C}^{212}$, quando os compostos orgânicos sofrem combustão e volatilização com consequente perda de massa. A perda em massa de matriz orgânica e o, decorrente, aumento da porção inorgânica, por esta perda, com a ação de altas temperaturas, poderia levar ao aumento da microdureza da resina composta213,214.

O calor também seria fator de polimerização adicional com o objetivo de aumentar o grau de conversão, melhorando suas propriedades mecânicas ${ }^{215,216}$, o que poderia elevar sua microdureza. 0 calor próximo à temperatura de transição vítrea (TG) contribui para o aumento do grau de conversão da resina, proporcionando à matriz uma estrutura mais homogênea e resistente ${ }^{217}$. A TG é usualmente expressa como a temperatura em que a energia de ativação para o movimento cooperativo das cadeias poliméricas é atingida, fazendo com que o material passe de sólido rígido para borrachóide. Isso permite que as cadeias deslizem umas sobre as outras quando uma força é aplicada ${ }^{212}$.

Assim, o calor em uma temperatura superior à TG, enfraquece as interações moleculares e, como consequência, as propriedades dos materiais são otimizadas, já que radicais presos têm a oportunidade de reagir com o ganho de energia. Por outro lado, o aquecimento excessivo da resina composta pode gerar perda de massa da matriz orgânica e acarretar aumento da microdureza ${ }^{216,218}$. Todavia, os resultados encontrados no presente estudo, em submissões até $300^{\circ} \mathrm{C}$, contradizem esses argumentos.

Quanto ao CIV submetido às altas temperaturas, verificou-se que houve aumento significante $(\mathrm{p}<0,05)$ em sua microdureza Knoop, sendo mais intenso quanto maior a temperatura de exposição, até $300^{\circ} \mathrm{C}$. Em $100^{\circ} \mathrm{C}$, a microdureza elevou-se, aproximadamente, em cinco vezes, comparada à média antes da ação do calor. A $200^{\circ} \mathrm{C}$, a elevação da microdureza foi ainda maior, chegando a um aumento em torno de 20 vezes ao valor da média inicial. Nas restaurações expostas a $300^{\circ} \mathrm{C}$, o índice de aumento da microdureza manteve-se bastante alto, sendo um pouco superior comparado ao aumento em $200^{\circ} \mathrm{C}$.

Na distinção entre os materiais estéticos, o CIV submetido a $200^{\circ} \mathrm{C}$ e $300^{\circ} \mathrm{C}$, tem sua microdureza Knoop bastante elevada, mostrado pelos altos valores de $\Delta K H N$, tornando a microdureza deste material tão alta que ultrapassa os padrões de microdureza de uma resina composta. Com isso, quando os dois materiais são 
submetidos ao calor, em temperaturas de $200^{\circ} \mathrm{C}$ a $300^{\circ} \mathrm{C}$, é possível distingui-los apenas por meio da análise da microdureza Knoop.

No CIV, a exposição prematura à umidade ou ressecamento excessivo, podem causar efeitos deletérios ao material, uma vez que a água é essencial para a formação da matriz do cimento, sendo extremamente importante a manutenção do equilíbrio hídrico ${ }^{75}$. Se ocorrer a perda de água (sinérese), haverá alterações dimensionais que poderão afetar a adesão à estrutura dental e as propriedades mecânicas do material, indicando que as propriedades iniciais do material podem não ser as mesmas após algum período.

Os maiores valores de microdureza Knoop são verificados em áreas compostas por maior quantidade de partículas de vidro ${ }^{219}$. Pela ação do calor, ocorre perda de água e redução da matriz do CIV, com isso há um aumento proporcional do percentual de partículas de carga. Maior concentração de partículas de sílica e uma microestrutura mais integrada contribuem para maior dureza. Alguns trabalhos ${ }^{220-222}$ observaram aumento das propriedades mecânicas, como a dureza, do CIV devido ao ressecamento deste material.

Alguns autores $220,223,224$ afirmam que, geralmente, ocorre um aumento nos valores de microdureza dos CIVs com o passar do tempo. Esse aumento da microdureza, provavelmente, está relacionado com a reação ácido-base que se dá de maneira lenta e contínua, onde prótons atacam e degradam a estrutura do vidro de aluminosilicato, liberando íons cálcio, estrôncio e alumínio que reagem com os grupos carboxílicos. Esta última reação, que forma a ligação cruzada das cadeias de policarboxilatos, é um processo contínuo e que perdura por um longo período ${ }^{75}$.

Entretanto, nos testes às baixas temperaturas $\left(2,5^{\circ} \mathrm{C},-20^{\circ} \mathrm{C}\right.$ e $\left.-80^{\circ} \mathrm{C}\right)$, realizados neste estudo, mesmo após 30 dias de submissão ao frio, não ocorreram mudanças significativas $(p>0,05)$ na microdureza de nenhum dos materiais estudados, inclusive $o$ CIV. Talvez o período de 30 dias tenha sido curto para a ocorrência de tais modificações ou a ação do frio tenha retardado a reação ácido-base do CIV.

Como as baixas temperaturas avaliadas não causaram mudanças nesta propriedade mecânica, a distinção entre os materiais estéticos, após submissão ao frio, pode ser realizada pelo estudo da microdureza Knoop, porque o padrão de dureza da 
resina composta é bastante distinto do CIV. As resinas compostas apresentam maiores valores de microdureza superficial em relação aos CIVs, fato que pode estar relacionado ao tipo e quantidade de carga inorgânica em volume em sua composição ${ }^{74}$.

Em relação ao amálgama de prata, foi utilizado neste estudo o amálgama précapsulado gs-80 (SDI ${ }^{\circledR}$ ), que contém partículas esféricas e alto teor de cobre. Composto por: prata $(40 \%)$, estanho $(31,3 \%)$ e cobre $(28,7 \%)^{225}$. Os maiores valores de microdureza são obtidos nos amálgamas com alto teor de cobre quando comparados ao amálgama convencional $226-228$.

De acordo com os resultados obtidos para o amálgama de prata, não houve alteração significativa ( $>0,05)$ da microdureza a $100^{\circ} \mathrm{C}, 200^{\circ} \mathrm{C}$ e $300^{\circ} \mathrm{C}$. Portanto, é possível afirmar que, somente por meio da análise da microdureza Knoop, não há como determinar se o amálgama foi exposto ao calor, nem sob qual temperatura este material foi submetido, até $300^{\circ} \mathrm{C}$.

Certos pesquisadores $227,229-231$ relataram que a microdureza superficial do amálgama é uma propriedade tempo-dependente. Nonaka, et al. ${ }^{227}$ (1996) notaram que a microdureza do amálgama após 168 horas do polimento era maior do que após 24 horas. Provavelmente, devido ao menor teor de mercúrio, que se evapora com o tempo e maior quantidade de reações de cristalização, tendo mais fases g do que fases g1 e g2, que apresentam menores durezas comparadas à fase $\mathrm{g}^{209,232}$.

Entretanto, nos testes às baixas temperaturas, mesmo após 30 dias de submissão ao frio, não ocorreram mudanças estatisticamente relevantes ( $p>0,05)$ na microdureza de nenhum dos materiais estudados, inclusive o amálgama. Talvez o período de 30 dias tenha sido insuficiente para a ocorrência de tais modificações. Porém, como os estudos são voltados para fins periciais, este período de tempo pode ser considerado prolongado, em relação à permanência ou descoberta de um corpo ou ossada humana em condições ambientais de frio extremo.

A distinção entre os materiais estéticos estudados é passível de ser realizada apenas por meio da análise da microdureza Knoop, pois o padrão de microdureza da resina composta é bastante distinto do CIV, independentemente da ação do frio, até mesmo porque as baixas temperaturas, até $\left(-80^{\circ} \mathrm{C}\right)$ por 30 dias, não foram capazes de gerar alterações significativas na microdureza desses materiais restauradores. 
Nos resultados da microdureza, foi visto alto desvio padrão nas leituras dos três tipos de materiais restauradores, tanto nos testes ao calor como ao frio. Para os materiais estéticos, este fato pode ter ocorrido, pois no momento em que o penetrador do aparelho pressiona o material restaurador, existe a possibilidade de atingir partículas de carga, de maior dureza, e em outras marcações atingir a matriz, gerando certa diferença nos valores de microdureza de uma mesma restauração. No calor, outro fator limitante, referente ao CIV, e prejudicial para avaliação da microdureza ocorrido após a queima a $300^{\circ} \mathrm{C}$, é o surgimento de microtrincas na restauração, desse modo, o penetrador ao pressionar a superfície da restauração pode realizar a marcação justamente em cima de uma dessas trincas ou em suas proximidades e causar pequena movimentação de uma porção da restauração, o que certamente influenciará na avaliação da microdureza.

Em relação ao amálgama, o mesmo pode ocorrer em relação aos cristais de fase gama 1 e fase gama 2. Por ser uma liga metálica em que há duas fases, uma (gama 1) mais resistente que a outra (gama 2), muitas vezes a ponta penetradora pode ser posicionada sobre uma ou outra fase, o que leva ao grande desvio padrão.

Acidentes envolvendo vítimas mortas pelo congelamento e, principalmente, vítimas carbonizadas são eventos constantes no cotidiano das pessoas nos dias atuais. Os testes propostos neste trabalho mostraram-se práticos, viáveis e capazes de auxiliar a Odontologia Legal, durante o confronto com fichas odontológicas ante mortem das vítimas desses tipos de acidentes, o que pode facilitar o processo de identificação humana e a elucidação da ocorrência da ação do calor ou do frio sobre as mesmas. 
Conclusões 



\section{CONCLUSÕES}

Com base nos resultados encontrados no estudo, concluiu-se que:

- O calor foi capaz de produzir alteração de cor nos dois materiais estéticos estudados, sendo mais intensa quanto maior a temperatura de submissão, até $300^{\circ} \mathrm{C}$. As alterações de cor foram mais significativas para o CIV em todas as temperaturas analisadas.

- 0 calor não foi capaz de produzir alteração na rugosidade de superfície da resina composta. No CIV, promoveu alteração de rugosidade em todas as temperaturas analisadas, sendo mais significante na submissão a $300^{\circ} \mathrm{C}$. No amálgama, provocou alteração de rugosidade apenas quando exposto a $300^{\circ} \mathrm{C}$.

- 0 calor não foi capaz de produzir alterações de microdureza na resina composta e no amálgama. No CIV, promoveu aumento da microdureza, sendo mais intenso à medida que a temperatura de submissão foi maior, até $300^{\circ} \mathrm{C}$.

- O frio foi capaz de produzir alteração de cor nos dois materiais estéticos estudados, com intensidades similares entre ambos, em todas as baixas temperaturas, quando analisados após 7 dias. Com 30 dias de exposição ao frio, as alterações foram mais significativas para a resina composta.

- O frio, nas temperaturas avaliadas e nos períodos de tempo propostos, não foi capaz de produzir alterações na rugosidade de superfície nem na microdureza dos três materiais restauradores selecionados.

- Os materiais estéticos podem ser distinguidos, pela análise de cor, a partir de $200^{\circ} \mathrm{C}$ até $300^{\circ} \mathrm{C}$ e quando submetidos a $\left(-80^{\circ} \mathrm{C}\right)$, tanto em 7 dias como em 30 dias

- Não há como determinar o tempo a que o CIV e a resina composta foram submetidos à ação do frio.

- Testes de rugosidade e microdureza podem distinguir os materiais estéticos, independentemente, da ação do calor ou do frio. 

Referências 



\section{REFERÊNCIAS}

1. CFO. Consolidação das Normas para Procedimentos nos Conselhos de Odontologia. Aprovada pela Resolução CFO 63/2005.

2. Brasil. Decreto $\mathrm{n}$ o 5.081, de 24 de agosto de 1966. Regula o exercício da Odontologia. Disponível em <http://www.planalto.gov.br/ccivil_03/leis/15081.htm>; Acessado em 11 de junho de 2015.

3. Vanrell JP. Odontologia Legal \& Antropologia Forense. 2 ed. Rio de Janeiro: Guanabara Koogan; 2009.

4. Espíndula A. Perícia Criminal e Cível: uma visão geral para peritos e usuários da perícia. 4 ed. Campinas, SP: Millennium; 2013.

5. Silva M. Compêndio de Odontologia Legal. Rio de Janeiro: Medsi; 1997.

6. Silva RHA. Orientação Profissional para o Cirurgião-Dentista: Ética e Legislação. São Paulo: Santos; 2010.

7. Leite VG. Odontologia Legal. Salvador: Nova Era; 1962.

8. Oliveira RN, Silva SFS, Uchôa DP, Mesquita RA, Nunes FD. Presença de fungos na dentina humana: implicações arqueológicas e forenses. Brazilian Dental Science. 2004;7(3):87-90.

9. Fachone P, Velho L. Ciência Forense: Interseção Justiça, Ciência e Tecnologia. Revista Tecnologia e Sociedade. 2007;4:139-161.

10. Peres AS, Peres S, Nishida CL, et al. Peritos e perícias em Odontologia. Revista de Odontologia da Universidade Cidade de São Paulo. 2007;19(3):320-324.

11. Gruber J, Kameyama MM. O papel da Radiologia em Odontologia Legal. Pesqui Odontol Bras. 2001;15(3):263-268.

12. França GV. Medicina Legal. 9 ed. Rio de Janeiro: Guanabara Koogan; 2011.

13. Jobim LF, Costa LRS, Silva M. Identificação Humana - Identificação Médico Legal, Perícias Odontológicas, identificação Humana pelo DNA. 2 ed. Campinas, SP: Millennium; 2012.

14. Couto MISBG. Importância dos registros dentários em situações de grandes catástrofes. Porto: Instituto de Ciências Biomédicas Abel Salazar, Universidade do Porto, Portugal; 2009.

15. Arbenz GO. Medicina Legal e Antropologia Forense. São Paulo: Atheneu; 1988.

16. Couto RC. Perícias em Medicina \& Odontologia Legal. Rio de Janeiro: Med Book; 2011.

17. Galvão LCC. Medicina Legal. São Paulo: Santos; 2012.

18. Spitz WU. Medicolegal investigation of death: Guidelines for the application of pathology to crime investigation. 4 ed. Springfield, IL: Charles C Thomas Pub Ltd; 2006. 
19. Tilstone WJ, Savage KA, Clark LA. Forensic science: An encyclopedia of history, methods, and techniques: ABC-CLIO; 2006.

20. INTERPOL. Disaster Victim Identification Guide. Lyon: OIPC/ICPO - INTERPOL; 2014.

21. Jackson ARW, Jackson JM. Forensic Science. 3 ed. Pearson: Prentice Hall; 2011.

22. Araújo MEC, Pasquali L. Datiloscopia: A determinação dos dedos. 1 ed. Brasília: LabPAM; 2006.

23. Clayton TM, Whitaker JP, Maguire CN. Identification of bodies from the scene of a mass disaster using DNA amplification of short tandem repeat (STR) loci. Forensic Science International. Nov 1995;76(1):7-15.

24. Allen-Hall A, McNevin D. Human tissue preservation for disaster victim identification (DVI) in tropical climates. Forensic Science International:Genetics. Sep 2012;6(5):653-657.

25. Marin L, F. M. Odontología Forense: Identificación odontológica de cadáveres quemados. Reporte de dos casos. Revista Estomatología. 2004;12(2):57-70.

26. Bittencourt EAA, Koshikene D, de Freitas Junior DT, et al. Disaster carbonized victims identification in State of Rondonia, Brazil. Forensic Science International: Genetics Supplement Series. 2009;2(1):248-249.

27. Senn DR, Stimson PG. Forensic Dentistry. 2 ed. New York: CRC Press - Taylor \& Francis; 2010.

28. Rodríguez Cuenca JV. Introducción a la Antropología Forense. Análisis e interpretación de restos óseos humanos. 1 ed. Bogotá: Anaconda Editores; 1994.

29. Silva SCP. A contribuição da perícia odontológica na identificação de cadáveres. Porto: Departamento de Odontologia, Universidade do Porto; 2007.

30. Miyajima F, Daruge E, Daruge Júnior E. A importância da Odontologia na identificação humana: relato de um caso pericial. Arq. Odontol. 2001;37(2):133142.

31. Herschaft EE, Alder ME, Ord DK, Rawson RD, Smith ES. Manual of Forensic Odontology. 4 ed. Saratoga Springs, NY: American Society of Forensic Sciense; 2006.

32. Silva RF, Prado MM, Barbieri AA, Daruge Júnior E. Utilização de registros odontológicos para identificação humana. RSBO (Impr.). 2009;6(1):95-99.

33. Bowers CM, Bell GL. Manual of Forensic Odontology. 3 ed. Saratoga Springs, NY: American Society of Forensic Scense; 1995.

34. Silva RHA. Estudo de frequência alélica de cinco loci STR do cromossomo X na população do estado de São Paulo e sua contribuição na identificação humana: Faculdade de Odontologia, Universidade de São Paulo - FOUSP; 2007.

35. Glass RT, Von Fraunhofer JA. Practical Forensic Dentistry - theory and practice of forensic dentistry. Deutschland: VDM; 2009.

36. Okoye MI, Wecht $\mathrm{CH}$. Forensic investigation and management of mass disaster. Tucson: Lawyers \& Judges Publishing Company, Inc; 2007. 
37. Paranhos LR, Caldas JCF, Iwashita AR, Scanavini MA, Paschini RC. A importância do prontuário odontológico nas perícias de identificação humana. RFO, Passo Fundo. Jan-Abr 2009;14(1):14-17.

38. Maciel SLM, Xavier YMA, Leite PHAS, Alves PH. A documentação odontológica e a sua importância nas relações de consumo: um estudo em Campina Grande-PB. Pesq Bras Odontoped Clin Integr. 2003;3(2):53-58.

39. Silva AAL, França DCC, Aguiar SMH, Spadácio C, Daruge Jr E. Nível de conhecimento dos cirurgiões-dentistas sobre a qualidade dos prontuários odontológicos para fins de identificação humana. ROBRAC: Rev Odontol Bras Central. 2010;19(51):340-346.

40. Clark D. An analysis of the value of forensic odontology in ten mass disasters. International Dental Journal. 1994;44(3):241-250.

41. Fereira JL, de Fereira AE, Ortega AI. Methods for the analysis of hard dental tissues exposed to high temperatures. Forensic Science International. Jul 2008;178(2-3):119-124.

42. Spadácio C. Análise dos principais materiais dentários restauradores submetidos à ação do fogo e sua importância no processo de identificação. Piracicaba: Faculdade de Odontologia de Piracicaba, Universidade Estadual de Campinas FOP/UNICAMP; 2007.

43. Patidar KA, Parwani R, Wanjari S. Effects of high temperature on different restorations in forensic identification: Dental samples and mandible. Journal of Forensic Dental Sciences. 2010;2(1):37-43.

44. Woisetschläger M, Lussi A, Persson A, Jackowski C. Fire victim identification by post-mortem dental CT: radiologic evaluation of restorative materials after exposure to high temperatures. European Journal of Radiology. 2011;80(2):432440.

45. Melani R. Identificação Humana em vítimas de carbonização: análise odontolegal através da microscopia eletrônica. Piracicaba: Faculdade de Odontologia de Piracicaba, Universidade estadual de Campinas - FOP/UNICAMP; 1998.

46. Moody GH, Busuttil A. Identification in the Lockerbie air disaster. The American Journal of Forensic Medicine and Pathology. Mar 1994;15(1):63-69.

47. Michaud CL, Foran DR. Simplified Field Preservation of Tissues for Subsequent DNA Analyses*. Journal of Forensic Sciences. 2011;56(4):846-852.

48. Silver WE, Souviron RR. Dental autopsy. USA: CRC Press - Taylor \& Francis Group; 2010.

49. Rötzscher K, Grundmann C, Benthaus S. The effects of high temperatures on human teeth and dentures. Int Poster J Dent Oral Med. 2004;6(1):1-4.

50. Gonçalves SPG, de Paula Xavier AA, Pilatti LA. Tomada de decisão no tratamento de emergências. Revista Produção Online. 2007;7(7):97.

51. Aragão R. Incêndios e explosivos: uma introdução à engenharia forense. Campinas, SP: Millennium; 2010. 
52. Costa CN, Silva VP. Dimensionamento de estruturas de concreto armado em situação de incêndio. Métodos tabulares apresentados em normas internacionais. V Simpósio EPUSP sobre estruturas de concreto. Anais. EPUSP, São Paulo. 2003.

53. Marella GL, Perfetti E, Arcudi G. Differential diagnosis between cranial fractures of traumatic origin and explosion fractures in burned cadavers. Journal of Forensic and Legal Medicine. 2012;19(3):175-178.

54. Hill AJ, Lain R, Hewson I. Preservation of dental evidence following exposure to high temperatures. Forensic Science International. 2011;205(1):40-43.

55. Coma JMR. Antropología Forense. Madrid: Ministerio de Justicia; 1999.

56. Merlati G, Danesino P, Savio C, Fassina G, Osculati A, Menghini P. Observations on dental prostheses and restorations subjected to high temperatures: experimental studies to aid identification processes. Journal of Forensic Odonto-stomatology. 2002;20(2):17-24.

57. Silva RF, Daruge Júnior E, Pereira SDR, Almeida SM, Oliveira RN. Identificação de cadáver carbonizado utilizando documentação odontológica - Relato de caso. Rev. Odonto Ciênc. 2008;23(1):90-93.

58. Yamamoto K, Ohtani S, Kato S, Sugimoto H, Miake K, Nakamura T. Morphological changes in human and animal enamel rods with heating-especially limits in temperature allowing discrimination between human and animal teeth. The Bulletin of the Kanagawa Dental College: BKDC/KDS. 1990;18(1):55-61.

59. Myers SL, Williams JM, Hodges JS. Effects of extreme heat on teeth with implications for histologic processing. Journal of Forensic Sciences. 1999;44(4):805-809.

60. Fairgrieve S. SEM analysis of incinerated teeth as an aid to positive identification. Journal of Forensic Sciences. 1994;39(2):557-565.

61. Pereira RM. A contribuição da odontologia legal na identificação humana em acidentes aeronáuticos. São Paulo: Faculdade de Odontologia, Universidade de São Paulo; 2003.

62. Blau S, Briggs CA. The role of forensic anthropology in Disaster Victim Identification (DVI). Forensic Science International. 2011;205(1):29-35.

63. Franceschini N, Furlan MMDP. Hipotermia e Seu Uso na Prática Médica. Revista Saúde e Pesquisa. 2011;5(1):105-119.

64. Anjos CN, Cerqueira LA, Santiago GP, Moraes TM. O potencial da hipotermia terapêutica no tratamento do paciente crítico. Mundo saúde (Impr.), São Paulo, SP. 2008;32(1):74-78.

65. Perry AG, Potter PA. Fundamentos de enfermagem. 7 ed. Rio de Janeiro: Guanabara Koogan; 2004.

66. Giesbrecht GG. Cold stress, near drowning and accidental hypothermia: a review. Aviation Space and Environmental Medicine. 2000;71:733-752.

67. Mondelli J, Ishikiriama A, Francischone CE, Navarro MFdL, Galan Júnior J. Dentística restauradora: tratamentos clínicos integrados. Dentística restauradora: tratamentos clínicos integrados. São Paulo:Pancast; 1990. 
68. Center ADAS. Key dental facts: American Dental Association, Survey Center; 2000.

69. Drummond JL, Cailas MD, Croke K. Mercury generation potential from dental waste amalgam. Journal of Dentistry. 2003;31(7):493-501.

70. Dalla Costa R, Cossich ES, Tavares CRG. Influence of the temperature, volume and type of solution in the mercury vaporization of dental amalgam residue. Science of the Total Environment. 2008;407(1):1-6.

71. de Andrade MV, de Oliveira LGF, Menezes Filho PF, Silva CHV. Tendências das resinas compostas nanoparticuladas. International Journal of Dentistry. 2009;8(2):153-157.

72. Ferraz da Silva JM, Maranha da Rocha D, Kimpara ET, Uemura ES. Resinas compostas: estágio atual e perspectivas. Rev Odonto. São Bernardo do Campo: Metodista. 2009;16(32):98-104.

73. Queiroz VAO. Uso do cimento de ionômero de vidro na prática odontológica. Bauru: Faculdade de Odontologia de Bauru, Universidade de São Paulo FOB/USP; 2003.

74. Bertolini MJ, Zaghete MA, Gimenes R, de Paiva-Santos C, Palma-Dibb RG. Caracterização de cimento odontológico obtido a partir de um vidro preparado pelo método dos precursores poliméricos. Química Nova. 2005;28(5):813-816.

75. Mount GJ. Atlas de cimentos de ionômero de vidro: guia para o clínico. 2 ed. São Paulo: Santos; 1996.

76. Fook A, Azevedo VVC, Barbosa WPF, Fidéles TB, Fook MVL. Materiais odontológicos: Cimentos de ionômero de vidro. Rev Eletrônica Mat Processos. 2008;3(1):40-45.

77. Spadácio C, Oliveira OF, Benedicto EN, Daruge Júnior E, Paranhos LR. Análise do comportamento de restaurações estéticas sob a ação de calor e sua importância no processo de identificação humana. RFO, Passo Fundo. 2011;16(3):267-272.

78. Leitão J, Hegdahl T. On the measuring of roughness. Acta Odontologica Scandinavica. 1981;39(6):379-384.

79. Pires-de-Souza FCP, Casemiro LA, Garcia LFR, Cruvinel DR. Color stability of dental ceramics submitted to artificial accelerated aging after repeated firings. Journal of Prosthetic Dentistry. Jan 2009;101(1):13-18.

80. Matos IC, Sab TBB, Chacur NC, Guerra RF, Miranda MS. Utilização de dentes bovinos compossível substituto aos dentes humanos nos testes in vitro: revisão de literatura. UFES rev. odontol. 2008;10(2):58-63.

81. Turssi CP, Messias DF, Corona SM, Serra MC. Viability of using enamel and dentin from bovine origin as a substitute for human counterparts in an intraoral erosion model. Brazilian Dental Journal. 2010;21(4):332-336.

82. Schilke R, Lisson JA, Bauß O, Geurtsen W. Comparison of the number and diameter of dentinal tubules in human and bovine dentine by scanning electron microscopic investigation. Archives of Oral Biology. 2000;45(5):355-361.

83. Lamosa AC. Comparação da dentina de dentes humanos e de dentes bovinos através de microscopia eletrônica de varredura. Rio de Janeiro: Faculdade de Odontologia, Universidade do Estado do Rio de Janeiro; 2001. 
84. Reeves G, Fitchie J, Hembree J, Puckett A. Microleakage of new dentin bonding systems using human and bovine teeth. Operative Dentistry. 1995;20(6):230235.

85. Reis AF, Giannini M, Kavaguchi A, Soares CJ, Line S. Comparison of microtensile bond strength to enamel and dentin of human, bovine, and porcine teeth. The Journal of Adhesive Dentistry. 2003;6(2):117-121.

86. Attin T, Wegehaupt F, Gries D, Wiegand A. The potential of deciduous and permanent bovine enamel as substitute for deciduous and permanent human enamel: erosion-abrasion experiments. Journal of Dentistry. 2007;35(10):773777.

87. Tanaka JLO, Medici Filho E, Salgado JAP, et al. Comparative analysis of human and bovine teeth: radiographic density. Brazilian Oral Research. 2008;22(4):346-351.

88. Souza-Gabriel AE, Colucci V, Turssi CP, Serra MC, Corona SAM. Microhardness and SEM after CO2 laser irradiation or fluoride treatment in human and bovine enamel. Microscopy Research and Technique. Oct 2010;73(11):1030-1035.

89. Silva R, De la Cruz B, Daruge Jr E, Daruge E, Francesquini Jr L. La importancia de la documentación odontológica en la identificación humana: relato de un caso. Acta odontol. venez. 2005;43(2):67-74.

90. Paiva LAS. Patologia forense nas mortes com evidente ação do fogo. Saúde, Ética \& Justiça, São Paulo. 2006;11(1/2):1-7.

91. Richards N. Fire investigation-destruction of corpses. Medicine Science Law. 1977;17(2):79-82.

92. Espina E, Barrios F, Ortega A, Mavárez M, Espina O, Fereira J. Cambios estructurales en los tejidos dentales duros por acción del fuego directo, según edad cronológica. Ciencia Odontológica. Enero-Junio 2004;1(1):38-51.

93. Moreno S, León M, Marín L, Moreno F. Comportamiento in vitro de los tejidos dentales y de algunos materiales de obturación dental sometidos a altas temperaturas con fines forenses. Revista Colombia Médica. 2008;39(1s1):28-46.

94. Vázquez L, Rodríguez P, Moreno F. In vitro macroscopic analysis of dental tissues and some dental materials used in endodontics, submitted to high temperatures for forensic applications. Revista Odontológica Mexicana. July-September 2012;16(3-ING):171-181.

95. Botha CT. The dental identification of fire victims. The Journal of Forensic Odonto-stomatology. 1986;4(2):67.

96. Miguel R, Sosa JA. Comportamiento de las piezas dentarias y sus restauraciones frente a la acción de la temperatura. Rev. Fac. Odontol.(B. Aires). 1996;16(41):7580.

97. Steagall W, Silva Md. A importância da Dentística na identificação pelos dentes, no arco dental. Rev. paul. odontol. 1996;18(5):23-34.

98. Moreno S, Merlati G, Marin L, Savio C, Moreno F. Effects of high temperatures on different dental restorative systems: Experimental study to aid identification processes. Journal of Forensic Dental Sciences. 2009;1(1):17-23. 
99. Spadácio C, Oliveira OF, Daruge E, Paranhos LR. Análise do comportamento do amálgama de prata sob a ação de calor e sua importância no processo de identificação humana. RGO - Revista Gaúcha de Odontologia. 2011;59(1):41-44.

100. Hallmann L, Ulmer P, Reusser E, Louvel M, Hämmerle CH. Effect of dopants and sintering temperature on microstructure and low temperature degradation of dental Y-TZP-zirconia. Journal of the European Ceramic Society. 2012;32(16):4091-4104.

101. Dos Santos PA, Dibb RGP, Corona SAM, Catirse ABE, Garcia PPNS. Influence of fluoride-containing solutions on the translucency of flowable composite resins. Journal of Materials Science. 2003;38(18):3765-3768.

102. Powers JM, Dennison JB, Koran A. Color stability of restorative resins under accelerated aging. Journal of Dental Research. 1978;57(11):964-970.

103. Stober T, Gilde H, Lenz P. Color stability of highly filled composite resin materials for facings. Dental Materials. 2001;17(1):87-94.

104. Vichi A, Ferrari M, Davidson CL. Color and opacity variations in three different resin-based composite products after water aging. Dental Materials. 2004;20(6):530-534.

105. Janda R, Roulet JF, Latta M, Steffin G, Rüttermann S. Color stability of resin-based filling materials after aging when cured with plasma or halogen light. European Journal of Oral Sciences. 2005;113(3):251-257.

106. Sarafianou A, Iosifidou S, Papadopoulos T, Eliades G. Color stability and degree of cure of direct composite restoratives after accelerated aging. Operative Dentistry. 2007;32(4):406-411.

107. Billmeyer FW, Saltzman M. Principles of color technology. 2 ed. New York: John Wiley \& Sons; 1981.

108. Wyszecki G, Stiles WS. Color science: concepts and methods, quantitative data and formulae. Vol 8. 2 ed. New York: John Wiley \& Sons; 1982.

109. Ragain JC, Johnson WM. Color acceptance of direct dental restorative materials by human observers. Color Research and Application. Aug 2000;25(4):278-285.

110. Della Bona A, Barrett AA, Rosa V, Pinzetta C. Visual and instrumental agreement in dental shade selection: Three distinct observer populations and shade matching protocols. Dental Materials. Feb 2009;25(2):276-281.

111. Ozat PB, Tuncel I, Eroglu E. Repeatability and reliability of human eye in visual shade selection. Journal of Oral Rehabilitation. Dec 2013;40(12):958-964.

112. Bahannan SA. Shade matching quality among dental students using visual and instrumental methods. Journal of Dentistry. 2014;42(1):48-52.

113. Powers J, Bakus E, Goldberg A. In vitro color changes of posterior composites. Dental Materials. 1988;4(3):151-154.

114. Horn DJ, Bulan-Brady J, Hicks ML. Sphere spectrophotometer versus human evaluation of tooth shade. Journal of Endodontics. 1998;24(12):786-790. 
115. Molenaar R, ten Bosch JJ, Zijp JR. Determination of Kubelka-Munk scattering and absorption coefficients by diffuse illumination. Applied Optics. 1999;38(10):2068-2077.

116. Zimmerli B, Koch T, Flury S, Lussi A. The influence of toothbrushing and coffee staining on different composite surface coatings. Clinical Oral Investigations. Apr 2012;16(2):469-479.

117. Paravina RD, Ontiveros JC, Powers JM. Accelerated Aging Effects on Color and Translucency of Bleaching-Shade Composites. Journal of Esthetic and Restorative Dentistry. 2004;16(2):117-126.

118. Yannikakis SA, Zissis AJ, Polyzois GL, Caroni C. Color stability of provisional resin restorative materials. The Journal of Prosthetic Dentistry. 1998;80(5):533-539.

119. Rich DC, Billmeyer FW. Small and moderate color differences. IV. Color-difference-perceptibility ellipses in surface-color space. Color Research \& Application. 1983;8(1):31-39.

120. Alandia-Román CC. Análise da estabilidade de cor e rugosidade de superfície de compósitos submetidos à fumaça de cigarro. Ribeirão Preto: Faculdade de Odontologia de Ribeirão Preto, Universidade de São Paulo; 2011.

121. Mundim FM. Influência do envelhecimento artificial acelerado sobre a estabilidade de cor, opacidade e densidade das ligações cruzadas de compósitos odontológicos armazenados em diferentes ambientes e tempos de armazenagem. Ribeirão Preto: Faculdade de Odontologia de Ribeirão Preto, Universidade de São Paulo; 2007.

122. Dietschi D, Campanile G, Holz J, Meyer J-M. Comparison of the color stability of ten new-generation composites: an in vitro study. Dental Materials. 1994;10(6):353-362.

123. Nasim I, Neelakantan P, Sujeer R, Subbarao CV. Color stability of microfilled, microhybrid and nanocomposite resins - An in vitro study. Journal of Dentistry. 2010;38:e137-e142.

124. Reis AF, Giannini M, Lovadino JR, Ambrosano GM. Effects of various finishing systems on the surface roughness and staining susceptibility of packable composite resins. Dental Materials. 2003;19(1):12-18.

125. Um CM, Ruyter I. Staining of resin-based veneering materials with coffee and tea. Quintessence International (Berlin, Germany: 1985). 1991;22(5):377-386.

126. Ferracane J, Moser J, Greener E. Ultraviolet light-induced yellowing of dental restorative resins. The Journal of Prosthetic Dentistry. 1985;54(4):483-487.

127. Aguilar FG. Avaliação da cor e opacidade de compósitos diretos protegidos com selantes de superfície submetidos ao envelhecimento artificial acelerado. Ribeirão Preto: Faculdade de Odontologia de Ribeirão Preto, Universidade de São Paulo; 2008.

128. Horsted-Bindslev P, Mjör I. Modern concepts in operative dentistry. Copenhagen: Munksgaard; 1988. 
129. Soares LES, Cesar ICR, Santos CGC, et al. Influence of coffee on reflectance and chemistry of resin composite protected by surface sealant. American Journal of Dentistry. 2007;20(5):299-304.

130. Asmussen E. Factors affecting the color stability of restorative resins. Acta Odontologica Scandinavica. 1983;41(1):11-18.

131. Douglas W, Craig R. Resistance to extrinsic stains by hydrophobic composite resin systems. Journal of Dental Research. 1982;61(1):41-43.

132. Akcelrud L. Fundamentos da ciência dos polímeros. 1 ed. Barueri, SP: Manole; 2007.

133. Cook WD, Chong MP. Colour stability and visual perception of dimethacrylate based dental composite resins. Biomaterials. 1985;6(4):257-264.

134. Roulet JF. Degradation of dental polymers. Vol 1. Basel: S Karger Ag; 1987.

135. Asmussen E. Clinical relevance of physical, chemical, and bonding properties of composite resins. Operative Dentistry. 1984;10(2):61-73.

136. Janda R, Roulet JF, Kaminsky M, Steffin G, Latta M. Color stability of resin matrix restorative materials as a function of the method of light activation. European Journal of Oral Sciences. 2004;112(3):280-285.

137. Carvalho Jr OB. Avaliação in vitro da dureza superficial, da contração de polimerização e da rugosidade de 29 resinas compostas. São Paulo, Universidade de São Paulo; 2002.

138. Anfe TEA, Caneppele TMF, Agra CM, Vieira GF. Microhardness assessment of different commercial brands of resin composites with different degrees of translucence. Brazilian Oral Research. 2008;22(4):358-363.

139. Machado L, Matos JR. Análise térmica diferencial e calorimetria exploratória diferencial. São Paulo: Artliber; 2004.

140. Carmichael AJ, Gibson JJ, Walls AW. Allergic contact dermatitis to Bis-GMA dental resin associated with sensitivity to epoxy resins. Brazilian Dental Journal. 1997;183:297-298.

141. Nie J, Linden L, Rabek J. A reappraisal of the photo polymerization kinetics of TEGDMA initiated by camphorquinone $\mathrm{N}, \mathrm{N}$ dimethyl $\mathrm{p}$ toluidine for dental purposes. Acta Polymer. 1998;49:145-161.

142. Imazato S, Tarumi H, Kobayashi K, Hiraguri H, Oda K, Tsuchitani Y. Relationship between the degree of conversion and internal discoloration of light-activated composite. Dental Materials Journal. 1995;14(1):23-30.

143. Øysæd H, Ruyter I, Kleven IS. Release of formaldehyde from dental composites. Journal of Dental Research. 1988;67(10):1289-1294.

144. Yap A, Lee H, Sabapathy R. Release of methacrylic acid from dental composites. Dental Materials. 2000;16(3):172-179.

145. Schulze KA, Marshall SJ, Gansky SA, Marshall GW. Color stability and hardness in dental composites after accelerated aging. Dental Materials. 2003;19(7):612-619.

146. Ruyter IE, Nilner K, Moller B. Color stability of dental composite resin materials for crown and bridge veneers. Dental Materials. Oct 1987;3(5):246-251. 
147. Seghi RR, Hewlett ER, Kim J. Visual and instrumental colorimetric assessments of small color differences on translucent dental porcelain. Journal of Dental Research. Dec 1989;68(12):1760-1764.

148. Johnston WM, Kao EC. Assessment of appearance match by visual observation and clinical colorimetry. Journal of Dental Research. May 1989;68(5):819-822.

149. Noie F, O'Keefe KL, Powers JM. Color stability of resin cements after accelerated aging. The International Journal of Prosthodontics. 1994;8(1):51-55.

150. Rodriguez G, Pereira S. Current trends and evolution on dental composites. Acta Odontologica Venezolana. 2008;46(3):1-18.

151. Senawongse P, Pongprueksa P. Surface roughness of nanofill and nanohybrid resin composites after polishing and brushing. Journal of Esthetic and Restorative Dentistry. 2007;19(5):265-273.

152. Hirata R, Ampessan RL, Liu J. Reconstrução de dentes anteriores com resinas compostas-Uma seqüência de escolha e aplicação de resinas. JBC - Jornal Brasileiro de Clínica \& Estética em Odontologia. 2001;5(25):15-25.

153. Papadopoulos T, Sarafianou A, Hatzikyriakos A. Colour stability of veneering composites after accelerated aging. European Journal of Dentistry. 2010;4(2):137-142.

154. Söderholm KJ, Zigan M, Ragan M, Fischlschweiger W, Bergman M. Hydrolytic degradation of dental composites. Journal of Dental Research. 1984;63(10):12481254.

155. Matthews FL, Rawlings RD. Composite materials: engineering and science. Boca Raton, FL, USA: CRC Press LCC; 1999.

156. Kawaguchi M, Fukushima T, Miyazaki K. The relationship between cure depth and transmission coefficient of visible-light-activated resin composites. Journal of Dental Research. 1994;73(2):516-521.

157. Bagheri R, Burrow MF, Tyas M. Influence of food-simulating solutions and surface finish on susceptibility to staining of aesthetic restorative materials. Journal of Dentistry. May 2005;33(5):389-398.

158. Samra APB, Pereira SK, Delgado LC, Borges CP. Color stability evaluation of aesthetic restorative materials. Brazilian Oral Research. 2008;22(3):205-210.

159. Türkün LS, Türkün M. Effect of bleaching and repolishing procedures on coffee and tea stain removal from three anterior composite veneering materials. Journal of Esthetic and Restorative Dentistry. 2004;16(5):290-301.

160. Ferracane JL. Hygroscopic and hydrolytic effects in dental polymer networks. Dental Materials. 2006;22(3):211-222.

161. Deville S. Freeze-casting of porous ceramics: a review of current achievements and issues. Advanced Engineering Materials. 2008;10(3):155-169.

162. Eldiwany M, Friedl K, Powers J. Color stability of light-cured and post-cured composites. American Journal of Dentistry. 1995;8(4):179-181. 
163. Buchalla W, Attin T, Hilgers R-D, Hellwig E. The effect of water storage and light exposure on the color and translucency of a hybrid and a microfilled composite. The Journal of Prosthetic Dentistry. 2002;87(3):264-270.

164. Uchida H, Vaidyanathan J, Viswanadhan T, Vaidyanathan TK. Color stability of dental composites as a function of shade. The Journal of Prosthetic Dentistry. 1998;79(4):372-377.

165. Leibrock A, Rosentritt M, Lang R, Behr M, Handel G. Colour stability of visible light-curing hybrid composites. The European Journal of Prosthodontics and Restorative Dentistry. 1997;5(3):125-130.

166. Brandão RB, Martin C, Catirse AB, De Castro e Silva M, Evison MP, Guimarães MA. Heat Induced Changes to Dental Resin Composites: A Reference in Forensic Investigations?*. Journal of Forensic Sciences. 2007;52(4):913-919.

167. Pueyo VM, Garrido BR, Sanchez JAS. Odontologia Legal y Forense. 1 ed. Barcelona: Masson; 1994.

168. Rios D. Avaliação do desgaste e rugosidade superficial de materiais utilizados para selante, submetidos à escovação com dois diferentes dentifrícios. Bauru: Faculdade de Odontologia de Bauru, Universidade de São Paulo; 2000.

169. da Costa J, Adams-Belusko A, Riley K, Ferracane JL. The effect of various dentifrices on surface roughness and gloss of resin composites. Journal of Dentistry. 2010;38(2):e123-e128.

170. Kanter J, Koski RE, Martin D. The relationship of weight loss to surface roughness of composite resins from simulated toothbrushing. The Journal of Prosthetic Dentistry. 1982;47(5):505-513.

171. Goldstein GR, Lerner T. The effect of toothbrushing on a hybrid composite resin. The Journal of Prosthetic Dentistry. 1991;66(4):498-500.

172. Heintze S, Forjanic M. Surface roughness of different dental materials before and after simulated toothbrushing in vitro. Operative Dentistry (University of Washington). 2005;30(5):617-626.

173. Teixeira EC, Thompson JL, Piascik JR, Thompson JY. In Vitro Toothbrush-Dentifrice Abrasion of Two Restorative Composites. Journal of Esthetic and Restorative Dentistry. 2005;17(3):172-181.

174. Amaral CM, Rodrigues JA, Guilherme Erhardt MC. Effect of whitening dentifrices on the superficial roughness of esthetic restorative materials. Journal of Esthetic and Restorative Dentistry. 2006;18(2):102-108.

175. Pires-de-Souza FCP, Garcia LFR, Hamida HM, Casemiro LA. Color stability of composites subjected to accelerated aging after curing using either a halogen or a light emitting diode source. Brazilian Dental Journal. 2007;18(2):119-123.

176. Batista WVB. Avaliação da eficiência do polimento efetuado em superfícies de vidro e de amálgama, por pontas de "borracha abrasiva" ou pastas para polimento, em relação à perda de massa e à rugosidade. Bauru: Faculdade de Odontologia de Bauru, Universidade de São Paulo; 2003.

177. Martínez MAJA. Avaliação do desgaste e da rugosidade superficial de uma resina composta, após escovação simulada, em função de diferentes energias e fontes de 
luz usadas na polimerização. Bauru: Faculdade de Odontologia de Bauru, Universidade de São Paulo; 2004.

178. Whitehead SA, Shearer AC, Watts DC, Wilson NHF. Comparison of methods for measuring surface-roughness of ceramic. Journal of Oral Rehabilitation. Jun 1995;22(6):421-427.

179. Whitehead SA, Shearer AC, Watts DC, Wilson NHF. Surface texture changes of a composite brushed with "tooth whitening" dentifrices. Dental Materials. Sep-Nov 1996;12(5-6):315-318.

180. Ehrnford L, Derand T, Larsson LA, Svensson A. An abrasion test for composite resins. Journal of Dental Research. 1980;59(4):716-720.

181. Powell JM, Phillips RW, Norman RD. In vitro wear reponse of composite resin, amalgam, and enamel. Journal of Dental Research. 1975;54(6):1183-1195.

182. Prakki A. Resistência ao desgaste de cimentos resinosos submetidos à ciclagem de $\mathrm{pH}$ e escovação simulada. Bauru: Faculdade de Odontologia de Bauru, Universidade de São Paulo; 2003.

183. Liberman R, Geiger S. Surface texture evaluation of glass ionomer restorative materials polished utilizing poly (acrylic acid) gel. Journal of Oral Rehabilitation. 1994;21(1):87-94.

184. de Araujo M, Araújo RM, Marsilio AL. A retrospective look at esthetic resin composite and glass-ionomer Class III restorations: a 2-year clinical evaluation. Quintessence International (Berlin, Germany: 1985). 1998;29(2):87-93.

185. Sasaki MT, Silva R, Araújo MAM, Krabbe DFM, Damião AJ. Avaliação da rugosidade superficial de cimentos de ionômero de vidro com diferentes sistemas de acabamento e polimento. Rev Odontol UNESP. 2000;29(1/2):81-92.

186. Papagiannoulis L, Tzoutzas J, Eliades G. Effect of topical fluoride agents on the morphologic characteristics and composition of resin composite restorative materials. Journal of Prosthetic Dentistry. Apr 1997;77(4):405-413.

187. El-Badrawy WA, McComb D. Effect of home-use fluoride gels on resin-modified glass-ionomer cements. Operative Dentistry. Jan-Feb 1998;23(1):2-9.

188. Marghalani HY. Effect of filler particles on surface roughness of experimental composite series. Journal of Applied Oral Science. Jan-Feb 2010;18(1):59-67.

189. Gladys S, Van Meerbeek B, Braem M, Lambrechts P, Vanherle G. Comparative physico-mechanical characterization of new hybrid restorative materials with conventional glass-ionomer and resin composite restorative materials. Journal of Dental Research. 1997;76(4):883-894.

190. Turssi CP, de Magalhaes CS, Serra MC, Rodrigues AL. Surface roughness assessment of resin-based materials during brushing preceded by $\mathrm{pH}$-cycling simulations. Operative Dentistry. Nov-Dec 2001;26(6):576-584.

191. Roselino LMR. Efeito da escovação e do envelhecimento artificial acelerado sobre a alteração superficial de materiais restauradores estéticos. Ribeirão Preto: Faculdade de Odontologia, Universidade de São Paulo; 2012. 
192. Yap AUJ, Lye KW, Sau CW. Surface characteristics of tooth-colored restoratives polished utilizing different polishing systems. Operative Dentistry. Nov-Dec 1997;22(6):260-265.

193. Momoi Y, Hirosaki K, Kohno A, McCabe JF. In vitro toothbrush-dentifrice abrasion of resin-modified glass ionomers. Dental Materials. 1997;13(2):82-88.

194. Garcia FCP, Wang L, D'Alpino PHP, Souza JB, Araújo PA, Mondelli RFL. Evaluation of the roughness and mass loss of the flowable composites after simulated toothbrushing abrasion. Brazilian Oral Research. 2004;18(2):156-161.

195. Yap A, Yap S, Teo C, Ng J. Comparison of surface finish of new aesthetic restorative materials. Operative Dentistry (University of Washington). 2004;29(1):100-104.

196. Ellakuria J, Triana R, Minguez N. Effect of one-year water storage on the surface microhardness of resin-modified versus conventional glass-ionomer cements. Dental Materials. 2003;19(4):286-290.

197. Leite JBBC, Giro EMA, Cruz CAS. Estudo comparativo da dureza superficial de cimentos ionoméricos restauradores submetidos a condições de umidade e dessecamento. Rev. odontol. UNESP. 1999;28(1):119-135.

198. Ganime MM, Giorgi MCC, Dias CTS, Paulillo LAM. Avaliação de dureza knoop de resina composta ativada por diferentes fontes de luz. Brazilian Dental Science. 2010;11(3):74-80.

199. Lopes GC, Bonissoni L, Baratieri LN, Vieira LCC, Monteiro S. Effect of bleaching agents on the hardness and morphology of enamel. Journal of Esthetic and Restorative Dentistry. 2002;14(1):24-30.

200. Powers JM, Sakaguchi RL. Craig's Restorative Dental Materials. 12 ed. St Louis, Missouri: Mosby Elsevier; 2006.

201. Couto MGP, Francisconi PAS, Nagem Filho H, Couto Júnior MP. Estudo do "creep" em cinco resinas compostas fotopolmerizáveis. Rev. Fac. Odontol. Bauru. 2000;8(3/4):37-42.

202. Peutzfeldt A. Resin composites in dentistry: the monomer systems. European Journal of Oral Sciences. 1997;105(2):97-116.

203. Chain MC, Baratieri LN. Restaurações estéticas com resina composta em dentes posteriores. Vol 12. São Paulo: Artes médicas; 1998.

204. Turbino ML. Profundidade de polimerização de resina composta ativada com laser de Argônio. São Paulo, Universidade de São Paulo; 2004.

205. Rode KM, de Freitas PM, Lloret PR, Powell LG, Turbino ML. Micro-hardness evaluation of a micro-hybrid composite resin light cured with halogen light, lightemitting diode and argon ion laser. Lasers in Medical Science. 2009;24(1):87-92.

206. Kobussen GA, Craig BD, Halvorson RH, Doruff MC, Bigham WS. Optical properties of highly aesthetic composite restoratives. Journal of Dental Research. 2009;88(Spec Iss A):1508.

207. Beech D, Jalaly T. Clinical and laboratory evaluation of some othodontic direct bonding systems. Journal of Dental Research. 1981;60(6):972-978. 
208. Pintaúde G. Análise dos regimes moderado e severo de desgaste abrasivo utilizando ensaios instrumentados de dureza. São Paulo: Faculdade Politécnica da USP, Universidade de São Paulo; 2002.

209. Anusavice KJ, Shen C, Rawls HR. Phillips Materiais Dentários. 12 ed. Rio de Janeiro: Elsevier; 2013.

210. McCabe JF, Walls AWG. Applied dental materials. 8 ed. Oxford: Blackwell Science; 1998.

211. Basting R, Serra M, Rodrigues A. In situ microhardness evaluation of glassionomer/composite resin hybrid materials at different post-irradiation times. Journal of Oral Rehabilitation. 2002;29(12):1187-1195.

212. Santana IL, Pacheco DAP, de Carvalho FLGL, Raposo CC, Júnior AAC. Caracterização térmica de compósitos dentais e sua impotância nas propriedades mecânicas. Revista de Pesquisa em Saúde. 2011;12(3):28-31.

213. Bağis $\mathrm{YH}$, Rueggeberg FA. Mass loss in urethane/TEGDMA-and BisGMA/TEGDMA-based resin composites during post-cure heating. Dental Materials. 1997;13(5):377-380.

214. Dionysopoulos P, Watts D. Dynamic mechanical properties of an inlay composite. Journal of Dentistry. 1989;17(3):140-144.

215. Loza-Herrero M, Rueggeberg E, Caughman W, Schuster G, Lefebvre C, Gardner E. Effect of heating delay on conversion and strength of a post-cured resin composite. Journal of Dental Research. 1998;77(2):426-431.

216. Miyazaki CL, Medeiros IS, Santana IL, Matos JdR, Rodrigues Filho LE. Heat treatment of a direct composite resin: influence on flexural strength. Brazilian Oral Research. 2009;23(3):241-247.

217. Bağis YH, Rueggeberg FA. Effect of post-cure temperature and heat duration on monomer conversion of photo-activated dental resin composite. Dental Materials. 1997;13(4):228-232.

218. Peutzfeldt A, Asmussen E. The effect of postcuring on quantity of remaining double bonds, mechanical properties, and in vitro wear of two resin composites. Journal of Dentistry. 2000;28(6):447-452.

219. Xie D, Brantley W, Culbertson B, Wang G. Mechanical properties and microstructures of glass-ionomer cements. Dental Materials. 2000;16(2):129138.

220. Okada K, Tosaki S, Hirota K, Hume W. Surface hardness change of restorative filling materials stored in saliva. Dental Materials. 2001;17(1):34-39.

221. Yap A, Cheang P, Chay P. Mechanical properties of two restorative reinforced glass-ionomer cements. Journal of Oral Rehabilitation. 2002;29(7):682-688.

222. Aliping-McKenzie M, Linden R, Nicholson J. The effect of saliva on surface hardness and water sorption of glass-ionomers and "compomers". Journal of Materials Science: Materials in Medicine. 2003;14(10):869-873.

223. Cattani-Lorente MA, Godin C, Meyer JM. Mechanical behavior of glass ionomer cements affected by long-term storage in water. Dental Materials. 1994;10(1):3744 . 
224. Mojon P, Kaltio R, Feduik D, Hawbolt EB, MacEntee MI. Short-term contamination of luting cements by water and saliva. Dental Materials. 1996;12(2):83-87.

225. Soprano V. Estudo de parâmetros para ensaios de microdureza em amálgama de prata, resina composta, dentina e esmalte bovinos. São Paulo: Faculdade de Odontologia, Universidade de São Paulo; 2008.

226. Patsurakos A, Moberg LE. Corrosion behavior and microhardness of three amalgams. European Journal of Oral Sciences. 1988;96(4):376-383.

227. Nonaka T, Gabrielli F, Ribeiro SA, Centola ALB, de Sá DN. Amálgama DentalEstudo da microdureza superficial. Efeito da brunidura. Semina: Ciências Biológicas e da Saúde. 1996;17(2):206-213.

228. Donassollo TA, Leivas LL, Osinaga PWR, Demarco FF. Microdureza do amálgama: influência da liga e do tratamento superficial. RPG rev. pos-grad. 2003;10(3):204210.

229. Vieira DF, Benvenga RG, Santos JFF. Influência do acabamento superficial e da idade do amálgama sobre a sua dureza superficial. Rev Fac Odontol, São Paulo. 1970;8:83-93.

230. Centola ALB. Microdureza das margens de restaurações de amálgama. Efeito do uso de instrumentos rotatórios em ultra-alta velocidade. Ribeirão Preto: Faculdade de Odontologia de Ribeirão Preto, Universidade de São Paulo; 1987.

231. Silva AB, Centola ALB, Turbino ML, Froner IC, Nascimento TN. Microdureza de amálgama: efeito da brunidura pós-escultura e da brunidura pré e pós-escultura. Rev. Odontol. Univ. São Paulo. 1994;8(3):193-197.

232. Boyer DB, Edie JW, Chan KC. Effect of clinical finishing procedures on amalgam microstructure. Journal of Dental Research. 1980;59(2):129-133. 
